\title{
Zur Geschichte
}

der

pharmazeutisch-

\section{chemischen}

Destilliergeräte

von

Hermann Schelenz.

Mit vielen Abbildungen im Text.

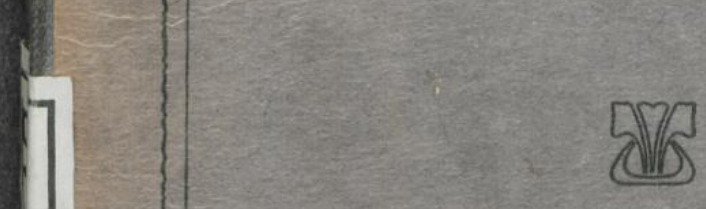

Im Buchhandel

zu beziehen durch Julius Springer, Berlin.

$$
\text { rgrr. }
$$




\section{ULB Düsseldorf}

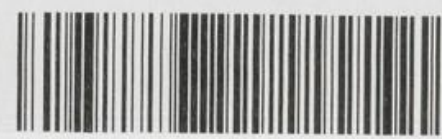

$+417086601$ 

Vom selben Verfasser erschienen:

Kosmetik. Heft 203 der Virchow-Holtzendorffschen Vorträge. Neue Folge. Neunte Serie. Hamburg, Verlagsanstalt und Druckerei A.-G. (vormals J. F. Richter). 1894.

Frauen im Reiche Aesculaps. Ein Versuch zur Geschichte der Frau in der Medizin und Pharmazie. Leipzig, Ernst Günther. 1900.

Geschichte der Pharmazie. Berlin, Julius Springer. 1904.

Pflanzensammlungen und Kräuterbücher. Cassel 1905.

Pharmakognostische Karte zu den Arzneibüchern Europas. 2. Auflage. Leipzig-Wien, Freytag \& Berndt.

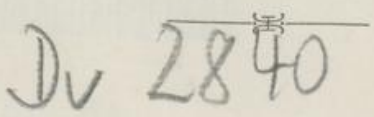




\section{ZuR GESCHICHTE \\ DER}

\section{PhaRMAZEUTISCH-CHEMISCHEN}

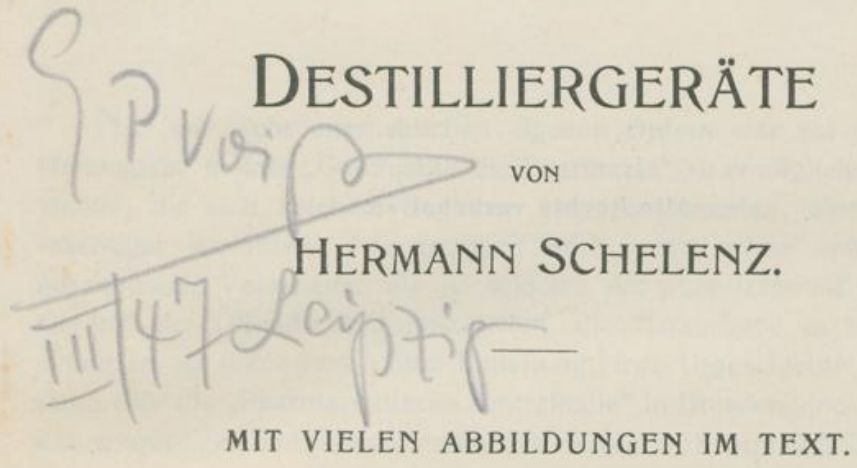

है? 
Alle Rechte vorbehalten.

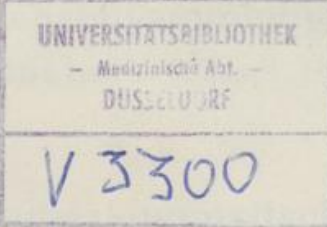




\section{Vorwort.}

Nur mit nicht unerheblichen eigenen Opfern war vor 6 Jahren die Herausgabe meiner "Geschichte der Pharmazie" zu ermöglichen. Die Umstände, die sich solchem Beginnen entgegenstemmten, sind wohl noch mächtiger geworden. Sie zwangen mich, statt meine seit Jahren angesammelten Vorarbeiten als "Geschichte der pharmazeutisch-chemischen Geräte" der Öffentlichkeit mitzuteilen, die Herausgabe in kleineren Abschnitten zu versuchen. Eine Einleitung, ihre Urgeschichte, brachte im Jahre 1907 die "Pharmazeutische Zentralhalle" in Dresden, und dem überaus liebenswürdigen Entgegenkommen der Herren Schimmel \& Co. in Miltitz, die der Wissenschaft nicht nur durch ihre vortrefflichen Halbjahresberichte, sondern auch durch die Herausgabe des im Jahre 1899 zum ersten Male erschienenen und jetzt zum zweiten Male aufgelegten, auch die Geschichte behandelnden Werkes "Die ätherischen Öle" von E. Gildemeister und Fr. Hoffmann*) dienten und dienen, verdanke ich jetzt, daß ich die vorliegende Arbeit nicht nur als Beilage zu den gedachten Berichten, sondern auch im Buchhandel der breiten Öffentlichkeit darbieten kann.

Daß Deutschlands Handel und Gewerbe auf der Welt voran ist, verdankt es der Einsicht, daß beide auf dem Grunde der Wissenschaft schaffen müssen, daß sie sie als Helferin nicht entbehren können. In werktätiger Dankbarkeit stehen beide ihr zur Seite. Ein Mäzenatentum aber, wie das eben erwähnte, die Ausübung eines solchen nobile officium ist doch wohl

*) 1900 erschien in Milwaukee eine von Edward Kremers in Madison besorgte englische Bearbeitung unter dem Titel "The volatile oils" unter denselben Auspizien. 
unendlich selten, und es ist um so schätzenswerter, als es sich um das Werk eines völlig abgesondert stehenden, weder durch Amt noch Titel legitimierten Privatgelehrten handelt. Auch an dieser Stelle spreche ich den Herren meinen verbindlichsten Dank für das mir bezeigte und von mir als Ehre empfundene Wohlwollen aus.

Daß ich keine eingehende Geschichte der Destilliergeräte schreiben wollte und konnte, braucht kaum bemerkt zu werden. Nur die Merksteine auf dem Wege ihrer Entwicklung durfte ich vorführen. Trotzdem ich auch in dieser Arbeit im Grunde wieder das nicht eben erhebende Wort „Es ist alles schon dagewesen" als berechtigt nachweise, so hoffe ich doch, daß sie sich Freunde erwirbt. Was sie als der Verbesserung, der Ergänzung bedürftig ansehen, bitte ich mir mitzuteilen.

Zur leichteren Benutzung und um das Werkchen möglichst nützlich zu gestalten, gab ich ihm ein eingehendes Inhaltsverzeichnis mit auf den Weg.

Casse1, im April 1911.

Hermann Schelenz. 
Es kann dem Naturmenschen, der jedenfalls Alles, was ihm auffiel, dem Kinde gleich unbewußt auch zum Munde führte, um es zu untersuchen, nicht entgangen sein, daß manche Pflanzen und Pflanzenteile sich durch bittern oder säuerlichen, andre durch einen auffällig kühlenden $\mathrm{Ge}$ schmack auszeichneten, und letzte Eigenschaft, noch mehr ein kaum je fehlender Begleitumstand, ein nachhaltiger Duft mußte dem wohl empfindlichsten Sinnesorgan, der Nase, aufgefallen sein. Ja sie mag in solchen Fällen den Menschen erst auf die Spur solcher Gewächse geführt haben. $\left.{ }^{1}\right)$ Unbewußter Trieb leitete ihn sicher dazu, solche duftende Pflanzenteile, gleich dem Salz, zu Würzzwecken seiner urwüchsigen Nahrung zuzusetzen und später zu Arzneizwecken zu benutzen. Das Hantieren mit ihnen mußte lehren, daßs die riechenden Teile beim Reiben sich den Händen mitteilten und an ihnen haften blieben, daß sie in gewissen Teilen vorwiegend vorhanden waren, beim Zerbrechen oder Zerreiben aus den Schalen citronenähnlicher Früchte z. B. herausspritzten oder hervortropften, daß sie in wäßrige Auszüge übergingen, daß, wenn diese Ruchstoffe erhitzt wurden, sie sich verflüchtigten, in Dampfform a ufwärtsstiegen, und daß sie das ebenfalls taten, daß sie sich den Dämpfen mitteilten, wenn wäßrige Pflanzenauszüge zum Verdampfen gebracht wurden.

Die urwüchsige Hütte, die sich über dem Herde, dem Wahrzeichen, dem Mittel- und Kernpunkt der Wohnstätte erhob, gab dem Menschen, richtiger der F rau, der das Walten am Herdfeuer, das Priestertum des Herdes zufiel und in übertragener und erweiterter Bedeutung noch zufällt, vollauf Gelegenheit, die tappenden allerersten, dann zielbewußt weitere Versuche auf dem Gebiete der Naturlehre, der Küchenchemie, der Grundlage unsrer Chemie anzustellen. Es konnte ihr nicht entgehen, daß der Rauch harzreicher Hölzer sich zum guten Teil in Gestalt fester Stoffe,

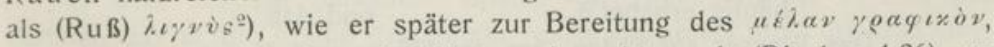
des Atramentum librarium, der Tinte gebraucht wurde (Dioskor. 1,86), an

4) Erinnert sei an die vortreffliche Nase der Hunde, an die Vorliebe der Taube für An is, die der Bienen und Schmetterlinge für woh1riechende, die mancher Fliegen für stinkende (Aas-) Pflanzen, ferner daran, daß Katzen sich auf dem ihnen angenehmen B aldrian, Hunde auf starkriechendem Käse oder faulendem Blut wälzen, um sich geradezu zu parfümieren.

2) Vgl. hierzu die sagenförmige Überlieferung von dem Vorkommen von Ammonium (Carbonat) in dem Ruß über dem Feuer aus Kameldünger in der Oase des Jupiter Ammon. 
der Unterseite des Blattdaches absetzte, während in Sonderheit feuchtes Brennmaterial heller gefärbte Verbrennungsstoffe gab, die (so weit sie nicht durch die Öffnungen in die Luit strömten, die unterseits, da wo das Dach auf den Wänden auflag, gelassen waren, oder durch die, welche an der höchsten Stelle ausgespart war), tropfbar flüssig sich festsetzten und, besonders wenn Regen das Dach außen kühlte, regellos heruntertropften (destillierten), wenn nicht der Zufall, später der ihn zum Zweck gestaltende Mensch die einzelnen Tropfen in irgendeiner Art, durch Überstehenlassen des Daches, durch Anbringen eines vorspringenden Holzteiles, der die Tropfen zum Zusammenlaufen zwang, durch eine Rinne nach einer bestimmten Stelle hin ableitete.

Ganz ähnlich vollzog sich in den Wohnräumen der Höhlenbewohner die Entwicklung des Dampfes, seine Verdichtung, die Kondensation, das Tropfbarflüssigwerden an den festgeschlossenen Decken und Wänden der Höhle, und viel deutlicher mußten diese Erscheinungen und erst recht das Destillieren, das Herabträufeln von der Decke und das Herabrinnen an den Wänden vor Augen treten, und es muß ihn geradezu zum Anlegen von Rinnen gezwungen haben.

Dafür, daß der Mensch sich das Weltall seiner engen Behausung ähnlich gestaltete, daß er sich die staunenerregenden Vorgänge darin so erklärte wie die ihm täglich vor Augen tretenden in seiner Hütte, ist erklärlich. Die Überlieferungen uralter Völker (vgl. die der Bibel) und ihr Wortschatz beweisen das ebenso wie die uns geläufige Muttersprache. Über dem Erdboden breitet sich des Himmels [mit der Vorbedeutung des deckenden, des Dachs] Zelt oder Gew ölbe [eine bogenförmige Bedeckung. Wölben steht dem griechischen $\approx \delta \dot{\lambda} \approx o$ s, Busen sprachlich nahe], das Coelum

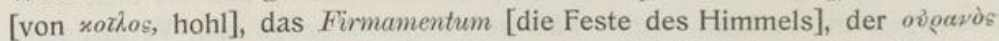
[sanskr. Varunas, der Gott des Wassers]. Gebildet ist diese Decke, dieses Dach von den Wolken [vielleicht von einer vorgerm. Wurzel, welge-feucht], dem Nebel [altd. Nift, wie das griech. $\nu \varepsilon \varphi \dot{\varepsilon} \lambda \eta$ und lat. nubes, eines Stammes].

Der Mensch mufte beobachten, wie sich Feuchtigkeit aus dem Boden, aus Wasserläufen und den Seen in Gestalt von Dunst, Nebel, Wolken aufwärts hob,

daß Samen des Wassers

Sich mit den Wolken zugleich aus allen vorhandenen Dingen häufig erhebet ${ }^{1}$ ), und daß

Das Wasser auf Erden, das der Flüsse und Meere

Löst sich in leichte, flüchtige Teil' auf,

Die nicht fähig man ist, mit der Schärfe des Auges zu fassen und daß es sich sammelt

Hoch in den Wolken und stürzt als fließender Regen nieder zur Erde.

1) Lucrez, Von der Natur der Dinge, VI., $470 \mathrm{ff}$. 
Gleiche, geradezu Uransichten spiegeln sich auch wieder in dem, was Plinius im zweiten Buch über die Entstehung des Hagels aus gefrorenem Regen, des Reifs und des lockern Schnees aus Nebel mitteilt und was ihm und andern klassischen Vorbildern Megenberg ${ }^{1}$ ) nacherzählt:

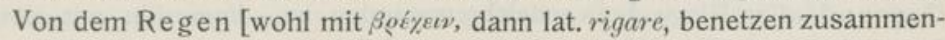

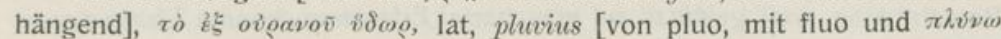
zusammenhängend].

Er kumpt von wäzzrigem dunst, den der sunnen hitz auf hât gezogen in daz mitel reich des luftes, wann von der Kelten, diu dâ ist, entsleuzt

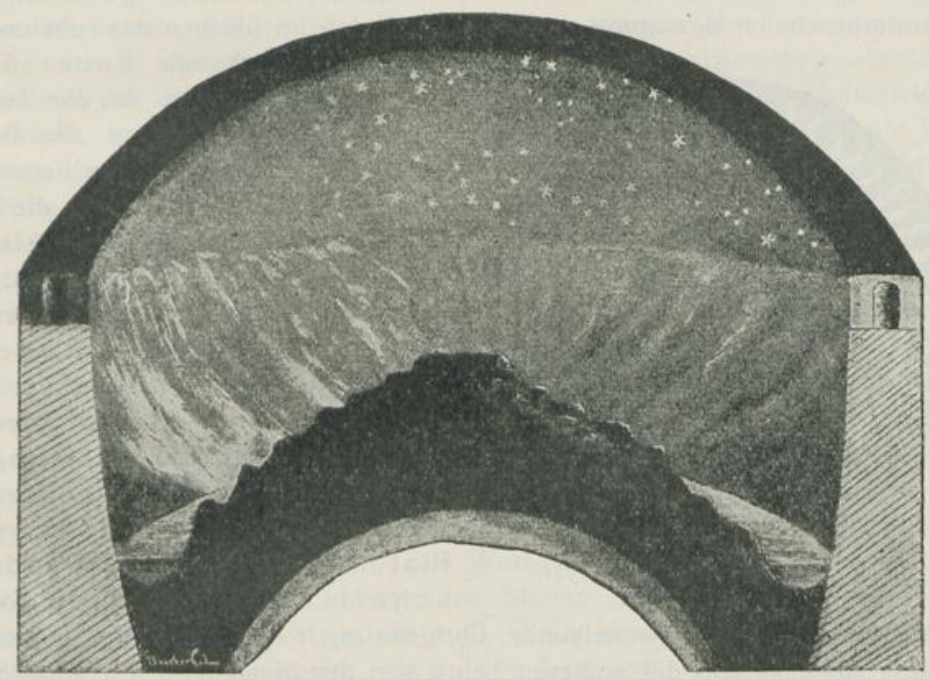

Abb. 1. Die Welt nach der alten Chalder Vorstellung.

sich der dunst wider in wazzer, der von dem wallenden hafen (dem kochenden Topf) gêt ob dem feur: wenn der dunst die kalten eisneinne [eisernen] hafendecken rüert, sô entsleuzt er sich in wazzers tropfen").

Folgerecht erzählt derselbe Verfasser vom Tau [sanskr. dhaw, rinnen], 1at. Ros, griech. @óoos [alles, was rinnt] ${ }^{3}$ ).

Er wird aus gar behendem zartem wäzzrigem luft, der sô lind und zart ist, daz er die Kelten des miteln reichs des luftes nicht erleiden mag.

Wie die Welt nach der alten Chalder Vorstellung in ihrer ganzen Eigenart ausschaute, zeigt Abb.1, wie das Mittelalter sie, das Universum, den Makrokosmos (nach Aristoteles) stilisiert, darstellte die weitere.

1) Konrad v. Megenberg, Das Buch der Natur, herausgegeben von Dr. Franz Pfeiffer. Stuttgart, Karl Aue, 1861.

2) S. $81,5 \mathrm{ff}$.

ग) S. $83,18 \mathrm{ff}$. 
Ganz dieselben Uransichten führten, abgesehen davon, daß sie sich ebenfalls in den Göttersagen des Altertums erkennen lassen, schließlich auch zu den Anschauungen der alten Philosophen über das All, das Universum, das aus einer Einheit, einem Grundprinzip, einem Urgrund aller Dinge [gewandelt] entstanden ist. Immerhin mit einiger Berechtigung, weil gestützt auf mancherlei Erfahrung, konnte Thales von Milet $(640-550$ v. Chr.) aussprechen, daß das Wasser das Prinzip, das Erste, der Urgrund des Alls wäre, daß aus ihm Alles entstanden sei. Und weiter war Heraklit ebenso berechtigt, auf Grund ähnlicher Be-

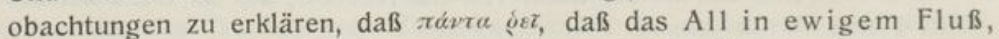
in unterbrochener Bewegung und Wandlung, daß im übrigen das ruhelose,

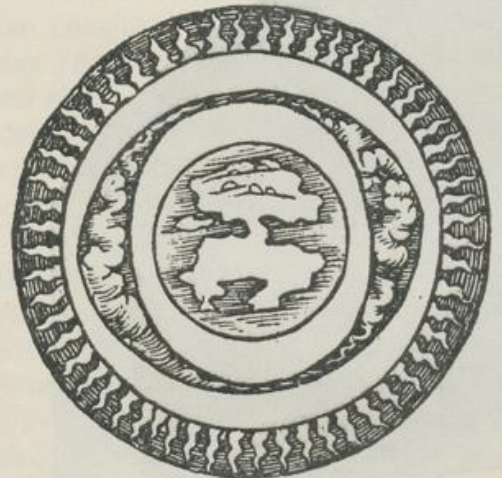

$A b b$. 2. Das Universum nach Ryff. züngelnde, flackernde $\mathrm{Feuer}$ die stetige Kraft sei, die da die Zersetzung, Wandlung, und die Belebung durch seine Wärme hervorrufe. Es sind das Grundlagen, die in weiterer Entwicklung Empedokles (495-435 v. Chr.) dazu führten, die vier Elemente, Wasser, Feuer, Luft und Erde, als die Grundlagen des Alls anzusehen, die durch eine entfremdende Macht, vez\%os, zur Trennung und Zersetzung, durch eine befreundende, qiliia, zur Verbindung veranlaßt würden. In Platos Lehre von der Verwandtschaft des Ähnlichen (die auf dem Gebiete der Arzneikunde, übrigens auch im Opferkultus in dem Similia similibus und der späteren Lehre von den Signa naturae praktische Erfüllung fanden) aus dem Kreislauf der Elemente von oben nach unten und umgekehrt (mit dem Symbol des Ringes des Platon, der goldenen Kette des Zeus, des Homers, später des Superius et inferius Hermetis) ${ }^{1}$ ) fanden sie weiteren Ausbau. Auf ihnen fußte noch lange die Wissenschaft von dem Bau, dem Werden und der Art der Welt (in naiver Art stellt sie die Abbildung 2 aus dem XVI. Jahrhundert dar), und aus ihnen folgte die Annahme der Möglichkeit des Übergangs eines Stoffes in den andern, der Transmutation, die das Alchemistentum späterer Zeit im Auge hatte, und die scheinbar ja von den alten Metallurgen erreicht wurde, wenn sie (Zink-, Zinn-, Arsen-, Kupfer-, Antimon-)Erze, die ja offensichtlich mit Gold gar nichts zu tun hatten, in ein Metall verwandelten, das wenigstens

1) Vgl. unten die griechische Erklärung der alten Destilliergeräte S. 24. 
dem Äußern nach Gold war. Vgl. den betr. Abschnitt in meiner „Geschichte der Pharmacie".

Schon das Leben im allerersten Urzustand, in der flüchtig aufgebauten Hütte konnte und muß den Menschen, wie schon gesagt, einige "phytochemische" Entdeckungen machen gelassen haben. Er mußte gewahr werden, daß manches Holz kienig war, d. h. daß Harz schon zu gewöhnlicher Zeit aus Verletzungen heraustrat, noch mehr, wenn es erwärmt und angezündet wurde, daß es an der Luft erhärtete, daß solche Hölzer leicht entzündbar, mit leuchtender, wabernder Lohe ${ }^{1}$ ) brannten, die vortrefflich für Leuchtzwecke und zum Verscheuchen wilder Tiere gebraucht werden konnte, daß Verbrennungsgase entstanden, die ätzend rochen und ätzend riechende und schmeckende Flüssigkeiten absetzten, die wie die Gase selbst auf tierische Stoffe erhaltend (fäulniswidrig) wirkten, daß weiter aus solcher Lohe reichlich der schon erwähnte Ruß sich absetzte, und Holz ganz im allgemeinen unter gewissen Umständen, wenn die Verbrennung z. B. durch aufliegende Asche oder sonst wie beeinträchtigt wurde, im wesentlichen seine Form behielt, aber schwarz wurde und eine Kohle gab, die flammenlos brannte ${ }^{2}$ ) und dem Verfaulen völlig widerstand.

Die Richtigkeit solcher Annahme beweisen Ausgrabungen aus uralter Zeit, beweist das Tun und Treiben zeitgenössischer "Wilder", beweist der in Betracht kommende Wortschatz, von dem nur der klassische, selbstverständlich auf eine lange Reihe von Vorläufern, auf eine lange Geschichte zurückblickende erwähnt werden soll. Auf das griechische ì $\eta$ iv $\eta$ und

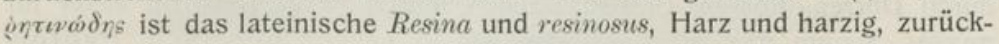
zuführen. Fumus, xásvos sind die Worte für Rauch. Aus ihm setzt sich

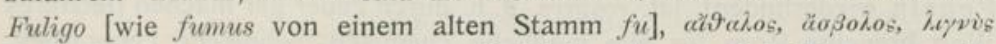
Ruß ab. Im Fumarium wurde z. B. Wein altern und haltbar gemacht,

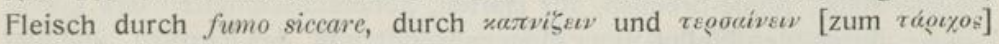
gedörrt oder geräuchert. Aus Kienholz, Taeda und $\pi \varepsilon v \eta \eta$ wurde die Kienfackel, taeda [sprachlich verwandt mit] $\delta a t_{s}$ oder $\delta \dot{\varphi} s$ gespalten und geschnitzt, aus der man Harz oder Pech pix, zioøa wie eine Träne, lacrima, dáav (ov) ausschwitzen, exsudare, lacrimare, exdaxpviev sah usw. ${ }^{3}$ ), wie man das übrigens bei einer Menge von als Arznei- und Rauchmitteln gebrauchten Harzen, Gummiharzen usw., bei Myrrha, Euphorbium, Ladanum, Opium usw. genugsam beobachtet hatte. Daß auch das Austreten von Pflanzen-Gummi und Gummiharzen beobachtet wurde, sei nebenbei bemerkt. Lange war ja Gummi (arabicum) und Scammonium bekannt.

1) Darüber vgl. Plinius $16,19$.

2) Daß der Kohlendampf, wohl Kohlenoxydgas, giftig wirkte, berichtet schon A ristoteles, ihm nach Lucretius Carus usw.

3) Das Darstellen von Fackeln, die schließlich auch unterseits in Teer oder Pech gctaucht wurden, wie das von $\pi v \rho e \mathcal{L} \alpha$, igniaria, Feuerzeugen wurde jedenfalls schon in grobem Makstabe betrieben. 
Kaum wesentlich bessere Lebensverhältnisse waren für Zunahme chemisch-technischer Erkenntnis nötig. Auf hier und dort angezündeten Lagerfeuern, dann auf dem fest abgegrenztem, schließlich erhöhten Herde machte der Mensch seine ersten küchen-, phyto-, iatro- und technischchemischen Beobachtungen. Blinder Zufall lehrte ihn dort die Anfänge der Keramik, der Töpferkunst. Lange jedenfalls bevor der Wilde an ein überirdisches, übersinnliches Wesen, eine Gottheit, dachte, die das All geschaffen, mit der er durch himmelwärts steigenden Brandgeruch glaubte in eine Art persönliche Verbindung treten zu können, um von ihr Gaben „per fumum und Erlaß von Strafen zu erbitten, nach Gebilden aus der tierischen und pflanzlichen Umwelt (wie ich das in einer früheren Arbeit geschildert habe) formte er seine Tongeräte. Nach dem Muster unzweifelhaft der Hütte, in der er die Destillation des Holzes hatte beobachten müssen, oder nach dem Muster des Alls, wie er es sich dachte (vgl. die Abbildung 1), richtete er sich ganz unzweifelhaft bei der Konstruktion, dem Aufbau der ersten Vorrichtungen oder Geräte, deren er sich bediente, als er sie zielbewußt vornahm (und nicht wie Höfler, m. E. allzusehr aufgehend in seinen geradezu klassisch verarbeiteten Anschauungen über das Opferwesen ${ }^{1}$ ), das schildert).

Solche Geräte waren jedenfalls nötig, um die Grundlagen für unsre moderne Destillation zu entdecken. Denn solange war die Hüterin der Küche lediglich auf, modern gesprochen, pyrochemische Arbeiten angewiesen, auf Verdaulichmachen der tierischen und pflanzlichen Produkte

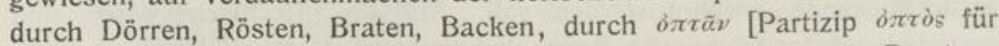
$\pi \tau_{\tau} \grave{s}$, Stamm $\pi \varepsilon \pi$ in $\pi \dot{\varepsilon} \sigma \sigma \omega$, das wir in unserm peptisch, Pepton, Pepsin wiederfinden], lat. coquere, d. h. durch Feuer gar machen [letzteres Wort brauchte Rom für alle mögliche chemisch-technische Feuerarbeit, Ziegel-, Kalk-, Kohle-Brennen, für Härten, Silberausschmelzen usw.], concoquere, durch (den Einfluß einer Magenabsonderung, des Pepsin, und die) Körperwärme gar machen, verdauen.

Erst beim Erhitzen der Milch, dem vermutlich allerersten Kochversuch ${ }^{2}$ ) wird die am Herd hantierende Frau erfahren haben, daß die am Deckel sich festsetzende Flüssigkeit wasserklar, anders wie die Milch aussah und schmeckte, dann daß Würzstoffe, mit Wasser gekocht, dem Dampfe und dem durch Abkühlung daraus verdichteten Wasser ihre

1) In "Die volkstümliche Organtherapie“, Stuttgart, Berlin, Leipzig 1908, S. 15, sagt er: Der Brandopfergeruch sollte durch keine andre Feuerunterlage beeinträchtigt werden. Im Laufe der Zeit verwandelte sich der Opferaltar aus Ziegelsteinen in einen irdenen Hafen und dieser mit der Zeit in den Destillier-Helm des mittelalterlichen Chemikers, der seinen Vorläufer haben dürite in dem Weihrauchrus liefernden Ziegelerdetiegel mit Deckel, wie ihn Dioskorides I, 84 schilderte, daß diese Wandlungen wirklich nicht in Frage kommen, dürfte jeder Leser ohne weiteres zugeben.

7) Vgl, meine erste Arbeit „Zur Geschichte der chemischen Geräte”, Pharmaz. Zentralhalle $1907,36 \mathrm{ff}$. 
Riechstoffe abgaben ${ }^{1}$ ), und andere hierher gehörige phytochemische Tatsachen ${ }^{2}$ ).

Andere als Küchengeräte konnten - wie sie im übrigen auch jetzt noch völlig selbstverständlich in der chemischen Technik verwandt werden - für die ersten Destillationen nicht in Anwendung gezogen werden, und sie wurden später in zweckdienlicher Art um- und ausgestaltet.

Für die vermutlich allererste, die Holzdestillation konnte man eines Geräts völlig entraten. Der erste, der meines Wissens eine solche, übrigens aufs eingehendste beschreibt, ist Theophrast, geboren 370 v. Chr. in Eresos auf Lesbos. Er stützt sich vermutlich auf eigene Anschauung, dabei doch unzweifelhaft auf eine Arbeitsart, die auf frühere Jahrhunderte, Jahrtausende alte Erfahrung zurückblicken kann. Er beschreibt ${ }^{3}$ ) das Kohlenbrennen folgendermaßen:

In einer tennenähnlich gestampften, vermutlich nach der Mitte hin flach trichterförmig geneigten, der Herdplatte entsprechenden Fläche war

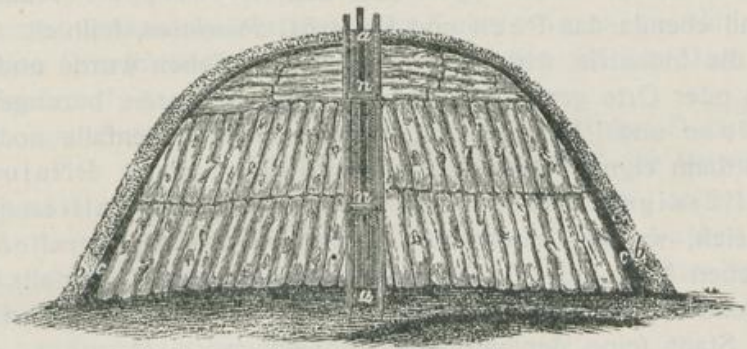

Abb. 3. Kohlenmeiler.

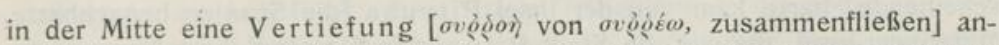
gebracht, wohinein die flüssigen Schwelprodukte zusammenlaufen sollten. Von ihr aus ging ein ǒ $\chi \varepsilon \tau o$ s, eine vermutlich oder jedenfalls unterirdische Röhre, ein Canalis etwa 16 Ellen weit, und endigte dort, also außerhalb des Meilers in einer Auffanggrube. In ihr sammelten sich die flüssigen Destillationsprodukte, und in ihr setzten sich nach dem Abkühlen die einzelnen Bestandteile, flüssiger Teer, Teerwasser, Holzessig usw. ab.

1) Daß die Kunst des Salbenbereitens, die Pharmacie, von Köchen in den ägyptischen Tempeln in ihrer Grundlage festgelegt wurde, behauptet auch Plutarch. „Die Küchenkunst ist für uns (Chemiker) in vieler Beziehung äußerst nützlich", sagt eine $300 \mathrm{n}$. Chr. in Ägypten abgefaste Abhandlung. Die Arbeiten von Coelius Apicius haben jedenfalls auch pharmazeutischen oder phytochemischen Wert. Der Titel „Opus mulierum “, für ein alchemistisches Werk von 1550 , soll jedenfalls, hier allerdings unzweifelhaft spottend, an grundlegendes Frauenwerk erinnern, d. h. an Küchenarbeit.

2) Vgl. weiter unten, daß Megen berg erklärt: der dunst von rosen oder w ein prennen in wazzer entsleuzt, daz selbig wazzer von dem ding smeckt, dâ von der dunst kommt. Vgl. ev. auch oben S. 5 .

2) Historia plantarum, Buch IX, 1, 3, vgl. Plinius 16, 8.

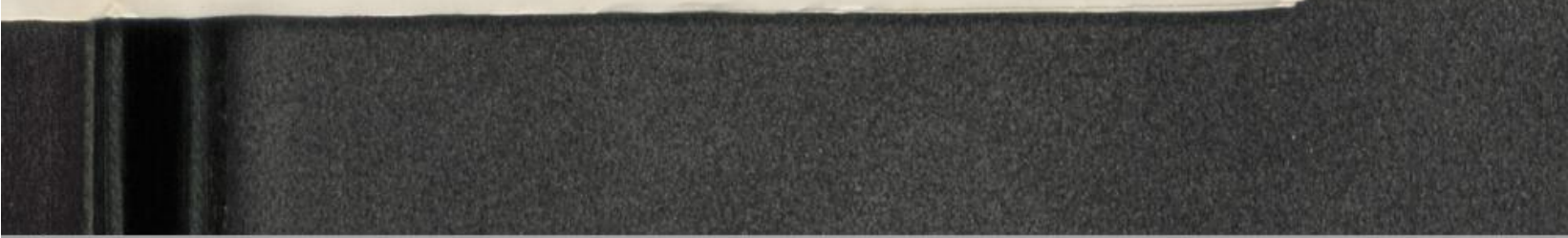


Hören wir weiter, daß das auf der Tenne stehend aufgehäufte Spaitholz außen mit Erde, Lehm oder Rasenstücken, wie mit einem Deckel oder Dach soweit bedecktgehalten ward, daß nur soviel Luft zutreten

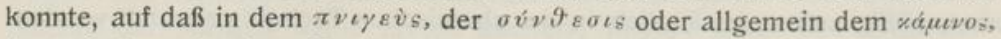

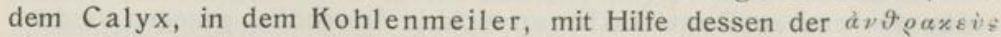

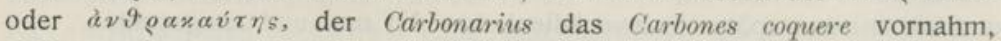
das Brennen eben unterhalten, eine Verbrennung aber vermieden wurde, so erkennen wir in dieser Vorrichtung, wie sie noch jetzt wohl hier und dort von Köhlern aufgebaut und betrieben wird, die wesentlichsten Teile eines Destilliergeräts: ein Gefäß zur Aufnahme des Destillierguts, einen Deckel, ein Ablaufrohr, ein Auffanggefäß.

Daßs solche Industrie im Altertum bekannt war, beweisen die oben angeführten Namen für die Rohstoffe und die Erzeugnisse aus ihnen, be-

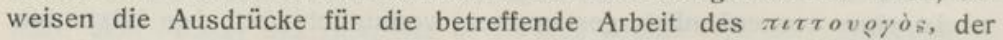
aus Kiefern-, Fichten-, Cypressen-, Wacholder-, Zedern-Holz')

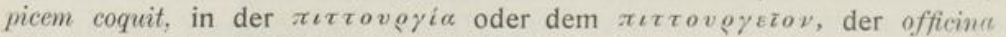
picaria und ebenda das Pech und Pechöl, Pisselaion, feilhielt.

Daß die Industrie wirklich im Großen betrieben wurde und manche Gegenden oder Orte geradezu durch sie bekannt waren, bezeugen wieder Dioskorides und Plinius ${ }^{2}$ ) auf Grund zumeist jedenfalls noch älterer Autoren ${ }^{3}$ ) dann eigner Wahrnehmungen in Buch 1, K. 92. Plinius spricht von dem flüssigen Kiefern- und Fichtenharz aus Gallien (jedenfalls Südfrankreich, welches noch viel Terpentin liefert), Tyrrhenien (am Tyrrhenischen Meer, der Westküste Italiens), Galatia (jedenfalls im nördlichen Kleinasien; vielleicht Ober-Italien?) und in Kolophon, einer jonischen Stadt (eine der vorgeblichen Geburtsorte Homers, nach der noch jetzt dem Harz sein Name gegeben wird). Das feinste, durchscheinende, harte kam von der Insel Pityusa [die Spanien benachbarte Mittelmeer-Insel, die wie die Stadt Pitueia in Mysien ihren Namen von ihrem Reichtum an Fichten, xitvs, erhalten hat]. Seine Darstellung, die nicht hierher gehört, beschreibt derselbe Schriftsteller im folgenden Kapitel 93.

Das Gerät, das man auf Grund solcher Kohlenbrenn-Erfahrung, dann unter Anlehnung an die Hütte und das auf seinem Herde gebrauchte Gerät $\left.{ }^{4}\right)$ in Benutzung ziehen oder anfertigen konnte und mußte, finden

1) Plinius 16, 16, 19, 23. 14, 25. Die jeweilige Arbeit dauerte zwei Tage. Wächter paßten auf, Flammenausbruch zu verhüten, Gebete wurden gesprochen, um von den Göttern Segen für die Arbeit zu erflehen. Theophr. I. cit.

2) Pech wurde zum verpichen von (Wein-) Fässern und TongefäBen (vasa und dolia. picata), und neben Gips zum verschließen $(14,27,15,18$. Cato r. r. 25. Colum ella 14, 4, 4. Horaz, Carm. 3, 8, 10. Martial 13, 107), Teer zum Dichten der Schiffe und der Hausdächer (Plin. 16, 23. Dioskor. 1, 98. Plin. 36) verwandt.

$\left.{ }^{2}\right)$ Vgl. über ihre Vorläufer meine Gesch. d. Pharmacie, S. 194.

4) Die für seine Darstellungen gebrauchten tierischen oder pflanzlichen Urformen kommen praktisch hier nicht mehr in Betracht. Nur ihre noch gebrauchten Namen erinnern an sie. 
wir bei Dioskorides bei Arbeiten beschrieben, die, weil es sich um ein festes Destillationsprodukt handelt, wir eine Sublimation nennen würden, dann bei Plinius bei der Beschreibung der nach moderner Bezeichnung trocknen Destillation von Teer und Holzessig, einer verfeinerten Kohlenbrennerei.

Dioskorides läßt, um Weihrauchruß, $\alpha i \vartheta \dot{\imath} \lambda \eta \lambda\langle\beta \alpha \nu \omega \tau o \tilde{v}$, zu bereiten ${ }^{1}$ ), einen irdenen Grapen oder Tiegel so mit einem kupfernen in der Mitte durchbohrten, gewölbten Gefäß bedecken, daß dieses, von einigen Steinchen am Rande unterstützt, genügend großen Zwischenraum läßt, um durch ihn hindurch mit einer Zange, vorher in Brand gesetzte Stückchen Weihrauch in den Grapen zu legen. Es ist das ein Gerät, das, einer Hütte im Kleinen ähnlich, bedeckt ist mit einem Dach, das, wie in den Uranfängen des Hausbaus und noch in den hochkultivierten Zeiten des Unglücks von Pompeji, mitten ein Loch zur Ventilation und zum Durchlassen des Rauchs hatte (Vgl. oben S. 4).

Wenn Dioskorides an gleicher Stelle empfiehlt, den Kupferdeckel mittels eines großen wassergetränkten $\mathrm{Schwammes}$ zu kühlen, so erinnert diese Oberflächenkühlung wieder an den auf das Dach prasselnden kühlenden Regen.

Auch um Sublimationen handelt es sich bei der Darstellung der $\approx \alpha \delta \mu \varepsilon i \alpha$, eines unreinen Zinkoxyds, das sich bei der Verhüttung von Kupfer- und Silbererzen an der Decke der Schmelzöfen ansetzt und für dessen Auffangen man später spitz zulaufende eiserne Auffangerohre, Acestides, dxeorides anbrachte $\%$ ). Daß diese Destillation oder Sublimation jedenfalls in recht großem Maßstabe, in Häusern und Kammern vorgenommen wurde, belegt die folgende Beschreibung:

Hüttenrauch, (Pompholyx) sieht fettigweiß aus. Er ist so leicht, daß es in die Luft fliegt. Eine Art ist fettigbläulich, die andre reinweiß, äußerst leicht. Erstere entsteht, wenn die Hüttenleute feine gestoßene Kadmeia (bei der Verhüttung des Kupfers in den Akestiden sich ansetzend, Dioskor. 5, 84) in größerer Menge aufschütten. Der daraus aufsteigende, sehr fein verteilte Rauch wird Pompholyx genannt. Nicht allein aus dem (zinkhaltigen) Kupfererz wird Pompholyx bereitet, sondern auch aus Kadmeia. (Dasselbe berührt auch Galen auf Grund

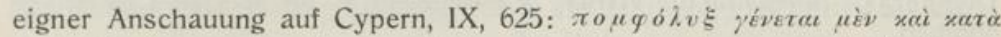

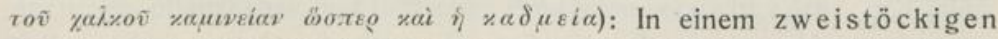
Hause wird unten ein Schmelzofen gebaut; mit dem oberen Stockwerk, das Löcher oder Schornsteine zur Abführung des Rauchs hat, steht er durch eine Öffnung in Verbindung. Seitwärts hat der Raum mit dem

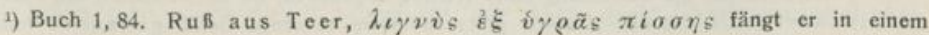
$\varkappa \hat{\lambda} i \beta \alpha \nu \circ s$, einem pfannenähnlichen Gefäß auf, das über die Flamme von in einer Lampe mit Docht brennendem Teer gehalten wird, eine Vorrichtung, die wieder an die Hütte mit dem unter dem Dach qualmenden Feuer gemahnt.

7) Dioskorides 5, 96. Plinius 34, 22. 
Schmelzofen eine Öffnung, durch die die Düsen aus Blasebälgen Luft zuführen, und eine Tür für den bedienenden Arbeiter. In einem Seitenraum stehen die Blasebälge. Wenn die Kadmeia in Rauch aufgeht, steigen die feineren, leichteren Teile in das obere Stockwerk, wo sie sich an den Wänden festsetzen wie Knäuel Wolle ${ }^{1}$ ). Der schwerere Hüttenrauch fällt auf den Boden.

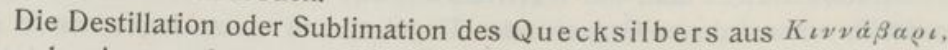
Cinnabaris, wurde aus Eisengefäßen vorgenommen, die in Tongefäßen, also Capellen zur Schonung standen ${ }^{2}$ ) und darin längere Zeit erhitzt wurden. Bedeckt waren die eisernen Gefäße (das Metall sollte jedenfalls dem Zinnober den Schwefel entziehen, und eine tönerne Capelle wählte man wohl, damit sich das freiwerdende Quecksilber, das „mit seinem Geifer alle metallenen Gefäße zerfrißt $\left.{ }^{3}\right)^{\prime \prime}$, nötigenfalls darin ansammelte), mit einem Deckel, dem Ambix, der mit Ton verkittet ${ }^{4}$ ) war. Aus dem darin sich abscheidenden „Ruß" konnte das Quecksilber abgetrennt werden.

Den von ihm beschriebenen Teerdestillationsapparat kannte Plinius kaum auf Grund eigner Anschauung ${ }^{5}$ ). Er hätte sonst vermutlich eingehender, anschaulicher darüber berichtet. Nach dem Muster des oben nach Theophrast beschriebenen Meilers, weiter nach den sonst genannten Vorbildern konnte aber sein Furnus [ebenso wie Fornax und Fornus, franz. Four, Fourneau, Fournaise, am Rhein die Farnüß vom Stamme For und verwandt mit ferveo und ЭÉoouce warm werden] zur Aufnahme der zu destillierenden Taeda nur gestaltet sein aus Ziegelsteinen, ähnlich einem Backofen damaliger oder noch nicht lange vergangener Zeit oder aus Ton oder Metall und dann vermutlich gestaltet wie die uralten Mi (die in den, noch vor kurzem zum Versandt des Luccaöls gebrauchten

1) Spätere Lana philosophorum. Diosk. 5, 84, 85. Das Hinzuführen von Luft, um das Metall zu oxydieren und zugleich um den Zug zu befördern, bezeugt ebenfalls schon eine weit vorgeschrittene Technik.

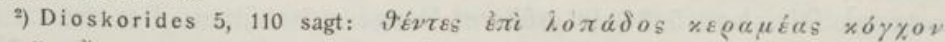

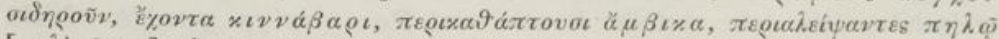

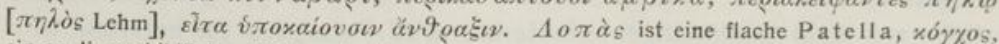
ein an die vorbildliche gleichnamige Muschel erinnerndes tieferes Gefäß. Vgl. unten. Plin, 34, 41. Theophrast, De lapidibus 60 . Vitruv, De architectura 7, 8. Vgl. auch unten die indische Arbeitsart.

э) Plinius $33,82$.

4) $\mathrm{DaB}$ die Alten auch andern Kitt kannten, mit dem sie zerbrochenes Glas zusammensetzten, geht aus des Plinius Äußerung hervor: Ne quid desit ovorum gratiac, candidum ex his admixtum calci vivae glutinat vitri fragmenta 29,51 . Mit Kalk nnd Eiweiß, auch mit geschmolzenem Schwefel kitteten herumziehende Gewerbsleute zerbrochenes Glas.

$\left.{ }^{5}\right)$ Lediglich auf die Gewinnung einer Kohle abgesehen, ist unzweifelhaft die Vorschrift, die Dioskorides 1, 133 bei 'Axaxia gibt: In einem tönernen Gefäß gebrannt (oder auf Kohle unter Beihilfe eines Blasebalges), soll Akaziengummi als Heilmittel verwandt werden. Ähnliches bezweckt das Brennen der Ölbaumblüten (der 'A yoreitcia) in einem festverschlossenem Tongefäß (Dioskorides 1, 118, Plinius 23,35), einer Vorrichtung, wie sie auch jetzt bei der Knochenverkohlung und bei der Verkoakung gängig ist. 
Tongefäßen ihre Nachkommen haben), wie längliche Kürbisse. Sie wurden mit den zersägten Holzscheiten gefüllt und umgekehrt über eine Grube gestellt, wie sie die Meiler auch hatten, vermutlich mit Lehm luftdicht darauf befestigt und durch außen aufgeschichtetes Feuer erhitzt. „Das erste läuft wie Wasser durch eine (vielleicht seitlich angebrachte) Röhre ab." Aus Cedrus (vielleicht einer Juniperusart) ward auf diese Art das

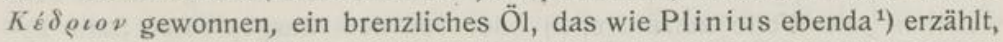
neben dem (Teer-)Wasser (und dem Holzessig) zur Haltbarmachung von Leichnamen, also zum einbalsamieren in Ägypten benutzt wurde

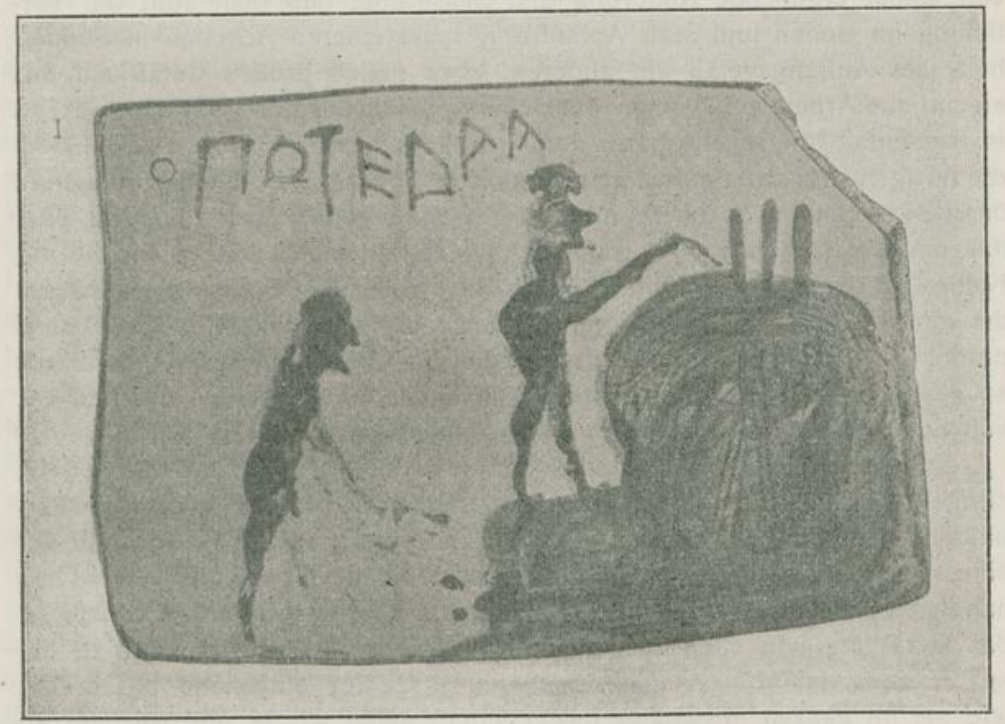

Abb. 4. Vermutlich verfeinerte Darstellung eines Schwelprodukts nach einer Tontafel im Königl. Museum in Berlin.

Ein so gestalteter Apparat wurde sicherlich zu den Zwecken trockener Destillation, wie sie begreiflicherweise die Jahrhunderte durch an allen möglichen pflanzlichen und tierischen Produkten versucht wurde, und dann in Sonderheit von den Arabern, die zeitweise die einzigen Hüter pharmazeutisch-chemischer Wissenschaft und Praxis waren, benutzt, um aus ihnen den Träger der Würzstoffe, deren Anwesenheit Geruch und Geschmack gleicherweise verriet, in konzentrierter und handlicher Form auszuziehen, soweit man sich nicht damit begnügte, sie nach uralt überkommener Art durch Ausziehen mit Öl und anderen Lösungsmitteln darzustellen ${ }^{2}$ ) oder,

1) Plinius 16, 21. Vgl. auch Theophrast $9,3$.

) Das Buch XIII bei Plinius z. B. handelt davon. 
wie es bei den Ölen der Citrusarten jedenfalls wohl geschah (Medische Äpfel waren den Griechen wohlbekannt, Plinius spricht von Citronenöl, und es kann den Alten gar nicht entgangen sein, daßs der Riechstoff schon beim Verwunden der äußeren Schichten der Schale, von der als seines Trägers allerdings erst Oribasius im VI. nachchristlichen Jahrhundert spricht, herausspritzte ${ }^{1}$ ), also äußerst leicht zu gewinnen sei), vielleicht mit Wolle aufzunehmen oder von dem ausgepreßten Safte abzuschöpfen usw.

Es war eine als wesentlich zu bezeichnende und in der Praxis sich von selbst ergebende Änderung und Besserung, daß man statt der Vertiefung im Boden und statt Ablaufrohr, bei kleineren Arbeiten in Sonderheit, als Auffangsgefäß ein anderes, etwa gleich großes Gefäß auf das eigentliche Arbeitsgefäß (man bezeichnete solche später wohl als „activa instrumenta" im Gegensatz zu den „passiva", den Vorlagen u. dgl., die die fertigen Präparate aufnehmen) festkittete, dieses letztere eingrub und um das verkehrt stehende obere, mit dem Vegetabil gefüllte Feuer schürte, oder daß man feststehende oder tragbare, aus Metall angefertigte Öfen, die mit Kohlen angeheizt, schon vielfach im Altertum gebraucht wurden (das Museum der auf dem Boden von Pompeji ausgegrabenen Geräte zeigt ebenso praktische wie künstlerisch hervorragende Stücke!) für den Sonderzweck so gestaltete, daß das Auffangegefäß in einen Raum herrunterreichte, der von dem Feuerraum durch eine Scheidewand getrennt war.

Es ist ebenso natürlich und selbstverständlich, daß der Praktiker die nötigen Gefäße, aus Zweckmäßigkeitsgründen z. B. der leichteren Verbindung mit den Auffangegefäßen wegen, immer mehr der Gestalt der einerseits verjüngten Streitkolben oder ähnlicher Flaschenkürbisse nahebrachte, daß er Cucurbitae konstruierte und verwandte. Ordnete er das Gerät an, wie eben dargelegt, so zeigt sich bei solcher Arbeit, die später als Destillatio per descensorium z. B. Geber eingehend beschreibt, wie sie im ganzen Mittelalter unzweifelhaft geübt wurde und wie sie tatsächlich auch jetzt noch z. B. bei der Darstellung des (hier allerdings nicht ganz hingehörigen) Seefelder Teers, des Ichthyols und wohl auch noch bei der des Ol. Juniperi oxycedri oder cadinum in Anwendung kommt.

Megenberg in der Mitte des XIV. Jahrhunderts beschreibt, fußend auf früheren Vorschriften, die Art der Destillation des Öls aus dem Kranwitpaum- oder lateinisch Juniperus-[er leitet das Wort beiläufig von zĩe ab und übersetzt es danach in Feuerbaum] Holz folgendermaßsen und bestätigt damit das Gesagte: Man nimt zwên erein (erzene) häfen und setzet sie über enander, und der obere hafen schol ain loch hân an dem podem. denselben obern hafen schol man fülllen mit dem kranwitholz, daz trucken sei, und schol den wol vermachen, daz ihts (nichts) dar auz

1) Daß noch jetzt z. B. das Citronenöl auf diese Art dargestellt wird, sei nebenbei bemerkt. 
rauhs müg kommen, und schol ain grôz feuer umb die häfen machen. wenn dann das holz inwendig erhitzt, so fleuzt das öel auz dem obern hafen in den untern, aber das ist wenig (S. 325).

Es ist das ganz und gar die Art, wie Mesue etwa 300 Jahre früher sein Wacholderholzöl, übrigens auch (aus mit Öl getränkten Ziegelsteinen sein Ziegelsteinöl) das Ol. de lateribus, philosophorum oder sapientiae destillierte, und ein Gerät, wie es z. B. Walter Ryff beschrieb und in seinem Destillierbuch, Frankfurt 1567; darstellte. Vgl. die Abb.

Auf ganz andern Vorraussetzungen und der Erfahrung, daß gewisse Stoffe wie Wolle (erst durch Lowitz' Entdeckung der aufsaugenden Kraft der Kohle ist man wohl auf den Gedanken gekommen, diese Erscheinung der schon von Leonardo da Vinci 1490 entdeckten Capillarität zuzuschreiben) ${ }^{1}$ ) die aromatischen Stoffe mit besonderer Vorliebe aufnehmen und festhalten, beruht eine andre, dem Sinne des Wortes nach nicht hergehörige Art der Gewinnung ätherischen Öls durch Verflüchtigung zugleich mit Wasserdämpfen mittels Erwärmung und nachheriger Verdichtung, deren hier gedacht werden muß. Dioskorides erwähnt sie in den Kapiteln 95, 105 des ersten Buches.

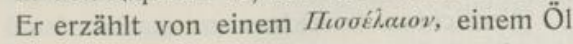
aus einem jedenfalls flüssigen Harz, wie anzunehmen Terpentin, das von sehr fettem (also kienigem) Kiefern- oder Fichtenholz gesammelt wird, also jedenfalls freiwillig

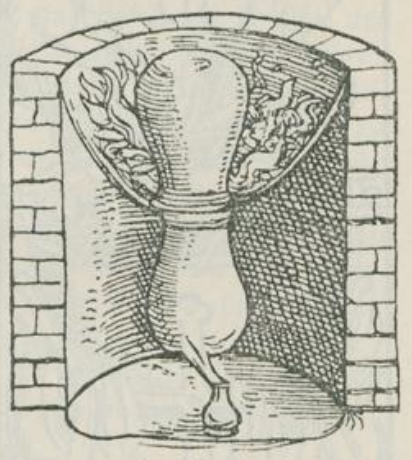

Abb. 5.

Absteigende Destillation nach Ryff. aus ihm ausfließst. Verschiedene Über-

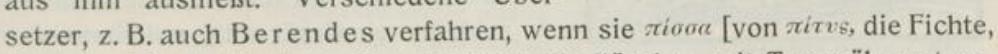
danach pix], und insbesondere die $v$ yod̀, die flüssige, mit Teer übersetzen, nach dem alten Sinne des Wortes richtig. Denn ursprünglich war Teer; engl. tar, ganz wie tioox, das vom germanischen drewo [englisch tree und ähnlich in andern Sprachen], dem Baum, abfließende Weichharz, während er jetzt im Arzneibuch als Pix liquida zum Destillationsprodukt aus den rohen Harzen oder dem harzigen Holz geworden ist, und der Name des Baumes, der nach Dioskorides 1, Kap. 91 das beste Harz lieferte,

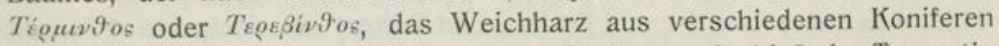

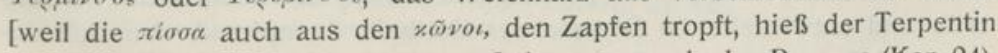
auch $\left.\tilde{\omega}^{\prime} \nu_{0}\right]$ bezeichnet. Aus diesem Lebenserzeugnis des Baumes (Kap. 94), bei dem der wäßrige (oder flüssige) Teil etwa wie Molken über dem gewonnenen Käse sich abscheidet, wird (nach Kap. 95, für $\varkappa \dot{\varepsilon} \rho o s$ in Kap. 105) das Pisselaion, aus dem Tegeßiv 9os sein yozous durch Kochen erhalten.

1) Vgl. dazu weiter unten seine Vorläufer. 
Über dem Gefäß wird reine Wolle ausgebreitet und wenn sie mit dem verdampfenden Öl getränkt ist, in ein Gefäß ausgequetscht.

Daß solche Arbeit später wirklich ausgeführt worden ist, habe ich nicht feststellen können; daß man ihrer gedacht hat, das beweist eine Stelle in des pseudonymen Euonymus Philiater bekanntem Werk "Ein köstlich theurer Schatz", Zürich $1555^{1}$ ) und eine zugehörige Abbildung, wie sie nach des Dioskorides eben erwähnten Äußerungen leicht entworfen werden kann. Vielleicht ist der Schwamm, der später in das aufsteigende Kühlrohr gesteckt werden sollte, auch noch eine Erinnerung an Dioskorides. Vgl. die Abb. 6 und weiter unten.

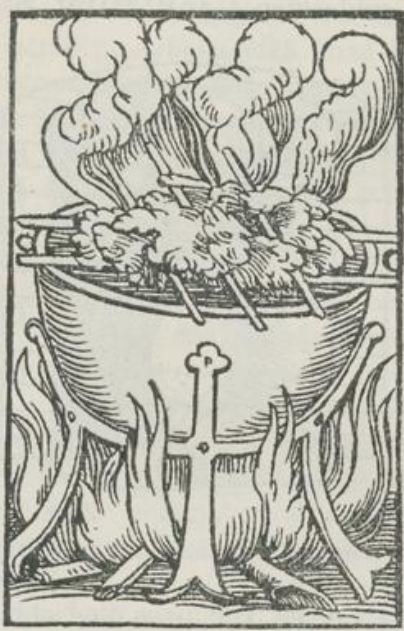

Abb. 6. Auffangen des Destillats durch Wolle nach Euonymus.

Tatsächlich muß man im IV. vorchristlichen Jahrhundert eine Destillation in unserm Sinne und ein Gerät gekannt haben, denen ähnlich, wie sie eine spätere Zeit, wie wir sehen werden, in Anwendung gezogen hat. Denn A ristoteles, geb. 384 in Stageira auf der makedonischen Halbinsel Chalkidike, berichtet in seinen Meтвwoohoyexì II, 3, daß es möglich sei, bitteres, ungenießbares Seewasser durch Überführung in Dampf mittels Feuer und späteres Verdichten trinkbar zu machen, und an andrer Stelle erzählt er von einer „entflammbaren Ausdunstung des Weins" ${ }^{2}$ ), die ähnlich durch Verdampfung und Wiederverdichtung darzustellen sei. Zu solcher Arbeit war entschieden ein Gerät nötig, vollkommener, wie die schon geschilderten, die darzustellen die damalige Glas- und Tontechnik in vollstem Maße hinreichte.

Daß man in ähnlicher Art Ruchstoffe aus den vielen bekannten riechenden Harzen und Pflanzenteilen darstellte oder darzustellen versucht hat, wird nirgends berichtet. Plinius erzählt, „die Wälder hätten früher die schätzenswertesten Ruchstoffe besessen", d. h. man sammelte in ihnen (und, was zuzusetzen ist, auf Feldern und Triften) die riechenden Pflanzenteile und entwickelte im Dienste der Gottheit, ihr opfernd, den Duft dadurch, daß man sie (wie Plinius z. B. hervorhebt, Cedern- und Citronenholz) in Brand setzte. Später erst „gefiel es dem Luxus, die Ruchstoffe zu vermischen und aus allen einen einzigen zu machen" und zwar in der Ge-

1) Vgl. meine Geschichte S. 410.

2) Plinius erzählt von Falerner Wein, der sich (also durch seinen Alkoholgehalt) dadurch auszeichnete, daß er sich anzünden lasse. Buch 14, 8 . 


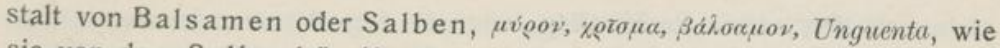

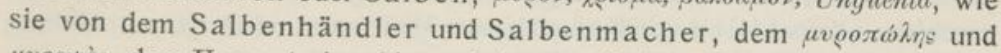
uvesqòs, dem Unguentarius, hie und da, wo die betr. Pflanzenteile wuchsen oder besonders vorteilhaft zu erlangen, oder die Fabrikate besonders gut zu handeln waren, in Capua (in der Gasse der Seplasiarii) geradezu „,en gros" dargestellt wurden. Zu Trojas Zeiten kannte man solche Salben noch nicht wie Plinius weiter ${ }^{1}$ ) berichtet. „Die Salben müssen eine Erfindung der Perser gewesen sein. Sie triefen davon und vertilgen durch Anwendung künstlicher Wohlgerüche den aus ihrem Halse sich entwickelnden Gestank" (jedenfalls nach, den Römern unerträglich riechendem Allium).

Denkt man an den Reichtum des genannten Landes an Ruchstoffen, zieht man weiter die körperlichen Verhältnisse seiner Bewohner in Betracht, so ist des Plinius Bericht immerhin glaubhaft, und ebenso der fernere, daß bei der Eroberung des Lagers von König Darius Alexander einen wohlversorgten Salbenschrank erobert hat. Durch ihn kam vielleicht erst das Vergnügen an solchen Parfüms nach Rom und wurde $\mathrm{zu}$ den löblichsten und anständigsten Gütern über das Leben hinaus gerechnet.

Um die riechenden Bestandteile in konzentrierte, dem erwünschten Zweck besonders gut dienende Form zu bringen, wurden die betreffenden Pflanzenteile mit Wein, in den allermeisten Fällen mit Öl in Glasgefäßen an der Sonne digeriert²), dann durchgeseiht und bis zur Honigdicke (und Verjagung der Feuchtigkeit) gekocht.

Es ist selbstverständlich, daß diese bei nicht zu hoher Temperatur dargestellten Fettauszüge, gleich den modernen aus Südfrankreich,

1) Buch 13, Kap. 1.

2) Plinius 13, 73. Wenn auch nicht geradezu hierher gehörig, so verdient doch erwähnt zu werden, daß das Altertum sich sehr genau bewußt war, daß störende Einflüsse den äußerst empfindlichen Ruchstoffen ferngehalten werden mußten und daß dementsprechend nur reinstes, geruchloses ÖI verwendet werden durfte. Lucrez sagt in seinem oben erwähnten Buche 2, 820: Wenn aus Mairan und Myrrhe und aus des Jasmines

Nektarblüten man duftsüßhauchende Salben bereitet,

Suchen vor allem man muß, womöglich geruchlosen Öles

Reine Natur, wovon kein Hauch die Nerven berühret;

Daß zum mindesten nicht es die eingemischeten Düfte

Mit dem eigenen Geruch ansteck' und solche verderbe.

Gieich interessant sind die Ausführungen desselben Schriftstellers, Anschauungen seiner Zeit, sich aufbauend auf den Ansichten der alten Philosophen, Empedokles, Heraklit usw., über das Wesen des Stoffs (Buch 4, 675 ff. vgl. auch S. 4):

Diese Gerü che nun selbst, die reizend berühren die Nase,

obzwar einige sich weiter als andere verbreiten,

Nimmer erreichen sie doch des Schalls und der Stimme Verbreitung,

Noch viel weniger auch des weithin tragenden Auges.

Mühvoll aus dem Innern des Ruchstoffs entwickelt sein Duft sich.

Das ergibt sich daraus, daß All', was zerbrochen, stärker

Duftet, noch stärker zerriebenes und was vom Feuer versengt ward.

Es sind größer sodann die kleinsten riechenden Theilchen

Als die Träger des Schalls, indem sic steinerne Mauern,

Welche jene leichtlich bezwingen, nimmer durchdringen. 
viele von den zarten Ruchstoffen, wie sie dem Altertum erstrebenswert erschienen, (aus Lilien von Korinth, aus Majoran und Quitten [-Blüten] von Kos, aus Rosen, die ihrer Farbenpracht und ihres Geruchs wegen unendlich geschätzt und in vielen Spielarten ganz im großen gezogen wurden, die Centifolia in Campanien und um Philippi in Griechenland, andere in Kyrene usw.) ${ }^{1}$ ) in sich aufnahmen und eine gewisse Zeit unverändert bleibende, die gekochten (wahre Olea cocta, nicht zu ihrem Vorteile zum Teil brenzlich geworden) unbegrenzt haltbare Zubereitungen darstellten.

Gerade die Rose, deren Geschichte sich im Dunkel der Sage verliert, wird es vermutlich auch gewesen sein, deren Duft der Mensch, der an ihr garnicht achtlos vorbeigehen konnte, vermutlich in erster Reihe möglichst lauter und rein darzustellen sich bestrebt haben wird.

In einer Rose, so erzählt eine Sage, soll eine der Gattinnen des Gottes Wischnu gefunden sein: mit der Gottheit wird die göttliche Blüte in Verbindung gebracht. Auf einem Weiher von Rosenwasser (vielleicht erst nur Wasser, in das man Blätter geschüttet, um deren Wohlgeruch ihm mitzuteilen) hat, so erzählt die Sage, ein indischer Großser seine Herzenskönigin in einem prächtigen Nachen gerudert. Durch die Sonnenstrahlen sollen auf dem Wasser sich Rosenöltropfen ausgeschieden haben. Auch bei Jericho sollen (wirkliche) Rosen angebaut worden sein, jedenfalls ob ihres Ruchstoffs, und um ihn irgend wie zu gewinnen. Persien (Farsistan mit den Rosen von Schiras) war als Rosenland seit ältesten Zeiten berühmt, und daß die gedachte Provinz dem Khalifen Mamoun (810-817) alljährlich 30000 Flaschen Rosenwasser als Tribut abliefern mußte, daß sie später 800 Kameellasten desselben Präparats an Saladin schicken mußte, damit mit ihm der Tempel von Jerusalem gereinigt werden sollte, ehe er ihn 1188 betrat, das läßt die Annahme gerechtfertigt erscheinen, daß man diesem Lande, der Überlieferungen durch Plinius gemäß, die Erfindung der Salbendarstellung und die der Destillation, und zwar zuerst die des Rosenwassers verdankt.

Wie der Destillationsapparat ausgesehen hat, in dem Aristoteles die Destillation des Meerwassers und die des Weins beobachtet hat oder hätte beobachten können, und in dem vielleicht um dieselbe Zeit schon Rosenwasser destilliert wurde, das ist weder in Beschreibungen noch in Nachbildungen auf unsere Zeit gekommen. Erinnern wir uns aber der in Betracht kommenden allerersten Urformen und der recht genauen Beschreibungen Theophrasts, des Dioskorides und Plinius, halten wir daneben, was eine spätere Zeit auf Grund alter Überkommenheit von handwerksmäßig arbeitenden Vorfahren - die Techniker, die am Feuer arbeitenden Banausen [ $\beta \dot{\alpha} v \alpha v \sigma o r]$, zu denen unzweifelhaft auch die hier in Betracht kommenden Unguentarii, Myrepsoi, Balsamkocher (Destillateure?), die Rokeach des alten Testaments gehörten, vererbten ihre

1) Plinius 21, 10. Vgl. auch meine Geschichte d. Pharmazie an den in Betracht kommenden Stellen.

rei

bis

ge:

Wi

sol

ver

dal

obı

bits

Tol

$\operatorname{leg}$

bl

Lel

$\mathrm{De}$

dut

licl

C'as

aus

alle

$J u$

jen

der

Stc

spä

an

leit

gef

$\mathrm{Tu}$

trö

Re

unc

str

daf

tec

top

Cul

sta

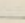

une 
rein „empirisch", erfahrungsmäßig erlangtes Können, ihre „Kunst", wie es bis vor wenig Jahrzehnten Regel war, mündlich, höchstens in ungelenk geschriebenen Rezeptbüchern ${ }^{1}$ ) von Generation auf Generation. Die Wissenschaft kümmerte sich um diese Handwerke oder Gewerbe nicht, sondern sah eher verachtungsvoll auf sie herab! - für urwüchsige Geräte verwandte (vgl. weiter unten!), so ist es leicht, sich auszumalen, wie die damaligen Geräte ausgesehen haben mögen. In mehr oder weniger nach oben verjüngten, gewöhnlichen Kürbissen [oder Schröpfköpfen, Cucurbitae] oder Flüssigkeitsbehältern aus Tierblasen [Vesicae] gleichenden Tongefäßen wurde das Destilliergut, Rosenwasser, auf dem wohl gelegentlich wirklich Öltropfen geschwommen sein mögen, oder Rosenblätter und Wasser erhitzt. Geschlossen wurde mit Hilfe von Kitt aus Lehm [Lutum von $\lambda \hat{v} \omega$, aufgelöste, erweichte Erde] das Gefäß mit einem

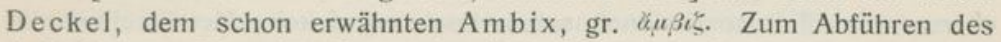
duftbeladenen Dampfes diente eine Ablauf-Röhre, ein Canalis aus pflanzlichen Stoffen aus (Schilf-) Rohr, Canna oder $x \dot{\alpha} \nu v a$ [hieraus das Wort Canalis], oder aus großem Calamus, xá̉huos [rein lateinisch Arundo, das auch zum Schreiben benutzt wurde], aus cyprischem Donax (botanisch allesamt wohl nach jetziger Bezeichnung Arundo-Arten), weiter solche von Juncus- und Cyperus-Arten, Fistulae aus Sambucus und im Orient Bambrs. jenachdem sie die Umwelt bot, oder aus Knochen, z. B. den Tibiae, den Schienbeinen verschiedener Tiere, die, beiläufig gesagt, ja auch den Stoff (und die Namen) für verschiedene Blas-Instrumente gaben. Erst eine spätere Zeit setzte (wie wir später sehen werden mit manchen Ausnahmen) an Stelle der genannten Naturerzeugnisse (zuerst übrigens wohl zu Wasserleitungszwecken) kunstreich aus zwei röhrenförmigen Stücken zusammengefügte oder aus einem Rund-Holz ausgebohrte oder aus Metall gefertigte Tubi, Röhren.

Unter diese Röhre mußte selbstverständlich zum Auffangen der abtröpfelnden, destillierenden [de stillare] Flüssigkeit ein Gefäß, ein Receptaculum, gesetzt werden. Ganz, wie es Dioskorides beschreibt, und ganz nach dem Muster des kühlenden, auf das Dach der Hütte strömenden Regens konnte der Deckel gekühlt werden.

Es scheint nun aus späteren Analogien gefolgert werden zu dürfen, daß erst eine vorgeschrittene Zeit - abgesehen davon, daß die Glastechnik viel jünger ist als die Töpferkunst - an Stelle dieser ziemlich topfähnlichen Tongeräte gläserne, wohl auch metallene, an Stelle der Cucurbitae geradezu flaschenförmige (auch Streitkolben ähnlich gestaltete (Gefäße) $\left.{ }^{2}\right)$ in Gebrauch stellte, die, schräg gelegt, wohl in das

\section{1) Vgl. unten.}

2) Ein Blick in die Sammlung trojanischer, ägyptischer und anderer Altertümer zeigt die unendliche Vollendung des betreffenden Kunsthandwerks, im übrigen berichtet schon Horaz, daß , pile proecincta" waren ,lag(o)enis catenatis", daß an den Türpfosten der W ein s ch enken Flaschen als Wahrzeichen an Kettchen angehängt waren usw. 
Vorlegegefäß gesteckt wurden oder aber gestatteten, mit leichter Mühe einen übergreifenden Ambix oder geradezu eine helmähnliche Galea überzustülpen und aufzukitten [ursprünglich kütten, von Kütte, Quitte, Cydonia, mit ihren Klebstoff enthaltenden Samen], die seitwärts nach unten eine Ablaufröhre, einen Canalis angesetzt trug oder in ihn auslief, die selbst, besonders wenn sie in Tätigkeit kam, den Vergleich mit einer Nase oder einem Schnabe1, Rostrum nahelegte, der aus einem Kopfe hervorragte, während das Ganze immerhin bei einiger Phantasie mit einem Menschen verglichen werden konnte.

Man hat unter den trojanischen Gefäßfunden geradezu Destilliergefäße erblicken zu können vermeint - wenn nach Plinius zu Trojas Zeit selbst (also wohl im XII. Jahrh. v. Chr.) die Darstellung von Salben unbekannt war, vermutlich mit Unrecht. Ihre kunstreiche Gestalt läßt, ebenso wie die damals auch schon hoch entwickelte Metalltechnik die Möglichkeit von Destillationsarbeiten selbst in verhältnismäßig entwickelten Apparaten, wie ich sie zuletzt beschrieb, wohl zu. Daß sie geübt wurde, ist nicht nachzuweisen, ebensowenig, wenn sie zuerst in die Erscheinung trat. Ihr Werdegang aber kann sich kaum anders abgespielt haben, wie ich ihn beschrieb, und, wie überall auf dem Gebiete der Naturwissenschaft und der mit ihr in Verbindung stehenden Künste und Gewerbe, werden deren Angehörige des Dioskorides Werk als Richtschnur, als Berater genommen haben, bis Euricius Cordus als erster an dem Gebäude von dessen Wissenschaft rüttelte.

Die kaum anzuzweifelnde Tatsache z. B. der frühzeitigen Bekanntschaft des Altertums mit dem griechischen Feuer, d. h. einem Terpentindestillat ${ }^{1}$ ) belegt immerhin die Vornahme von Destillationen in großem Maße. Daß die Chinesen "griechisches" Feuer lange, viel früher gekannt haben, ist bei dem unzweifelhaft äußerst hohen Kulturstand des Reichs der Mitte vor jener Zeit schon recht gut möglich. Gleiches gilt für das sagenumwobene Indien; daß Assyrien, Persien, daß schließlich das Wunderland Cham, das ja die Wiege der Chemie gewesen sein soll, zum mindesten die Anfangsgründe der Destillation, wie ich sie oben beschrieb, gekannt und ausgeübt hat, läßt sich daraus schließen, daß in den ägyptischen Tempeln Parfüms aller Art, Salben, Räuchermittel u. dgl. angefertigt wurden, deren dem profanen Volk gegenüber jedenfalls zunftgeheimnisvoll gehütete Vorschriften die Tempelmauern von Edfu z. B. auf unsre Zeit brachten ${ }^{2}$ ).

1) Es soll mit einer Art großen Blaserohrs, wie es der Überlicferung nach auch zum Anblasen von Feuer gegen die Verteidigungswerke gebraucht wurde, auf die Schiffe gespritzt worden sein. 350 soll man es gekannt haben. Unter Konstantin IV. soll es, also in den Jahren 668-75, bei der Abwehr der Konstantinopel bedrohenden Araber eine große Rolle gespielt haben. Vgl. meine Arbeit über das Felssprengen des Hannibal nach Livius und Feuersetzen in „Zeitschrift für das gesamte Sprengstoffwesen“, München 1908.

$\left.{ }^{2}\right)$ Vgl. oben S. 15, übrigens auch O. v. Lippmann bei Diergart S. 149.

ge

wu

sel

Ge

det

so

hilt

für

lati

unl

pil.

$\mathrm{Pe}$

zus

un

zut

ges

ger

der

Da

set

Ko

fins

ste

anc

scr

hat

ges

sar

X.

mil

ein

$\mathrm{Wi}$

xas

we

läß

tun

Fol.

dem

Kur

des 
Bildliche Darstellungen der in Betracht kommenden Destillationsgeräte kamen, bis auf die oben S. 13 wiedergegebenen, wie schon gesagt wurde, nicht auf unsre Zeit, trotz der unendlichen Schreib- und Zeichenseligkeit der Ägypter, ebensowenig, als solche ohne weiteres erkennbare Geräte selbst. Das spricht aber durchaus nicht gegen die Möglichkeit der Vornahme von Destillationen in früher Vorzeit, denn in den so oder so bezeugten, wie überall nach den Mustern derselben einfachen Naturhilfsmittel zum Teil mit staunenswerter Kunstfertigkeit gearbeiteten Geräten für den Haus- und Küchengebrauch konnte man mit leichter Mühe Destillationen ausführen, wie sie zu vermuten sind, wenn wir den, wenn auch unbestimmten Angaben von Aristoteles und den vielsagenden der Kompilatoren Plinius und Dioskorides trauen.

Nach ägyptischen Vorbildern, darf man annehmen, baute eine ihrer Persönlichkeit nach wenig gekannte Kleopatra ihre Destillierapparate zusammen, die allerersten Geräte, die in guterkennbaren Abbildungen auf unsre Zeit gekommen sind, und die der genannten Dame die Ehre haben zuteil werden lassen, im allgemeinen als die erste Destillateurin angesehen zu werden. Mit der in der Chemie jedenfalls nicht ganz ungewandten, durch ihre männerberückende Schönheit berühmten, durch deren Anwendung berüchtigten Königin hat sie sicherlich nichts zu tun. Daß sie von Zosimus (Anfang des III. Jahrh. geboren) erwähnt wird, setzt sie jedenfalls früher, etwa ins II. Jahrh. n. Chr. Von einem Chemiker Komanos oder Komarios soll sie unterwiesen worden sein.

Eine Handschrift, die in der S. Marco-Bibliothek in Venedig sich befindet, gibt (Fol. 6) eine Arbeit von ihr, xovaozosei⿱ , wieder. In ihr ist sehr steif, mit Zirkel und Lineal, wie stilisiert, ein Gerät abgebildet, das nichts andres als ein Destillationsapparat sein kann. In einer andern Handschrift in der National-Bibliothek von Paris tragen die skizzenhaften Frei-

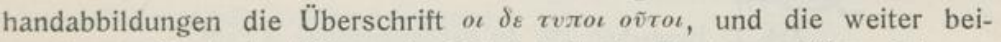
gegebenen Worte bestätigen die Richtigkeit der Deutung. Wenn ich zusammenfasse, was in den verschiedenen, entweder ebenfalls etwa aus dem X. oder XI. Jahrh. stammenden Handschriften oder späteren Abschriften ${ }^{1}$ ) mitgeteilt ist, so handelt es sich um einen Ofen, der im wesentlichen einem kleinen, jetzt auch schon der Geschichte anheimgefallenen tragbaren

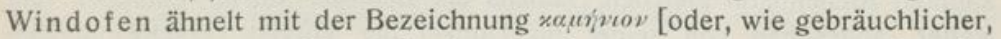

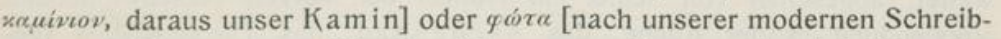
weise richtiger qõ $\tau$. Die Bezeichnung macht es wahrscheinlich oder läßt wenigstens die Deutung zu, daß man hier als Wärmequelle Beleuchtungsmittel, Lichte oder Lampen benutzte], auf dem ein flaches Gefäßs

1) z. B. aus der prachtvollen im Besitz der Casseler Landesbibliothek, Ms. chemica, Fol. 1. Die Sammlung stammt von dem bekannten Magier und Alchemisten Dr. John Dec, dem Günstling der Königin Elisabeth von England. Sie kam aus dem Besitz des Kurfürsten Joachim Friedrich von Brandenburg in den Besitz des Landgrafen Moritz des Gelehrten nach Cassel. Vgl. meine Arbeit, "Goldmachen am hessischen Hofe". 
zu stehen scheint, das man immerhin als eine Kapelle nach zeitläufiger Bezeichnung ansehen darf, die mit Wasser gefüllt gewesen sein kann, oder, was als natürlicher, frühzeitiger angesehen werden kann, mit Asche.

Was solche Wärmeschutz- vielleicht auch -Erhaltungsapparate anbetrifft, so wissen wir, daß Hippokrates sich eines dizhom um seine Ptisane vor dem Anbrennen zu schützen, und Theophrast ähnlich bei der Extraktion seiner Wärmstoffe verfuhr. Daß Synesios einen $\lambda \dot{\varepsilon} \beta \eta \bar{s}$ unter das Destillationsgefäß brachte, zeigt die betreffende Zeichnung (S. 24). O. v. Lippmann konnte in einer tiefgründigen Arbeit über das Wasserbad') nachweisen, daß aus dem Balneum Maris durch

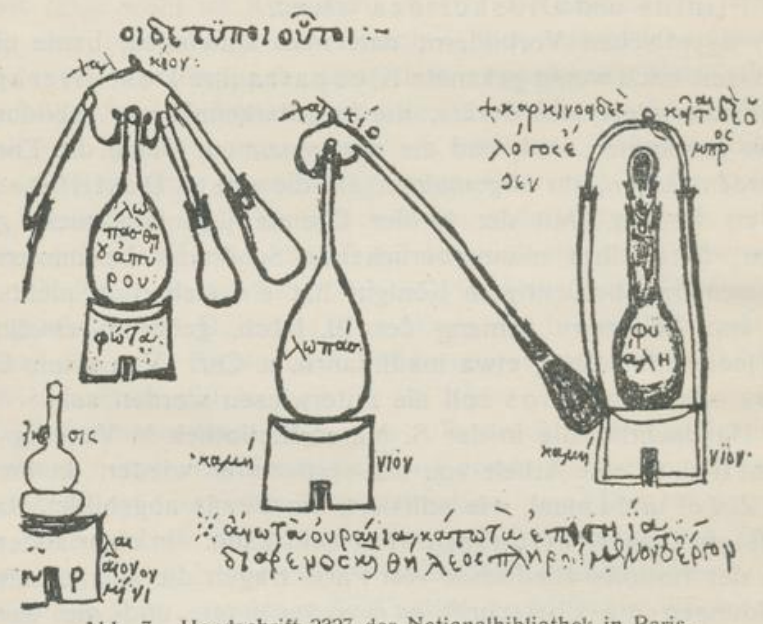

Abb. 7. Handschrift 2327 der Nationalbibliothek in Paris.

mißbräuchliches oder mißverständliches Einsetzen der Jungfrau Maria an Stelle der ägyptischen Göttin und Repräsentantin des Meeres, der Isis, und durch spätere Verwechsiung der ersteren mit der wenig bekannten Alchemistin gleichen Namens ein Balneum Mariae entstand, daß weiter, abgesehen von seiner im Dunkel der Vorzeit verschwindenden Verwendung in der Küche, das Aschenbad, das Thermospodion [ge-

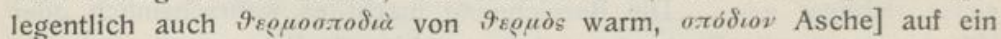
langes Alter zurückblicken kann. Coelius Apicius²) spricht jedenfalls (220 n. Chr.) in seinem Kochbuch, das griechische, speziell alexandrinische Herkunft verrät, von ponere in cinere calido oder supra thermospodium.

1) Diergarts Kahlbaum-Gedächtnisbuch.

2) Vgl. Schuchs Ausgabe, Heidelberg 1874, S. 69, 72, 74, 90, 71, 73, 74, 90. Vgl. auch oben. 
In der Kapelle steht ein flaschenförmig gestaltetes Gefäß, das zumeist

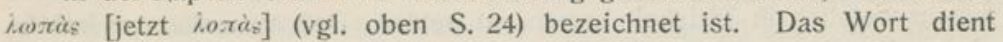
allgemein für den Begriff Gefäß. Die kopfförmige (an das Hüttendach erinnernde) Erweiterung ist in einem Falle quái. $\eta^{1}$ ) genannt, zufällig wohl nur, weil die Stelle mehr Platz dafür bot als die mehr in Betracht kommenden unteren Teile. Der Kopf ist in einigen Zeichnungen ganz helmähnlich und so dargestellt, daß unten ringsherum eine Ausbuchtung oder eine Art Krempe, noch besser ein Sims, entsteht, wie bei späteren Helmen, Tropfensammlern, Dephlegmatoren oder wie man sie nennen will.

Daß man unzweifelhaft imstande war, solche Geräte aus Glas darzustellen, sagte ich schon oben. Daß sie auch aus Erz gefertigt wurden, verrät das in einigen Fällen beigefügte Wort yaìxiov.

Aus dem Helm (in einem Falle steht neben ihm, vielleicht sich auf die senkrecht aufstrebende Verlängerung

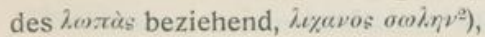
Zeigefingerrohr) ragten eine, an andern Stellen zwei und drei Abfall-, Destillationsröhren heraus. An

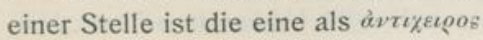
$\sigma \omega \lambda_{\nu} \nu \nu$ [Daumenröhre] bezeichnet, und wenn man den Helm als Handfläche, die Abfallröhren als Finger ansehen will, so kann in derselben Abbildung ein undeutliches Wort immerhin uxoòs [also kleine (Finger-)

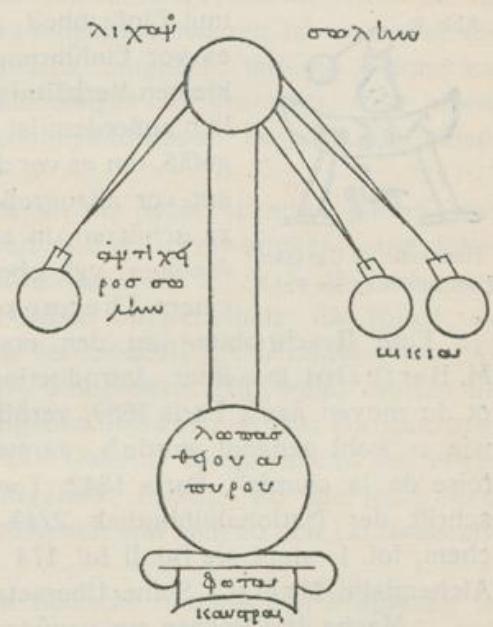

Abb. 8. Handschrift der San Marco-Bibliothek in Venedig. Röhre] klein gelesen werden ${ }^{3}$ ).

Die genannten Röhren münden in kolbenförmig gestaltete Vorlegegefäße ohne Bezeichnung. Daß es sich in unserm Falle nur um wirkliche Destillations-, keineswegs Sublimationsgefäße handelt, dürfte jeder Sachverständige ohne weiteres erkennen: Sublimate würden sich im

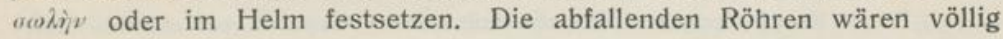

1) An einigen Stellen steht dabei $\vartheta \varepsilon\llcorner o v$ arvoov. An eine Destillation von A Iumen, der gelegentlich, oder von Sulfur, der ebenso bei den Alchemisten A pyron, aber auch seit klassischen Zeiten Theion, das Göttliche, hieß, ist sicher nicht zu denken, und es kommt unzweifelhaft hier der spätere geheimnisvolle $\mathrm{Sulfur}$, das Primumens metallorum in Betracht, von dem es später hieß, daß die „Chymisten von ihm viel Redens gemacht und es für eine tingierende Materie des Steins der Weisen angesehen hatten".

${ }^{2}$ ) In der Casseler Handschrift ist beigeschrieben "maistre tuiau", Hauptrohr.

a) Interessant ist immerhin, daß die Ausdrücke $\lambda \epsilon \beta \eta \bar{s}$ und $\sigma \omega \lambda \eta \eta \nu$ noch in Griechenland gänge sind (vgl. die neue Pharmacopoea von Dambergis, S. 84), daß im Übrigen die Destil-

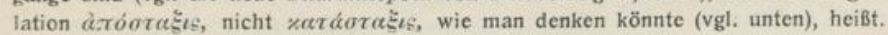


zwecklos. Warum ihrer gelegentlich mehrere vorgesehen waren und augenscheinlich in Tätigkeit kamen, ist unklar. Daß sie einer Art fraktionierten Destillation dienen sollten, ist kaum anzunehmen. Man hätte auch „Fraktionen" nicht mit ihnen erzielt. Von einer Kühlvorrichtung ist keine Andeutung da.

In der auf S. 22 erwähnten Handschrift der Bibliothek in Paris heifst

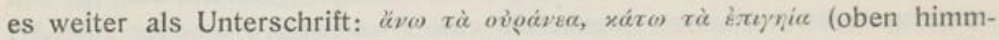
lisches, unten irdisches) ${ }^{1}$ ).

An einer andern Stelle (in der Casseler Handschrift Bd. 1 S. 64 v.) ist eine Darstellung einer Destillationsvorrichtung, die trotz ihrer Kleinheit

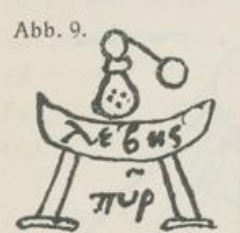

Handschr. d. Casseler Landesbibl. Chem. Fol. 1 . und Einfachheit aufs deutlichste ein Gerät zeigt, wie es vor Einführung der Gasbeleuchtung und Heizung in kleinen Verhältnissen gang und gebe war. Ganz deutlich außerdem ist hier wiedergegeben, daß das Destilliergefäß, um es vor der direkten Flamme oder das Destilliergut vor allzugroßer Erhitzung und vor dem Anbrennen zu schützen, in einem $\lambda \hat{\varepsilon} \beta \eta$ s mit Wasser) also einem $\delta i \pi \hat{\lambda} \omega, \mu \alpha$, vgl. oben S. 22) oder mit Asche darin (in einem Thermospodium) stand.

Eine Beschreibung $\mathrm{zu}$ den erstgenannten Abbildungen, die zuerst M. Berthelot in seiner „Introduction à l'étude de la chimie des ancients et du moyen âge", Paris 1889 , veröffentlicht hat und die einen Tribikus, wie er wohl genannt wurde ${ }^{2}$, darstellen soll, gibt Höfer in seiner „Histoire de la chimie", Paris 1842, Tome 1, S. 255 nach der Pariser Handschrift der Nationalbibliothek 2249-2252 (im Casseler Thesaurus, Ms.

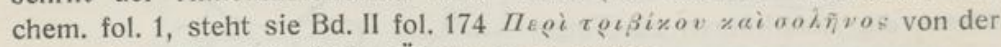
Alchemistin Maria). Seine Übersetzung lautet:

Mache drei Röhren aus genügend dickem Erz, sechzehn Cubitus lang. Die Öffnungen oder Zungen, an der Unterseite des Ballons angebracht, müssen genau anschließen. Sie selbst reichen in kleinere Ballons. Eine dickere Röhre verbindet das Kochgerät (die Blase, unter der Feuer angelegt wird) mit dem gläsernen Ballon, und der Apparat trägt wider alles Erwarten den Geist empor. Nachdem man die Röhren befestigt

1) Eine in Memphis gefundene Tempelinschrift lautete: Ov pavo. $\alpha \nu \omega \cdot$ ov oqvo $x \alpha \tau \omega \cdot$ $\alpha \sigma \tau \varepsilon \rho \alpha \cdot \alpha \nu \omega \cdot \alpha \sigma \tau \varepsilon \rho \alpha \cdot * \alpha \tau \omega \cdot \pi \alpha \nu \cdot \alpha \nu \omega \cdot \pi \alpha \nu \cdot \tau o v \tau o \cdot \psi \alpha \tau \omega \cdot \tau \alpha v \tau \alpha \cdot \lambda \alpha \beta \varepsilon \cdot x \alpha t \cdot$ $\varepsilon v \tau v{ }^{\circ}$. was Schmieder (S. 67) etwas frei übersetzt: Himmel oben, Himmel unten. Sterne oben, Sterne unten. Was nun oben, ist auch unten. Solches nimm zu deinen Glück! Die Worte sollen wohl an altgriechische Philosophie erinnern und sind mystisch verbrämt worden. Vielleicht liegt dieser Text dem obigen zugrunde, vielleicht denkt er an den abwärts fliefienden kühlenden Regenquell. Vgl, auch oben S. 6.

7) Der Name, den ich sonst weder in dem einschlägigen Schrifttum noch in den Wörterbüchern der klassischen Sprache finde, ist wohl mißverständlich und falsch im Andenken einerseits an dem Alem-bieus, andrerseits an Composita von tres [tri-vius] gebildet worden, wenn,

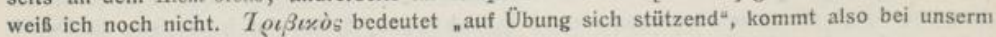
Gerät keinenfalls in Betracht. 
hat, lutiert man alle Verbindungsstellen aufs beste. Man muß Sorge tragen, daß der Glasballon über der Blase genügend stark sei, um nicht durch die Hitze, die das Wasser nach oben treibt, zu zerbersten.

Daß auf der Abbildung (S. 22) rechts noch ein, hier dem Äußern nach nicht hergehöriges Gerät abgebildet ist, zeigt, daß man sich doch klar darüber war, daß bei den in ihm vorgenommenen Arbeiten, bei $\mathrm{Di}$ gestionen, Zirkulationen (vgl. weiter unten) in der Tat eine Destillation stattfand, bei der, wie in der Hütte von dem Dach und den Wänden die verflüchtigte Flüssigkeit nach der Verdichtung in den unteren Teil des Gefäßes zurückfiel. Es handelt sich um eine geschlossene - es ist immerhin möglich, daß der Hals zusammengeschmolzen ist - quáîn, die in einer Kapelle auf dem zaứriov steht, umgeben, um die Wärme zusammenzuhalten und vielleicht gleichmäßiger $\mathrm{zu}$ gestalten, von einem Zylinder und bedeckt mit einem halbkugelförmigen Deckel, mit einem Knopf oben auf.

Auf dem Boden Alexandrias hatten die Araber kennen gelernt, was eine klassische Zeit dort aufgespeichert und die „Philosophen“, aus deren Arbeiten eben einiges angeführt worden ist, aus ihnen in Weisheit und Afterweisheit zusammenfaßten: im Streben unzweifelhaft, die Kunst, zu entdecken, unedle Metalle in edle zu verwandeln, und Arzneien, um das Leben zu befestigen und zu verlängern, zu bereiten. Nur wenig dürften sie von den Kenntnissen des Orients als eigenes in Basra, Kufa, Damascus, $\mathrm{Bagdad^{1 }}$ ) verwandt haben, wo sie das Gelernte festigten und vertieften, und noch weniger nach Spanien mitgeführt haben, wo sie jetzt ihre Wissenschaft zur höchsten Blüte entwickelten und sich zu den Lehrmeistern des Abendlandes aufschwangen.

Ohne Destillation konnten die in Betracht kommenden Präparate, in allererster Reihe solche aus der anorganischen Chemie, Essig-, Salpeter-, ja Schwefelsäure, nicht dargestellt werden. Sie finden wir bei dem, in seiner Echtheit allerdings angezweifelten Geber, Abu Musa Dschabir, dem angeblichen Schüler von Abu Abdallah Dschafir el Sadik aus der Mitte des VIII. Jahrhunderts. Die benutzten Geräte glichen aller Wahrscheinlichkeit nach den eben beschriebenen, ihnen auch sicher das zum Darstellen des hier zuerst Lebenswasser genannten, belebend auf den Organismus des Trinkers wirkenden Destillats aus Weißwein. Geber destilliert auch Marchasit (auch Quecksilberchlorid) aus Aludeln, aber auch per alembicum und per descensorium, wie es in der Übersetzung heißt, jedenfalls aus drei verschiedenen Geräten. Die ersten beiden Namen lernen wir weiter unten kennen.

In das Reich der Fabel wurde im Allgemeinen die Nachricht verwiesen, daß sich aus dem Rauch des Kamelmist-Feuers in den Hütten in der Oase des Jupiter Ammon (so wenig unmöglich solche Erscheinung

2) Vgl. meine Geschichte der Pharmacie S. 270 ff. 
vom chemischen Standpunkt aus erscheint) in den Rauchfängen A m moncarbonat ansetze. Eine solche Sublimation in der Hütte, die ich als Vorbild des späteren Destillations- oder Sublimationsgerätes anspreche, wird aber völlig glaublich durch einen Bericht von al Dimaschquî (vgl. auch weiter unten). Bei ihm heißt es (ganz ähnlich in den Mafâtîh): „Das flüchtige Nuschâdir ${ }^{1}$ ) wird aus dem Mist [ar. Zibl] von Kamelen und andern Vierfüßlern gewonnen, in den Schornsteinen der Bäder, besonders in Ägypten in der Provinz Sa'id". Kaum werden wir bei den „Schornsteinen“ an verhältnismäßig enge Röhren denken, wie sie jetzt gebaut werden, sondern an mehr oder weniger spitz-trichterförmige Rauchfänge, wie sie über alten Kaminen (auch zum Zweck des „Räucherns") weit aufgebaut waren. Immerhin waren sie die Vorbilder für die Akestiden und die späteren langgestreckten Giftkanäle ${ }^{2}$ ). Nur nach dem Vorbilde der Räume, in denen man solche zufällige chemische Arbeit sich abspielen sah, hat man unzweifelhaft das Gerät für die zielbewußte Arbeit gebaut.

Und das geschah sicherlich in Venedig, das im IX. Jahrh. die Hauptoder richtiger im Grunde die einzige Einfuhrstelle, der Haupthandelsplatz für Drogen aus dem Lande der aufgehenden Sonne war ${ }^{3}$ ). Es erscheint geradezu als Selbstfolge, daß man dort nach dem Muster der Produktionsländer Salmiak, Zinnober usw. selbst dargestellt oder wenigstens gereinigt hat, durch Sublimation oder Destillation in allererster Reihe unfehlbar ${ }^{4}$ ).

Bei Geber finden wir auch die später Destillatio per filtrum genannte, mit Destillation allerdings gar nichts zu tun habende Art des Übersaugens von Flüssigkeiten über den Rand in nebenstehende Gefäße mit Hilfe von Papier- oder Zeugstreifen oder Dochten, was beweist, daß er oder der kaum viel spätere wahre Verfasser seiner Werke und noch viel früher der erste Hersteller des Dochtes für die Lampen die Erscheinung der Capillarität lange vor Leonardo da Vinci kannte.

Schon Jahrhunderte vor Geber war im übrigen in Europa ein wahres, reines ätherisches $01^{5}$ ) bekannt, denn Aetius von Amida, der in

1) Noch im XVIII. Jahrh. finde ich (bei Ernsting z. B.) als gleichbedeutend mit Sal armoniacum Nestudar, Nosadar, Nusiadal, Nysadir und ähnlich, auf das genannte Wort zurückzuführen, genannt. [Der Name kommt wohl aus dem chinesischen Nau-scha für ein Ammonsalz und persisch daru]. Es soll in Badachsan und den NuschadirBergen in China im Lande Farganato gefunden worden sein. Ammonverbindungen dürfte man danach lange in China gekannt haben. Das man Ammoniak in der Gestalt von fa ulem Urin in Alt-Rom sammelte und für Reinigungszwecke verwandte, sei nebenbei bemerkt.

$\left.{ }^{2}\right)$ Vgl. St a plet on, Sal Ammoniac. Memoirs of the Asiatic Society of Bengal. 1906. S. $26 \mathrm{ff}$.

3) Vgl. auch meine Geschichte d. Ph. S. 364 u. a. O.

4) Hasselquist berichtete (in der ersten Halfte des XVIII. Jahrh.) nach Hören-Sagen von über 25 Fabriken, die aus Ochsen- und Kamelmist in Ägypten Salmiak anfertigten, der nach Venedig ging. Die geheimgehaltene Art seiner Darstellung glich sicher uralter Methode. Von damals moderner Kultur war das Land sicher unbeleckt.

3) Abgesehen von dem, den hier allein in Betracht kommenden pflanzlichen Ölen in vielen Eigenschaften sehr nahestehenden Steinöl, dem Nephtar der Israeliten, dem Mįdeice thao Nágita. 
dessen zweitem Viertel am Hofe Justinians als Comes obsequii lebte [als Oberster der Leibwache] und nebenbei sich mit Arzneikunde aus Liebhaberei beschäftigte, erwähnt $\mathrm{C}$ aphura, unzweifelhaft unsern $\mathrm{C}$ ampher, als kostbaren Bestandteil einer Salbe.

Jedenfalls war er im Vaterlande des Campherbaums lange bekannt, und es ist zu vermuten, daß der Zufall dazu geführt haben wird, ihn, auf dessen Spur der Geruch hingeleitet haben muß, in einer Art darzustellen, die kaum von der noch üblichen abgewichen sein wird: durch Auskochen des Holzes, Abschöpfen des auf der erkalteten Brühe abgeschiedenen festgewordenen Öls oder durch Sammeln des Dampfes in erst lose übergestülptem, nach einer Seite geneigten und dort einen „Tropfenfall“ bildendem Dach, oder in einem fest aufliegenden mit nach außen abführender Tropf-Röhre versehenen Deckel.

Daß die Ruchstoffe sich in öligen Tropfen auf den Wässern abschieden, mit denen man sie aus den duftigen Pflanzenteilen ausziehen wollte, auf $\mathrm{Narden}^{-1}$ ) und RosenWässern, die der Orient sicherlich seit uralter Zeit zu ParfümZwecken dargestellt hat, muß den betr. Künstlern oder Handwerkern unzweifelhaft aufgefallen sein, und man darf aus dem, was oben von den bez. Kenntnissen der Alten gesagt werden konnte, schließen, daß Destillationen von Ruch-

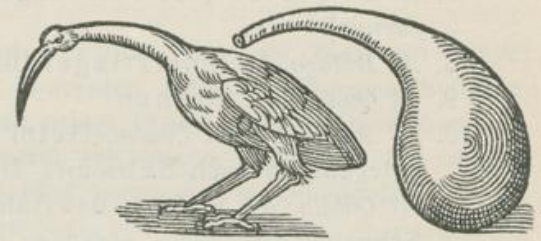

Abb. 10. Storchschnabel nach Porta. wässern wirklich vorgenommen worden sind, daß es sich bei den oben gemachten Angaben über Rosenwasser wirklich um, nebenbei sicherlich in größerem Maßstabe angefertigte Destillate gehandelt hat. Nachrichten darüber schlummern vermutlich in handschriftlichen Mitteilungen im Orient und harren sprach- und sachkundiger Entdecker. Aus arabischen Werken, die wir zum größten Teil nur aus mittelalterlichen lateinischen Übersetzungen kennen, berichtete erst in allerletzter Zeit Eilhard Widemann in vortrefflichster Art und erklärte manche, auch sprachliche Unklarheiten ${ }^{2}$ ), und die von ihm zugegebenen Faksimile-Wiedergaben der Zeichnungen der benutzten Geräte unterstützen das Gesagte anders wie die mittelalterlichen bildnerischen Beigaben, die nach den oft mangelhaft verstandenen Texten oder ungelenk nach den im Maurenland geschauten Geräten gezeichnet worden sein mögen, das die wißbegierige Welt damals ebenso aufsuchte, wie einige Jahrhunderte später das gelobte Land Italien.

Der Rhazes des Abendlandes, Abu Bekr Mohamed Ben Zakerija el Razi, wie ich ihn auf S. 277 meiner Geschichte schrieb (Wiedem ann gibt

1) Vgl. Marcus 14, 3. Johannes 12, 3 auch Plinius 12, 26. Von Kulturen von Ruchpflanzen berichtet die Bibel an vielen Stellen. Von Jerichos Rosen war oben die Rede.

2) Vgl. Diergarts Kahlbaum-Gedächtnisschrift S. $234 \mathrm{ff}$. 
den Namen etwas anders), der „arabische Galen“, an der Wende des IX. Jahrhunderts kannte zweifellos 'Araq [Ahn des Worts Arrak. Im Orient noch viel gebraucht] al Khamr [durch Gährung] assakar [aus Saccharnm, Zucker], der jedenfalls nur in schon recht vollendeten Geräten destilliert werden konnte. Wenn weiter der sog. „Kalender von Cordova" des Harib aus dem Jahre 921 die für die Destillation von Rosenwasser geeignetsten Zeiten aufzählt, so bestätigt das nur, daß Rhazes dieses Präparat dargestellt hat.

Er zählte (nach arabischer Gewohnheit?) am Anfange seiner Schriften die von ihm angewandten Geräte auf und beschrieb sie ${ }^{1}$ ). Eine solche Vorrede findet sich auch in dem Kitâb al Asrâr. [nach anderen Quellen schrieb ich Ketaab], dem „Buch der Geheimnisse", und die dort gegebene Aufzählung lautet (soweit sie hier in Betracht kommt) nach einer Handschrift in der Leipziger Stadtbibliothek (Codex K. 215 No. 266 S. 4 v. bis 5 v.) in wörtlicher Übersetzung ${ }^{2}$ ):

Vierter Abschnitt über die Kenntnis der Geräte. Es sind dies:

1. Al Kar, Ofen [wie Furn abgeleitet, jedenfalls vom lateinischen furnus].

3. Al Bûtaqa, Schmelztiegel [ihm wohl auch nur ähnliches Gefäß].

9. Al Quar $\left.\left({ }^{(} a\right)^{3}\right)$, Kolben.

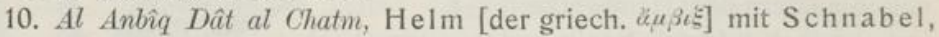
gelegentlich auch Schwanz Dunâba.

11. Al Qâbila, die Vorlage, das Aufnahmegefäß (man steckt darein den Schnabel des Anbriq, ergänzen die Mafatîhi).

12. Al A'mâ, der Blinde.

13. Al 'Amjâ, die Blinde.

15. Al Mauqid, Ofen, Herd.

16. Al Aqdâh (Plural von Qudali), Trinkbecher, nach Berthelot auch Retorte.

14. Al Atâl, Aludel.

[Diese Verdeutschung der arabischen Bezeichnung zeigt, wie man auch bei diesem Wort $^{4}$ ) mit den gewohnheitsgemäßen Versuchen, sie etymologisch aus klassischen Worten - hier aluta Leder (= Schlauch ähnlich geformt) - zu erklären, fehl ging.]

1) Auch hier war unzweifelhaft das Arabertum für unser mittelalterliches Schrifttum vorbildlich: die vielen Werke de secretis (von Cardanus, Wecker u. a.), die von den zumeist die Lande durchstreifenden "Chymisten" von ihren Reisen mitgebracht oder nach der Sitte der Zeit aus früheren oder zeitgenössischen Rezept-Sammlungen abgeschrieben haben, folgten den Spuren des Rhazes und ihnen traten weiter Libav und seine Nachfolger, Schröder, Lémery, Spielmann, Hagen usw. bis Berzelius nach.

2) Hie und da gestattete ich mir, einige wohl geläufigere Kunstausdrücke einzusetzen.

3) An anderer Stelle, bei $I b n$ al 'Atrwam, auch al Batn und Quâdûs, d. h. die Eimer an den Schöpfrädern, also ihnen ähnlich gestaltet. Die Liste in den Mafatih al ' Uhim vergleichen den Kolben "derer, die das Rosenwasser darstellen", geradezu mit einen Schröpfkopf. Ernsting führt noch als Synonym für Kolben Alcara an.

4) Vgl. meine Arbeit in der Chemiker-Zeitung, Cöthen 1909, Juni. 
17. Al Qanân̂̀ (Plural von Qinnîna), Phiolen (langhalsige Kolben).

18. Al Qawârîr (Plural von Qarûra), langhalsige Flaschen.

19. Al Salâja, Stein, auf dem Wohlgerüche gerieben werden.

21. Al Atûn, kleiner Ofen.

22. Al Tâbistân, größerer Ofen.

23. Al Nâfich, Nafsihi, der sich selbst Blasende (sc. Ofen, Authepsa).

Einige von diesen Geräten sind bei den Goldschmieden und anderen Leuten bekannt, andere sind nicht bekannt. Wir wollen, was nicht bekannt ist, erläutern.

(Wenn Rhazes hier daran erinnert, daß einige Geräte (z. B. der Blasebalg, die Blechschere, der Hammer usw., die hier nicht in Betracht kommen und deshalb nicht genannt wurden) den Golds chmieden und anderen Leuten bekannt seien, so scheint mir auch das dafür zu sprechen, daß er in erster Reihe bei den andern an mit Küchengeräten hantierende Leute und die engen Beziehungen zwischen der Küche und dem erst pharmazeutischen, dann den chemischen Gewerben denkt, wie oben klargelegt werden sollte.)

Der Tiegel, der Sohn des Tiegels. Es ist dies ein Tiegel (Butaqa) über einem andern. Im untersten Teil des obersten befinden sich ein oder mehrere Löcher. Man bringt in ihn das, von dem man will, daß es hinabsteige, zusammengeknetet mit Natrûn und Öl. Man umgibt ihn mit Kohle und bläst darauf. (Vgl. unten das Koshti-Geräth.)

(Das ist unzweifelhaft wohl eine Saigervorrichtung, aber auch ein Gerät zu einer Destillatio per descensum, ganz wie schon Plinius sie beschreibt. Das geht noch deutlicher hervor aus der weiter unten auf S. 242 am selben Ort übersetzt wiedergegebenen Handschrift, den scbon erwähnten Mafâtîh al 'Ulum. In dessen Liste heißt es:)

Al Bût eber [persisch, dasselbe Wort wie unser "über"] Bût, Tiegel (oder allgemein tief-tiegelförmiges Gefäß). Es ist dies ein Tiegel, der an seinem untersten Ende durchlöchert ist und auf einen andren gesetzt wird. Die Verbindungsstelle zwischen beiden wird mit T on gut gedichtet. Dann schmilzt man den Körper im oberen Tiegel; er fließt in den unteren, und seine Schlacke $\left(\right.$ Chabat) ${ }^{1}$ ) sowie sein Schmutz bleiben im oberen. Man nennt das Verfahren „das Herabsteigen machen" [descendere].

1) Es handelt sich bei diesem Worte, wie ich andern Orts (z. B. in der Cöthener Chemiker-Zeitung) ausgeführt habe, sicher um die sprachliche Grundlage der viel erörterten und äuferst gewunden (z. B. von Littré) erklärten Redensart kaput sein, gehen und sch lagen. Alle Rückstände, alle ausgebrauchten, damals als wertlos, wie Schlacke [beim Daraufschlagen von Eisen], abfallenden Stoffe waren den arabischen Lehrmeistern der nach Spanien wandernden Nordeuropäer, deren Fachsprache latein war, Chabat. Sie hörten aus dem Worte heraus oder bildeten sich das ihnen geläufige $\mathrm{C}$ a put. Porta nennt seine Destillationsrückstände $\mathrm{Faeces}$ (das, was bei der Lebensdestillation des Mikrokosmos, vgl. am Schluß, als abgebraucht abfällt) oder Sordes (Schmutz, was bei dem Destillieren non nisi simplicium cadaver remanet, ut corpus vita penitus viduatum). Als Teil des Ganzen setzte man das Caput mortuum ein, weil es gleicherzeit schaurig-mystisch anklang. Erst später verwandte man 
(Es handelt sich bei dieser Arbeit wie bei unserm „Aussaigern" unzweifelhaft um ein Destillieren im Ursinne des Wortes. Ganz unzweifelhaft gehört hierher, was Ernsting in der zweiten Hälfte des XVIII. Jahrhunderts von der Destillatio per descensum calida oder Transsudatio berichtet:

„Es destillieren auf solche Art noch etliche alte Mütterchens das Rosenwasser, da sie über einen Topf ein Tuch spannen, darin sie Rosenblätter legen und einen Deckel darüber machen, einen glühenden Stein darauf legen, worauf das Wasser durch das Tuch in den untersten Topf schwitzet." (Vgl. unten die Destillation von Nelkenöl durch Lémery.)

Folgerecht gehört dann aber in der Tat auch die daran knüpfend besprochene Destillatio per descensum frigida hierzu. Als Beispiel bringt Ernsting:

„Wenn man etwas über ein Filtrum tut als Sal Tartari, Nitrum fixum. stellt es an einen kalten Ort, so fließset oder schmilzt es endlich wegen der Luft, die sich hinein ziehet, und läuft durch das Filtrum per deliquium."

An diese tatsächlich nicht zum Destillieren gehörige Arbeit erinnert noch das Synonym Ol. Tartari per deliquium für den Liq. Kali carbonici der Arzneibücher.)

Der Kolben und der Anbiq mit dem Schnabel dienen zum Destillieren von Flüssigkeiten. Der Kessel (Qidr), welcher über ihn geschoben wird, hat die Gestalt eines Kochtopfs (Mirgal). Die Gurke ist in dem Wasser eingetaucht, das höher steht als die Stoffe (Dacdâ, eigentlich Heilmittel), die sich in ihr befinden. Bei dem Herde (Mustauqad) befindet sich ein Kessel mit heißem Wasser, um aus ihm in den Kessel zuzugießen, wenn es abnimmt. Man muß acht geben, daß der untere Teil des Kolbens (Gurke?!) nicht den untern Teil des Kessels berührt.

(Es handelt sich also hier um eine Destillation im Wasserbade, ein [vgl. oben S. 22] Diploma, wie es schon als von Dioskorides [2, 86 und 3,87 ) angegeben, erwähnt wird. In der Gurke - Kürbis wäre wohl eine richtigere Übersetzung, da doch wie es scheint, nur solche für flaschenähnliche Gefäße gebraucht worden sein dürften - finden wir wohl das erstemal, die später als Kunstausdruck gängige Cucurbita. Daß ein Topf mit heißem Wasser vorgesehen ist zum Ersatz des verdampften, eine Nachfüllvorrichtung zum erhalten eines konstanten Niveaus, spricht für den Praktiker Rhazes).

Man sublimiert bisweilen in verkitteten Kolben, die in dem Herd über einer Unterlage (Sakin) von Ton befestigt werden, oder es (das

das allgemein gültige Wort für ein Sonder-Caput, den Colcothar [was wohl ganz willkürlich gebildet ist], den Rückstand bei der Destillation des Nordhäuser Vitriolöls. Kaput gegangenes oder geschlagenes ist dem Abfall gleich saft- und kraftlos, wie Schlacke, unter die man ja nicht mehr nur Hammerschlag, sondern die vielen „toten ${ }^{*}$ Abfallstoffe rechnet, die das Kreuz der Schlackenhalden bilden. 
zu sublimierende) wird auf einen Kessel gesetzt, in dem sich Asche befindet, und unter den man Feuer macht. Dies ist für die Lernenden näher liegend (ratsamer?). Oder der Kolben wird auf einen Backstein aufgestellt, auf dem sich Asche befindet. Die Asche wird an die Seiten des Kolbens angestopft.

(Es handelt sich also hier wieder um ein Aschenbad, wie es oben schon als bekannt erwähnt worden ist (S. 22), um eine Capella cinerea, wie die Vorrichtung in späterer Zeit genannt wurde. Was die Stelle betrifft, über einer „Unterlage von Ton", so muß sie wohl als ein „Beschlagen" mit Ton gedeutet werden, und diese Deutung wird als berechtigt erwiesen durch eine andre Anweisung in den schon erwähnten

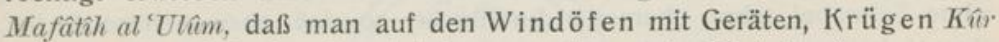
arbeitet, die mit Lehm bestrichen wurden, arab. Mutajjan.)

$A l^{\prime}$ Amja, die $\left.{ }^{1}\right)$ Blinde dient zum Lösen der Geister und der Körper (d. h. flüchtiger und fester Stoffe). Sie ist ein Anbiq, dessen Vorderteil keinen Kanal hat (in dem Mafâtîh al 'Ulûm steht geradezu: Anbiq ohne Ansatz). Sie dient zum Hineinbringen dessen, was man in dem Kolben durch eine scharfe Flüssigkeit lösen will. Man setzt auf sie den Anbiq und macht die Verbindung fest. Das ist das (mit Ton) verschmierte Bad (al Hamâm al madmûm).

(Es handelt sich um ein blindes Digeriergefäß, wie wir es oben schon kennen lernten und noch kennen lernen werden, um einen Kolben, auf dessen Hals ein Helm mit geschlossener Ablaufröhre (Schnabel, Schwanz wird sie oben No. 10, S. 28 genannt), gekittet ist.)

Al $A^{c} m \hat{a}$, der $\left.^{2}\right)$ Blinde, ist ein Becher (Qadah), der aufgepaßst ist. Man setzt ihn über einen Kolben, in den man die zu lösenden Dinge bringt. Man hängt ihn über einem Herde auf und bringt unter ihn das Feuer einer Lampe (Maschial) oder einer Kerze (Qandîl) oder einer Kohle oder von heißer Asche. Man achte darauf, daß es nicht erlischt oder erkaltet, ehe sie (die Dinge) gelöst sind und sich dann verdickt haben.

(Auch hier hat man es mit einem geschlossenem Digeriergefäß zu tun, in dem Lösungen vorgenommen werden sollten, so daß die Lösungsmittel vor Verdampfen geschützt werden und in ständigem Kreislauf zirkulierend verdampfen und, im obern Teile kondensiert, wieder zurücktropfen, destillieren. In den später im Bilde wiederzugebenden Gefäßen finden sich solche, die aus dem Blinden oder der Blinden entstanden sein können. Noch im XVIII. Jahrhundert unterschied man zwischen Alembicus rostratus und coecus. Es erschien jedenfalls immer noch zweckmäßiger, sowohl das Destillations- wie das Zirkuliergefäß (für Lösungen und Digestionen) aus zwei Gefäßen zusammenzusetzen. Das später noch zu besprechende „hermetische" Verschließen schon setzte das Gefäß der

1) Weiter unten wird beschrieben, wie die „Kugel in Zeug eingeschnürt und darum entsprechend Ton geschmiert", wie sie also auch "beschlagen" wird. S. 239 bei Wi edemann.

) Hier schon die Trennung der Geräte nach dem Geschlecht. Vgl. unten. 
Gefahr des Zerbrechens aus. Sein Öffnen bedeutete zumeist wohl das Ende des Gefäßes.)

Al Atâl dient zur Sublimation trockner Körper (die Mafâtîh setzen zu: aus Glas oder Ton gefertigt. Er hat die Gestalt eines Korbes mit einem Deckel und Schlauch, also wohl mit nach oben schlauchähnlich ${ }^{1}$ ) ausgezogenem Deckel. Er dient zum Sublimieren von Quecksilber, Schwefel, Arsen [arab. Zarnich, wie er noch bei Ernsting genannt wird] oder Auripigment), der Anbîq zur Destillation von Flüssigkeiten, Phiolen zum tachnî (Erwürgen) von Sublimaten, die Becher (Agdâh) sind erforderlich zum Erhitzen (Taschwồja).

(Man kann immerhin annehmen, daß die Atâl, gestaltet wie Anbiq ohne Schnabel, aber oberseits durchlocht, so daß oben weitere Anbiq darauf befestigt werden konnten, im wesentlichen den späteren Aludeles ähnelten, als deren Erfinder (seine Aludelesketten liegen) für gewöhnlich, wie das voraufgehende zeigt, sicher mit Unrecht der Spanier Barba angesehen wird. Daß sie wirklich Al Atâls, schnabellose, blinde Anbiqs waren oder aus ihnen hervorgingen, dafür spricht auch, daß Libav eine Reihe solcher aufeinander gereihter An biq abbildet ${ }^{2}$ ) und beschreibt, ferner daß z. B. Ernsting 1710 noch sagt: Blinde Helme, Alembici coeci werden immer einer auf den andern gesetzt, soviel man davon nötig hat, daher heißt solches Gefäß Alembicus continuatus s. Capitella sibi invicem imposita im Gegensatz zur Cucurbita coeca, dem einfachen oben zugestopften oder verschmolzenen Kolben.)

Daß die Sublimationsgefäße Al Atâl und Al Aqdâh zum „Tachnîq" dienen sollen, zum „erwürgen", ist wohl richtiger so zu deuten, daß das Sublimat schließlich die oberen Teile, den aufgesetzten blinden Ambik oder die geschlossene Röhre des langhalsigen Kolben zusetzt, also "erwürgt".

Daß der „Ambik zum Destillieren dient", läßt vermuten, daß damals zu solchem Zweck zusammengesetzte Geräte, keine „Retorten“ gebraucht wurden.

Die zum Erhitzen gebrauchten Aqdâh waren wohl wirklich topfoder becherähnliche Gefäße, zu allen möglichen Arbeiten brauchbar, die in den späteren Urinalia, Buccia, Ova vitrea (vgl. weiter unten), dann in den Zuckergläsern, wie sie die Küche und die Apotheke als Aufbewahrungsgefäße nutzten und spät erst in den Bechergläsern Nachfolger fanden.

Die angegebenen Wärmequellen, Lampe und Licht, zeigen, daß die Annahme, es handle sich bei den qũ $\tau a$ der Kleopatra wirklich um dieselben, in erster Reihe zur Beleuchtung gebrauchten Gegenstände, berechtigt ist. Beide waren schon in klassischen Zeiten so vervollkommnet, daß sie sicherlich auch zum Erwärmen benutzt wurden da, wo es sich

1) Vgl. oben die Rauchfänge, in denen sich das Kamelmist-Sublimat ansetzte.

$\Rightarrow$ Vgl, unten die Abb. U anf der Planche seconde nach Lémery. 
um Erzielung einer langdauernden, gleichmäßigen oder (durch mehr oder weniger starkes Herausziehen des Dochtes oder Anwendung mehr oder weniger Lichter) beliebig zu verstärkenden oder zu verringernden Hitze handelte ${ }^{1}$ ). Später kann ich sie nochmals erwähnen.

Noch wenige Worte über den sich selbst blasenden Ofen Al Tannûr: Sein unteres Ende ist enger als sein oberes. Er ist auf drei Füße gestellt und in seinen Seiten befinden sich Löcher. Er wird auf eine Bank gestellt. In der Mitte an seinem untersten Ende befindet sich

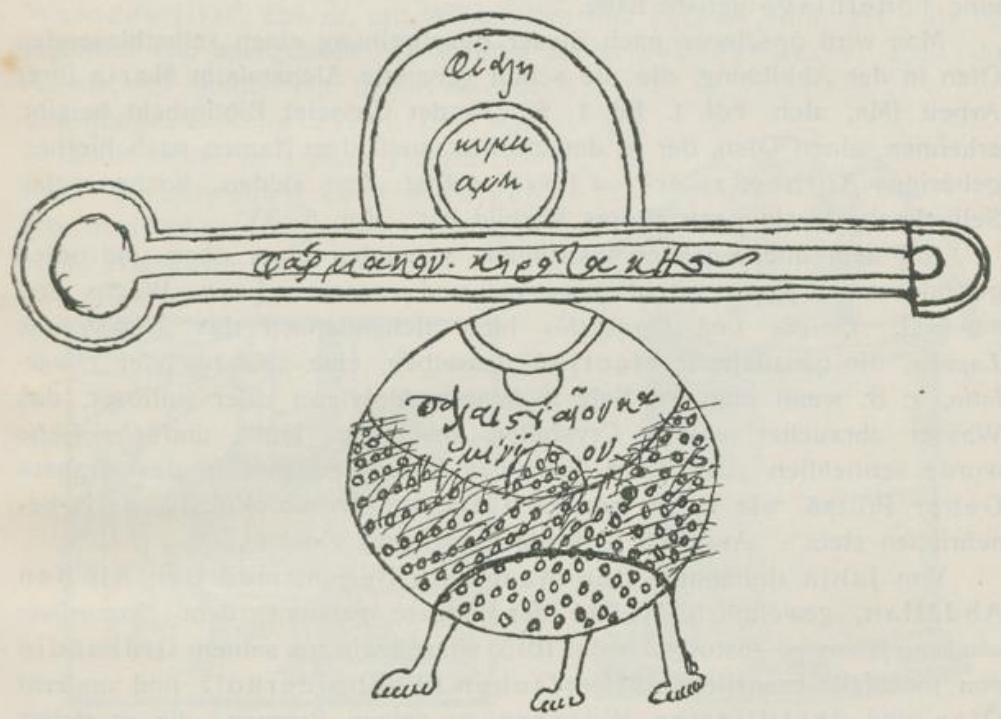

Abb, 11. Vermutlich eine Authepsa.

eine Öffnung (Kuwva), um aus ihm die Asche zu nehmen. In seinen untersten Teil bringt man die Kohle und setzt in ihn, was man kalzinieren will, und es wird mit Kohle (vermutlich das Gefäß ringsherum) bedeckt. Du stellst ihn auf, wo ihn die Winde treffen, und sein Feuer ist sehr kräftig.

Sprachlich ist Al Tannûr, der wieder aus dem altorientalischen Heizgerät Tennor oder Tendo(u) $r$ hervorgegangen sein dürfte, unzweifelhaft der Vorläufer des künftigen Athanor, und seine Herleitung von a จávatos sicher so falsch wie die der Aludeles von Aluta. Sonst aber handelt es sich augenscheinlich nur um einen Windofen, einen

1) Appul. met. IV. 18 p. 28 f. zählt hierher gehörig auf: Taedis, lucernis, cereis, sebaceis et ceteris noeturni luminis instrumentis clarescunt tenebrae. 
Anemius [ävepos Hauch, Wind] oder Furnus ventosus, so genannt, weil, wie Ernsting, fast mit des Rhazes Worten, erklärt: weil der Wind oder die Luft unten durch das Aschenloch zieht, er also selbst das Feuer anbläst und das noch mehr natürlich, wenn er hoch „auf der Bank" oder da steht "wo ihn die Winde treffen". In den Mafâtîh al 'Ulûm heißt es, daß Boden und Wände des „Geräts mit eigenem Zug" durchlöchert gewesen seien, also ganz wie das klassische Beispiel der 'A vi óxu und Foculi, und daß es eine Unterlage von Ton gehabt habe, daß es, modern zu reden, also unzweifelhaft mit Ton gefüttert gewesen sei oder eine Toneinlage gehabt habe.

Man wird unschwer nach dieser Beschreibung einen selbstblasenden Ofen in der Abbildung, die die schon genannte Alchemistin Maria ihrer Arbeit (Ms. alch. Fol. 1. Bd. 1, S. 175 der Casseler Bibliothek) beigibt, erkennen, einen Ofen, der in der antiken, auch dem Namen nach hierher-

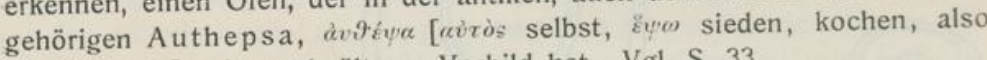
Selbstkocher] sein noch älteres Vorbild hat. Vgl. S. 33.

Auf dem querliegenden Instrument, scheinbar einer oben und unten

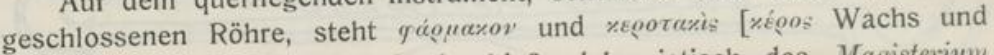

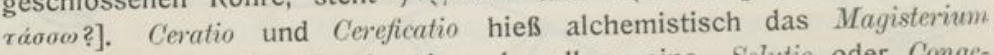
Lapidis, die gänzliche Perfection desselben, eine ,Solutio oder Congelatio, z. B. wenn man ein Salz in Wasser solvieret oder auflöset, das Wasser abrauchet und zu Crystallen anschießen läßt", und Cereficatio wurde schließlich „der dritte Grad des Feuers genannt in des Arabers Geber Prozeß, wie es in (wessen?) Theatr. Chymic. Vol. IV. p. 38 beschrieben steht". Arabisch hieß die Cereficatio Taschmi.

Von Jahja (Johannes) Ben Maseweih Ben Ahmed Ben Ali Ben Abdallah, gewöhnlich Mesue der Jüngere genannt, dem Exangelista pharmacopoeorum, gestorben wohl 1015, wissen wir aus seinem Grabaddin von jedenfalls brenzlichen ätherischen (Wacholderholz und andern) Ölen und destillierten Wässern zu seinen Sirupen, die er sicher selbst darstellte.

Der ziemlich gleichzeitige Abul Kasim el Zahravi. der abendländische (A) Bulkasis lehrt Essig durch Destillation reinigen (und verstärken), er destilliert Wein, sublimiert Salmiak aus (Kamel-)Dünger, er nennt den "Athanor" usw. Rosenwasser lehrt er ohne und mit Wasser darstellen. Ersteres röche übel (jedenfalls etwas brenzlich). Bei dem Verfahren "mit Wasser" handelt es sich - die lateinische Übersetzung ist sehr verworren - allem Anschein nach um eine Destillation aus verbessertem Wasserbade. Das Aufnahmegefäß [er nennt es Berchile, was dazu geführt hat, irrtümlich hie und da das ganze Gerät so zu nennen] wird von einem nebenstehenden aus gespeist und die Glas- oder Tonkolben, deren Helme unter Zuhilfenahme von Leinenstreifen aufgedichtet sind, werden in ähnlicher Art fest und dicht in die ausgesparten Löcher des Deckels gesetzt. Es würde sich also um ein Gerät handeln, das eine Verbindung 
von den in den Abbildungen 12 und 13 wiedergegebenen ohne weiteres verständlichen dargestellt haben mag.

Es dürfte nicht zum wenigsten das Verdienst von Arnaldus v. Villanova gewesen sein, daß er, zeitweise wenigstens in Barcelona Araberwissenschaft studierend (von $1281 \mathrm{ab}$ ), das dort geschaute vermutlich erst nach Salerno, dann nach Montpellier und Paris und dadurch nach dem Norden gebracht hat. Er, allem Anschein nach, benutzte zuerst das arabisierte, altorientalische Wort für äußerst fein verteiltes ') Antimon, $K o c h l$, die färbende Grundlage der Augenschminken, als Alkohol, für sein Weindestillat, das er, mit Würzstoffen und Zucker „konfiziert", als belebendes und anregendes Arzneimittel zuerst Lebenswasser, Aqua vitae nannte. Er stellte ein Oleum mirabile dar, das größtenteils Terpentinöl war, er auch lehrte in seinem Traktat „De vinis" die Darstellung eines weinigen Rosmarindestillats, der künftigen Aqua Hungarica.

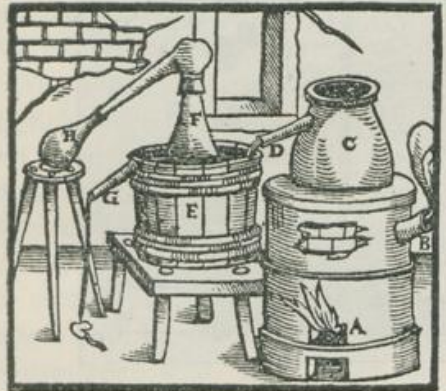

Abb. 12. Destillation aus dem Wasserbade nach Lonicer.

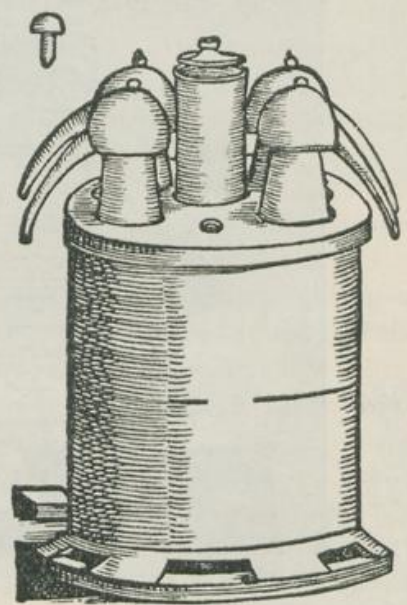

Abb. 13. Destillation aus dem Wasserbade mit Füllofen nach U1stad.

Daß um dieselbe Zeit in Arabien, im Orient die, wie schon gesagt, sicherliche uralte Darstellung von Ruchwässern wirklich in großem Maße geradezu fabrikmäßig betrieben wurde, belegt in einer Art Weltbeschreibung aus dem XIII. Jahrhundert Dismaschqî. Er beschreibt") und erläutert bildlich die damals in A1 Mizza bei Damaskus betriebene Darstellung (Isticlwâq) von Wasser aus Rosen"), Ochsenzungen,

1) An diese alte Bedeutung erinnert noch der in der Pharmazic übliche Kunstausdruck "alkoholisiertes*, d. h. höchst fein verteiltes Pulver, z. B. Ferrum alcoholisatum.

${ }^{2}$ ) Wiedemann macht auf sie I. c. auf S. 246 aufmerksam, ed. Mehren arab. Text S. 53 und 194. Übersetzung v. Mehren S. 58 und 264.

3) 20 Zentner besonders gute kosteten, wie Dismaschqî angibt, im Jahre $665 \mathrm{v}$. Chr. in Damaskus 22000 Dirham. Rosenwasser wurde in Gûr in der Nähe von Schiras (später Fairuzâbâd) vorzüglich dargestellt, aus leuchtend roten Rosen. 
$\left(\right.$ Buglossum $\left.^{1}\right)$, Seerosen $\left.{ }^{2}\right)$, Levkojen $\left.{ }^{3}\right)$, Moschusweide (?), Orangenblüten $\left.{ }^{4}\right)$, Cichorie $^{5}$ ) usw.

Nach der Abbildung, die vermutlich der Wirklichkeit sehr wenig entspricht, und der von Wiedemann beigegebenen Beschreibung lagen kolbenähnliche Destillationsgefäße in einem turmähnlichen Ofen in mehreren Geschossen, radial über- und nebeneinander gebettet, auf Unterlagen von persischem Rohr, so daß ihre Hälse (Halq) und ihre Mündungen

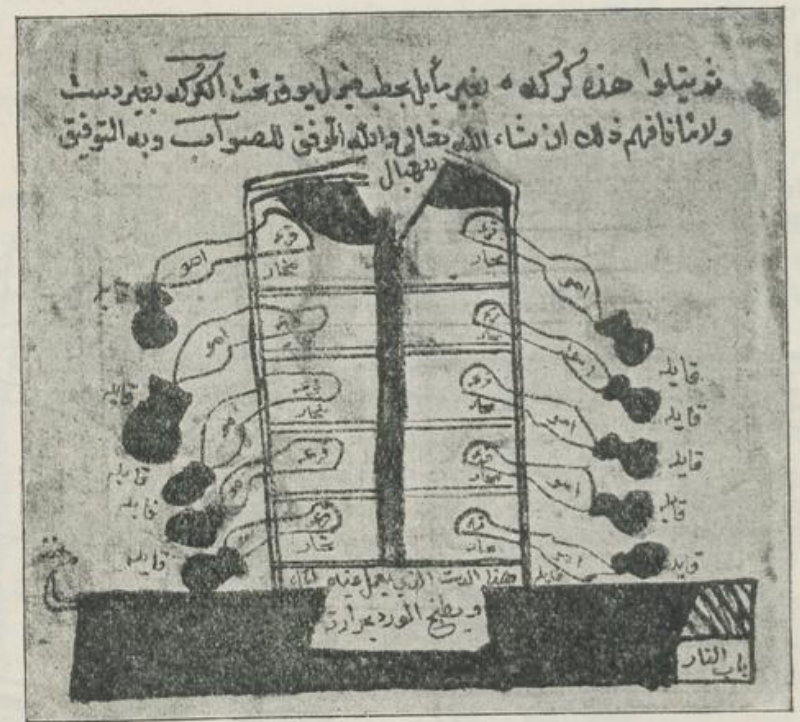

Abb. 14. Altarabische Destillation von Ruchwässern im Dampfbad.

1) Vermutlich Anchusa Italica bei Dioskorides. Aqua Buglossi, zumeist wohl Boraginis, oder beide gehörten neben Aq. Rosarum und Violarum zu den Aquae quatuor florum cordialium.

5) Nymphaea alba führt Dioskorides auf.

3) Flores Cheiri, Goldlackblüten vermutlich.

4) Daraus ginge, die richtige Übersetzung vorausgesetzt, hervor, daß schon vor Porta, gest. 1615, die Blüten der Pflanze destilliert wurden, die ihre Heimat in Indien haben sollen. Es soll die Pflanzen schon im IX. Jahrhundert von den Arabern in Syrien und Arabien und etwa ein Jahrhundert später in N.-Afrika, Spanien und Italien eingeführt worden sein. 1598 erwähnt Matthioli das Wasser als viel gebraucht. In Frankreich wird im XVI. Jahrhundert cine Destillation von Eau de Nafe oder Naphe erwähnt, 1600 wurde es in England gegen Pest gebraucht und in einem französ. Tarif als Preis des cent pesant (des Zentners) 3 Livres angegeben. Auch der Name, ital. Nanfa und Lanfa vom arab. Nafah spricht für arab. Herkunft des „Wohlgeruchs". 1681 erst soll eine Herzogin Flavio Orsini, Prinzessin Neroli, das Öl in die Mode gebracht und Veranlassung zum jetzt gebräuchlichen Namen gegeben haben.

5) Aq. Cichorii war noch vor nicht langer Zeit im Gebrauch. Der Same gehörte als Sem. Serrioloe zu den Quatuor semina frigida minora, neben Sem. Endiviae, Lactucae und Portulacae. 
(also ihre Anbiq) heraus in die Vorlagen hineinreichten. Mitten soll ein Schacht aufwärts gehen über einem Wasserkessel, dessen Inhalt von einer seitlichen Feuerungsanlage aus ins Sieden gebracht wird. Für den Rauchabzug ist gegenüber ein Rohr eingesetzt. Der Dampf soll von dem Mittelschacht aus die Kolben umspielen und schließlich oben entweichen. Daß diese Wärmequelle für eine Destillation nicht hinreichen konnte ist klar, ebenso wie, daß in den, in etwas an die bei der alten Destillation des Nordhäuser Vitriolöls gebrauchten Gefäße erinnernden Kolben eine Destillation ganz ausgeschlossen war. Der Zeichner wollte vermutlich Öfen darstellen, gleich "quibus", wie Matthioli ${ }^{1}$ ) im XVI. Jahrhundert berichtet, „Veneti

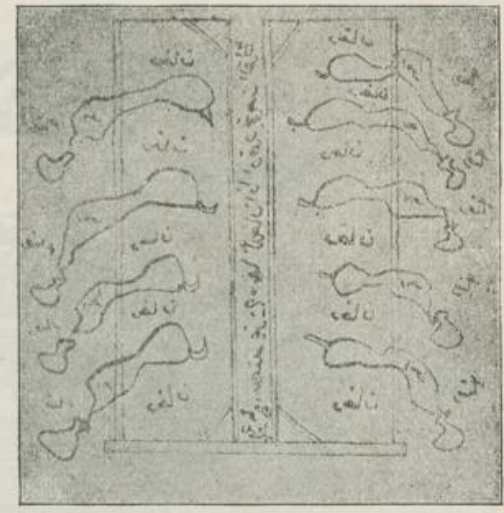

Abb. 15. Altarabische Ruchwasserdestillation. ac Neapolitani utebantur, fornaces qui vitreis alembicis abundant ${ }^{42}$ ), um möglichst an Feuerungsmaterial und Platz zu sparen. In beiden Fällen sind sehr niedrige, tatsächlich korb- oder schröpfkopfähnliche Kolben verwandt, in einem Falle mit $\mathrm{Helmen}$, die immer eine Art Krempe oder Sims haben, im andern Falle ihn entbehren. Oberseits tragen die letzteren Knöpfe angeschmolzen, an denen die Vorlagen festgebunden sind. Einen Ofen mit terrassenförmigem Aufbau und konischen $\mathrm{Helmen}$ wiederum mit simsähnlicher Auffangerinne zeigt die Abb. 16. Nach einem gleichzeitigen Vorbild. Auf der Abbildung S.17 sind Rosenhut-Alembik dargestellt.

Von anderen Abbildungen aus Dimaschqis Werk bringt Wiedemann noch eine, die immerhin ahnen läßt, daß die Retorte auch im Wasserbade richtiger nur im Dampf steht. Eine erfolgreiche Destillation ist auch hier wohl anzuzweifeln. Vgl. Abb. 18.

Wie ein konzentriertes zusammengesetztes,

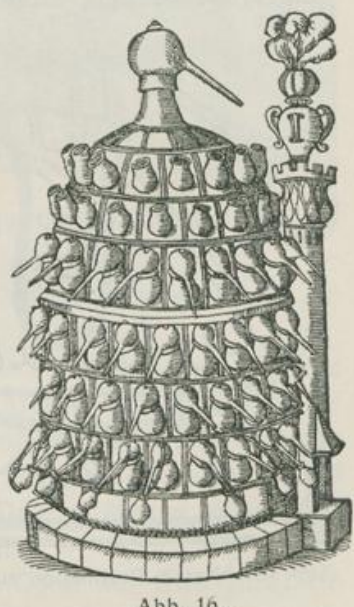

Italienisches Destillationsgerät. in erster Reihe Rosenwasser dargestellt wurde, beschreibt der schon

1) Vgl. dazu die Beschreibung des Apparates von Matthioli auf S. 45.

$\Rightarrow$ Vgl. auch unten S. 45. 
erwähnte Araber Al Gaubari in seinem „Buch von den Geheimnissen“. Im Kapitel über die der Arznei- und Würzwarenhändler (Apotheker, Drogisten), die sich übrigens „vieler Kniffe und Fälschungen schuldig machten“, sagt er:

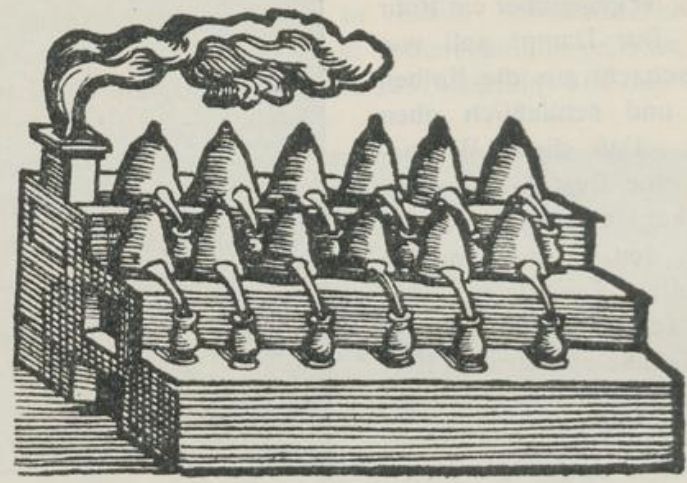

Abb. 17. Reihenweise angeordnete Destilliergerätc.

Herstellung des Rosenwassers: Sie nehmen iraqische Rosen, die einen Tag und eine Nacht in reinem kostbaren Rosenwasser mazeriert wurden, stopfen sie in einen Kolben und bringen in die (Ab-

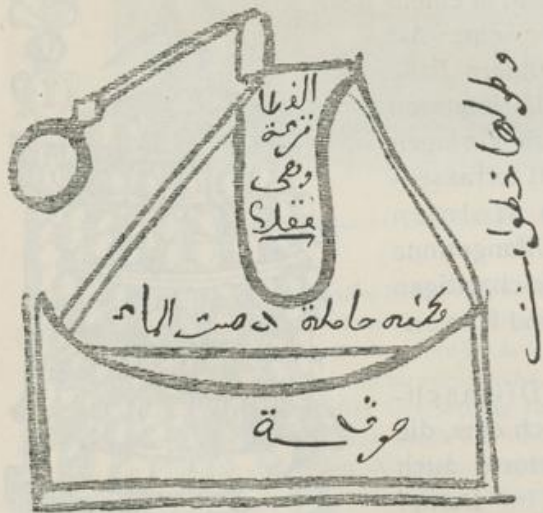

Abb. 18. Altarab. Destillation aus dem Dampfbade. lauf-) Röhre (Bulbula) des Anbiq ein Korn Moschus und setzen zu jedem Ratl Rosenknospen ${ }^{1)} 10$ Dirham Gewürznäglein (Kabsch Qaranful, vielleicht arabisierte Caryophylli) und 2 Dirham Cardamom (Hâl). Das destillieren sie auf gelindem Feuer über. Das Destillat bringt man in einen gläsernen Krug, dessen Hals man verschließt, setzt ihn in Baumwolle, dann in eine Schachtel und hütet es vor der Luft und davor, daß nichts von dem Geruch austritt.

Will man (gewöhnliches) Rosenwasser herstellen, so nimmt man süßes reines Wasser und bringt es in einem Kessel (Tingir) durch

1) Hier wohl ein syrisches Ratl, das viel schwerer ist, als das etwa $400 \mathrm{~g}$ wiegende von Bagdad. 1 Dirham $=$ etwa $3,1 \mathrm{~g}$. 
gelindes Feuer zum Sieden, bis ein Drittel fortgegangen ist. Dann nimmt man es herunter und schützt es vor Staub. Ist es erkaltet, so nimmt der, der das Elixir (das obige konzentrierte Destillat) bereitet hat, für jedes Bagdadische Ratl des gekochten Wassers 3 Dirham von dem Elixir. Die Öffnung des Zuflusses wird geschlossen, und es drei Tage in die Sonne gesetzt ${ }^{1}$.

Die Vorschrift ist auch aus dem Grunde interessant, weil das Abkochen des Wassers und Verdampfen bis auf zwei Drittel seines Gewichts sicherlich als ein Sterilisieren anzusehen ist, das demnach schon etwa 500 Jahre vor Spallanzani geübt wurde.

Es kann hier hintangestellt werden, ob der äußerste Osten, China, Indien, wie ich das annehme, seine Wissenschaft westwärts gegeben hat, ob die klassischen Völker umgekehrt sie wissenschaftlich befruchtet haben oder ob Ost und West ganz selbständig ihre eigenen Wege gingen; ich möchte auch dahingestellt sein lassen, ob die Werke, über die Praphulla Chandra $\mathrm{Ray}^{2}$ ) berichtet, wirklich der Zeit angehören, in die sie eingeordnet zu werden pflegen. Sie müssen aber doch an dieser Stelle erwähnt werden, weil sie allem Anschein nach auf uralte Muster

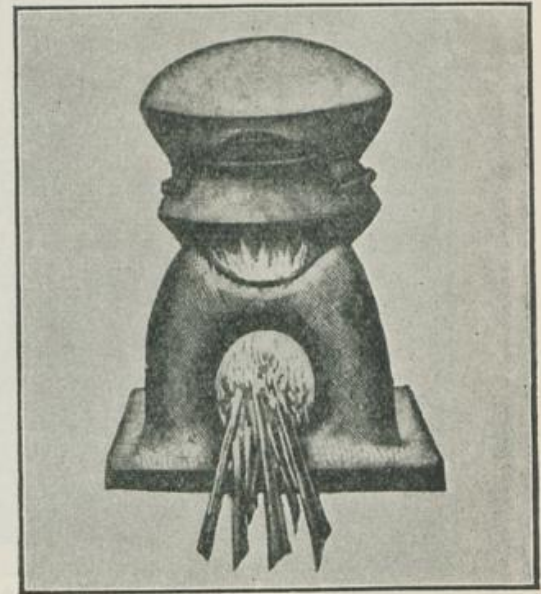

Abb, 19. Patana-Yantram. zurückblicken können und sich unzweifelhaft auf Erwägungen und Überlegungen stützen, die oben als allgemein maßgebend vorgetragen wurden.

Ray verlegt die Entstehungszeit des Rasaratna samucchaya, den Traktat über die Arbeiten mit Quecksilber und Metallen, verfaßt von Simhagupta, dem Fürsten der Ärzte, in den Anfang des XIV. Jahrhunderts. Das Werk gibt ja aber doch nur die Weisheit früherer Zeit wieder, und die aufgezählten und abgebildeten Yantra, die Geräte, ähneln sicher Vorläufern aus längst vergangener viel früherer Zeit.

Ein Blick auf das Patana-Yantram, das Gerät für Sublimation und Destillation, zeigt, daß es ,aus zwei übereinandergestülpten, grapenförmigen Gefäßen besteht", also im wesentlichen dem Gerät von Dios-

1) Wiedemanns Übersetzung, 1. cit. S. $249 \mathrm{ff}$.

2) In A History of Hindu chemistry, Calcutta 1902. 
korides gleicht. Es wird vollkommener durch das Verkitten mit einem zweifellos vortrefflichen Kitt aus Ton, Rohzucker, Eisenrost und Kuhmilch.

Der Koshti-Apparatus ist in erster Reihe für die Darstellung von Zink aus Galmei bestimmt, er gleicht ganz und gar den Geräten für absteigende Destillation bei Plinius. Das Anfachen des Feuers mit Hilfe eines Blase-Balgs [in des Worts ursprünglicher Bedeutung: eine zum Blasen eingerichtete, abgebalgte Tierhaut] ist eine Verbesserung.

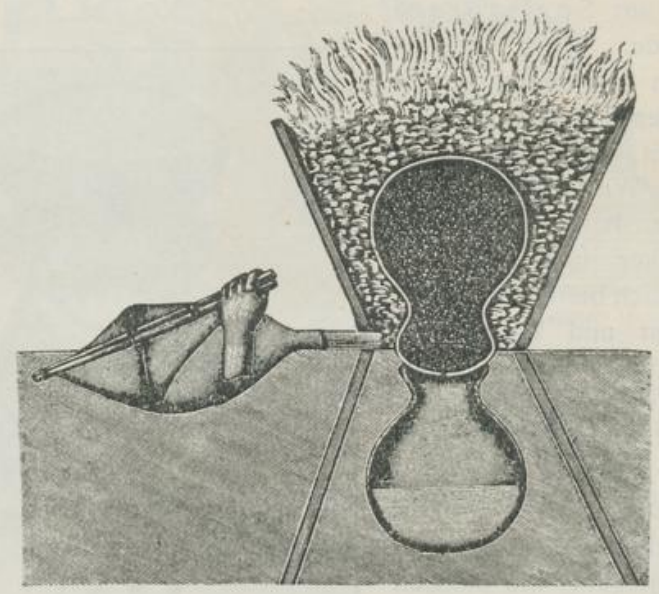

Abb. 20. Koshti-Apparatus.

Tiryakpatana yantram zeigt eine Destillationsvorrichtung mit allen für ihre Eigenart in Betracht kommenden Teilen. Einen auffallenden Unterschied zeigt das Ablaufrohr, vermutlich sich anlehnend an die "Schnauze", den Ausguß der krugförmigen Gefäße. Aus dem Kolben ab und nach unten geht es in ein ganz ähnlich gestaltetes Vorlagegefäß. Der Ambix ist hier lediglich Deckel. Die vorgesehene Kühlung ist immerhin als Vorsprung gegen die oben geschilderten Geräte aufzufassen.

Es dürfte kaum bestritten werden, daß im Abendlande Arnaldus von Villanova mit seinen Werken der Destillation die Bahn brach für ihren Eintritt zuerst in die "offiziellen", gesetzlich dafür bestimmten Stätten der Arzneibereitung, die Apotheken. Ihre Aufgabe, ihr Bestreben war ja, wie das der Urfrau am häuslichen Herde, aus den natürlichen Arzneistoffen geeignete Mittel auszuziehen, zu extrahieren, jetzt zu destillieren, und zu konfizieren. Erklärlich ist, daß auch K1öster, die frühzeitig die Arzneikunst erst für ihre Insassen und deren kranke Pfleglinge, 
dann für die Öffentlichkeit (vielleicht nicht so sehr aus charitativen Erwägungen als von der Erkenntnis der Richtigkeit des Spruchs: „Dat Galenus opes" getrieben, um ihren Säckel zu füllen) pflegten, die Destillation von Aqua vitae, dann von ätherischen Ölen eifrig, großzügig betrieben. Ich erinnere an das Kloster der Dominikaner Santa Maria Novella in Florenz, das, sicher nachdem lange vorher die Klosterapotheke solche Destillationen in beschränktem Maße vorgenommen und die zugrunde zu legenden Erfahrungen festgelegt hatte, Ruchwässer und Öle seit dem

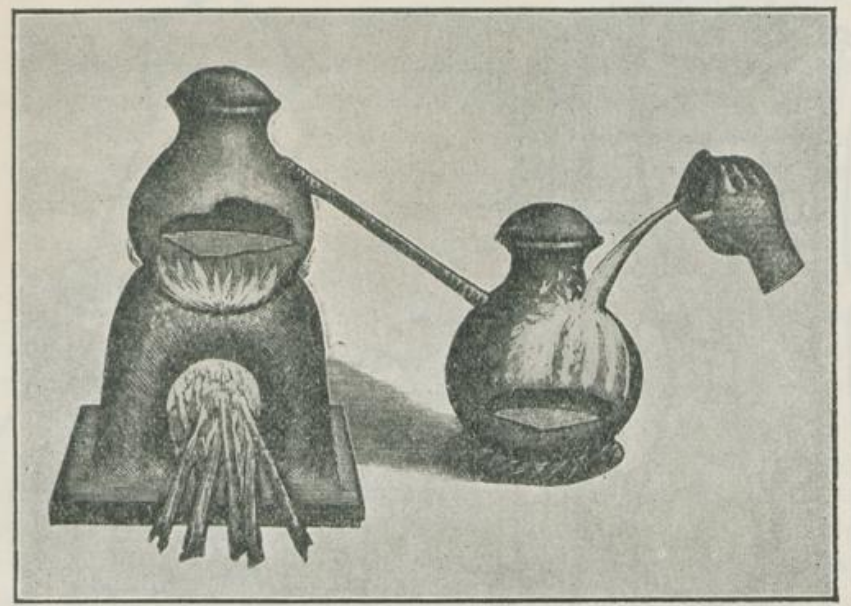

Abb. 21. Tiryakpatana Yantram.

Anfang des XVI. Jahrhunderts im Großen darstellte, jedenfalls zu großen Teilen mit Pflanzen, die sie selbst gezogen, dann an die Benediktiner und die Karthäuser mit ihren Aquae vitae, die ihren Namen in alle Welt brachten usw. ${ }^{1}$ ) Es ist übrigens völlig begreiflich, daß solche Hantierung auch andre Übergriffe in das Gebiet der gedachten staatlich überwachten und dafür geschützten Heil- und Arzneibeflissenen nach sich zog. Es begann die Zeit der von einem Heer handwerksmäßig arbeitende Wasserbrennern und-Brennerinnen (in England Aquavit-vomen) betriebenen Destillation von alkoholischen Lösungen ätherischer Öle und würziger und bitterer Extraktivst offe, die erst als arzneilich wirkende Lebenselixiere, als Confortantia, Stomachica, Aromatica, Carminativa empfohlen und getrunken wurden und die sehr bald die Maske des Heilmittels abwarfen, als Schnaps ein Genußmittel wurden und die Brannt-

1) In meiner Geschichte der Pharmazie findet man eine Menge von hierhergehörigen Angaben. 
weinpest entstehen ließen, gegen die schon frühzeitig behördliche Verordnungen erlassen werden mußten. Im übrigen wurden sie zur Besteuerung herangezogen und warfen auf diese Art dem Volke doch einigen wirtschaftlichen Nutzen ab.

Wie die Destilliergeräts chaften damaliger Zeit ausgesehen haben, das verraten uns, seit der Erfindung der Buchdruckerkunst, eine Menge von, wenngleich recht ungelenken Bildwerken. Es ist ohne weiteres verständlich, daß sich die „schwarze Kunst" mit großem Fleiß in den Dienst

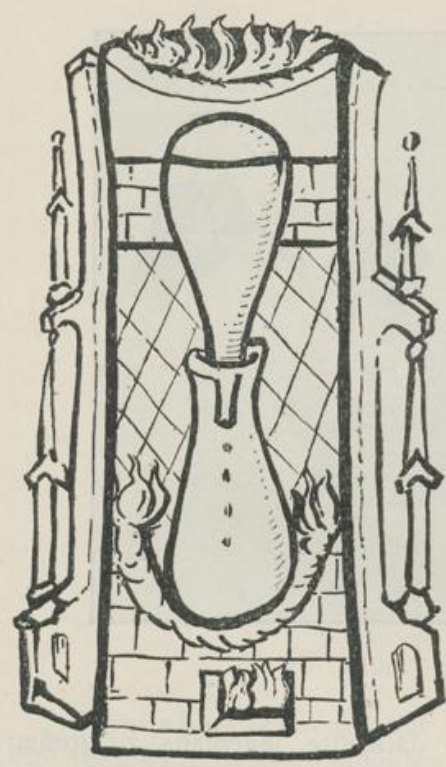

Abb.22. Digeriergerät aus dem XV. Jahrh.

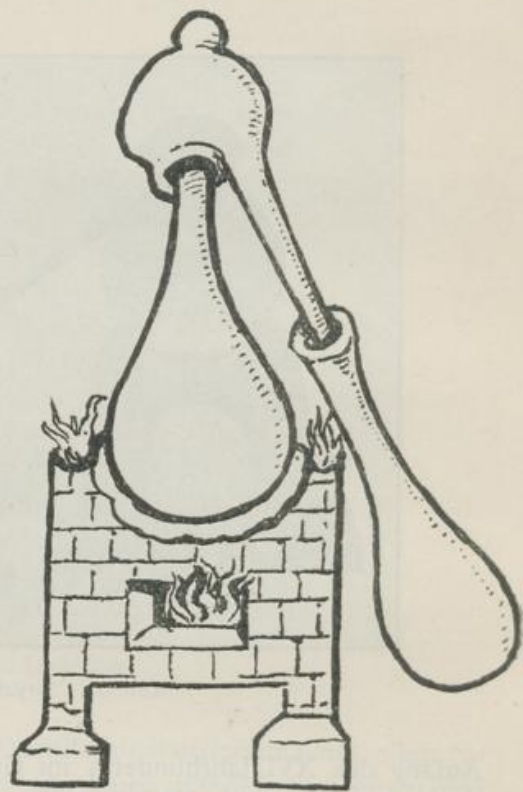

Abb. 23. Destilliergerät aus dem XV. Jahrh.

des Kampfes um das höchste Gut der Gesundheit stellte. Ihr galt ja der ganzen Naturwissenschaften, der "Physica“ und in Sonderheit zuerst der "philosophischen Kunst" der Alchemie ganzes Streben. Mit ihrer Universal-Tinktur, ihrem (El)Iksir mit dem Stein der Weisen wollten sie ja unedles Metall in Gold veredeln, weil im Grunde nur dieses allein das Leben lebenswert machte. Die ältesten Abbildungen von Geräten, die lediglich alchemistischen Zwecken dienten, enthält eine Handschrift des Nürnberger National-Museums jedenfalls aus dem Besitz des ersten Hohenzollernschen Kurfürsten Friedrich I. Die in ihm dargestellten Geräte $\left.{ }^{1}\right)$ erinnern unzweifelhaft an die oben erwähnten der Kleopatra u. a.

1) Die Abbildungen sind mir von der Direktion freundlichst dargeliehen worden. 
Interessant erscheint das Digeriergefäß mit der helmähnlichen Erweiterung, in deren Krempe unzweifelhaft sich z. B. Äther, Äthylnitrit u. dgl. nach dem Abkühlen der so lange unter Druck in Berührung gewesenen Chemikalien gebildet haben müssen. Vgl. unten.

Nachdem man sich von der Unerfüllbarkeit der ersehnten „Permutation“ überzeugt hatte, beschied man sich, die Chemie in den Dienst des Arztes zu geben, der Iatrochemie die Aufgabe zu stellen, durch Bekämpfen der Krankheit, durch Ersinnen von Vorschriften zu Aqua vitae, zu Elixir ad longam vitam, von Athanasia, Panaceen usw. wenigstens einen Teil der früher erstrebten Aufgaben zu erfüllen - und nebenbei Gold zu schmieden.

Nicht eben deutlich zeigt eine Abbildung aus einem, wohl dem ersten Buch, das sich mit Destillationen befaßt von Michael (Puff aus) Schrick, doctor der erczenei“, dem "Verzeichnis der ausgebrannten Wasser" zuerst Augsburg 1483, einen Apparat, wie ihn die schon genannten, vielen, später staats- oder stadtseitig "geschworenen“ Wasserbrennerinnen (das sie der Regel nach auch Heiratsvermittlerinnen waren, läßt vermuten, daß sie am Ende, wie ihre klassischen Vorgängerinnen die römischen Sagae, vor Nebengeschäften nicht zurückbebten, die das Licht des Tages scheuten) für ihre Arbeit brauchten. In der Hauptsache interessiert der jetzt turmähnlich hochgezogene Alembik, der sog. Rosenhut, der jedenfalls gar nicht übel im oberen Teile die schwerer siedenden Teile sich verdichten und zurückfallen ließ̧, während andre in dem zurückgekrempten untern Teil sich sammelten und je nachdem in die Blase zurück, oder (etwa wie aus dem, fast vier Jahrhundert später von Hermann Hager ersonnenen Dunstsammler) in das Ablaufrohr liefen. Ähnliche Rosenhüte sehen wir auf dem auf dem Bilde aus Hieronymus Brunschwyks „Liber de arte destillandi, das Buch der rechten Kunst zu destillieren die eintzigen Ding“, das zuerst 1500 in Straßburg und später noch unter vielfach wechselnden Titeln oft erschien, und auf dem andern von dem Meister des Trostspiegels vom Jahre 1530. Vgl. auch oben Abb. 17.

Beide Abbildungen zeigen gleicherzeit, wie das Destillieren von „wesentlichen" (weil sie das eigentliche "Wesen", den wirksamen Bestandteil der Pflanzenstoffe darstellten, die Quinta Essentia, das wahre Ens oder Esse [gr. ov̀oia] in ihnen. Die Franzosen behielten in der Hauptsache den Ausdruck essentielle bei, Lémery erwähnt nur, daß Boerhave sie Spiritus rector, Esprit recteur ${ }^{1}$ ) genannt habe, während wir, nach der

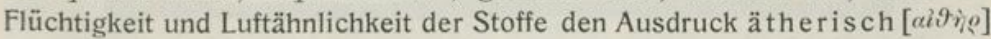

1) In seinem "Elementa chemiae" Lugdani Batav, 1732 spricht er die Meinung aus, daß die flüchtigen Öle aus einem in Wasser nicht löslichem, grobem harzähnlichem Stoff, der Mater oder dem Gas und einem subtilen, dem Äther ähnlichen, schon genannten bestünden, der in Wasser sich löse und das wesentliche, für den Geruch der einzelnen Stoffe eigentümliche darstellt, wåhrend die Mater stets dieselbe sei. Durch Luft und Luftzutritt und Entweichen des Spiritus werde das dick und harzig werden, das Verderben der Öle bewirkt. 


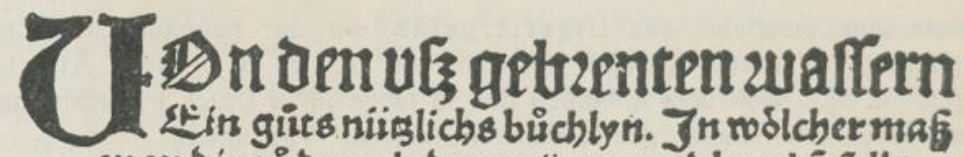
man Ote 3 is den glydern niisten vnd burbē foll/ als dasm mey ftex abichel Echicid boctor det erzmey diedēment ch ç befchrib ç hat.

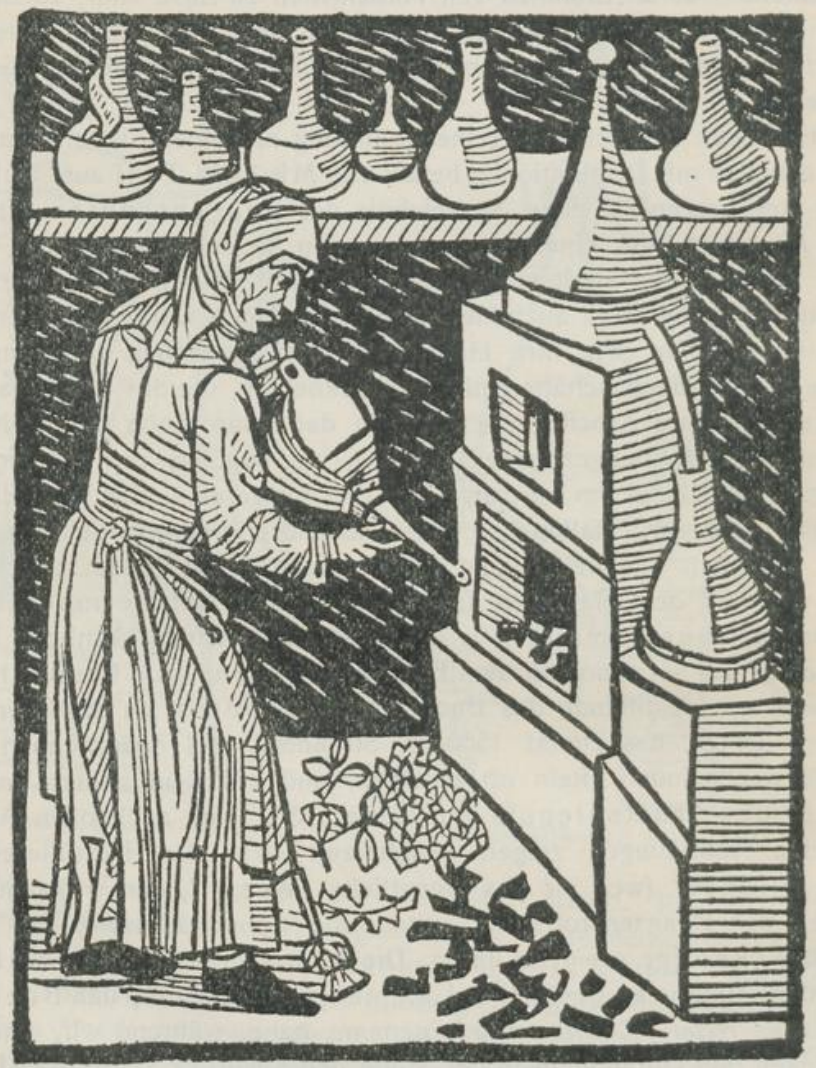

Abb. 24.

wählten) Ölen oder von mit ihnen beladenen Wässern gleich an Ort und Stelle in den Viridarien, den Kräutergärten abgezogen wurden, die häufig, zum Teil wie bei Bamberg auf dem Michaelsberg, bei Würzburg (Herbipolis), in Südfrankreich usw. in großem Maßstabe angelegt 
Ziber be arte oiftillandi. oe Simplicibus. Bas buch oet rechten lanit zü biftilieten oie eintsigẽ oing

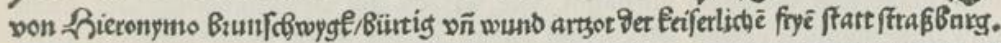

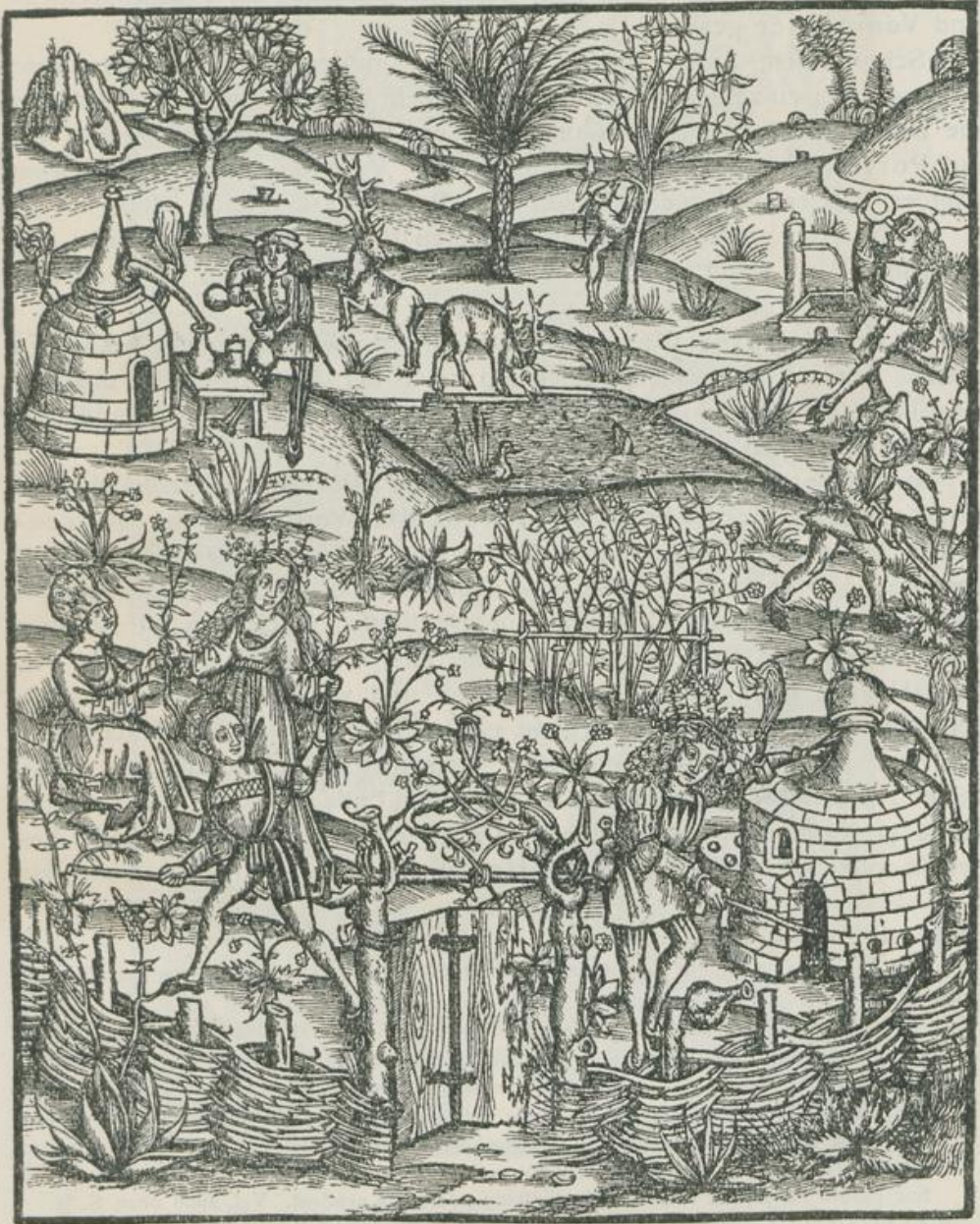

un getruckt ourcb oen woblgeacbte Fobannem grueninger 3 u जtrasgburg in oen acbte tag des mepen als man 3 elt pon oer geburt Cbristi funf 3 ebribundert. Xob sq got. Zanno 2500. 
wurden, übrigens zum „Zubehör" der Apotheken gehörten und als solche von ihnen geradezu gefordert wurden ${ }^{1}$ ). Vgl. Abb. 26.

Die letzte Abbildung, gleich der auf S. 38 aus Matthiolis') Werk, gegebenen, zeigt im übrigen, wie die Destillationsgefäße reihen- und staffelweise in den Öfen zwecks Ersparnis von Platz und Feuerung aufgestellt wurden, wenn man Destillationen aus kleineren, jedenfalls tönernen und gläsernen Gefäßen vornahm, wie wir es als Gepflogenheit, der nicht unwahrscheinlich ersten wirklichen Destillateure, dann der Neapolitaner und Venetianer gesehen.

Schon oben, S. 36, sprach ich kurz von der Darstellung der Aqua Naphae. Um zu zeigen, wie vorgeschritten, in wie großem Maßstabe schon die Destillation von Ruchölen und -Wässern betrieben wurde, möchte ich, auf Porta gestützt, hier einiges ausführen. Von Aqua Arantiorum flomm sagt er, daß es an Dauerhaftigkeit dem Rosenwasser gleich käme.

In Neapel werde aus handgepflückten Blüten so viel destilliert, daß die ganze Welt damit versorgt werde, die das Wasser zum Würzen der Speisen und zur Darstellung von Parfüms brauche.

Konzentriertes Wasser, ein eximia fragrans, also ein besonders starkes (etwa triplex), wurde nach Porta in der Art dargestellt, daß das Destillat stets "super recentiores flores irroratu.", also durch Destillation über neuen Blüten weiter angereichert wurde.

In gleicher Art verfährt man zu gleichem Zweck auch jetzt noch, und nennt die Arbeit cohobieren"). Mir ist das Wort zuerst bei Quercetanus in seiner "Pharmacopoea dogmaticorem restituta", Lipsiae 1613, aufgestoßen. Er rechnet die Cohobatio neben Exaltatio, Exhalatio, Circulatio und Recitificatio, ganz mit Recht, zur Destillatio. Nach ihm ist sie aber eine wiederholte Destillation, bei der das Destillat auf das abdestillierte (die Faeces) zurückgegossen und wiederum destilliert wird. Sein Endzweck ist also im Grunde ein möglichst großes Erschöpfen, ein Aussüßen [edulcorieren] oder Auslaugen [elicieren; nur diese beiden Ausdrücke dürften wenigstens bis zum Ende des XVIII. Jahrhunderts gänge gewesen sein] einer Menge Arznei(-Stoff), und ganz dasselbe bezweckt offenbar auch Anton de Heiden in seinem "Neuen Licht vor

) Gesch. der Pharmazie, S. 364 u. a.

2) Ich lasse hier noch die Beschreibung aus Opera quae extant omnia, Basileae 1565, de ratione destillandi aquas folgen:

Hac fornace utuntur Veneti ac Neopolitami, qui vitreis alembicis abundant. In qua una tantum die et nocte sicco ignis calore eliciunt aquae ultra centum libras. Fornax rotunda est, fornacibus, quae in Germanorum visuntur vaporariis, omnino similis. Continet haec circumcirca numerosa fictilia intrinsecus vitro incrustata, urinalis formam referentia et diligenti sane artificio argillaceo bero agglutinata, quibus singulis per totum fornacis ambitum singuli adduntur vitrei alembici, e quorum vertice ex globulo ad hoc parato recipientia crassiusculo funiculo adalligata pendent. Vgl. auch oben S. 37 .

${ }^{3}$ ) Nicht cohibrieren, wie irrtümlich in einer Arbeit in der Chemiker-Zeitung i. J. 1011 gesagt wurde. 
die Apotheker" Leipzig 1690: Das Cohobieren beschieht, sagt er, wenn das Destillierte zurückgegossen wird, umdestomehr alle Kraft aus dem

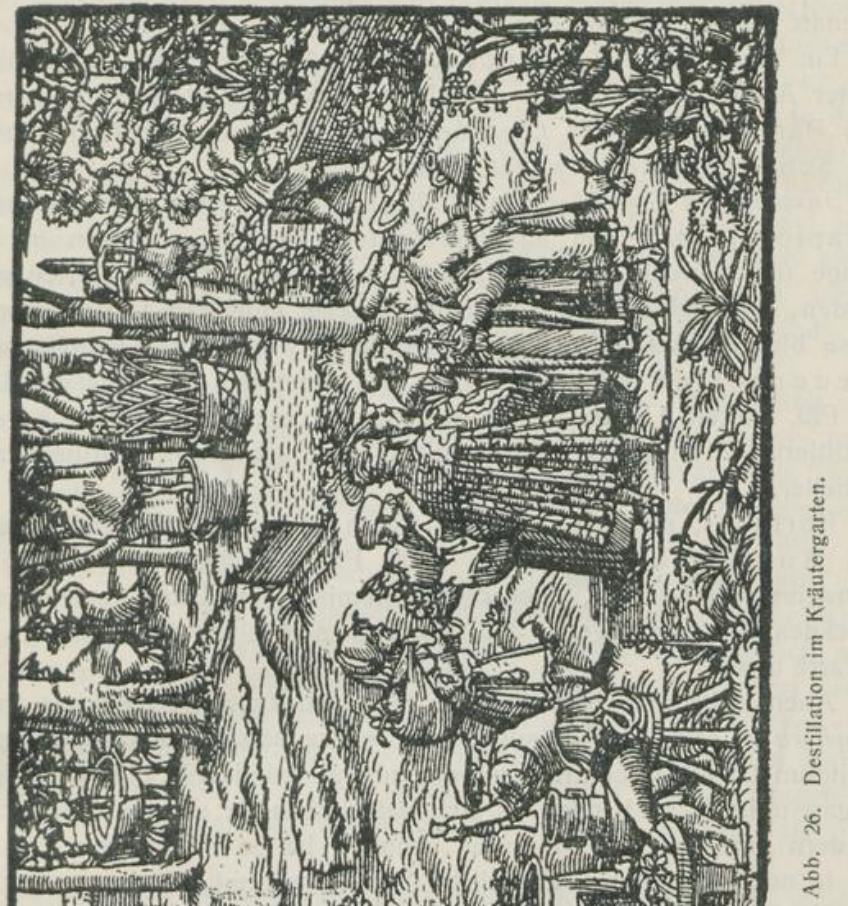

Caput morturm zu bekommen," und der geistvolle, eigentliche Begründer der Phytochemie Nicol. Lémery, dem es darauf ankommt, das 
Wesentliche, das Wirksame, die Quinta essentia, in aller erster Reihe der pflanzlichen Arzneistoffe von dem wertlosen, dem Caput morturu zu scheiden, erklärt „La cohobation se fait pour ouvrir les corps", um ihre Eigenart durch Herausziehen der Bestandteile zu erschließen.

Ein venalis wird aus Rückständen destilliert (die, jedenfalls nach uralter Art durch Ausziehen [Enfleurage] der Blüten mit Fett bereitet), zum Parfümieren der Clyyrothecae und Thoraces, der Handschuhe ${ }^{1}$ ) und Schnürbrüste verwandt wurden ${ }^{2}$ ).

Jasemini vel Gelsomini [das italienisierte Jesemin der Araber, z. B. Serapions] flores von ausgezeichnetem Geruch, wüchsen in solcher Menge und würden so geliebt, daß die Pflanzen in allen Gärten gezogen würden, und keine Frau sich nehmen ließe, einige in Töpfen zu pflegen. Diese blühten das ganze Jahr. Aus ihnen würden im Dampfbade durch wiederholtes Rückgießen des Destillats aus Glasgefäßen aus 600 Pfd. Blüten 1 Unze $(30$ g) rötliches Öl erzielt. Das aus A b s y n th destillierte Öl ist blau; wird es mit Wasser wiederum destilliert, so wird es heller.

Porta ist, so weit ich sehen kann, der erste, der über eine Reihe von Ausbeuten berichtet. 100 Pfd. frische Kamillen gäben 2 Drachmen grün es, ebensoviel Artemisia eine Unze ebenso gefärbtes (trocknes Kraut weniger), 300 Pfd. A n is 1 Unze Ö1, das im Winter erstarrt usw.

Auch sehr uneigentliche Öle führt Porta an. Wenn er ausführt: "Caphura in aqua forti dissolvatur et supra aquam manabit Ol. excellentissimum Caphurae contra cancros, ubera malefica et plagas. Cum oleo vulgari unitur", so handelt es sich natürlich nicht um ein ätherisches Öl, sondern um Campher-Säure. Ähnlich ist es mit seinem Ol. Vitrioli, das ja noch jetzt unter demselben Namen bekannt ist.

Noch an eine Bemerkung sei erinnert. Wenn Caryophylli [„sunt flores" zeigt, daß Porta sich über ihre botanische Eigenart klar ist] nicht zerkleinert, heil destilliert und dann getrocknet werden, „denuo revendi possunt nec fraus detegitur nisi gustu experimentum sumatur". Es wurden sicherlich abdestillierte Nelken gehandelt, und nur der Geschmack war der Helfer, der damals den Betrug klarstellen konnte.

Ganz ebenso wird man vermutlich in Frankreich gearbeitet haben, wo schon im XIV. Jahrhundert Ruchgewächse, in der Bourgogne z. B. Lavendel, Borago, Salvia, Vinca, Veilchen und Rosen, Plantago und Lilien in großen Mengen angebaut wurden, um getrocknet verwandt und zu Ruchwässern destilliert zu werden. In der Nähe von Dijon sollen elf Öfen in Tätigkeit gewesen sein, wie Baudot ${ }^{3}$ ) berichten kann.

1) Shakespearez. B. erwähnt solche.

7) Im Jahre 1582 führt die Frankfurter Taxe das Wasser an, aber ohne Preis.

5) Baudot, La pharmacie en Bourgogne, Paris 1905, S. 63. 
Es wird wohl wieder der Anregung des schon erwähnten Arnaldus von Villanova ${ }^{1}$ ) zuzuschreiben sein, daß ganz allgemein statt kupferner Gefäße, die er bei der Verwendung von salzigen, sauren und süßen Stoffen für Nahrungszwecke verwarf ${ }^{2}$ ), für „Wasserbrennerei“ (z. B. durch eine Verordnung von 1551 in Nürnberg) die Anwendung gläserner geboten wurde. Um dieselbe Zeit allerdings wurden auch schon in ihrer Art vortreffliche $z$ innern ${ }^{3}$ ) und jedenfalls auch verzinnte Kupferapparate für größere Destillationen von Kupferschmieden geliefert, die in ihrer Kunstfertigkeit, wie das jedes Museum zeigt, kaum hinter der der zeitgenössischen zurückstanden. Daß die Hofapotheke in Dresden einen Destillierapparat von Georg Storm in Augsburg bezog läßt darauf schließen, daß dieser Kupferarbeiter sich wohl eines besondern Rufs als Spezialist im XVI. Jahrhundert erfreute.

Eine andre Abbildung aus Brunschwik (er hat sie in Wahrheit von Ulstadt übernommen) ist aus zwei Gründen interessant. Erstmals zeigt sie eine Einrichtung, die ebenfalls geeignet war, eine Ersparnis an Heizmaterial und Arbeit zu Wege zu bringen, wie sie in der Zeit der Alchemisten, die lange Tage und Nächte ihre Arbeit bei gleichbleibender Hitze erhielten, wirklich nötig war. Es handelt sich tatsächlich um eine Art von Dauerbrenner, in dem das Urbild der spätern Meidingerschen-, Schwedischen- usw. Füllöfen sich darstellt. Man stellte ähnlich, wie ich das für Braunkohlen jetzt noch hier auf dem Lande gesehen habe, neben den eigentlichen Ofen einen oben luftdicht durch einen Deckel verschließbaren, mit dem Heizraum in Verbindung stehenden "hohlen Turm" (den jetzigen Füllschacht"). Der wurde mit „toten“ Kohlen angefüllt. "So wie sich die Kohlen im Feuerherde verzehren, so machen sie den

1) In der Tat haben die Alten die Schädlichkeit von Kupfer gekannt und gleicherweise die des Bleies. Gegen die erste schützte man sich durch Verzinnen (wie z. B. Theophrast in $\pi \varepsilon \rho i$ h 69 \% Vgl. Plin. 34, 47, 48), gegen Bleivergiftung durch Verwendung von Tongeräten. Vitruv sagt beiläufig (VIII, 7) „Viel gesünder ist Wasser aus irdenen wie aus bleiernen Röhren, denn das Blei scheint ungesund zu sein“. Vgl. übrigens die ausgezeichnete Arbeit von Kobert über Bleivergiftung im klassischen Altertum. (Diergarts Kahlbaum-Buch.) Megenberg spricht auch von der Schädlichkeit der Kupfergefäße: "Wann man kupfereine vaz verzint, da wird ezzen und trinken pezzer in und vertreibt die vergift des rosts an dem Kupfer". (S. 480, 20 ff.). Etwa gleichzeitig mit der Nürnberger Verordnung wandte sich im Ausland übrigens auch Ambroise Paré und Benedetto Ventori aus Faenza gegen die Verwendung von Kupfergeräten.

7) Geber verwandte vermutlich tönerne, bleiglasierte Gefäße, wenn der Ausdruck Vasa terrea plumbata, so ausgelegt werden darf. Vgl. auch Matthiolis Beschreibung in der Fußnote S. 46?2.

a) Daß es im XVI. Jahrhundert zum mindesten schon (Shakespeare erwähnt siez. B.) in England Pewterer [von Spiauter, das später für Zink gebraucht wurde. Vgl. meine Geschichte S. 490 u. a.], Zinnarbeiter gab, bezeugt das Vorhandensein solcher Gewerbtreibender. Daß sie auch unter der Reihe der Kurpfuscher genannt werden, läBt immerhin den Gedanken aufkommen, daß sie die Instrumente, die sie fertigten, auch anzuwenden unternahmen. 
Kohlen im Turme Platz. Diese fallen vermöge ihrer Schwere herunter und werden genötigt, den entstandenen leeren Raum zu füllen."

Und dieses dauernde, nicht verlöschende „unsterbliche" Gerät wurde jetzt (im Gegensatz zu dem einfachen Windofen, Anemius [vgl. oben S. 19], der stetes Aufpassen verlangte [vgl. die Abb. S. 34]), zum „,chymischen Ofen", zum Athanor (bei dem man nicht mehr an das arabische, oben genannte Wort dachte, sondern, wie es noch jetzt erster Drang ist, gelehrt

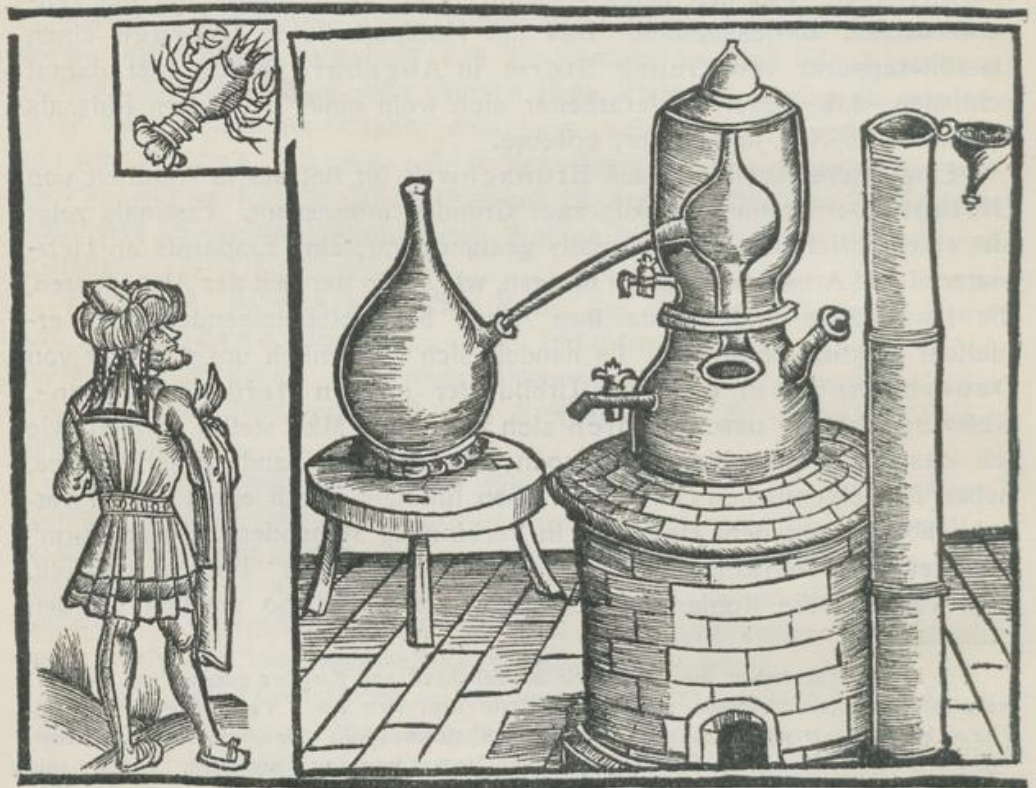

Abb. 27.

Strohkranz, Mohrenkopfkühlung, Füllschacht.

an ältere, oben schon erwähnte griechisch-lateinische Quellen) oder, ähnlich bezeichnend, zum Furnus Acediae [ $\left.\dot{\alpha} \varkappa \eta \delta \eta_{i}\right]$ oder Jncuriae [beides bdeutet: sorgenfrei] und Piger Hinricus, dem faulen Heintz. [Heinrick, Heinz war seit alten Zeiten sprichwörtlich die Bezeichnung für einen sonderbaren Menschen. Vgl. Knökern Hinrik, Freund Hein, den roten Heinz (=Colcothar).]

Weiter zeigt die Abbildung zum ersten Male eine Kühlvorrichtung und zwar eine, die, wie nach dem Werdegange des Destillationsapparates gar nicht anders zu erwarten, übrigens auch ganz zweckmäßig ist, a uf dem Alembik angebracht ist. Statt daßs man nach klassischem Vorbild 
den Deckel mit einem mit kaltem Wasser getränktem Schwamme überfuhr oder ein Tuch auflegte und dies mit Wasser netzte (Porta kühlt beispielsweise ,,madidis linteis" oder , spongia aqua frigida imbibita"), umgab man den Helm mit einem Gefäß, das man mit Wasser füllte. Daß man an eine Erneuerung dachte, geht aus dem seitwärts angebrachten Hahn hervor; daß man nicht wußte oder nicht daran dachte, daß das warm gewordene Wasser nach aufwärts steigt, verrät die Lage des Ablaufhahnes ziemlich am untersten Ende des Kühlwassergefäßes. Der Name Mohrenkopf für diese Kühlvorrichtung ${ }^{1}$ ) ist lediglich auf phantastische Vorstellungen zurückzuführen, die für die damaligen Chemiker bezeichnend sind und die sie gelegentlich jedenfalls auf $\mathrm{Ab}$ - und Irrwege führten, weit $a b$ von den Richtwegen, die nüchterne Beobachtung ihnen gewiesen hätte. Eine Ausgeburt reger Phantasie, in diesem Falle sicher des Zeichners, und ein Ergebnis seines Dranges zum Stilisieren ist die Abbildung des Destilierapparates, die ebenfalls der schon genannte Brunschwik bringt. Vermutlich nur der Symmetrie wegen stellt er ein sehr hohes und enges Rohr in die Mitte, und aus zwei seitwärts aufgestellten sich „selbst anblasenden" Windöfen läßt er in diesem Falle schon von Retorten ähnlichen, unzweifelhaft gläsernen Destilliergefäßsen die röhrenförmigen Verlängerungen ihrer Hälse in schlangenähnlichen Windungen aufwärts durch das Kühlgefäß gehen und oben in fest verbundene oder aus einem Stück verfertigte Receptacula austreten. Auch hier ist der Ablaufhahn tief unten angebracht.

Wenn das auch nicht von wesentlicher Bedeutung ist, so soll doch nicht zu bemerken vergessen werden, daß auf beiden Bildern die Auffangegefäßse unzweifelhaft auf Unterlagen stehen, die als Strohkränze anzusprechen sind, wie sie, mit Bleistücken beschwert auch an die Vorlagen gebunden wurden, um sie im Kühlwasser untergetaucht zu erhalten. Vgl. Abb. 27.

Auch die Abbildung von dem Meister des Trostspiegels zeigt, daß die Apparate für kleinere Arbeiten aus Glas (vgl. oben S. 47) dargestellt wurden - im wesentlichen natürlich nach uraltem Muster. An Stelle der Blase traten Gefäßse, deren Hals immer mehr eingezogen, verengert ward, Kolben. Ernsting nennt dafür als weitere Namen Alcara, Botia, Botus [am Ende verstümmelt aus Botrus, Bótovs, oder Buccia] barbatus, Kymia, Onbelcata, Onbelcora [Umbilicata?], griech. oєxíc [der Schröpfkopf], arab. Cara, Charha, Haraha, ital. Zucca [Kürbis], franz. Alambic, welche Namen aus dem Vorhergegangenen so leicht zu deuten sind wie der zumeist gebrauchte Cucurbita [lat. Kürbis]. Schon Paré?) wendet auch das Wort [angeblich aus dem Keltischen oder vom lat. Matara ab-

1) Vgl. unten S. 65, übrigens den aus umgekehrten Erwägungen unrichtigen Ablauf Abb. 12.

7) Vergleiche dazu die lediglich auf ganz äuß̉erliche Ähnlichkeit sich gründenden Namen Mönch und Nonne und Dame Jeanne, englisch Demijohn für Flaschen. S. a. folgende Seite Filioli, und weiter unten, was über Amplexicatio auf S. 58 gesagt ist. 
stammender Name] Mat(he)ras ${ }^{1}$ ) an, das wohl, latinisiert, zu Matracium wurde. Halte ich Libavs Metretae daneben, so ist mir höchst wahrscheinlich, daß man in der Wortbildung die phantastisch-geschlechtliche Ergänzung der Herrenkolben, der Magistrales erblickt, die ursprünglich vielleicht nur Harnkolben, Urinalia waren, die besonders weite Öffnungen zeigen. Weiteren Anhalt für die früher schon geäußerte Annahme, daß man Hausund Küchengeräte in das Laboratorium überführte und zu chemischen Geräten erhob, geben die, oben noch weiter offenen Matulae [ursprünglich das Wort für Nachttopf]. Sehr lang- und dünnhalsige Kolben nannte man Phiolae [qiaia], Buccia [buccea Mundvoll?], Ovum vitreum, philosophicum, Locus chimicus, Mebellum [?], Urinale sublimatorium. Für gewöhnlich waren sie und die Kolben im allgemeinen unten rund gestaltet, fundo globosae, man hatte aber auch Cucurbitae fundo lato, also richtige Stehkolben).

Den Hals der Kolben für Destillationszwecke ließ man für gewöhnlich etwas kegelförmig nach oben sich verengen. Das geschah, um seinen Durchmesser bequem dem des überzustürzenden und aufzukittenden Helms anzupassen und zwar in der Art, daß man den Hals durch Überstreifen eines entsprechend weiten (zwei verschieden große waren zumeist durch einen Stiel miteinander verbunden, so daß einer die Handhabe für den andern bildete) glühend gemachten Sprengrings oder durch Anzünden einer mit Kienöl getränkten (Ulstadius empfiehlt Schwefelfäden), um die betreffende Stelle geschlungenen Schnur erhitzte und durch aufgesprengtes Wasser plötzlich abkühlte ${ }^{3}$ ).

Dem Dache nachgeahmt zeigte sich im Durchschnitt der Helm, der Alembik. Wie schon gesagt, war er, um die schwerer siedenden, bald verdichteten Destillationsprodukte aufzunehmen, oben sehr bald mit einer Krempe oder mit mehr oder weniger großen simsähnlichen Ausbuchtungen versehen, von denen aus, oder über denen das Ablaufrohr die verdichteten Gase ableitete.

1) Vgl. auch oben S. 12.

2) Die Phiolen (Violen und Filioli sind ganz mißverständliche willkürliche Bildungen. Bei den Filioli schwebte der Einbildungskraft der Chemiker vielleicht wieder der Vergleich mit dem Makrokosmos, die Folgerung aus den Magistrales und Metretae vor Augen) sind die Muster für die noch in den $70 \mathrm{er} \mathrm{Jahren} \mathrm{des} \mathrm{vorigen} \mathrm{Jahrhunderts} \mathrm{für} \mathrm{Tropfen} \mathrm{gebrauchten}$ Nönnchengläser und die noch länger vergessenen Blätterchen der Apotheker. Letztere hatten einen tief eingebogenen Boden und dienten zur Aufnahme ganz geringer Mengen von Arznei. Erstere sind die Vorfahren der noch zu nennenden modernen A mpullen, die als A mpoule durch Limousin in Paris als Behältnisse für sterilisierte Arzneilösungen seit der Verwendung des Tuberculins Anfang der $90 \mathrm{er}$ Jahre in Gebrauch gezogen worden sind und recht gut, wenn man keine deutschen Namen findet, Ampullen nicht (feiner?) franzősisch genannt werden sollten. Vgl. S. $55^{3}$.

3) Ulstadius, Prof. der Heilkunde in Freiburg, sagt 1526 im Caelum Philosophorum: Wann du aber es öffnen wilt, so vmbwickel den Halß des Glas mitt einem schwebelfaden sechs oder siebenfältig herumb gewunden, den zünde dann an hübschlich mit einem wachskertzlein und so der Faden gar außgebrannt ist, so bricht das Glab daselbst ab. Oder laß dir drei oder vier eisne Instrument machen zweyer elenbogen lang, deren jedes an jedem ort zween ring hat. Auß welchem mach einen der dir fugt, glüend heiß vnd zwingen vmb den Halß deß glaßs, so bricht es oder knallt gar baldt ab. 


\section{Libet de ante Biftil}

\section{landi oe compofitis.}

ZaG bûch oet waren kunlt zü oiftillieren bie

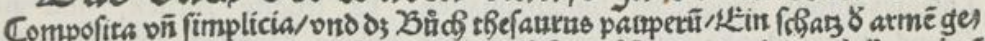

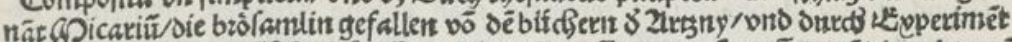

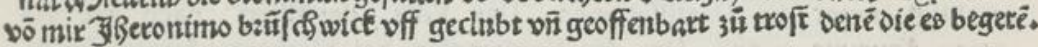

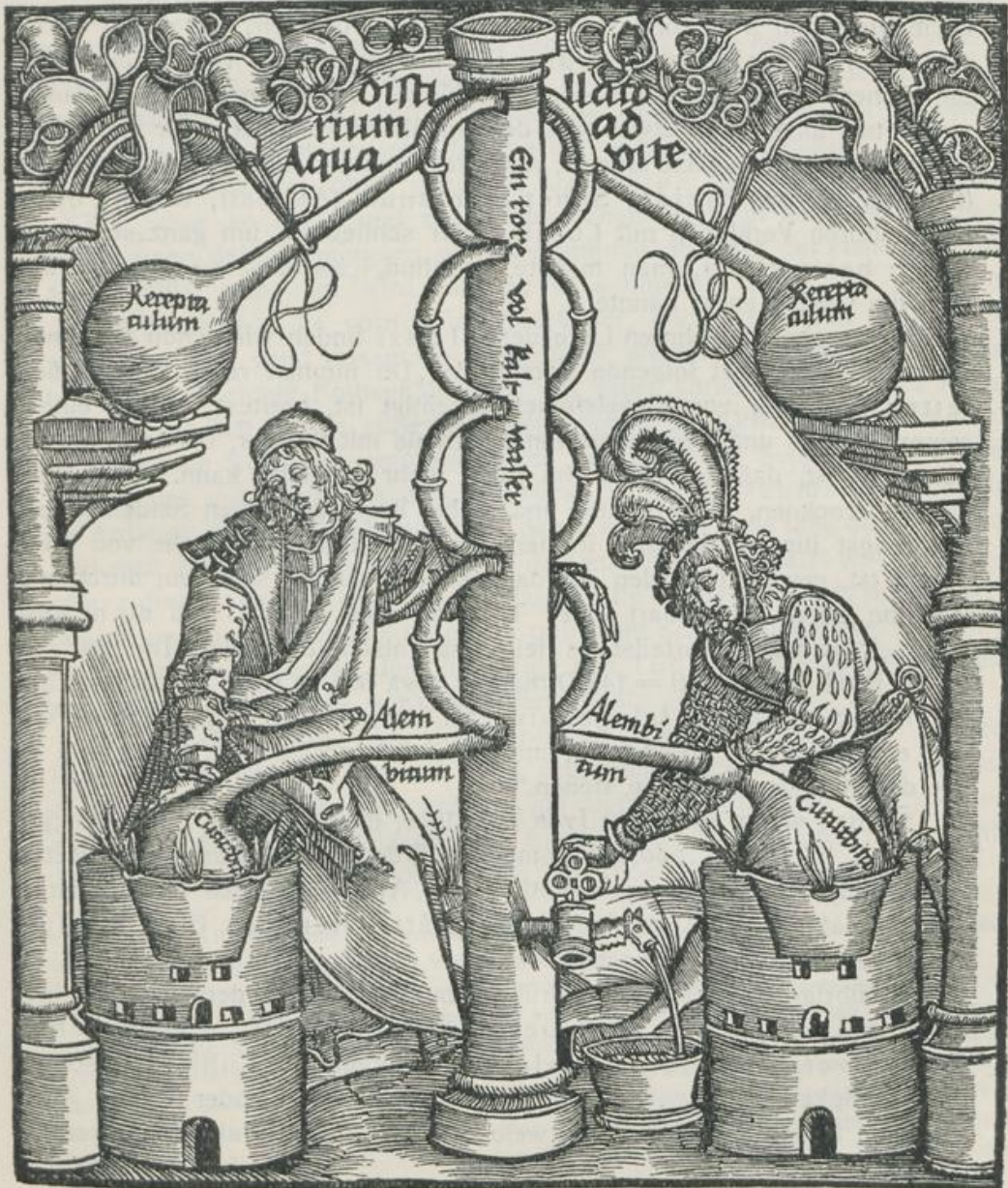

getruckt un gendigt in die keisserlicbe irye statt झtrassburg uff sanct Matbis abent in oem jar 1507. 
Bei allen den Arbeiten, die da bezwecken, aus den verschiedenen von der Natur gelieferten Rohstoffen die wirksamen Stoffe in Lösung zu bringen, zu extrahieren, bei den, je nach der unter oder am Siedepunkt liegenden Temperatur jetzt Infusionen oder Decoctionen genannten Arbeiten, schloß man die betreffenden Gefäße, um ein Verdampfen des Lösungsmittels möglichst hintanzuhaiten. Es tropfte zurück, und auf Grund dieser Beobachtung rechnete man solche Arbeiten, immerhin berechtigt, unter die Destillationen. Das Volk "destilliert" nach wie vor seine Aquavite u. dgl. Um das Verdampfen bei hierhergehörigen, in Alchemistenzeiten Tage und Nächte währenden Arbeiten, bei dem Putre-

cieren, Digerieren, Extrahieren hintanzuhalten, vermutlich auch, um sicher zu gehen, daß unberufene Jünger der hermetischen Kunst nicht etwa in der Zeit etwas von dem Inhalt entwendeten oder die Arbeit durch schädliche Zusätze störten, verschloß man die „Kolben" mit Stopfen (Obturatoren) aus Kreide, Suber montanum (Asbest), Wachs oder Kork, durch Verkleben mit Lutum, oder schließlich, um ganz sicher zu gehen: hermetisch, man machte sie blind, "matracia coeca", oder wie man die Gefäße sonst nannte.

In der oben erwähnten Liste des Al Razi finden wir schon für einen Ton der Weisheit folgende Vorschrift: „Du nimmst roten und weißen fetten Ton, der von Kieselsteinen gereinigt ist, breitest ihn auf einem reinen Ort aus und besprengst ihn mehrmals mit Wasser, bis er so flüssig geworden ist, daß die Hand ihn nicht mehr betasten kann. Dann läßt du ihn trocknen, pulverst ihn und siebst ihn durch einen Seidenlappen, besprengst ihn mit Wasser, in dem Reiskleie (Suhâla), die von Mehl befreit ist, geweicht worden ist; dann knetest du ihn sehr fein durch und läßt ihn gären (chammar) einen Tag und eine Nacht. Und du nimmst feines Reismehl, verteilst es fein und mischt dann den Ton zu. Zu jedem Ratl Ton (1 Ratl=144 Dirham = etwa $500 \mathrm{~g})$ setzt du 10 Dirham Kochsalz und 3 Ratl feingepulverte Tonware (also gebrannten Ton) und eine Handvoll Tierhaare, möglichst fein geschnitten, zu. Lasse es vor dem Gebrauch 3 Tage stehen."

Ähnlich waren die Luta [von iv́w, löse, durch Wasser zeitweise „gelöste", d. h. weich, bildsam gemachte Erde, Lehm] zusammengesetzt. Durch längeres Kochen, gelegentlich mit Alaun, wurden sie haltbarer, durch Zusatz von Wasserblei, Silberglätte, Mennige, Eiweiß, Blut, Mehl besser klebend gemacht ${ }^{1}$ ).

$\mathrm{Im}$ übrigen wurde $\mathrm{Blase}$ drübergebunden und beiderseits mit Bindfaden fest verschnürt. Zu feuerbeständigem Kitt wurden Lehm, Glaspulver, Eisenteile, Bleiglanz genommen. Kuhhaare sollten ihm Festigkeit geben. Die Namen Lutum Sapientiae oder Lutum philosophorum zeigen schon an sich, welcher Wertschätzung sie sich erfreuten.

1) Vgl. oben S. $10^{2}, 40$. 
Glauber soll seine Vorschrift für 200 Gulden verkauft haben. In einem Werke aus dem XVIII. Jahrhundert finde ich, ein Zeichen ihrer Wertschätzung, noch etwa ein Dutzend Vorschriften für Kitte verzeichnet.

Was den tagtäglich sprichwörtlich gebrauchten hermetischen Verschluß, das Sigillum oder die Signatura Hermetica betrifft, der so dicht sein sollte, wie das Geheimnis, das die hermetische Kunst umwob, so fand ich ihn, ohne den die Araber ja nie eine „Blinde“ hätten herstellen können, unter diesem Namen ${ }^{1}$ ) zuerst bei Libav erwähnt, der ihn sicher aber älteren Vorbildern, wie er sie in großer Menge anführt, entnommen hat. Auf S. 2 Abs. 9 seiner Alchymia (im Kommentar auf S. 178 geht er noch weiter darauf ein) beschreibt er dieses "Artificium hermetice stringendi folgendermaßen: „Immittitur collum in prunas siniturque candescere, demissa simul forcipe ad locum signaturae. Ubi emollitum vitrum, comprimitur vel etiam obtorquetur forcipe ut undiquaque solidetur“.

Das drückt der oben genannte Ulstadius mit den Worten aus: "XXII. Steck so lange und so tief den langen Hals in den Ofen (Libav bildet einen dafür geeigneten oder bestimmten ab), das der Hals daß glaß schier glüet vnnd rot wird, alß ob er schmelzen wolte, so nim eyn "schmidtzang", die vorn glüend haiß sei, vnnd truck den Hals vnnd würg ihn vmb vnnd zusammen dieweil er glüet". Das haißt kurz: Der im Feuer erweichte Kolbenhals wird mit einer vorher erwärmten $\mathrm{Z}$ ange (vor kurzer Zeit wurde statt ihrer eine schon im XVIII. Jahrhundert vorgeschriebene Scheere empfohlen und der genannte Schluß ${ }^{2}$ ) als etwas ganz neues mitgeteilt) zusammengedrückt. Caspar Neumann empfiehlt im Anfange des XVIII. Jahrhunderts, den erweichten Hals lang auszuziehen, „wil man ihn vollends versiegeln, so darf man nur vermittelst einer Lötheröhre dieses Glas vollends zuschmelzen“. Es ist dieselbe Art, wie sie tagtäglich im chemischen Laboratorium und beim Schließen der Ampullen ${ }^{3}$ ) im modernen Sinne seit der Einführung des Tuberculins in den Arzneischatz in großem Maße ganz handwerksmäßig geübt wird.

Als noch bessere Art des Schlusses wird von demselben großen Praktiker empfohlen: „Wenn ich ein accurates Stück Glas nehme, so just die Runde des Glases hat, welches ich sigillieren will, und lege solches auf die Oeffnung des Glases und tractiere es nach obiger Manier mit Schmelzen, so wird sich solches als ein Knopf darauf anschmelzen".

1) Daß Al Razi unter seinen Geräten auch eine Scheere al Miqtac aufführt, läßt auch vermuten, daß die Araber den Verschluß kannten.

2) Vgl. meine Arbeit in der Cöthener Chem. Ztg. 1907, März 30: Der hermetische Verschluf,

a) Das Wort ist eine Verkleinerungsform von Amphora. An seinem Platze ist das Wort nicht. Tatsächlich wurden von unsern Vorgängern für solche Zwecke $\mathrm{Phiolen}$ benutzt. Libav sagt, sie zeigten als Eigenart „ex globoso ventre gracile collum in longum prominens. Ejus usus frequens, quia aptissimae sunt hermeticae signaturae“. Bis zur Gröte einer Nuß́ herab hatte man sie, und seit jener Zeit schloß man sicherlich in den chemischen Laboratorien kleine Mengen flüssiger Präparate in solchen Gefäßchen ein. Vgl. auch S. 52* und auf der Tafel aus B aumé unten Fig. 12, auf denen aus Lémery I, 2; II $r$ und $s$. 


$$
\begin{aligned}
& 88 \\
& 88800
\end{aligned}
$$


dem Beschicken „blind“ machte, am vollständigsten durch den „hermetischen Verschluß" (also so gestaltet, wie das Gefäß auf der Tafel aus dem Werke der Alchemistin Maria und die Abb. S. 20 es zeigen, und wie es noch jetzt geschieht, wenn man unter Druck arbeitet), und auf diese Art das Entweichen des verdampfenden Lösungsmittels (Menstruum) verhinderte. Man gestaltete sie zweckmäßig, tatsächlich schließlich zu (Extraktions-) Gefäßen mit, wenn auch gelegentlich nur angedeuteten Rückflußkühlern aus.

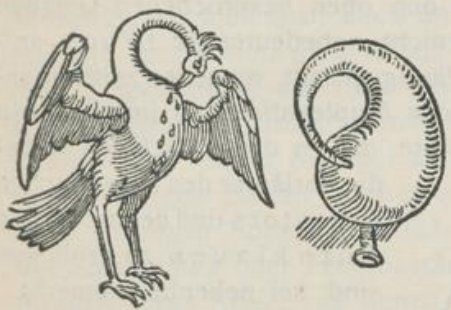

Abb. 31. Pelikan nach Porta.

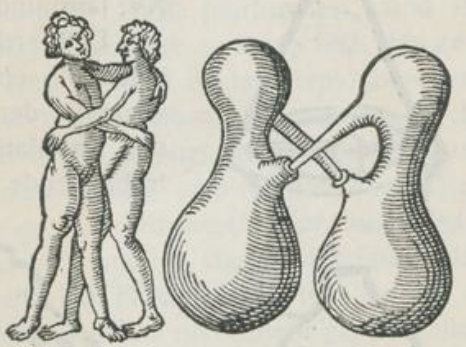

Abb. 32. Amplexantes nach Porta.

Wie Zirkuliergefäße, franz. Vaisseaux de rencontre, auch gestaltet waren, zum Teil um dem Pelikan, dem Geranium [yęáinov, Storchschnabel] usw. zu gleichen, wie man auf Grund entfernter Ähnlichkeit wohl eine Retorte (vgl. oben $\mathrm{S} .56)^{1}$ ) genannt hat, überall dienten sie „der Umtreibung einer auf- und niedersteigenden Destillation, einer chymischen Arbeit, da man nämlich eine flüchtige Sache auf eine Harte gießet in ein Gefäß und solches in Wärme hält, damit das, was aufsteigt, nicht weg kann, sondern wieder herunter auf die im Glase seiende Materie tropft" $)$.

Um solchen Zweck zu erreichen verschloß man erst nur den Gefäßhals, dann verband man zwei Kolben miteinander, so daß in dem

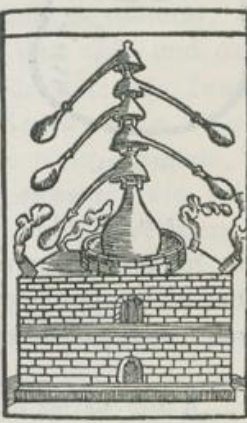

Abb. 33.

Gerät nach Porta. obersten eine Luft- oder Wasserkühlung stattfinden oder bewirkt werden konnte. Man ersetzte sie dann durch zwei nebeneinanderstehende Retorten,

1) Jean Baptista Porta scheint, was seine Phantasie betrifft, an erster Stelle zu stehen. In seiner Anweisung „De destillatione" bildet er neben den Vorbildern der Schildkröte, Testudo, dem Bär, Ursus, dem Pelican, die entsprechenden Geräte $a b$, auch ein solches, das einer sich emporringelnden Schlange gleicht, und ein andres mit fünf Ambik übereinander und fünf Abflußrohren zum Ableiten verschiedener "Fraktionen": die vorbildliche vielköpfige Hydra. Die Abbildungen 10, 29 u. 31-33 sind diesem Werk entnommen.

2) Bei Ernsting, auch die Planche seconde von Lémery, Fig. $S$. 
so daß die oben verdichteten Dämpfe der einen in die andere liefen und umgekehrt zu sog. Dy(i)otae oder Amplexantes ${ }^{1}$ ), ja man bemühte sich, offenbar eine bessere Kühlung insofern zu ermöglichen, daß man eine trichterförmige Einbuchtung herstellte, um dahinein Wasser oder einen mit Wasser vollgesogenen Schwamm zu legen, oder in dem

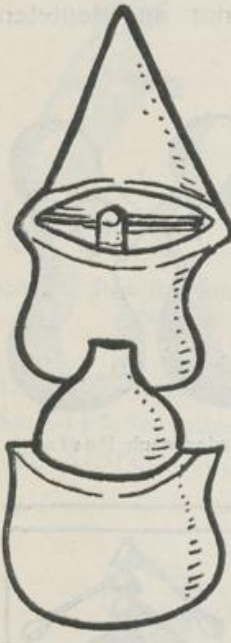

Abb. 34. man zu gleichem Zweck einen kopfförmigen Alembik anbrachte, wie ihn die schon erwähnte, in Nürnberg aufbewahrte Handschrift aus dem $\mathrm{XV}$. Jahrhundert auch schon bezeugt.

Daß sich in den oben besprochenen Gefäßen jedenfalls ein garnicht unbedeutender Druck entwickelte, der, beiläufig gesagt, mancher zeitraubenden Zirkulation oder Amplexation ein unerwünscht frühes Ende bereitete, daß in diesen Gefäßen somit

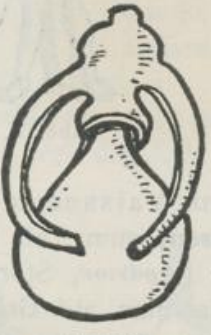

Abb. 35.

Digerier-(Circulier-) Geräte

nach der auf S. 42 erwähnten Handschrift. die Vorläufer des Papinschen

Digestors und der modernen A u to klaven zu erblicken sind, sei nebenbei bemerkt.

Brunschwik erklärt das Wesen der wahren Destillation und Dephlegmation mit den Worten: Dieweil die Geister, so über sich getrieben werden, viel reyner und subtiler seind, denn in solchem aufsteigen alles so schwer, irdisch oder flegmatisch ist, mit hinauf kommen mag. Darumb die geister des weins am flüchtigsten über sich, aber anderer materi, so mehr mit flegmatischer feucht behafft, under sich getrieben werden ${ }^{\circ}$ ).

1) Weil sie für die ,Amplexatio [das liebende Umfassen] oder die Basiatio [das liebende Küssen] d. h. die Vereinigung des Mercurii philosophorum oder weißen Weibes mit dem Fermento aureo oder dem roten $\mathrm{M}$ a n n e $\mathrm{e}^{\alpha}$ gebraucht wurden, wie es äußerst bezeichnend für die uferlose Phantasie der Alchemisten und ihrem Drang, die Vorgänge in den Retorten mit denen im Mikrokosmos Mensch und umgekehrt zu vergleichen, heißt. „Spagyrisch" hieß letzterer der Maritus, d. i. der Sulphur philosonum, Leo ruber, Fabrica, sein weißes Weib, Aqua mercorialis (andre Synonyma waren Alliaraeus, Aqua coelestis virginea und foetida, Gluten spagyricum aquilae, Jordan, Lac virginis, Leo viridis, deutsch stinkend Wasser, Giftwasser, Straußenmagen) Beya, und Dunstan kleidet (in seinem „Rosarium" S. 135) den zärtlichen Vorgang in folgende Worte: Wenn du das weiße Weib gebracht zum roten $M$ ann, da nehmen sie alsbald einander freundlich an, darauf empfänget dann das edle weiße Weib. Die zuvor waren zwey, sind worden nun ein Leib. Folgerecht gab es für gignere und producere auch ein Synonym foetisare, und das Produkt dieser Darstellung oder (Er-) Zeugung hieß Foetus spagyricus. Vgl. dazu auch die Trennung der Gefäße nach dem Geschlecht oben S. $51^{2}$ und S. 57, Abb. 32.

7) De arte destillandi. Vol. 2, lib, 1. 
Schröder faßt sich kürzer und erklärt in seiner Pharmacopoea medicochymica: Destillare $=$ Liquorem vi caloris attenuatum (durch die Gewalt des Feuers aus dünn gemachter Flüssigkeit) in recipiens appositum prolectare [Herauslocken]. Ernsting sagt sehr kurz: Distillatio ist oder geschieht, wenn man etwas aus einer Retorte, Blase, Kolbe etc. durch Hülfe des Feuers dessen Feuchtigkeit herausdestillieret oder heraustreibet, und er erklärt damit im Grunde gar nichts oder viel weniger als sein so viel früherer Vorläufer.

Ähnliche Unterschiede machte man im XVII. Jahrhundert, und im Wesentlichen hielt man auch im XVIII. Jahrhundert an ihnen fest. Hagen hält die Destillation ganz richtig für eine Art des Abdampfens, blos mit dem Unterschiede, daß man „bey jener das in Dünste verwandelte nicht achtet, bey dieser dasselbe aufgefangen wird". Weiter nennt er die Destillation fester Körper (wie bei den „Mineralsäuren, empireumatischen Ölen und flüchtigen Salzen") trockene, sicca, die flüssiger oder mit Zusatz. einer flüssigen Substanz feucht, humida, und in Berücksichtigung der Verschiedenheit „der Feuerbeständigkeit und Flüchtigkeit" teilt er sie in die drei alten Arten, von denen die per descensum nicht mehr gebräuchlich sein soll.

Wenn Megenberg im XIV. Jahrh. berichtet, daß man nach Albertus Magnus der Birken-„rind ausprenn (d. h. jedenfalls destilliere), alsô daz wazzer dar aus gêt, sô sei daz wazzer stinkend und zaeh und damit schmirben die Wagenläut ir wägen", so ist das jedenfalls ein Zeugnis dafür, daß man damaliger Zeit schon Birkenteer (Schwarzen Dägen) bereitete, vielleicht in alter Meilerköhlerei, wenn man nicht arbeitete, wie es in Anton de Heidens „Neues Licht vor die Apotheker, wie solche nach den Grundregeln der heutigen Destillierkunst ihre Arzeneien zubereiten sollen", Leipzig 1690, beschrieben ist:

„Die warme Destillatio per descensum findet man bey dem Pechschmelzen, da die Aeste des Baumes bei dem einen Ende angebrannt werden und am andern Ende läuft das Pech heraus als wie etwa das Wasser aus dem grünen Holtze. (Diese ist nicht mehr im Gebrauch).

In Böhmen habe ich gesehen, daß kleine Ofen gemacht werden auff die Manier wie die Bäcker-Öfen, nur daß solche hinten und vorne offen sind. Darein werden lange Stücken Holtz gelegt, also daß sie auf beiden Seiten herausgehen. Wenn solche an der einen Seite angesteckt werden, so läuft am andern Ende eine grüne Feuchtigkeit heraus wie die Pappel-Salbe, womit die Böhmen und Oesterreicher ihre Wagen schmieren."

Das bezeugt immerhin, daß man auch schon verbesserte Anlagen für Großbetrieb im Gebrauch hatte. Von Ölen, wie man sie wohl nur in kleinerem Maßstabe für die Apotheken darstellte, zählt Ernsting etwa

1) Vgl. auch oben S. 28 und weiter unten. 
hundert Jahre später auf: Ol. Buxi, Ligni Heraclini, sanctum, Rusci, ferner Ol. Cornu cervi, Succcini, Asphalti (früher wohl Gagates). Lémery liefs auch Ol. Caryophyllor. per descensum destillieren. Das folgende XVIII. Jahrh. empfahl feuchte Destillation. Man klagte, beiläufig gesagt, über die schon im Heimatlande der Droge vorgenommene Verfälschung ${ }^{1}$ ), die dann in Holland wiederholt würde.

Eingehend beschrieb Westrumb auch das hierhergehörige Sublimieren und Abdampfen. Alle drei gründen sich, wie er im $\S 148$ seines "Handbuchs der Apothekerkunst“", Hannover 1815, ausführt, darauf, „daß die Wärme die Kohäsionskraft der Körper vermindert und den Zusammenhang ihrer Teilchen aufhebt, daßs sie leichter werden als zuvor und sich in die Höhe heben können und verfliegen. Die tropfbar flüssigen Stoffe werden durch die Wärme in Dämpfe (Vapores), die trockenen aber in Dünste (Halitus) aufgelöst und von den fixen und feuerbeständigen geschieden oder getrennt, wenn sie vorher mit diesen gemischt oder vereinigt waren“. Und in $\S 150$ fährt er fort: „die Wärme verbreitet sich nach allen Seiten und setzt sich gern ins Gleichgewicht, oder mit andern Worten: ein erwärmter Körper setzt einen Teil oder so lange von seiner Wärme an den kältern Körper ab, den er berührt, bis beide einen gleichen Grad der Wärme haben. Berührt demnach der in Dampf oder Dunst aufgelöste Stoff einen kälteren Körper, so wird der Wärmestoff von diesem angezogen, er trennt sich von den Dämpfen, diese werden nun sichtbar und zu Nebel $\left.(\text { Nebula })^{2}\right)$. Nach und nach kehren sie aber in ihren vorigen Zustand zurück und nehmen die ihnen eigentümliche Form wieder an." In $\S 152$ scheidet er im übrigen von der feuchten und trockenen Destillation noch die Abstractio, „wo flüssige über trockene abgezogen werden“.

Die wahre Destillation schied man im XVI. Jahrh. nach der Lage der Destillationsgefäße zueinander in die Destillatio per ascensum oder recta, von der man als Unterabteilung noch eine schräge, per inclinationem ad latus oder obliqua, abtrennte, bei der die Dämpfe sich nicht hoch zu erheben gezwungen waren, sondern in den nebenan stehenden Recipienten strömten, und die Destillatio per descensum (Quercetanus sagt: für den Gagates, Guajac, Lign. Juniperi u. dgl.).

Weitere Merkmale für ihre Unterscheidung boten die verschiedenen Grade des angewandten Feuers oder andrer Wärmequellen. Mangels eines Wärmemeßinstrumentes griff man zu ziemlich abenteuerlichen, willkürlichen Bestimmungen der Gradus ignis ${ }^{3}$ ). „Sie werden vielfältig beschrieben und angegeben“, sagt Ernsting, „da zählet man bald vier, welches noch die beste Art ist, andre haben sechs, acht, zwölf, ja $\mathrm{Hel-}$ mont hat sechzehn gezählet, sie lassen sich nicht akkurat bestimmen",

$\left.{ }^{1}\right)$ Vgl. die oben mitgeteilte Angabe von Porta bez. des Nelkenöls S. 48, auch auf der Planche troise, Fig. $K$, das von Lémery benutzte Gerät.

7) Vgl. oben die sprachlichen Verhältnisse S. 2.

3) Vgl. unten. 
und es lag jedenfalls häufig genug im Interesse der Alchemisten, nach Belieben ihren gradus zu bestimmen, um sich auf die Art einen Entschuldigungsgrund für das Fehlschlagen der Arbeiten zu sichern '). Aufgezählt wird ein Ignis lapidis philosophici, „das sich ebenso schlecht beschreiben läßt wie die Bereitung desselben selbst", ein Ignis lentus oder blandus, ein gelindes, ein parabolicus, zu dem Anfachen mit einem Blasebalg gehört, das Ignis sapientium, durch Pferdedünger (vgl. weiter unten) erzielt, und Ignis suppressionis bei der Destillatio per descensum. Die vier Grade waren: „1. gelindes Feuer aus einem Balneo, so heiß, daß man die Hand anhalten kann, welches die Sonne hervorbringen kann, gleichsam einer Hühnerbrut ähnlich, für Digestionen u. dgl. (Vgl. auch die Destillatio calida.)

Der 2. Grad ist stärker, geeignet für die Destillatio per vesicam auch per alembicum ex arena.

Der 3. ist noch stärker, wird gebraucht für Destillierung aus Retorten aus trocknen Sachen und Sublimationen.

Beim 4. steht Alles in voller Glut, es ist offenes Feuer zum Destillieren der Spiritus minerales, besonders des Oleum vitrioli zum reverberieren und calzinieren."

Danach unterschied man dann Destillatio per balneum roris s. vaporis, per cinerem, arenam, weiter per limaturam ferri oder martis, ignem nudum usw., wie auch weiter unten noch ge-

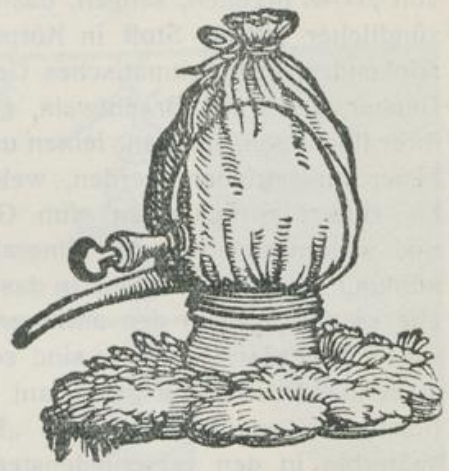

Abb. 36.

Kühlung nach Euonymus. zeigt werden wird.

Bis in den Anfang des XVI. Jahrhunderts hinein behalf man sich offenbar mit der Kühlung des Kopfes, des Alembik, mit dem Mohrenkopf oder Caput Aethiopis ${ }^{2}$ ) nach uraltem klassischen und nach dem noch älteren Vorbild des das Dach benetzenden und kühlenden Regens, wie ich es oben ausführte ${ }^{3}$ ).

Eine gar nicht üble Verbesserung ist die, daß Lonicer empfahl, eine Rindsblase, wie die Abbildung (aus Euonymus) zeigt, über dem Helm zu befestigen und in sie oben Wasser eintreten, unten durch eine Tülle

1) Vom Iquis Artephii heißt es: Pontanus hat wohl zweihundertmal gefehlet, ehe er dieses Feuer hat treffen können.

2) Vgl. oben S. 51.

3) Megenberg setzt die oben S. 3 gegebene Stelle fort (S. 81, 11 ff.: alsô geschiht auch dem dunst, der dâ kümt von rôsen prennen oder von wein prennen: wenne der den kalten pleienne huet [bleiernen, in Wahrheit wohl zinnernen Hut] rüert, sô entsleuzt er sich auch in wazzer, und smeckt das selbig wazzer vondem ding, da von der dunst kümt. Vgl. unten. 
und Stopfen oder einen Hahn ablaufen zu lassen. Zum bequemeren Entleeren (vielleicht auch, um den Hahn und "um viel Arbeit zu sparen") empfiehlt Euonymus II, S. 14 „Röhrlein, so Wasser ziehen“. Daß er sie, Winkelheber, abzubilden sich gemüßigt sieht, scheint mir zu beweisen, daß er noch wenig gebraucht und daß jedenfalls der Name Heber (vgl. weiter unten) noch nicht gänge war. Im Jahre 1781 finde ich ihn (und Stechheber ${ }^{1}$ ) aus Blech und Glas), aber 1818 bei Parkes steht er noch (trotzdem er auch von Demachy schon, wenigstens technisch verwertet wurde) als "gläsernes Werkzeug, um Flüssigkeiten regelmäßig abtropfen zu lassen" ohne Namen angeführt.

Weitere Verbesserungen solcher Kühlart, einer wahren Dephle g mati o, dazu bestimmt, das eigentliche $\mathrm{Phlegma}$ ) [ursprünglich gleich $q \hat{\lambda} \dot{\delta} \xi$ von $q \lambda \dot{k}$ y $\omega$, brennen, sengen, das lodernde Feuer, die Flamme, dann ein entzündlicher giftiger Stoff in Körper, Schleim] der alten Alchemiker, „ein stinkendes, empyreumatisches Gewässer ${ }^{3}$ ), bei Destillierung der flüchtigen Geister, als Wein, Branntwein, gegorenen Säften, deren Spiritus vermöge ihrer flüchtigen, luftigen, feinen und leichten Teile auch von dem gelinderen Feuer ausgetrieben werden, welche das wässerichte und schwere ${ }^{4}$ ) bis zuletzt zurücklassen“ (im Gegensatz zu dem Phlegma der "fixen und sauren Geister", der Mineralsäuren, das zuerst übergeht), durch Abkühlung zu verdichten und in das Destillationsgefäß zurückfallen zu lassen, ehe es den Weg in den abführenden Schnabel findet und destilliert, also wahre Rückflußkühler, sind schon im XV. Jahrhundert, wie das rechtsstehende Destillationsgefäß auf der ungelenken, aber völlig deutlichen Illustration aus Biringuccis „Pirotechnica" zeigt, konstruiert und späterhin in den verschiedensten Formen gebaut und verwandt worden. Der eigentliche Alembik, der $\mathrm{Helm}$ ist gelegentlich durch verschiedene Stockwerke, wie Savonarola z. B. empfiehlt ${ }^{5}$ ), in die Höhe geführt worden; er wurde, um die Dämpfe möglichst von kühlender Luft umspülen zu lassen, hin und her gekrümmt, an verschiedenen Stellen erweitert, um möglichst viel kühlende Fläche herzustellen, diese Erweiterungen wurden wie flache Becken gestaltet (also direkte Anfänge späterer Beckenkühlung, wie sie in den großen Branntwein-Brennereien in Anwendung kam und wohl noch kommt). Es scheint Ulstadt gewesen zu sein, der in seinem "Coelum philosophicum" s. "Liber de secretis naturae",

1) In Frankreich wurde für ihn im XVI. Jahrh. schon Pipette gebraucht.

2) Ernsting, Lexikon chymicum.

2) Vgl. oben Brunschwigk, S. 58, auf S. 34.

4) Vgl. auch die Abbildung aus Porta auf S. 57 und S. 63.

s) Demachy erzählt von einem „sonderbaren Denkmal des Vorurteils unsrer Vorfahren", das sich zu seiner Zeit noch in Paris erhalten hatte. "Eine sehr weite Blase ist mit einer Spiralröhre sechzehn Fuß hoch besetzt. Der Schnabel des Hutes ist fünf oder sechs Fuß lang und krümmt sich, um in einen sehr großen Wasserbehälter zu steigen, wo eine andre Schlangenröhre zwei FuB im Durchmesser und wenigstens zwanzig Schritt herabsteigt. Laborant im Großen 1784, S. 199. 
Argentor. 1528 aus verschiedenen Gründen, zuerst wohl, um den Dämpfen Schwierigkeiten (wie es die jetzt im Kleinen gebrauchten Glasperlen tun) in den Weg zu legen, dann um sie (er ist, denkt man an seine feine Verteilung und Kapillarität, in etwas der Vorläufer von Lowitz mit seiner Kohle!) zu reinigen, einen Schwamm in das Steigrohr steckte.

Er sagt: „Nimm einen reinen dünnen Schwamm und zerhaue denselbigen in so große Stuck, welche in der Größe sygend, daß sie oben für an allen orten inwendig der Kolbens mogind anrüren". Mit Hilfe von Schnüren sollen sie so befestigt werden, daß sie nicht in den Kolben fallen können. „Und dieselbigen schwämm söllend vorhin in baumoel gesetzt werden, und dannach wieder ein wenig ausgetruckt, damit nicht etwan das baumoel in den Kolben herabtrieffe... Und durch diesen

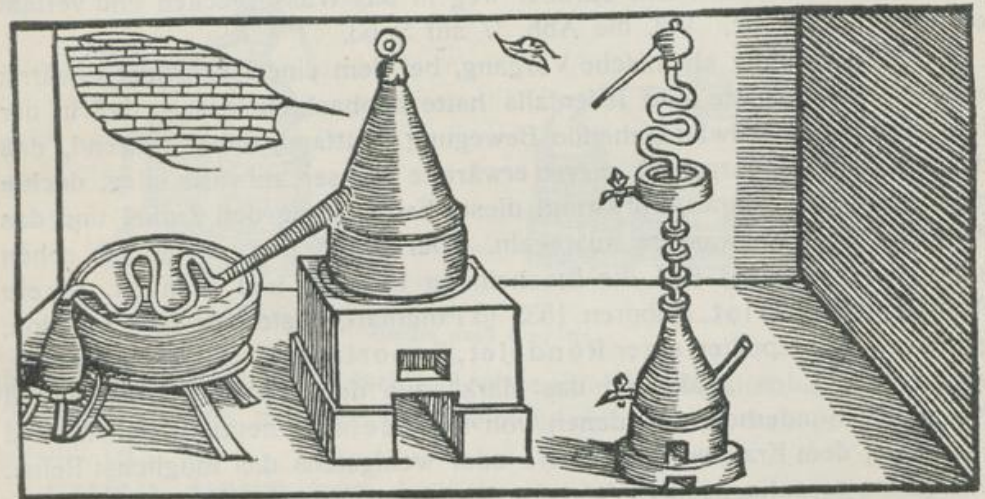

Abb. 37. Destilliergerät von Biringucci.

Schwamm werden die aufgetriebenen geister der aquae vitae simplicis seer wäsentlich und fein destilliert. Also was grober unreiner yrdischer und ungedöuvter [unverdauter] materie un substanz ist, mag von wägen des oels nicht durch den Schwamm gen und durchtringen."

An passenden Stellen ließ man natürlich von außen so gut wie möglich kühlendes Wasser auf die ganze Vorrichtung tröpfeln, wenn man nicht dem Mohrenkopf ähnliche Kühlgefäße unterwegs an geeigneten Stellen einschaltete.

Erst später offenbar dachte man, nur teilweise richtig, daran, den Schnabel abzukühlen, den schließlich nach dem „Dephlegmieren der wäßrigen, schweren", bei höherer Temperatur siedenden Stoffe „flüchtige, lüftige, feine, leichte", bei niederer Temperatur in Dampfform übergehende Teilchen, durchströmten. Das bewerkstelligte man in der Art, daß man das Ablaufrohr schräg nach unten durch ein Wassergefäß laufen 
ließ, wie es bei einfachen Destillationsvorrichtungen nach altem, unendlich oft im Bilde festgehaltenen Muster ${ }^{1}$ ) noch jetzt der Regel nach geschieht.

Im XV. Jahrhundert aber gab man dem Ablaufrohr auch schon, um das Destillat einen möglichst langen Weg in der kühlenden Flüssigkeit durchlaufen zu lassen und die Kühlfläche möglichst zu erweitern, die Gestalt hin- und hergekrümmter Schlangen. Libav spricht anfangs des XVII. Jahrhunderts in seiner "Alchymia recognita" von Stillatoria anguinis oder von Canales refrigeratorii (im Gegensatz zu recta via per dolium transeuntes) cum multiplici gyro, Serpentini nominati (S. 11 u. 311 ff.). Aber viel früher schon waren solche Kühl-Schlangen bekannt. Soviel ich erkunden konnte, ist die älteste bekannte Darstellung, die aus der eben genannten „Pirotechnica“, der ältesten technischen Chemie von Van occio Biringucci $\%$. Die Schlange durchbohrt hier die Wandungen des Kühlgefäßes nicht, sondern tritt darüber weg in das Wasserbecken und verläßt es in derselben Art. Vgl. die Abb. 37 auf S. 63.

Trotzdem jeder chemische Vorgang, bei dem eine Flüssigkeit erwärmt werden mußte, hätte und jedenfalls hatte beobachten lassen, daß in der Flüssigkeit eine aufwärtsgehende Bewegung stattfand, daher rührend, daß das am Boden naturgemäß zuerst erwärmte Wasser aufwärts stieg, dachte man lange nicht daran, auf Grund dieser Erscheinung den Zufluß und das Ablaufen des Kühlwassers zu regeln. Der erste, der, soviel ich sehen kann, davon spricht und die Erscheinung beachtet und ausnutzt, ist ein Arzt Claude Dariot, geboren 1533 in Pommart, gestorben 1594 in Dijon, gebildet in Montpellier unter Rondelet, Saporta usw. Ein freier Denker, versuchte er, den "Saft und das Mark“ aus den Lehren der Alten und Neuen, in Sonderheit aus denen von Paracelsus herauszuziehen, und er strebte, dem Kranken das Reine oder wenigstens das möglichst Reine, die Quinta essentia aus den Arzneistoffen darzureichen. Die Hauptaufgabe des damaligen, eines reinen Jatro-Chemikers [der als ureigentlichen Zweck der Chemie arzneiliche Bestrebungen ansah, wie bis in seine Zeit hinein auch Botanik im Grunde nur Pharmako-Botanik war] ist nach seiner Ansicht: Die Trennung der Bestandteile in den einfachen Arzneistoffen (den Simplicien, wie sie damals durchweg hießen), die Extraction derer, die der Sitz der ihnen von Gott mitgegebenen Tugenden sind. Heilkräftige Bestandteile wären im Pflanzen-, Tier- und Gesteinsreich vorhanden, im ersteren verhältnismäßig am geringfügigsten. Mit deren Bestandteilen, den einfachsten und leichtesten, den öligen, beginnt er, weil sie der vornehmste Sitz der Heilkraft seien und zu vergleichen mit dem feuchten Prinzip im menschlichen Körper und weil sie des Menschen Tätigkeit, auch die seines Geistes, ermöglichten und im Gange hielten.

i) Vgl. z. B. die Pl. $1^{\text {re }}$ v. Lémery, S. 75, Fig. $r$.

2) Der Arbeit Guareschis über ihn in seiner ausgezeichneten "Storia della Chimica* S. 444 entnehme ich die Abbildung mit des Verfassers freundlicher Erlaubnis. 
lich

eht.

um

keit

die

des

inis

um

ber

ich

sen

:io

ihl-

äßt

mt

der

laß

ate

las

ien

ein

on,

er,

nd

nd

ie,

be

ck

in

in-

en

lie

ge

m

in,

r-

?n

it,

Sein Zeitgenosse Quercetanus (in seiner „Pharmacopæa dogmaticorum restituta") kann, wie er sagt, die hervorragende Tüchtigkeit der Deutschen auf dem Gebiete der Destillation nicht unerwähnt übergehen. „Groß war stets das manchen Völkern gebührende Lob ob ihrer Leistungen. Der Deutschen Ruhm, daß sie mit unermüdlichem Fleiß stets bedacht sind, an ihrer Bildung zu arbeiten und zu erforschen, was noch Geheimnis deckt, wird stets währen", und wie er von einer Beschreibung des gewöhnlichen Destillationsapparats absieht, weil „Destillation ätherischer Öle aller Welt, auch denen Tyronibus [tiro, der Recrut], den Anfängern und Lehrlingen bekannt sei", so sagt auch Dariot kurz, für den großen Verbrauch berauschender Getränke in unserm Vaterlande recht bezeichnend, „der Apparat

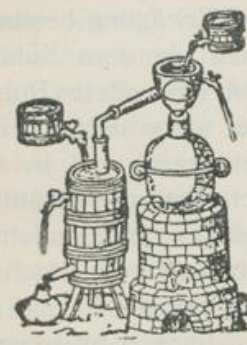

Abb. 38 .

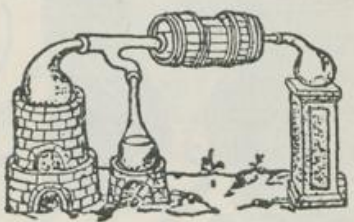

Abb. 39.

Geräte nach Dariot.

aus Kupfer, wie er in Deutschland allgemein zur Darstellung der Aquae vitae benutzt wird, hat eine Beschreibung nicht nötig, weil er allgemein bekannt ist".

Dariots Apparat zeigt deutlich die Abb. 38: zwei gleich große, annähernd halbkugelförmige Gefäße aus verzinntem Kupferblech (bereits oben S. 49 wurde darauf aufmerksam gemacht, daß in Nürnberg schon 1551 durch eine Ratsverordnung, um Vergiftungserscheinungen vorzubeugen, die bei dem manchen Destillationen vorangehenden langdauernden Putreficieren unendlich leicht vorkommen konnten, die Verwendung von lediglich „gläsernem Prennzeug $\left.{ }^{1}\right)^{\prime}$ geboten worden war) wurden wohl durch

1) Sehr früh scheint das Wort brennen bis zum gewissen Grade an die Stelle des lateinischen coquere getreten zu sein, im vorliegenden Fall zuerst in der Form prennen und brennen [vgl. Bernstein]. Megenberg spricht vom Rosen- und Weinprennen. An die schon nötige staatliche Überwachung und Besteuerung erinnert die Stelle (vgl, oben S. 42) von 1450 (Cod. Brandenburg. I, 25, 379): Bernewyn shal nemand in seinem huse schenken edder gesta darto setten. 1484 heißt es (interessant auch für die Schießpulverbereitung, in Z. f. N. Sachsen 1870): Scholde bussen pulver noch vele rysscher [rascher, wohl entzündlicher] werden, so ... besprenge dat (nicht mehr, wie es nach Jacobs, „Das Aufkommen der Feuerwasser am Niederrhein", in Köln 1373 geschah, mit Wein, sondern) myd bernewyne. Aus andern Gründen ist die Stelle aus dem XVI. Jahrh. bemerkenswert: „Ein Stallvogt trank La uge für (ge-) brannten Wien", aus welchem Ausdruck dann der uns geläufige Branntwein entstand. 
eine Nut oder sonst wie möglichst fest aufeinander gepreßt und dann mit einem der vielen bekannten und gebräuchlichen Kitte gedichtet. Die obere Hälfte verjüngte sich nach oben wie ein Kolben und ging schließlich in einen "Kopf" über, der durch die Mohrenkopfkühlung gekühlt wurde. Man sieht hier aber deutlich, daß der Ablaufhahn für das, wie Dariot sagt, meist aus einer Wasserleitung, wie sie häufig für häusliche

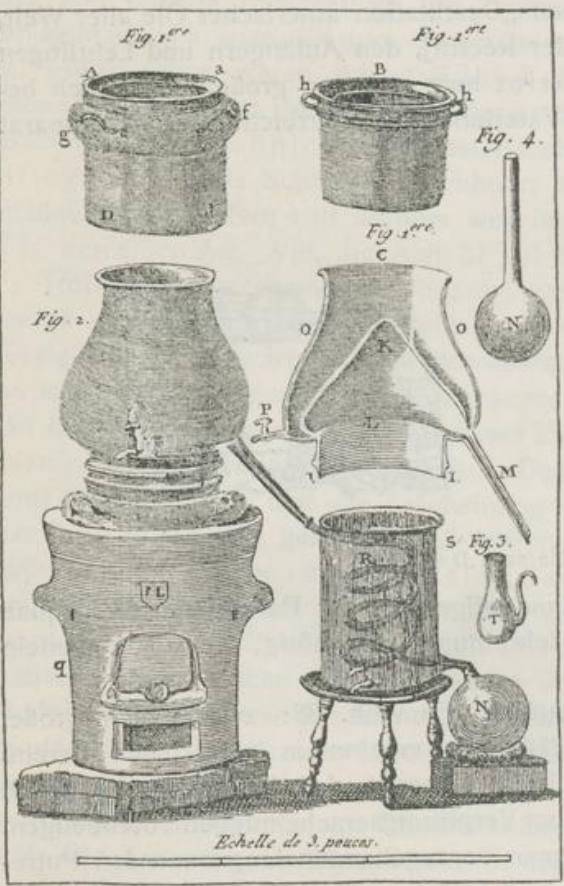

Abb. 40

aus Baumés „Élements de Pharmacie".

Zwecke vorhanden sei, entnommene Wasser hoch liegt, weil, wie er erklärt, „es an dieser Stelle sich stets zuerst erwärmt". Ganz dieselbe Erfahrung und Erwägung bestimmt ihn auch, in dem Kühlfaß, in dem ein weiteres Rohr steht, das unten seitwärts im Winkel abgeht und in das der Schnabel des Destillationsgefäßes hineinreicht, den Ablaufhahn hoch oben anzubringen ${ }^{1}$ ).

In zwei weiteren Abbil. dungen sehen wir ein langes, dünnes, lebhaft an die Röhrenform erinnerndes wa gerecht liegendes KühIfaß mit wasserdicht befestigtem Kühlrohr darin, das die wesentlichen Kennzeichen des späteren WeigelLiebigschen Kühlers zeigt. Wohl ist der Wasserzu- und -ablauf vom Zeichner nicht angedeutet, nach dem Vorerwähnten ist es aber völlig klar, daß er nur nach Maßgabe der Erfahrungen Dariots gearbeitet gewesen sein kann, die, wie es scheint, lange Zeit vergessen oder gering geachtet worden sind. Jedenfalls läßt Lémery (Vgl. seinen Cours de chymie, Paris 1687) das Wasser aus seinem Kühlfaß mit ${ }^{2}$ ) geradem Ablaufrohr, Baumé ein Jahrhundert später (Vgl. die Élements de Pharmacie von 1777) das aus seiner vortrefflich konstruierten Mohren-

1) Ich verdanke diese Abbildung der Liebenswürdigkeit von Herrn Dr. A. B a udot in Dijon, dem Verfasser des vortrefflichen Werks: „La Pharmacie en Bourgogne“, Paris 1905.

2) Vgl. die Planche 1ro Fig. r, und Planche seconde seines Werkes, Fig. q weiter unten. 
kopfkühlung ganz unten abfließen, und Demachy scheint der erste gewesen zu sein, der etwa zehn Jahre später Dariots Erfahrungen sich zunutze machte oder neu erfand ${ }^{1}$ ).

Daß es übrigens für Darstellung von „Prennzeug “ schon gewisse Spezialisten gab, wird dadurch belegt, daß der für die Hofapotheke in Dresden bestimmte von Georg Storm in Augsburg ${ }^{2}$ ) bezogen wurde. In Venedig z. B., wo die Fabrikation von allen möglichen Präparaten für den Gebrauch der Apotheker schon seit einem Jahrhundert nach persisch-arabischem Muster im Großen getrieben wurde, waren Geräte im Gebrauch, wie sie schon oben beschrieben worden sind (S. 37). Außerdem brauchte man Faule Heinze, Athanore oder wie solche Dauerbrenner genannt wurden.

Um sich gegen Bruch der Glasgefäße zu schützen, bediente man sich der Lorication, d. h. sie wurden mit einem Lorum [urspr. ein aus Leder gefertigter Panzer] oder Lutum aus Lehm, Blut, Rindshaaren usw., also ganz nach oben erwähnter arabischer Art beschlagen, oder aber man stellte sie, ebenfalls nach altem Muster, in Bäder aus Sand, Asche, Eisenfeile oder aus Wasser. Ein solches Diploma, wie es schon oben als längst") bekannt erwähnt ist, zeigt Ryff im Bilde. Frühzeitig wurde im übrigen auch

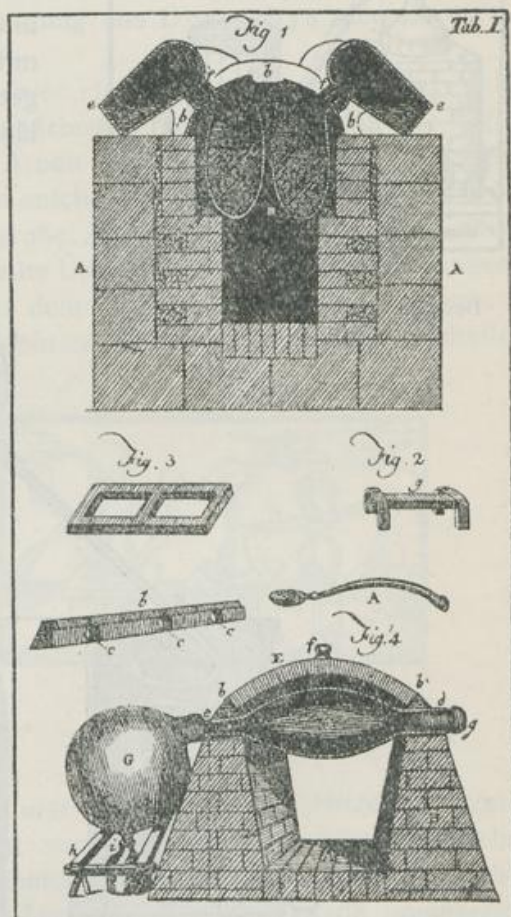

Abb. 41. "Scheidewassergaleeren" nach Demachys und $\mathrm{Hahnemanns}$ "Laborant im Großen". schon zum Destillieren saurer Flüssigkeiten, die schwer und stoßend siedeten und metallene Gerätschaften angegriffen hätten, tönerne Gefäße benutzt. Jedenfalls waren sie, einmal weil die Retortenform schwer nachzubilden gewesen wäre, auch ihre $\mathrm{Be}$ schickung mit zum Teil festen Körpern und ihre Entleerung von dem

1) Beiläufig gesagt bringt Liebigs $\mathrm{H}$ andwörterbuch auch noch die Abbildung einer Mohrenkopfkühlung mit Ablauf ganz am Boden. Abb. 47 auf S. 542, Bd. 2, 1842.

7) Vgl. oben S. 49 .

") Vgl. auch die Abbildungen. 
festen Rückstand - ganz allgemein Caput mortuum ${ }^{1}$ ) - viel Schwierigkeiten gemacht hätte, und die „oblique“ Destillationsart das gestattete, wie in der oben gegebenen arabischen Darstellung der Rosenwasserdarstellung, den Vorlagen gleichgestaltet krukenförmig. Aus ihnen

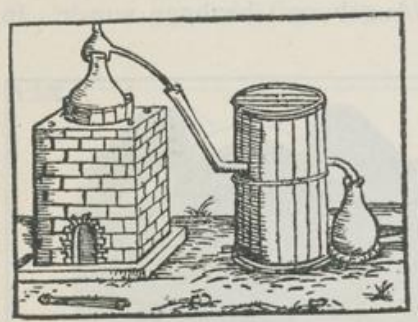

dürfte Scheidewasser, Aqua fortis, zuerst wohl in größeren Mengen in $\mathrm{Frankreich}$ destilliert worden sein, und im Andenken an die dort bekannten, mit zweireihig angeordneten Ruderern getriebenen Galeeren taufte man die länglichen Öfen, in denen über Holz-

Abb. 42.

Destilliergerät nach Euonymus.

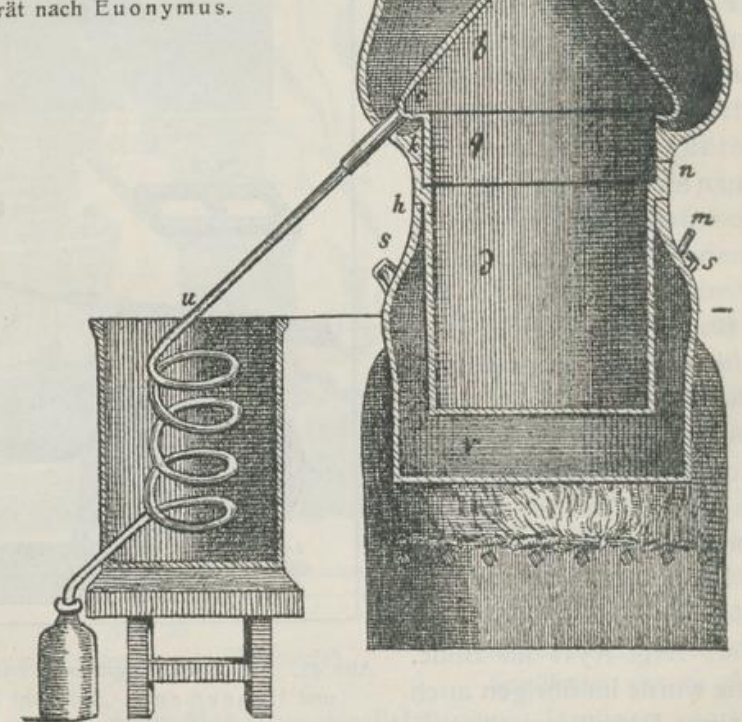

Abb. 43. Französischer Alambik mit „Serpentine" nach Demachy.

feuer zwei einander entgegengesetzt liegende $20-30 \mathrm{Cu}$ ines [die Etymologie ist unbekannt vgl. oben S. 56] erhitzt wurden, mit diesem Namen \%). Vor Demachy s Zeit, also vor dem letzten Drittel des XVIII. Jahrh., scheint der Name nicht vorgekommen zu sein, jedenfalls finde ich ihn vor ihm nicht erwähnt.

1) Vgl. darüber weiter oben S. $27^{1}$ ).

\%) Demachy in seinem "Destillateur des eaux fortes". 
Vom Westen her übernahm vermutlich Deutschland die Methode und „die schön angelegten Ofens, da wohl zwanzig, ja bis fünfzig Retorten eingelegt und mit einem Feuer destilliert werden konnten"1), also wohl Galeerenöfen, wie sie in Nordhausen seit dem XVIII. Jahrh. zur Bereitung des Nordhäuser Vitriolöls gebraucht wurden.

Daß in Frankreich auch schon rationeller eingerichtete, leicht zu beschickende und $\mathrm{zu}$ entleerende Einrichtungen für größeren Betrieb in Anwendung kamen, zeigt die Abbildung aus Demachys „Laborant im Großen", Fig. 4 der Abb. 41, S. 67.

Es war schon den Alten bei ihrer Holzdestillation aufgefallen, daß das Destillat je nach der Dauer der Arbeit verschieden geartet war (vgl. oben S. 11). Es mußten bei der Arbeit mit durchsichtigen, gläsernen Geräten solche Beobachtungen selbstverständ-

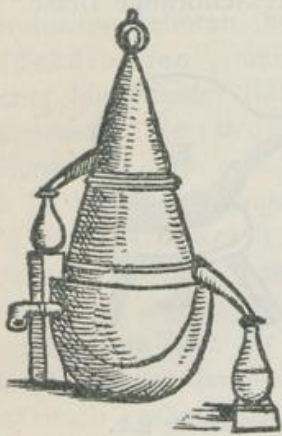

Abb. 44.

Destilliergerät nach $\mathrm{Ryff}$ lich in großer Anzahl gemacht worden sein, und man stellte Überlegungen und Untersuchungen an, um dem Grunde solcher Erscheinungen nachzuspüren. Daß die letzten Bestandteile

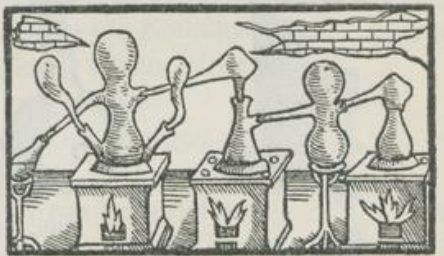

Abb. 45 .

Destilliergerät nach Euonymus.

aus flüssigen oder festen Stoffen erst bei vermehrter Hitze zur Verdampfung und Destillation gebracht werden konnten, erfuhr man sehr bald. Damit hatte man im Grunde entdeckt, daß die verschiedenen „Fraktionen" einen immer höheren Siedepunkt hatten. Gerade umgekehrt wie wir es jetzt zu tun pflegen, wie Enonymus Philiater es übrigens auch tat, wenn er, mit einer wechselnden Zahl von Lichtern (vgl. Abb. 65, S. 87) arbeitend, aus Wein die vier Elemente darstellte, ging er (II, S. 282) vor bei Anwendung des recht zusammengesetzten Gerätes, Abb. 45. Er beschreibt die Arbeitsart folgendermaßen:

„In dem öfelin auff der rechten Hand, aus welchem drey Feuerflammen gehn und schlahen, soll rein geräden sand gethan vnd ein Fevr darein, so groß bis in dritten grad gemachet werden.

1) Ernsting, unter Spirit. Vitrioli. Vgl. weiter unten. 
In andern ofen, so inmitten zwischen beyden steht, sol auch sand gethan vnd ein Temperiert Fevr bis in den andern Grad gemachet seyn, wie dann der Flamm im Ofenthürlein zeigt.

Im dritten öfelin sol ein Marienbad, vnd das allerlindest Fevrlein seyn".

Bei starkem Feuer bringt er also erst die ganze Flüssigkeit ins Sieden, und die Dämpfe treten in eine große Vorlage, die der in Lonicers Apparat (s. S. 52) entspricht, wo eine „Fraktion“ niederschlägt. Der größte Teil Dampf geht in den zweiten Apparat, wo er etwas geringerem Feuer ausgesetzt wird. Was dabei zum Kochen kommt, steigt in den letzten Alambik, und was in ihm bei Wasserbadwärme zum Sieden kommt, geht in die letzte Vorlage.

Wesentlich einfacher ist ein Gerät, das Ryff angibt und auf S. 69 abgebildet wurde. Im Wasserbade steht die kesselförmige Blase.

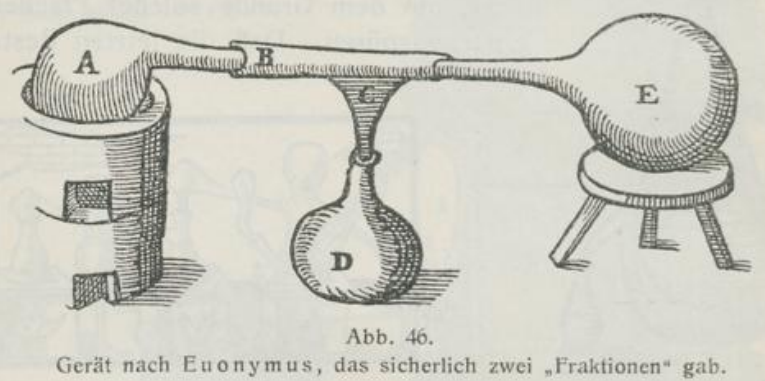

In verschiedenen Höhen des in eine spitze Pyramide ausgezogenen Helms (das auf S. 57 Abb. 33 abgebildete Gerät Portas stellt schon eine unbewußte Verbesserung dar. Jedenfalls hat es verschiedene Destillate gegeben) sind Ablaufschnäbel angebracht, aus denen unzweifelhaft verschiedene hochsiedende „Fraktionen", die leichteste aus der obern Röhre, ausgetreten sein müssen.

Im Jahre 1736 bildete G. H. Burghardt in ,Die zum allgemeinen Gebrauch wohleingerichtete Destillierkunst", Breslau 1736, einen bauchigen Vorstoß ab mit einer nach unten gehenden Abzweigung. Die Einrichtung gab jedenfalls zwei, wenn auch nicht wesentlich verschieden hochsiedende Fraktionen, sie gleicht im übrigen der von Dariot gegebenen noch zu besprechenden, allerdings zu andern Zwecken angebrachten Abzweigung, und sieht ihr Vorbild wohl in der von Euonymus wenigstens geplanten Einrichtung, die die Abb. 46 zeigt.

Daß man verschiedene Fraktionen auffing, belegt auch Lémery. Bei der Beschreibung der Destillation von Terpentinöl aus Terpentin erzählt er, daß nach Maßgabe der Verstärkung des Feuers die Farbe des 
Destillates dunkler wird, und daß Sorge getragen werden muß, die wasserklaren gelben und roten Anteile zu separieren, in verschiedenen Vorlagen aufzufangen. Zum Zweck der Trennung verschieden hochsiedender Körper, in seinem Falle ätherischen (Citronen-) Öls, gestalteten die Arbeitsart im Jahre 1833 Blanchet und Sell (Annal. d. Pharm. VI, 306) aus und gaben ihr den obengebrauchten Namen. 1838 untersuchte $\mathrm{Ph}$. Walter Pfefferminzöl in gleicher Art in Paris, und Gmelin (Handbuch d. Chemie, Bd. 7 a, S. 404) gebrauchte dafür den deutschen Namen „gebrochene Destillation". In Liebigs Handwörterbuch findet sich unter "Destillation" der Ausdruck noch nicht, erst 1854 im Text unter Pfefferminzöl.

Zur „Fraktionierung“, zu Siedepunktbestimmungen, die zu den täglichen Arbeiten im chemischen Laboratorium gehören, bedient man sich jetzt kleiner "Siedekölbchen", meist selbst vor der Lampe geblasener kugelrunder Kölbchen, in deren Röhre das tiefreichende Thermometer steckt. Das Dampfableitungsrohr tritt wenig nach unten geneigt heraus. Nach Ladenburgs Angaben bekommen die Kölbchen, die z. B. Schimmel \& Co. zu ihren vielen Untersuchungen brauchen, bestimmte Abmessungen.

Noch ein andres lehren Dariots Zeichnungen und der zugegebene Text. Er sagt im Kapitel V, Destillation der Gummata, daß der besonders bei ihrer Verarbeitung, selbst nach vorherigem Mischen mit Weingeist, Wein oder Essig auftretende höchst widerwärtige Nebengeruch vermieden werden könne, wenn die Öle mit, in Rotglut kalziniertem Eis envitri ol rektifiziert würden. Aber auch ohne weiteres, sofort könnten sie tadellos, am besten nach vorherigen Mischen mit Ziegelbruchstücken destilliert werden. Der „widerliche Geruch, entstehend da, wo sich die Dämpfe zur Flüssigkeit ver-

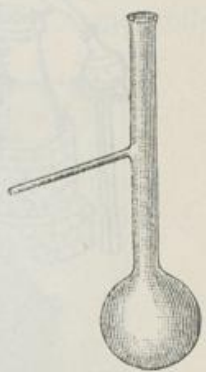

Abb. 47. Siedekölbchen.

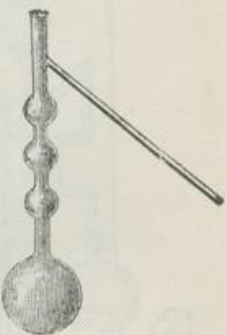

Abb. 48. Kölbchen nach Ladenburg. dichten, weil dabei „Empirephma" sich bildete", werde durch passende Kühlung gerade an der in Betracht kommenden Stelle verhindert, und zwar in folgender Art:

Man lasse eine zwei einen halben Fuß lange Röhre aus versilbertem Kupfer oder noch besser aus Silber machen, am untersten Ende etwa daumendick, oben weiter. Hier muß sie abzweigen, die gerade Fortsetzung nimmt die Dämpfe aus dem Destilliergefäß auf, die im Winkel abgehende die Dämpfe, die ein Kolben mit Wasser entwickelt, das unter dem Destillierapparat auf einem kleinen Windofen oder auf einem Dreifuß über freiem Feuer stehend, zum Sieden erhitzt wird." 
Besonders das Arbeiten mit einem Apparat, wie die erste Abbildung ihn zeigt (die Dämpfe treten direkt in den oberen Teil der krukenförmigen Blase), ist immerhin als der Anfang einer Destillation mittels Dampf anzusehen und muß, da der, wenn auch spät eintretende Wasserdampf

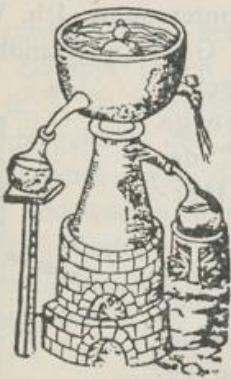

Abb. 49 . sicher eine Überhitzung des Destilliergutes und damit eine Bildung von Brenzstoffen in dem sich entwickelnden Öl unmöglich gemacht hat, verhältnismäßig gute Öle geliefert haben.

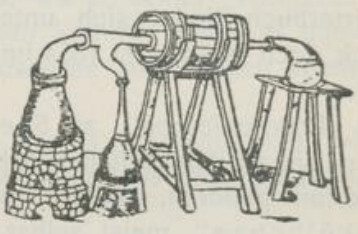

Abb. 50.

Dariots Geräte mit Zuhilfenahme von Wasserdampf.

Daß Dariots eben beschriebenes Kühl-, und sein jedenfalls wesentlich verbessertes Destillationsgerät in Deutschland irgend bekannt oder

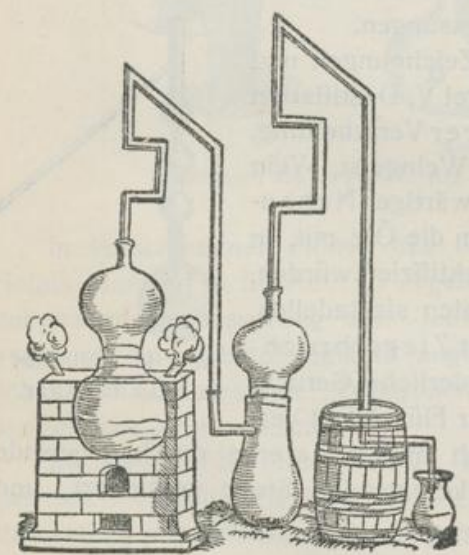

Abb. 51. Lonicers, irrtümlich als zur Dampfdestillation geeignet angesehenes Gerät. gar verwendet worden ist, habe ich nirgends entdecken können - auch Lémery $\left.{ }^{1}\right)$ sogar kennt sie nicht (läßt, wie oben gezeigt, ja auch das Kühlwasser ruhig am Boden der Kühlgefäße ablaufen).

Daß Lonicer die Dampfdestillation kannte, vermutet Peters. Die Deutung eines zweiten blasenähnlichen Gefäßes auf dem Fußboden neben der ersten Blase im Ofen, aus der durch ein vielfach gekrümmtes Rohr, dadurch jedenfalls abgekühlter Dampf, richtiger wohl nur Wasser, in den oberen Teil der zweiten Blase geleitet wird, als eigent liche Destillierblase zur Aufnahme des Destillierguts, die der ersten lediglich als Dampfentwicklungsgefäß ist falsch, wie aus Libavs Beschreibung des auch von ihm aufgenommenen zusammengesetzten Geräts hervorgeht. Er sagt (S. 34) „Ampulla, in quam desinit meatus primus et in qua colligitur aquositas, quae ne augeatur plus

1) Cours de Chemie, Paris 1687. S. unten Planche 1re $y$ und seconde $q$. 
gusto, per epistomium emitti potest in concham et ab oleo separari." Die „Ampulla" spielt also nur die Rolle eines Dephlegmators ${ }^{1}$ ). Es war übrigens Dampf als Heizmittel schon Jahrhunderte lang bekannt und wurde entsprechend (z. B. zur Heizung von Bädern, wie in der berühmten Göttinger Handschrift Bellifortis im Bilde gezeigt wird) gebraucht.

Schon oben auf S. 45 habe ich von Kohobieren gesprochen. Jedenfalls wurde es schon bei der Darstellung konzentrierter Ruchwässer angewandt, aber auch, und jetzt vermutlich immer mehr im Sinne von Quercetanus, um Körper (und zwar in erster Reihe pflanzliche Arzneistoffe)

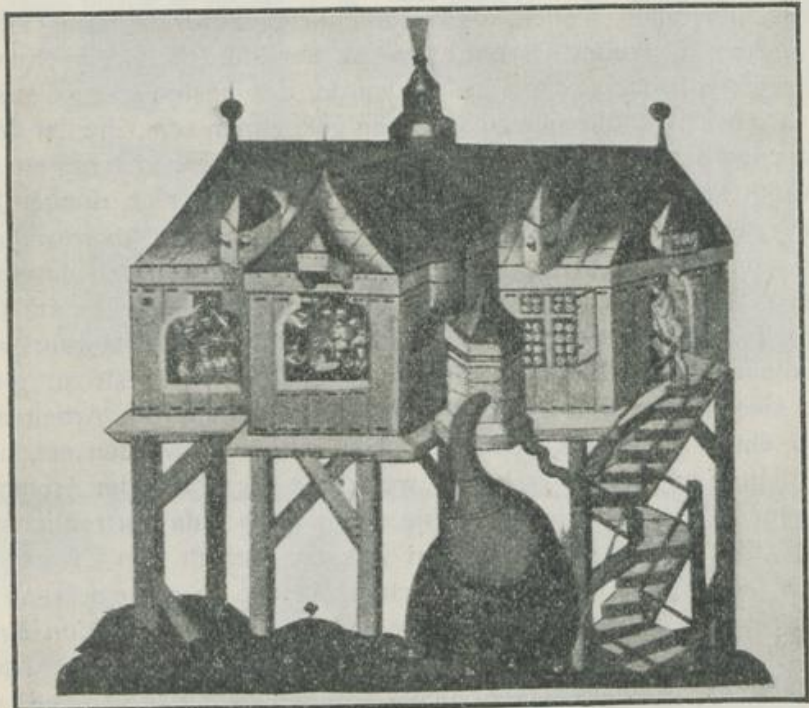

Abb. 52. Badehaus mit Heizung durch Dampf aus einem retortenförmigen Gefäß nach der Handschrift Bellifortis aus dem Anfang des XV. Jahrhunderts.

in ihre Bestandteile zu zerlegen, um aus ihnen das Wesentliche, die Quinta essentia auszuziehen, von dem Wertlosen, dem Caput mortuum zu trennen. Dementsprechend erklärt Lémery, der eigentliche Begründer der Phytochemie "La cohobation se fait pour ouvrir les corps", sie dient dazu, ihre Eigenart zu erschließen. Erst Caspar Neumann in seinem "Lehrbuch der Apothekerkunst" von 1786 spricht vom Zurückgießen des Destillats auf frische Rohstoffe, also von einem modernen Kohobieren und von der Absicht, die die Alten bei ihren Arbeiten in den Zirkuliergefäßen und Porta im Sinne hatten.

${ }^{1}$ Peters, Aus pharmazeut. Vorzeit 1, S. 162, 2. Aufl. 
Wenngleich Lémery bei seinem „per descensum" destillierten Nelkenöl (er nimmt die Operation in Wassergläsern vor ${ }^{1}$ ), die er mit einem Zeugstück so verbindet, daß dieses wie ein Trichter hineinhängt. Dahinein tut er die Nelken, darüber eine, sie fest nach außen abschließende metallene Wagschale, in sie glühende Asche, deren Wärme genügen soll, um erst Phlegma, dann Nelkenöl herabtropfen zu machen) sagt, daß es „klar und weiß" sei, und wenn nach andern Beschreibungen die damals dargestellten ätherischen Öle den modernen, aufs vorsichtigste destillierten Ölen ähnlich aussahen, so werden sie vermutlich doch häufig genug manches zu wünschen übrig gelassen haben. Es würde sonst - wenn wir nicht annehmen wollen, daß Höflichkeit und Dankbarkeit ihm die Feder führten - kaum Quercetanus, der der deutschen Kunst des Destillierens, wie oben schon gesagt wurde, das beste Zeugnis ausstellte, noch ausführlich auf die Öle zu sprechen gekommen sein, die der damalige Verwalter und Besitzer der Casseler Hofapotheke (es kann sich nur um sie und einen Apotheker Klagk gehandelt haben) darzustellen sich rühmen konnte.

Quercetanus beklagt, daß die ätherischen, die Olea aromatum, wie sie sich von den, größtenteils zur Bereitung von Sirupen dargestellten Wässern abscheiden, doch mancherlei Unannehmlichkeiten im Gefolge hätten, selbst wenn sie in kleinen Fläschchen (Phialae) aufbewahrt würden. Allen solchen Erscheinungen beuge vor und gestatte, sie in gleichem Geruch, Geschmack und gleich gefärbt zu erhalten, die Arbeitsart, die ihm von einem gelehrten deutschen Arzt mitgeteilt worden sei, nämlich die Destillation mit Manna coelestis, „weil diese die Kräfte der Aromata und ihre Tugenden an sich zieht und sie sogar noch aufs vortrefflichste verbessert." Es handelt sich um einen Zusatz, ähnlich den Ziegelsteinbrocken, den Lateres, wie sie schon Mesue in seinem Grabbadin und Abulkasis in seinem Liber servitoris zur Destillation eines $O l$. Latericium oder Laterinum (ein Substitut ist noch ein beliebter Handverkaufsartikel der Apotheken) gebrauchte, ähnlich dem Eisenoxyd, wie es Dariot empfiehlt, und andern wie Hefe, Honig, Petroleum, Terpentinöl, Küchensalz, Sal Alkali, Holzasche, Sal mirabile, Sal digestivum Sylvii (ein unreines Kaliumchlorid), „etliche thun sogar Salia acida oder das $O l$. vitrioli und Spirit. Salis $\left.{ }^{2}\right) \mathrm{zu}^{\prime}$, die später beliebt wurden,

1) Vgl. Troise planche von Lémery $k$ Abb. 54 .

\% Diesen Zusatz empfiehlt Glauber (Pharmacopcea spagyrica III S. 5 u. a.) zur Destillation, noch mehr aber zur Rectifikation. Seine Erfahrung belehrte ihn, das die Apotheker, da sie manche Öle nur einmal im Jahre brauchten "sie abgeben, so gut sie sie haben. Hilft es den Kranken nicht, so hilft es doch ihrem Beutel, ist aber nicht recht vnd vergleicht sich mit der christlichen Lieb gar nicht, es ist ein Ding, das das Gewissen beschwert. Es wird auch $\mathrm{Ol}$. Laterinum (das eben erwähnte über Ziegelsteinbrocken trocken destillierte Öl) und Cerae gefunden, aber mehrenttheils durch Stehen so veraltet, verrochen, dick, roth vnd zeh, sehr stinkend vnd vnkräfftig, den solche olea selten rectifiziert und also verkaufit werden, wie sie das erste mal per retortam übergehen. Solche Öle sollen von dem Sal volatizi geschieden, über ihrem Caput mortuum oder ein anderes Aschensalz denn mit Spiritus Salis rektifiziert werden." 
ten

mit

igt.

ade

oll,

es

rals

ten

iug

enn

die

des

Ite,

ige
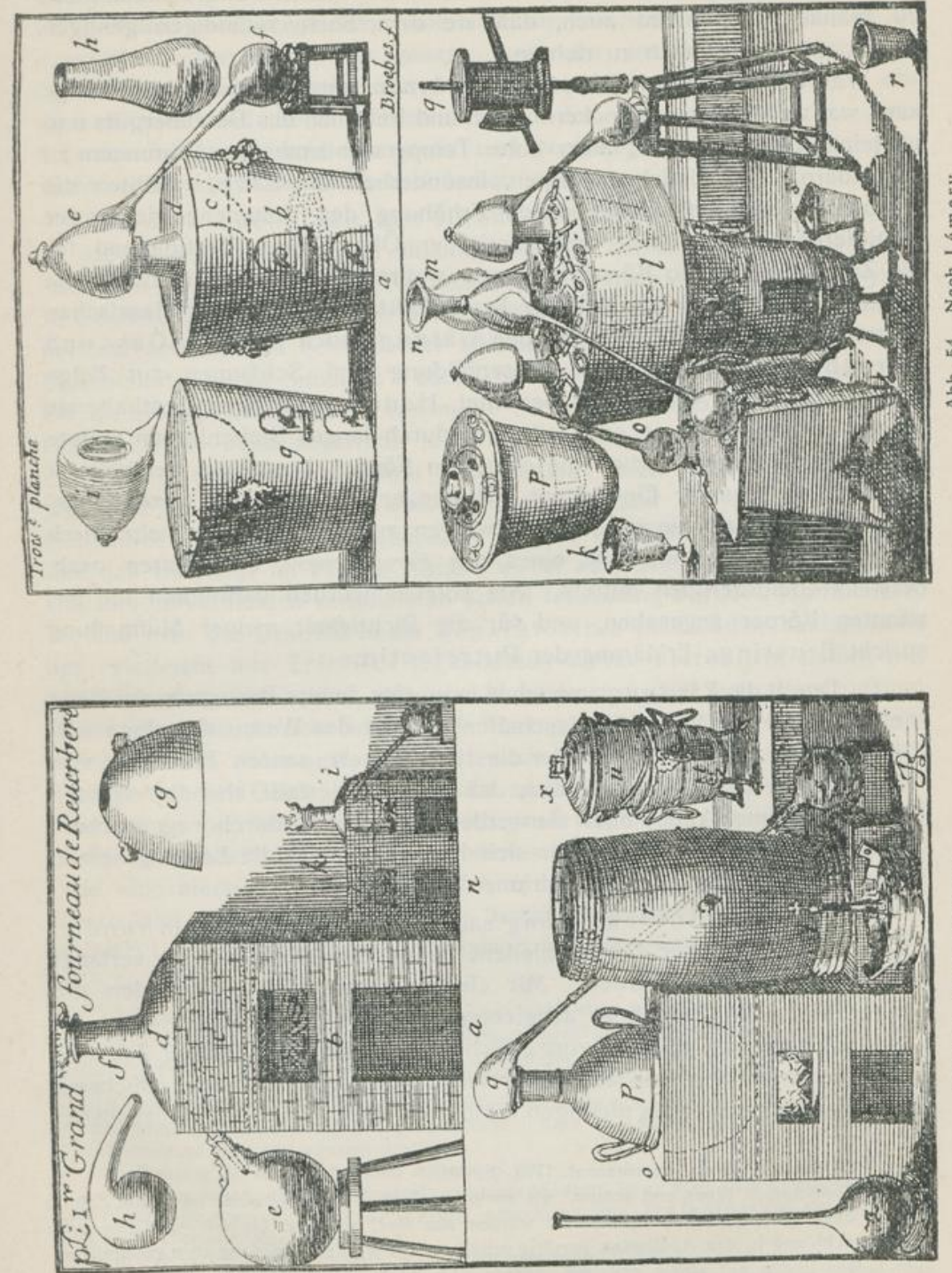

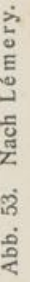


"damit der Oel besser von dem Kraut abgesondert werde ${ }^{a 1}$ ). Mehr als diese Andeutung gibt Quercetanus nicht, um seinen Gewährsmann nicht zu kränken. $\mathrm{Er}$ meint auch, daß sie dem Sachverständigen genügen werde, um sich danach zu richten.

Was bei den mineralischen Zusätzen nützlich war und in Frage kam, war wohl allein ein Lockermachen und Verteilen des Destillierguts und vielleicht das Bestreben, allzu hohe Temperatur und das Anbrennen zu verhindern. Die löslichen Körper, insonderheit die Salze, erhöhten die Ausbeute vermutlich etwas durch Erhöhung des Volumengewichts der destillierenden Flüssigkeit und damit der Ölausbeute. Bestimmend für die Zutat der meisten Körper aber war wahrscheinlich der Glaube an die "aufschließende" Wirksamkeit der Putrefaktion. Schon im klassischen Altertum hatte man beobachtet, daß Gärung, auch faulige, Gas- und Geruchentwicklung unter Blasenbildung und Schäumen zur Folge hatte. Daher hat, wie Livius berichtet, Hannibal Carbonate enthaltende Felsen mit Essig „putrefecit", und durch langes Stehenlassen meinte man, bei chemischer Arbeit die einzelnen Körper, besonders bei höherer Wärme, zu besserer Einwirkung aufeinander, zu einer Art Verdauungszweck, Digestio, wie im Magen, zwingen zu können, noch mehr durch Hinzufügen eines Fermentum, eines, das Fermentescere, das Gähren, arab. chammar, befördernden Mittels. Als solches wurden vermutlich die genannten Körper angesehen, und für die Richtigkeit meiner Mutmaßung spricht Ernstings Erklärung der Putrefactio:

"Durch die Fäulung verstehet man eine innere Bewegung der Teile einer Sache, wodurch die Beschaffenheit und das Wesen derselben verändert wird. Dadurch entweder die flüchtigen, sauren Teile teils von einer Sache losgemacht werden, daß man sie desfalls ehender erhalten oder bekommen kann; oder sie werden auch teils dadurch weggetrieben, nachdem man eine Sache vor sich hat, so man in die Faulung setzet, die entweder lang oder kurz drinnen stehen muß".

Bezüglich der Aufbewahrung sagt Quercetanus, daß in runden Büchschen je 15 bis 20 verschiedene Arten von Ölen, wie sie verlangt werden, aufbewahrt würden. Mit einem Zahnstocher ${ }^{2}$ ) würden die nötigen kleinen und doch so ausgiebigen Mengen herausgeholt.

Ein Vorrat von solchen vortrefflichen Sachen täte in jetziger Zeit den Apotheken mehr Not als eine Übermenge von goldstrotzenden Büchsen, die doch nichts weiter als nichtigen Wind enthielten. Unter den glänzendsten

1) Ernsting, Lexic. pharmaceut. 1770, S. 881 .

9) Dentiscalpia [dens und scalpo, wie sculpo kratzen, schaben], weibe oder rote Zahnstocher oder Bürsten, besser Zahnpinsel wurden aus Rad. Althaeae, Liquiritiae, Malvae und dgl. gemacht und in den Apotheken vorrätig gehalten. Sie wurden fingerlang eben geschnitten, auf ,beiden Enden mit einem spitzigen Messer oder noch besser Pfriemen, Nadel etc. eingekerbt, so daß deren Fibrae fein auseinander gehen und wie ein Pinsel gestaltet werden". Um sie rot zu färben, wurden sie mit einem Farbdecoct getränkt. 
und besteingerichteten öffentlichen und privaten Apotheken (Officinae) in Italien und Deutschland und andern Ländern habe er keine angetroffen die gleiche, geschweige denn überträfe die im Schlosse des Fürsten in Cassel (es kann sich, wie gesagt, wohl nur um dessen Hofapotheke handeln). Um sie einzurichten und auszustatten trügen nicht allein die vortrefflichen und hochberühmten Ärzte des Landgrafen Moritz von Hessen bei, sondern dieser große und hochmögende Herr scheue sich nicht, selbst Hand bei solchen Arbeiten anzulegen.

Um das Abscheiden des flüchtigen Öls [vgl. oben S. 43], des Ol. aethereum, ,weil sie sehr flüchtig und von der Luft [dem aì nach sich gezogen werden ${ }^{1}$ )" von dem mitdestillierten Wasser, dem Phlegma, zu trennen, bediente man sich allerlei Kunstgriffe, die auf die Verschiedenheit der spezifischen Schwere der Öle sich stützten und ihre allgemeine Eigenschaft, „aquae innatare" oder "fundum petere“, wie man letzteres bei Ol. Caryophyllorum und Cinnamomi beobachtet hatte. Quercetanus sagt kurz „ab aqua secernitur cum infundibulo (ut vocant)“, mittels eines Trichters. Man verfuhr und verfährt auch jetzt wohl noch gelegentlich in der Art, daß man das Destillat ,auf ein mit Wasser naß gemachtes Filtrum aus Löschpapier gießet, es läuft das Wasser durch und das Öl bleibt im Filtro zurück, wobei aber viel verschmiert wird ")". Um das zu vermeiden verfuhr man schon im Anfang des XVI. Jahrhunderts so, daß man das Destillat in ein Separatorium (Schröder bedient sich des, vielleicht aus Trichter ${ }^{3}$ ) gebildeten Worts Tritorium dafür), ein Scheideglas, das später, mit zwei Henkeln und einer lang ausgezogenen Spitze versehen, in den Scheidetrichter gewandelt wurde, tat. Eiförmig sahen sie aus, unten und oben hatten sie ein Loch. „Darinnen wird das flüssige mit den Oelen gegossen, und so hält man oben das Loch mit dem Daumen zu und läßt unten die Phlegma weglaufen, so bleibt das Oel im Glase zurück." Im XVIII. Jahrhundert wird das Separatorium geschildert „wie eine blecherne Pumpe gestaltet, unten ganz spitz mit einem weiten Bauch und oben einem Loche, an beiden Seiten oben zwei Ringe oder Halter $\left.{ }^{4}\right)^{\text {. }}$. Daraus, daß ich den Namen Heber oder Stechheber ${ }^{5}$ ) für

J) Caspar Neumann 1740. Im selben Jahre etwa kam der Name Äther für die versüßten Säuren und Naphthen" dann speziell für Schwefeläther auf. 1648 hatte "Glauber schon Äthylchlorür in seinem ,licblichen klaren Oleum vini" unter den Händen Gehabt, Hohenheim seinen Spiritus Vitrioli antepilepticus, jedenfalls einen unreinen Äther aus Wein und Vitriolöl, und etwa 1539 Valerius Cordus als ol. de Chalcantho im Laboratorium seines Onkels, des Apotheker Ralla in Leipzig (vgl. auch weiter unten) dasselbe reinere Schwefelpräparat destilliert.

2) Ernsting, S. 880. Vgl, unten Abb. 56 S. 79.

Dieses Wort, das niederdeutsch und niederländisch Trachter und Trechter lautet, stützt sich auf cinen n. lat. Tractarius, umgeformt aus Trajectorium von trajicere. [Vgl. dazu U-trecht, Mas-tricht.]

4) Ernsting, Lexic. chemic. S. 713, pharmaceutic. S. 880 .

5ie erste Abbildung von Stechhebern fand ich auf dem Bilde eines Distillierraumes bei $D$ em achy in Le distillateur d'eaux fortes, 1773 ; "Winkel-Heber" in Le fêvres "Chymischem Kleinod" von 1685. 
dieses Gerät nicht finde, ist wohl anzunehmen, daß es um diese Zeit deutsch noch als Pumpe ging. (Vgl. oben S. 62 die Bezeichnung „Röhrlin so Wasser ziehen" für den Winkelheber bei Euonymus Philiater.)

Handelte es sich um Olea fundum petentia, die man abheben wollte, so dachte man offenbar nicht daran, das Phlegma mit einer "Pumpe" oben abzuheben oder das schwere ÖI aus dem Separatorium zu unterst ablaufen zu lassen, sondern man goß etwas von dem wäßrigen Teil des Destillats oben ab, „löste darin soviel gemein Salz auf, als darin schmelzen will, und gießet dieses wieder zu dem Gefäß hinein und rühret um. Ist es nun so weit eingetränket, daß das Wasser schwerer als das Öl ist, so steigt es nach oben und setzet sich oben auf das Wasser als andere Öle". Caspar Neumann scheint diese Methode zuerst angegeben zu haben: „Mit Experimentis erwies er, wie er alle Olea essentialia nach seinem Belieben oben oder unten oder auch mitten im Wasser schwimmen lassen konnte $\left.{ }^{1}\right)^{\prime \prime}$.

Eine weitere Art der Absonderung der spezifisch verschieden schweren Flüssigkeiten, des zuerst fetten, dann des ätherischen Öls von dem beim Pressen, dann beim Destillieren mit gewonnenen Wasser, geschah, wie man noch bis ins XVII. Jahrh. hinein sagte, durch "Destillatio" per filtrum "), wie sie von (Pseudo-) Ge bers Zeit her auch jetzt noch gehandhabt wird. ,Man läßt die (Auffange-) Bouteille meist voll laufen und hänget oder bindet mit einem Faden sodann ein kleines Glas daran, daß dessen Mundloch genau an das andere passet, und macht sodann einen feinen Dacht [die eigentlich richtige aber dialektisch gebliebene Form für Docht] aus Baumwolle und stecket das eine Ende des Dachts in das leere Glas, das andere in die Bouteille oder Vorlage, darin sich der Oel über dem Wasser stehend befindet. Der Dacht soll den Oel gleich erreichen und nicht zuerst von dem Wasser eingetränket werden, so ziehet der Dacht den Oel in das leere Glas, welches auch niedriger gebunden werden und gleichsam her-

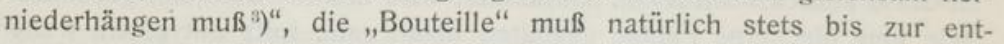
sprechenden Höhe gefüllt erhalten werden.

Daß man sich bestrebte, das Ex- oder Recipiens, das Receptaculum, das Auffanggefäß oder die Vorlage so einzurichten, daß die schon im Kühlgefäß oder in dieser selbst sich nach Maßgabe ihres verschiedenen Volumgewichts trennenden Flüssigkeiten, Phlegma zumeist zu unters, das wesentliche, das ätherische Ö1 zu obers abgesondert werden konnten, wird erst im XVIII. Jahrh. bekannt. Der erste, bei dem ich eine Vorrichtung beschrieben finde, die gleich als Vorlage benutzt werden kann, ist Moise Charas in seiner "Pharmacopée royale Galénique et chimique", Paris 1681. Was er sonst noch empfiehlt, sind ebenso wie die Vor-

${ }^{1}$ ) Ernsting, Lexic. pharmaceut. S.879; Neumann, Praelectiones chemic. 1740, S.697.

2) Libav sagt übrigens schon 1610, daf diese Destillatio nur nod tronsferendos liquores* dient, und Schröder beschreibt die Methode unter Filtrare.

3) Ernsting, Lexic. pharmaceut. 882. Vgl. die Abb. 53. 
richtungen von Homberg, Porta $u$. a. nichts andres als Scheidetrichter oder „Decanthier-Gefäße" in Trichterart. Es ist wohl als ziemlich wahrscheinlich anzusehen, daß Charas die Vorlage aus Italien, und dann wohl aus Florenz oder durch Vermittlung der Stadt, die schon lange Blumen destilliert hatte, kennen gelernt hatte. Baumé $(\dagger 1777)$ bildet sie $a b$ und beschreibt sie als ,Recipient, fait à peu près comme une poire allongée: au ventre un tube de verre, fait en $S$ par le haut" (S. 346 vgl. die Abb. 40 Fig. $3 T$ ). Macquer nennt sie, auf de la Garaye sich stützend, italienische Vorlagen und beschreibt sie, V. 501 und III. 703, folgendermaßen:

„Daß sie niemals voll werden, sondern das Wasser, so wie es nöthig wird, abläuft und das Oel darinnen zurückbleibt, erhält man durch ihre Bildung. Es sind nämlich gläserne Kolben, welche oberwärts so enge zusammenlaufen, daß ihr Hals oder ihre oberste Mündung nur ungefähr so weit ist, daß er den Schnabel der schlangenförmigen Röhre oder des

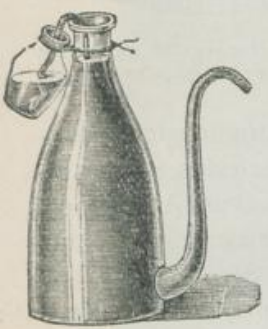

Abb. 55.

Destillatio per filtrum an Florentiner Flasche.

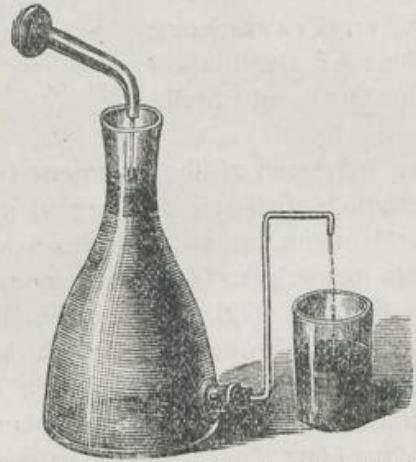

Abb. 56. Florentiner Flasche für l e i ch te Öle.

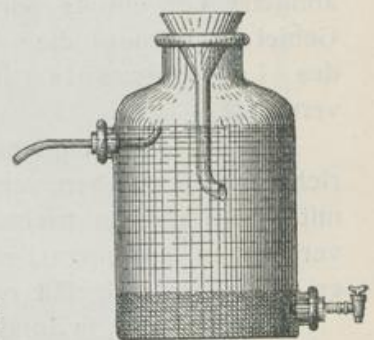

Abb. 57.

Florentiner Flasche für schwere Öle.

das

ler-

ent-

Helms aufnehmen kann. Eben diese Vorlagen sind überdieß gegen die Mitte des Bauchs mit einer zweyten Oeffnung versehen, an welche eine gläserne Röhre angeschmolzen ist, die so krumm läuft, daß sie längst der äußeren Seite der Vorlage bis drittehalb Zoll unter der oberen Oeffnung derselben senkrecht in die Höhe steigt, sodann aber gegen die dem Bauch der Vorlage entgegenstehende Seite wieder zurückgebogen ist, um die in selbige gestiegene Feuchtigkeit in ein anderes Gefäß hineinfließen zu lassen. Sie stellt ein römisches $S$ vor."

Es ist das die seit, wie es scheint, kaum mehr als 50 Jahren als Florentiner Flasche bezeichnete Vorlage, die auch in der Art (um die Höhe des Standes der Flüssigkeiten nach Belieben zu bestimmen) geändert wird, daß die nach oben möglichst kegelförmig gestaltete Flasche (um ähnlich wie bei den Erlenmeyerschen Kolben ein Anhängen der Flüssigkeiten tunlichst zu verhindern) unten einen Tubulus hat, in dem die $S$-förmige Röhre beweglich mittels eines Pfropfens befestigt ist. Daß eine 
kleine derartige in Oberscheden bei Göttingen gefundene, im Altertumsmuseum letzterer Stadt aufbewahrte, als „antik“ angesehene Flasche dieses Beiwort nicht verdient, brauche ich (wenngleich antike Technik sie unzweifelhaft hätte herstellen können) kaum hervorzuheben.

In dem Recueil des planches sur les sciences des arts liberaux et mechaniques avec leurs explications, Paris 1767 , wird auch eine für das Auffangen spezifisch schwerer Öle bestimmte Flasche (Fig. 91, 92) erwähnt und abgebildet, bei der das ebenfalls $S$-förmig gebildete Ablaufrohr für das Wasser oben angebracht ist. Solcher Vorrichtungen bedienen sich die mit, technisch nachgerade wohl kaum weiter zu verbessernden Geräten arbeitenden Firmen wie Schimmel \& Co.

Wie die Florentiner Flasche mit den einfachsten Mitteln herzustellen ist, konnte die genannte Firma in ihren Berichten vom Oktober 1910 auf S. 64 zeigen. Diese fast beckenähnliche Vorrichtung wird im Travankore Gebiet in Vorder-Indien bei der Destillation des Lemongrasöls an Ort und Stelle verwandt.

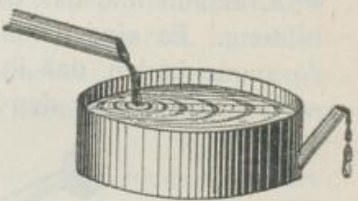

Abb. 58. Auffangegefäß nach dem Prinzip der Florentiner Flaschen.

Die Bulgaren blieben bei ihren altüberkommenen urwüchsigen Vorrichtungen und heben, vermutlich auch seit Urvaterzeit, noch das Rosenöl mit einem kleinen trichterförmigen, unten mit einem kleinen Ablaufloch versehenen, an einem Draht befestigten Gefäßchen in der Vorlage ab, um es in ein Sammelgefäß zu bringen. Vgl. die Abb. 59, S. 81.

Daß übrigens, in Sonderheit bei größeren, mehr fabrikmäßigen Arbeiten, wie sie hie und da (seit dem XVIII. Jahrh. vermutlich schon in Venedig und Florenz, dann in Südfrankreich, später in Deutschland, da wo Drogenanbau, z. B. bei Würzburg, im Harz, in Thüringen betrieben und, dort wo chemische Präparate hergestellt wurden) schon vorgenommen wurden, wie auch jetzt noch auf die einfachsten Geräte, auf große Töpfe, Ballons, Fässer zurückgegriffen wurde, wie sie eben vorhanden oder leicht und billig $\mathrm{zu}$ beschaffen waren, ist zu bemerken kaum nötig. Auch damals galt das Goethesche Wort: In der Beschränkung zeiget sich der Meister.

Was das Aufstellen oder Befestigen der Vorlagen, der unten gewölbten Kolben, Retorten usw. anbetrifft, so ist es natürlich, daß man aus der Praxis heraus, fast instinktiv analog den, den ersten Steinunterlagen nachgebildeten Dreifüßen oder den rundgestalteten Windöfen, auf die man, ohne die Gefahr des Umkippens die Geräte stellen konnte, ohne weiteres zweckmäßige Vorrichtungen erdachte. Kranzförmige Gebilde aus zusammengedrehten oder geflochtenen Stoffen gaben dem schwanken Gefäß nicht allein Halt, sondern sie schützten es auch vor dem Springen infolge von plötzlicher Abkühlung oder durch Aufstoßen auf die harte Unterlage. Kaum wird man von solch selbstverständlichen Gegenständen gesprochen haben, aber man sieht sie oft genug auf 
Iter-

Abbildungen (z. B. auf S. 53, Abb. 28) wiedergegeben. Unzweifelhaft steht die Vorlage auf einem Strohkranz, Stramen tortum, wie ihn schon Libav aufzählt, und wie er, mit Blei beschwert, auch benutzt wurde, um, über den Hals gestreift, Kolben u. dergl. am auftauchen zu verhindern. Hölzerne

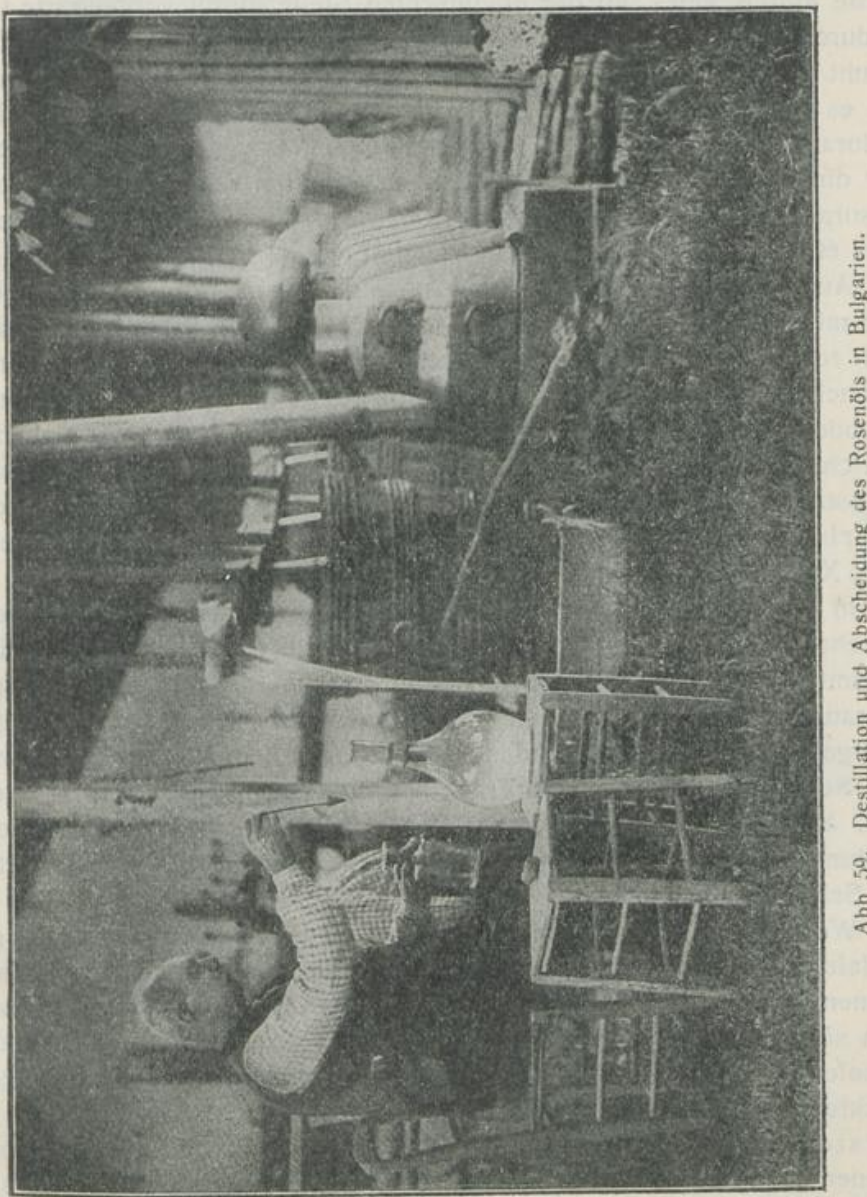

Dreifüße, Destillierknechte (aus klassischen eisernen Tripedes oder Tripodes und alchemistischen Sustentacula, Scamna [neutr. Bank] vielleicht nach arabischen Vorbildern, Alechil, entstanden), in Niederdeutschland Stridden dienten demselben Zweck. Durch untergelegte 
Klötze, Ziegelsteine u. dergl. wurden sie in passende Höhe gebracht, wenn man nicht Einrichtungen traf, ähnlich wie sie im klassischen Rom (nach dem Zeugnis von Pompejanischen Ausgrabungen) für hoch und niedrig zu stellende Lampen gebräuchlich waren. In einem röhrenförmig gestalteten Ständer bewegte sich der eigentliche Träger senkrecht auf und $a b$ und wurde mittels eines, an der erwünschten Stelle durch vorgebohrte Löcher hindurchgesteckten Splint festgehalten. Auf ähnlichen Voraussetzungen beruht ein verstellbares, durch eine Schraube feststellbares Tischchen, wie es Kunckel 1689 in den Miscellanea curiosa zum Tragen der Retorta perforata bei der compendiosen Darstellung von Aqua fortis empfiehlt. Der direkt tragende „Abacus sursum ac deorsum urgeri et in convenienti mesura adacto claviculo detineri potest". Vgl. die Tischchen auf der Abb. 60 des Laborators der Kapuziner-Apotheke in Paris.

Auch der Jenenser Prof. der Medizin Johann Wolfgang Wedel hat sich mit solchen Geräten beschäftigt. In einer Schrift, Jena 1730, De Remora [von remorari zurückhalten, aufhalten, also das Hemmniß, der Aufenthalt] s. machina, qua corpora ad desideratum punctum et elevata vel demissa in eodem firmiter detinentur" zeigt er im Bilde und beschreibt eine Hängevorrichtung, ähnlich der uralten germanischen mit einer sägeähnlichen Zahnstange oder mit einer Schraubvorrichtung. Noch früher hatte u. a. Boerhave solche Geräte behandelt und auch in seinen "Elementa chemiae" (Tab. XII, Fig. III) abgebildet.

In dem schon angeführten Recueil werden weiter Tischchen gezeigt, bestehend aus zwei rechteckigen, gleich großen Brettern. In dem den Boden bildenden sind nächst der Mitte der beiden Schmalseiten zwei senkrechte Schraubspindeln befestigt, die zwei Muttern tragen. Durch das gleichmäßige Drehen beider kann das lose auf ihnen liegende, für die Aufnahme der Schrauben durchbohrte Tragbrett auf und nieder bewegt werden. (Vgl. auch das Sustentaculum Weigels auf S. 86.) Es ist eine Vorrichtung, die einer Pflanzenpresse gleicht, bei der das obere lose Brett auf die Schrauben gelegt wird.

Wollte man den Retortenhals aus irgend einem Grunde verlängern, vielleicht auch, um ihn in den zu engen Hals der Vorlage einschieben zu können, dünner gestalten, ihm einen geringern Durchmesser geben, so half man sich einfach in der Art, daß man ihn in den entsprechend gestalteten zu solchen Zwecken aufbewahrten Hals einer andern, zerschlagenen Retorte steckte und auf diese Art ein Collum productius vitreum, einen VorstoB, eine Allonge bildete. Das machte sich in erster Reihe bei irdenen Retorten nötig. Später wurden solche Hilfsmittel aus Glas, Ton und für die feststehenden Metalldestillierapparate, möglichst zweckmäßig geformt, aus Zinn hergestellt.

Welchen Umfang Destillationen in den täglichen Arbeiten des Apothekers einnahmen, in dessen Arbeitsstätte noch bis in die erste Hälfte des XIX. Jahrh. ja im Grunde Alles sich abspielte, was auf Pharmazie und 
enn

ach

Chemie Bezug hatte, zeigt ein Blick in das Laboratorium der Apotheke des Kapuziner-Klosters in Paris'). Man wird wenig von dem vermissen, was ich von Geräten aufführen konnte. Wie viel üppiger es aus-

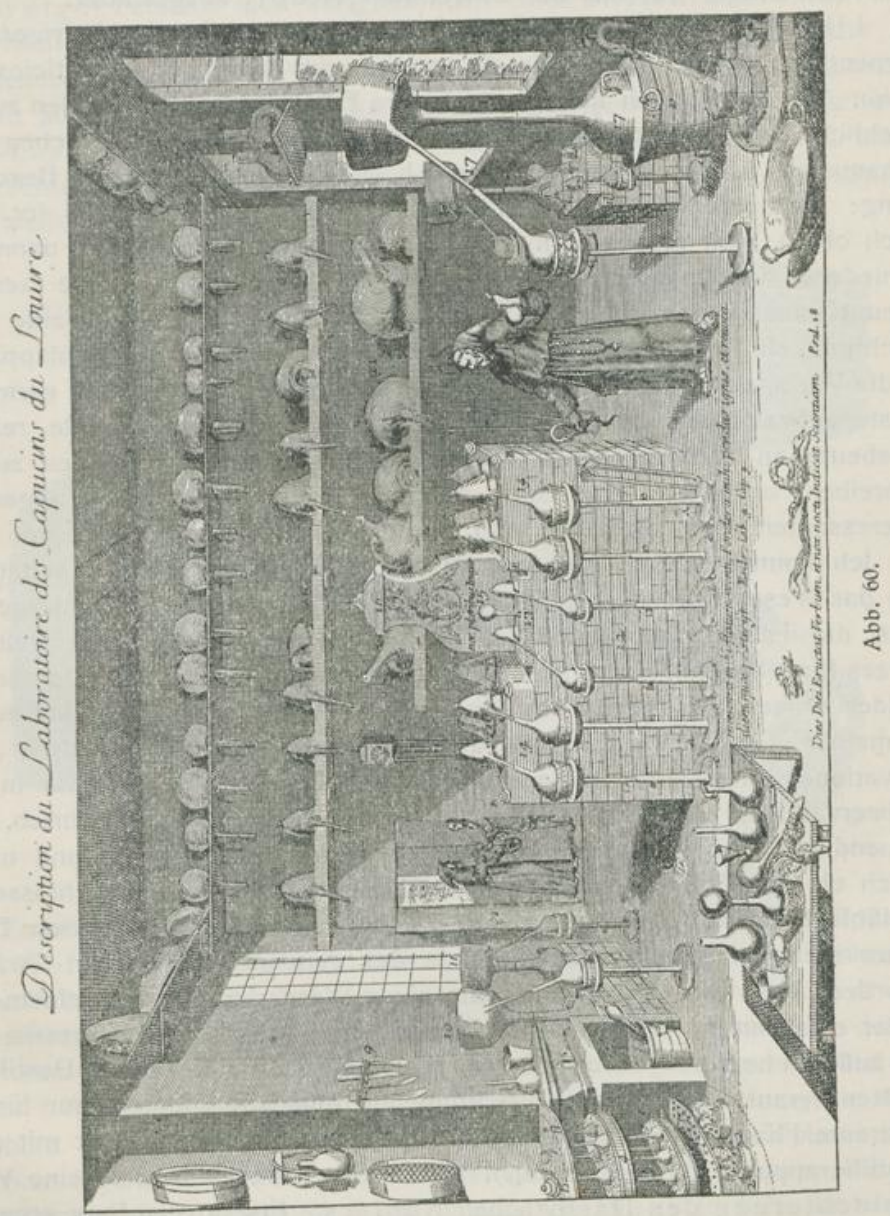

gestaltet war als das nicht viel frühere der Utrechter Univer'sität, zeigt dessen Abbildung, das nur zwei Destilliergeräte aufweist, die zu

1) Ich verdanke die Abbildung der besonderen Liebenswürdigkeit des um die Geschichte, nicht nur der Pharmazie hochverdienten Herrn Burghard Reber in Genf.

2) Vgl. Jorissen, Het chemisch Laboratorium Leiden. Leiden 1909. 
Lehr- und Versuchszwecken kaum geeignet erscheinen und zwei Öfen (einen „Athanor" mit Füllschacht), auf denen wohl aus Glasretorten destilliert werden konnte. Daß welche vorhanden sind, ist nicht zu sehen. Nicht viel reichhaltiger war das der Universität Altdorf ausgestattet.

Libav sagt von den Kühlvorrichtungen: Canales refrigeratorii serpentini, quorum dispositio (in spiritu vini destillando) artificiosa et varia. Aber tatsächlich bewegte sich ihre Eigenart nur, je nach den augenblicklich vorhandenen Räumlichkeiten, in oft ganz willkürlichen Anschauungen $\mathrm{u}$. dgl. vorgenommenen Abänderungen der weiteren Beschreibung: $a b$ operculo (der Destillierblase) sursum tendit canalis (er geht nach oben), inde revocatur in anfractus angulosos (ihm werden dann verschiedene Krümmungen aufgezwungen) committiturque vesicae aeneae, exeunt canales per dolia seu cupas in receptaculum (es folgt eine Ausbuchtung, ein Becken, schließlich geht das Rohr durch weitere Kühlapparate in die Vorlage). Deren Eigenart, die darauf abzielt, mit möglichst geringem Kostenaufwand und ebenso geringem Verlust die größtmöglichste, reinste Ausbeute an dem erstrebten Körper zu gewinnen, im einzelnen zu beschreiben, erforderte eine lange eigene Abhandlung, die des allgemein Interessanten zu wenig böte. Vgl. auch oben S. 60 u. 72.

Ich konnte schon einen, den Dariotschen Kühlapparat schildern, der das Wesentliche des späteren, sog. Liebigschen zeigt. Er, der jedenfalls die Laboratoriumspraxis völlig beherrscht, erfordert ein weiteres kurzes Eingehen auf seine geschichtliche Entwicklung. Es war der Greifswalder Universitätslehrer Chrn. Ehrenfried Weigel, der, wie ich schon in meiner "Geschichte der Pharmazie" angab, in seiner Dissertation „Observationes chemicae et mineralogicae" (Göttingen 1771) und zwar in der „Observatio 1, Destillatio spiritus vini“ eine Vorrichtung beschrieb, bestehend aus zwei verschieden starken übereinander gestülpten und unten durch ein ringförmig geschnittenes angelötetes Blechstück verschlossenen Weißblechröhren. Hier hat er ein Trichterrohr angelötet, dessen Ende höher stehen muß als das Oberende des geneigt aufgestellten Gerätes, aus dem das warm gewordene, aus einer Wasserleitung oder einem Behälter einströmende Kühlwasser ohne weiteres neben der beiderseits aus der äußeren hervorragenden inneren, zugleich der Ablaufröhre des Destilliergerätes herausläuft. Diese Vorrichtung mit dem angreifbaren, nur für indifferente Flüssigkeiten brauchbaren fest verbundenen, schlecht mit dem Destillierapparat zu verbindenden Ablaufröhren ist im Grunde eine Verschlechterung des Dariotschen Kühlers. Erst in der Pars secunda jener Observationes, Gryphiae 1773, bringt Weigel sie auf Dariots Höhe dadurch, daß er empfiehlt, eine gläserne Röhre, übrigens durch Eingipsen in der äußeren, weißblechernen zu befestigen. Sie ist die eigentliche Kühlröhre, die selbstredend die Destillation auch von sauren Flüssigkeiten gestattet. Nicht viel später, 1794, vervollkommnete Göttling den Kühler durch Anbringen einer Ablaufröhre und Liebig 1843 durch einfache 
Dichtung mittels Korken (seinen ersten Apparat aus dem Münchener Museum zeigt die Abbildung), und an ihre Stelle trat später eine noch bessere Dichtung mit Kautschukstopfen oder Röhren ${ }^{1}$ ).

Weigel bediente sich übrigens auch eines Sustentaculums, eines den Kühler gabelförmig umfassenden, durch Schrauben aneinander zu pressenden, auf- und abwärts zu bewegenden Halters, wie er, kaum geändert, auch jetzt noch seine Dienste tut ${ }^{2}$ ), nachdem ihm, wie es scheint, Gay-Lussac noch dadurch, daß er die Gabel rechtwinkelig auf einen senkrechten Träger schob und sie um ihre Längsachse drehbar einrichtete, eine weitere Verbesserung gab.

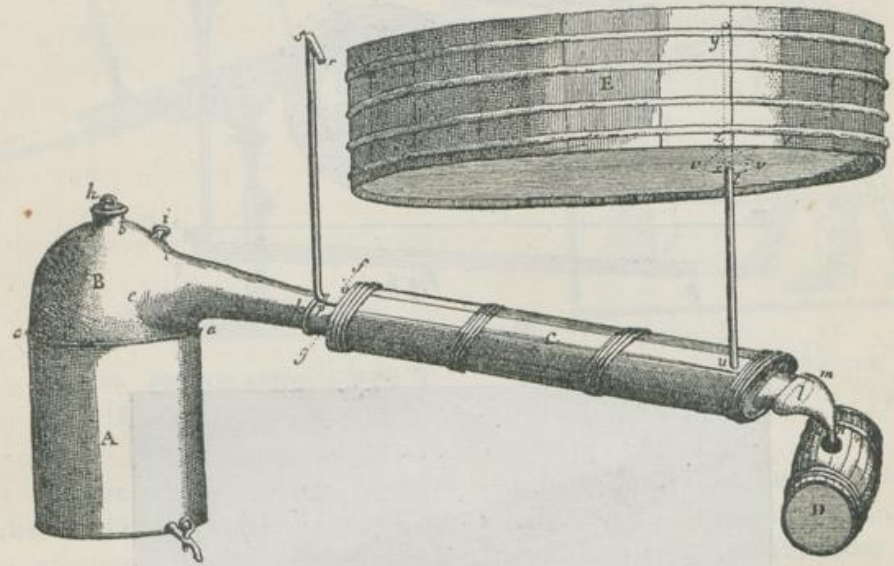

Abb. 61. Des jüngeren Gadolin Kühler.

Zur Destillation von Branntwein im Großen wurde ein Apparat nach Weigels (oder Dariots) Prinzip um des ersteren Zeit in Frankreich unzweifelhaft schon in Anwendung gezogen. Die betr. Veröffentlichung "Nouvelle Construction d'Alambic pour faire toute sorte de destil-

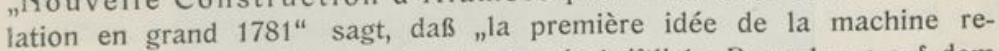
monte à l'année, 1770 " und wie eine handschriftliche Bemerkung auf dem Titelblatt des der Casseler Landesbibliothek gehörigen Exemplars sagt, ist Joao Hyacinthe de Magelhaens, gewöhnlich Magellan, wie ich in meinem Aufsatz (Zeitschr. f. angewandte Chemie 1910, 1978 ff.) zeigte, der Verfasser der Schrift, die dem Landgrafen geschickt worden war, „qu'on en repande la connaissance dans les états de Hessen-Cassel". Magellan

ग) Vgl, meine Arbeit in der Cöthener Chem. Ztg. darüber. Die Redaktion lieh freundlichst die Abbildungen.

2) Vgl. Max Speter, Geschichte der Erfindung des Liebigschen Kühlapparates. Cöthener Chem. Ztg. 1908, No. 1. 


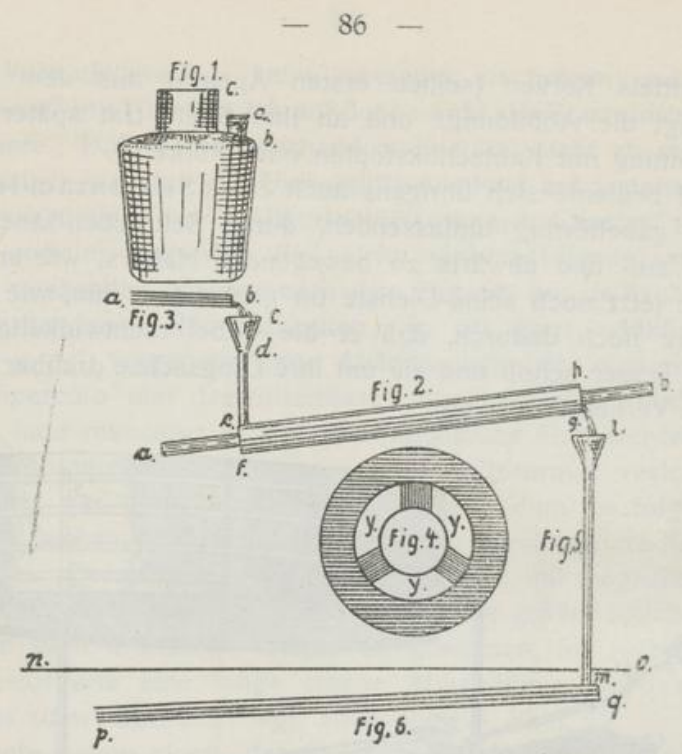

Abb. 62. Weigels Kühler.

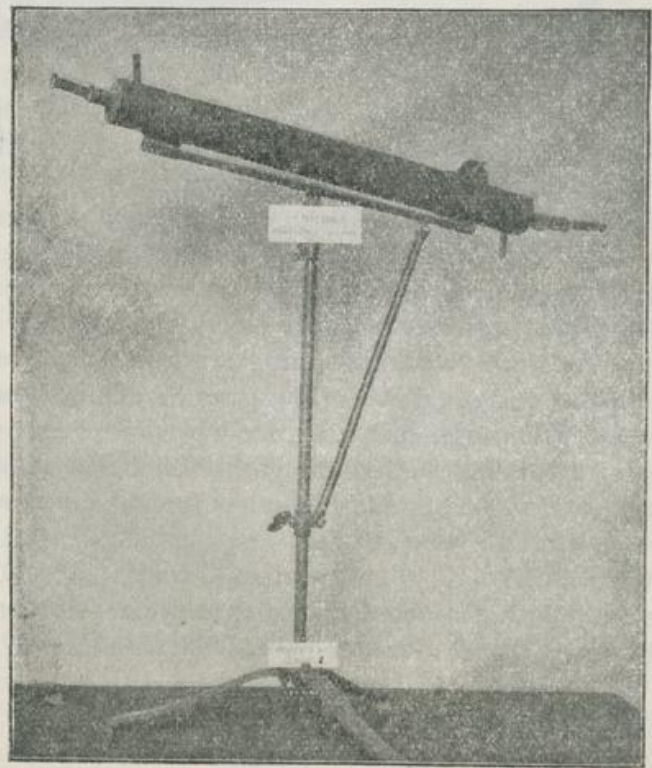

Abb. 63. Von Liebig selbst dargestellter Kühler. 
mag immerhin die Idee zu seinem Gerät etwa in Cognac-Brennereien aufgestellten größeren, nach Dariots Angaben gebauten, entnommen haben. Die wesentlichen Verbesserungen an dem von ihm durch vortreffliche Zeichnungen erklärten kann man ihm wohl kaum absprechen. Das Gerät, das Lord Phipps auf einer Fregatte zum Destillieren von Seewasser mitgenommen und 1774 beschrieben hatte, stützt sich wohl auf Magellans Arbeit. Vergl. S. 88.

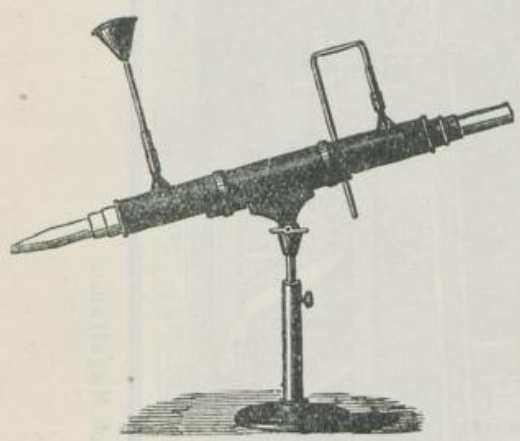

Abb. 64. Späterer etwas verbesserter Weigel-Göttlingscher Kühler.

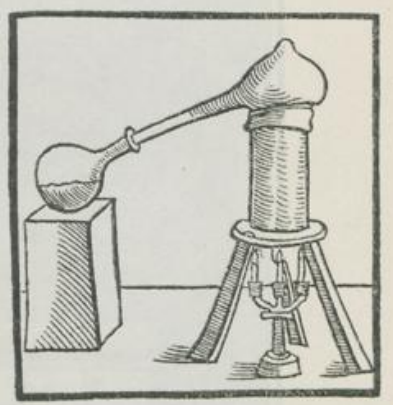

Abb. 65. Lichterfeuerung nach Euonymus. (Vgl. S. 69 u. 92.)

Für die Zwecke des pharmazeutischen Laboratoriums ${ }^{1}$ ), dessen Arbeiten täglich wechseln und in denselben uralten, einfachsten Geräten vorgenommen werden (im Gegensatz zu den Fabriken, die entweder überhaupt nur einen einzigen Gegenstand anfertigen oder verschiedene in, für je einen zweckmäßig ausgestaltetem Gerät) konstruierte als erster wohl der frühere Apotheker und spätere hervorragende Förderer der technischen Chemie Joh. Gottfr. Dingler in Augsburg, 1815 etwa, einen Apparat mit im Zickzack gehenden verhältnismäßig leicht zu reinigenden Kühlrohren"), nach ihm Gädda einen, bestehend aus zwei konischen, ineinander passenden Gefäßen, die recht schlecht zu reinigen waren. Beindorff in Frankfurt a. M.

1) Was Libav in seiner „Alchymistischen Practic" 1603 S. 131 über Beherzigung des späteren Goetheschen Wortes „In der Beschränkung zeiget sich der Meister ${ }^{\alpha}$ in den Laboratorien im Allgemeinen sagt, gilt ganz besonders auch jetzt noch für die der Apotheken:

${ }_{n}$ Man kann nicht an allen Orten allerley haben, muß sich ein Laborant mit mancherlei compendien behelfen, und darumb viel Formen erkennen lernen, sonst stehet die Kunst nicht in viele der Gläser, und könnte man mit einem geringen Zeug viel ausrichten.

Sonderlich ists ein behend Ding mit den öffen, wer dieser Form in genere und idealiter hat und sich um die Arbeit recht verstehet, kann nur ein einigen zu mancherley Nutz verwenden und leicht aus einer Form eine andere machen. Aber in großen beständigen Officinen muß man der Muster zu allerley chymischen Sachen mehr haben."

2) Buchners Repertor. 1817,3 , S. 137 u. 6, S. 142. Trommsdorfis lournal 11, 241. 


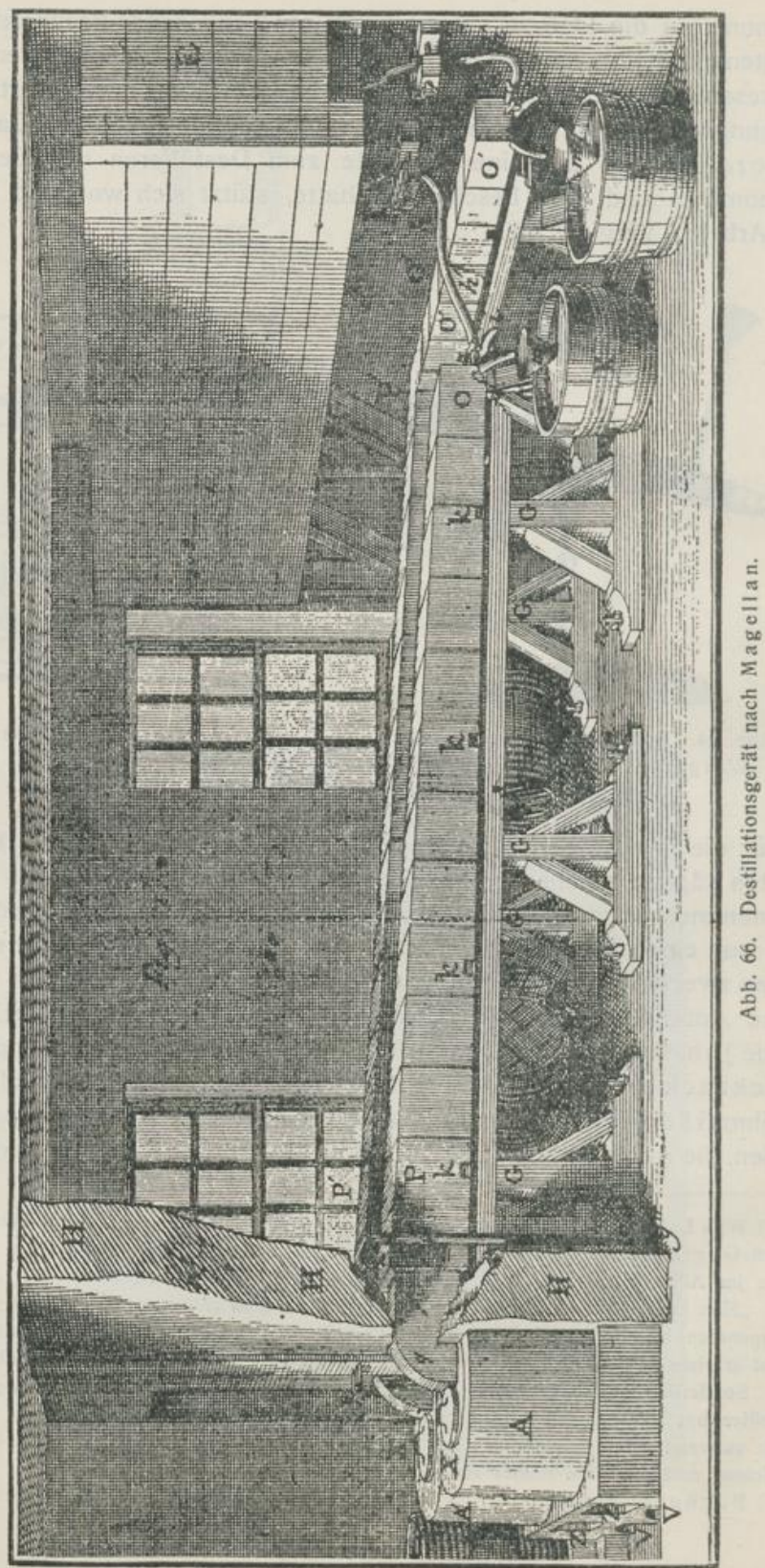




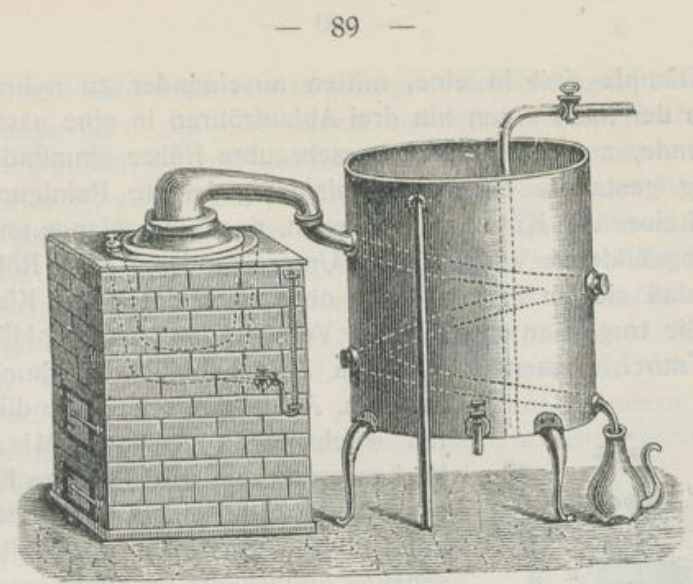

Abb. 67. Kühler nach Dingler.

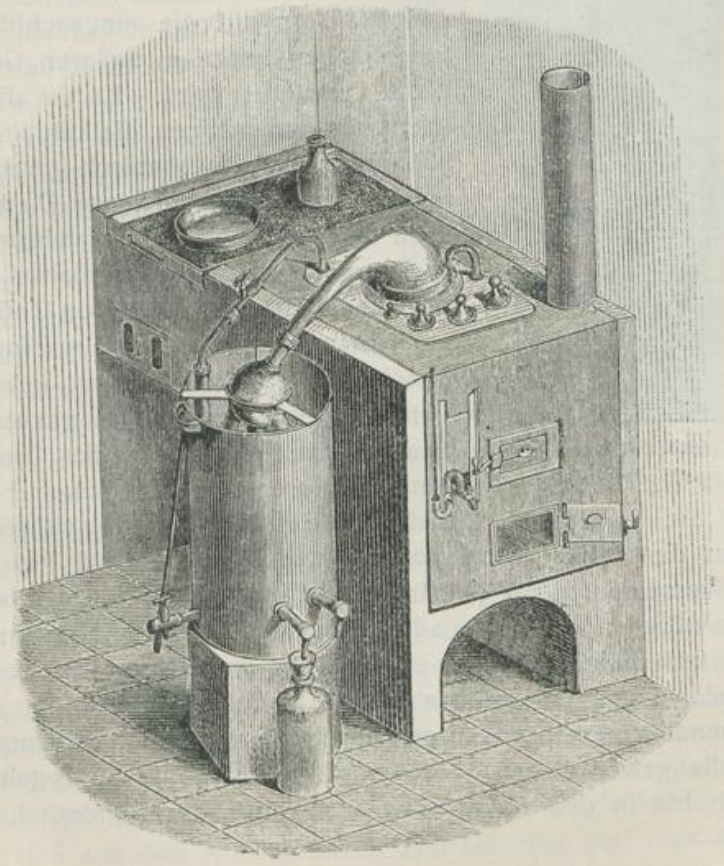

Abb. 68. Gerät nach Beindorff

schon mit Vorrichtung zum Destillieren mit Dampf. 
ließ die Dämpfe erst in eine, mitten auseinander zu nehmende Kugel treten, aus der nach unten hin drei Ablaufröhren in eine nach einer Seite hin abfallende, auf der höheren verschraubte Röhre einmündeten. Diese Einrichtung gestattete eine verhältnismäßig leichte Reinigung. Ähnlich war sie bei einer von Kölle empfohlenen, der Kühlschlange und Dinglers Gerät nachgebildeten Vorrichtung. Untereinander waren Röhren so angeordnet, daß sie im Zickzack von oben nach unten das Kühlfaß durchquerten. Sie trugen an ihren Enden Verschraubungen, mit Hilfe deren sie außerhalb durch passende U-förmige Zwischenstücke verbunden werden

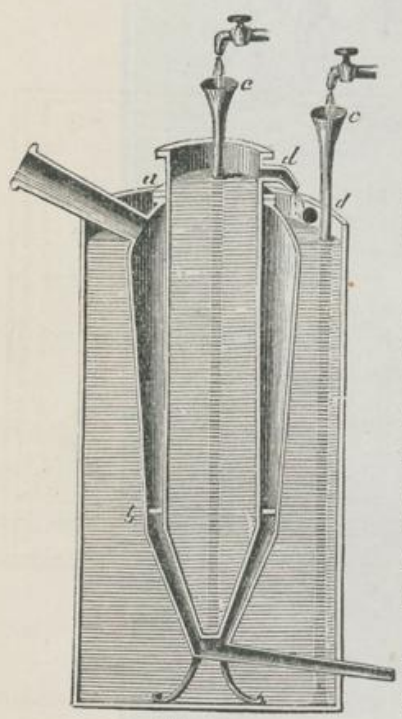

Abb. 69 .

Mitscherlichs Kühler. konnten. Am besten scheint für die angedeuteten wechselnden Arbeiten Mitscherlichs Verbesserung des Gäddaschen Kühlers ${ }^{1}$ ). In ein äußerstes im Kühlfaß befestigtes, oberseits mit Zufluß-, unterseits mit Abflußrohr versehenes, umgekehrt kegelförmiges Gefäß paßt je mit etwa $1 \mathrm{~cm}$ Abstand ein entsprechend kleineres, das lediglich durch den Druck des eigenen und des eingeleiteten, oben abfließenden Wassers auf die eingeschliffenen Dichtungsflächen mit dem äußeren Gefäß dampfdicht verbunden wird. Es ist dieses Gefäß leicht herauszunehmen, die kühlenden Flächen können bequem mechanisch gereinigt werden und längeres Durchleiten von Dampf beseitigt nach eigener langiähriger Erfahrung alle von der vorangegangenen Destillation etwa noch zurückgebliebenen riechenden Teile.

Ignis elambit, exhaurit resolutum sucum, transfert in vas superius ex inferiore, inde alembicus ex caudata nasutaque figura = penula [in diesem Falle das Diminutiv von penis]. Dieser übrigens schon bei Rhazes zu findende Ausspruch Libavs zeigt, welche

Rolle man dem alles bezwingenden (wie Plinius sagt) Feuer beimaßs.

Sehr verschieden war die Art, wie man das für die Destillation nötige Feuer, die nötigen Wärmegrade erzeugte \%). Bei manchen Arbeiten, bei denen es tatsächlich, in aller erster Reihe wenigstens, auf das „Herauslecken" oder "-saugen“, auf das Ausziehen von Arzneistoffen nach einem voraufgehenden putrefacere, digerere, circulare ankam, bediente man sich, da man die gewöhnlichen Wärmequellen nur wenig zu regeln imstande war, noch bis in den Anfang des XIX. Jahrh. der wunderlichsten Mittel.

1) Vgl. die Abb. 67-69.

2) Vgi. oben S. 61 . 
ugel ieite iese llich ers anrchsie den uteohs

So brauchte man nach unsern jetzigen Anschauungen tatsächlich nur für Digestionszwecke, um ein „Ignis sapientium, eine feuchte, gelinde Wärme" zu erzielen, wie sie der tierische Organismus beim Verdauungsprozeß entwickelt, des Pferdedüngers, des Fimus oder Venter equinus. In flachen Kästen oder im Keller wurde er wie in den Frühbeeten, gelegentlich, um die Hitze noch zu steigern, mit gelöschtem Kalk ausgebreitet, und dahinein wurden die mehr oder weniger fest verschlossenen Gefäße gestellt. Hierher gehört auch die Destillatio per formicas. Mitten in den kribbelnden, Wärme erzeugenden Ameisenhaufen wurde das betreffende Gerät gesetzt. Auch jetzt noch "digeriert" nicht, sondern „destilliert" das Volk seine weinigen und andern Auszüge, wie schon gesagt wurde in des Wortes tatsächlicher Bedeutung.

Ähnlich brauchte man wohl gärenden Brotteig, ja man umgab auch wohl das Gefäß mit Teig und setzte es dann zum Backen in den Backofen, den man auch sonst nach dem Backprozeß zum "destillieren" brauchte, man destillierte per panem. Zum gleichen Zweck benutzte man natürlich auch die verschiedenen Bäder, ganz so wie man das ja auch jetzt noch da tut, wo nicht der Großbetrieb, aufs vollkommenste eingerichtet, stets auf einen bestimmten Wärmegrad erhitzte Räume zur Verfügung hat. Libav behandelt das

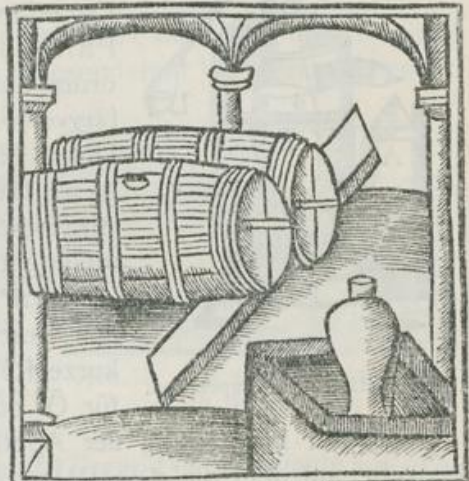

Abb. 70 .

Destillario per fimum nach Euonymus. Feuer in einem großen Artikel Pyronomia, „die öfters vor Chymia gebraucht wird“. Biringucci benent sein hervorragendes Lehrbuch [sehr charakteristisch für seine hohe Einschätzung] geradezu Pirotecnica (delle minere e metalli), und gelegentlich wird zu weiterer Kennzeichnung das Beiwort Hermetica beigesetzt. Im XVIII. Jahrh. unterschied man summarisch Calor artificialis und naturalis und reihte die vielen einzelnen Wärmearten der Quellen sinngemäß unter.

Daß die Alten Lampen, wie sie solche ja in einer Menge von Gestalten besessen haben, auch als Wärmequelle brauchten, kann ich nicht belegen - aber daß der Zufall, wenn nicht Überlegung dazu geführt hat, auf ihnen das und jenes, also auch wohl Flüssigkeit in einem Glas- oder andern Gefäß zu erwärmen oder warm zu halten, scheint über allen Zweifel erhaben, wie wir oben hörten. Aus der Bezeichnung qõ $\tau \alpha$ in den Abbildungen 7 u. 8 aus dem Anfang unsrer Zeitrechnung darf man auf ihre Anwendung schließen. Auf S. 33 hörten wir, daß die Araber bestimmt Kerzen oder Lampen, Quandil oder Masclial bei ihren Digestionen gebrauchten. 
Abbildungen aus dem XV. Jahrh. belegen sie. Euonymus Philiater zeigt (vgl. Abb. 65) einen dreiarmigen Leuchter, mit dessen Lichtern er nach demselben Gedankengange, wie er oben (S. 69) ausgeführt ist „aus eltestem Wein die 4 Element" (das erste, also am leichtesten siedende ist "scharpfes Wasser", das zweite noch "schärpfer", das dritte „süßlicht", das „beste, denn es ist das flüssige des Luffts in“, das vierte ist „ungeschmack“, geschmacklos) „fractioniert", um mit dem dicken Element und Goldblättchen Aurum potabile zu machen (IIf. 282). Weiter rühmt

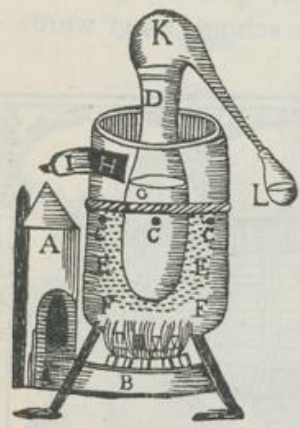

Abb. 71 .

A. de Heidens Lampenofen. Libav: Candelarum et ellychniorum [ $\left[2 \lambda \lambda_{2} \%-\right.$

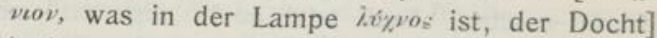
ignis temperari potest ad libitum propius, remotius admovendo et numerum augendo minuendove. Est etiam diuturnior minusque eget curae. Inde Philosophi ignem vocant trium filorum, duorum aut unius ita institutum $1 \mathrm{ychnuchum}$

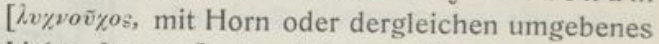
Licht, Laterne]. Im Jahre 1690 sehen wir bei A. de Heiden, in seinem "Neuen Licht vor die Apotheker" einen Destillationsapparat über einer vieldochtigen oder -flammigen Lampe (mit vielen "Tillen" [jetzt durchweg Tülle, vielleicht wie das französische douille, aus dem lat. ductile, kurze Röhre] mit einem höher stehenden Gefäß für Öl oder „Brandwein“.

Bei der Einrichtung der Apotheke nahm Renodaeus auf ein Brett bedacht, auf dem die destillierten Wässer, zu destillierende Präparate und andre Sachen stehen sollten, damit sie dort von den Sonnenstrahlen getroffen würden. In diesem Falle sollte vermutlich auch das Sonnenlicht seine Einwirkung ausüben ${ }^{1}$ ). Lediglich auf die Sonnenwärme, den Calor naturalis, kam es jedenfalls den Arabern, Libav und seinen Nachfolgern an, wenn sie ihre Destilliergeräte in die Sonne stellten, und es geht diese Absicht noch klarer aus dem Umstande hervor, daß sie die Sonnenstrahlen entweder mit Hilfe von mit Wasser gefüllten (Schuster-) Kugeln aus Glas oder mittels Brennspiegeln, per parabolas, auf die betreffenden Chemikalien wirken ließen. Es war später wohl erst der regsame Joh. Heinr. Pott, der, und zwar in der Mitte des XVIII. Jahrh., „um kleine Mengen flüchtiger Flüssigkeiten aus minder flüchtigen wirklich zu destillieren und schwer anschießende Salze zum Kristallisieren zu bringen", Sonnenwärme ausnutzen wollte. Er setzte die Schale mit den betr. Flüssigkeiten auf einen porzellanenen Teller und stürzte eine genau schließende Glocke darüber. Die in der Sonne sich verflüchtigenden, ver-

3) Conrad Gesner (Euonymus) empfiehit z. B. „Die Blumen der Spicken oder der Lavender solt Du eine kurze Zeit lang sonnen in einer großen gläsinen Retorte." 
dunstenden Teile schlugen sich an der Glocke $a b$ und rannen in den Teller hinunter.

Diese Vorrichtung verbesserte C. W. Gottl. Kastner, Prof. in Erlangen, 1819 , dahin, daß er statt des Porzellantellers einen flachen, dicht auf eine Flasche passenden Trichter nahm, durch den das Destillat sofort in diese abfloß, daß er außerdem bei Stoffen, die das Sonnenlicht ungünstig beeinflußte, die Glocke grün bemalte, um mehr Hitze zu erzielen, die Schalen aus schwarzem Steingut herstellen ließ usw. ${ }^{1}$ )

Es ist selbstverständlich, daß es möglich wäre, die durch riesengroße Spiegel aufgefangenen und auf einen Punkt geleiteten Sonnenstrahlen wie für andre technische Zwecke so auch für Destillationen zu verwenden. Daß man dahin gehörende Versuche gemacht hat, ist mir nicht bekannt geworden.

Schon frühzeitig ist jedenfalls Rosenwasser dort, wo die „Königin der Blumen" besonders zahlreich und mit besonderem Wohlgeruch begabt wuchs, wie schon oben gesagt wurde, in großen Mengen destilliert worden, und es ist ohne weiteres anzunehmen, daß unter solchen Bedingungen, ganz so, wie es später in Europa bei der Branntweindestillation geschah, einmal größere Gefäße aus dauerhaftem Metall dargestellt und gebraucht wurden, daß man anderseits durch zweckmäßige Aufstellung kleinerer Erspar-

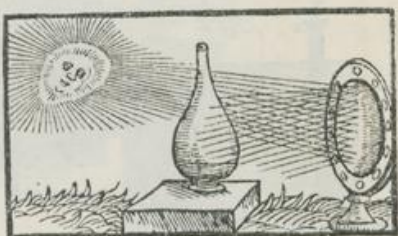

Abb. 72. Destillatio per parabolas nach Euonymus. nisse an Feuerungsmaterial zu machen versuchte. Der zum A tha n or gewordene $(A l)$ Tanu-Füllofen diente solchem Zwecke, die Anordnung der Destillierblasen, wie sie Eilhard Wiedemann in dem Kahlbaum-Gedächtniswerk aus der oben (S. 36) erwähnten Handschrift aus dem Anfange des XIII. Jahrh. von Al Gaubari hochverdienstlich veröffentlicht hat, ebenso. In ihr, ob nun die Gefäße übereinander oder, was mir eher anzunehmen erscheint, neben- oder hintereinander aufgereiht sind, sehen wir zugleich die ersten Galeerenöfen, wie wir sie, als bei der alten Art der Nordhäuser Vitriolöl-Fabrikation üblich, kennen. Ihre Anlage ergibt sich aus dem oben Gesagten und der Abbildung 41.

Rumford war der erste, der es für möglich hielt und versuchte, durch Einleiten von Dampf Flüssigkeiten zum Sieden zu bringen. 1810 brauchte Trommsdorff ihn in seiner Apotheke zu Kochzwecken, und Struve in Dresden folgte. Dem äußerst anschlägigen Altonaer Apotheker Heinrich Zeise aber erst verdankte der Dampf seine eigentliche Einführung als Koch- und Heizmittel in die Laboratorien der Apotheken und ganz allgemein in die Häuser. 1826 gab er eine „Praktische Anleitung zur vorteil-

1) Buchner, Repertor. 1819,418 , 
haften und sicheren Benutzung der Wasserdämpfe von einfacher und mehrfacher Spannung zumeist zu pharmazeutischem Gebrauch" heraus, und damit begann, nachdem Dariots, immerhin als Vorläufer einer Destillation mit Wasserdampf anzusehende Arbeitsart längst vergessen war, in Wahrheit die Verwendung dieser Heizquelle ihren Siegeslauf auch auf dem Gebiete der Destillation, und mit ihr hörten die Klagen über Anbrennen, über empyreumahaltige Öle usw. auf. Nur Dampfdestillation kommt wenigstens bei Körpern, deren Siedepunkt niedriger liegt als der des gespannten Dampfes noch in Frage, und nur seiner bedienen sich die wohl den breitesten Raum einnehmenden Branntwein-Fabriken (von "Brennereien" kann wohl nicht mehr die Rede sein) in Geräten, die auf Grund von Beobachtungen in den musterhaft eingerichteten Fabriklaboratorien von Spezialtechnikern ausgestaltet wurden. Bis in die zweite

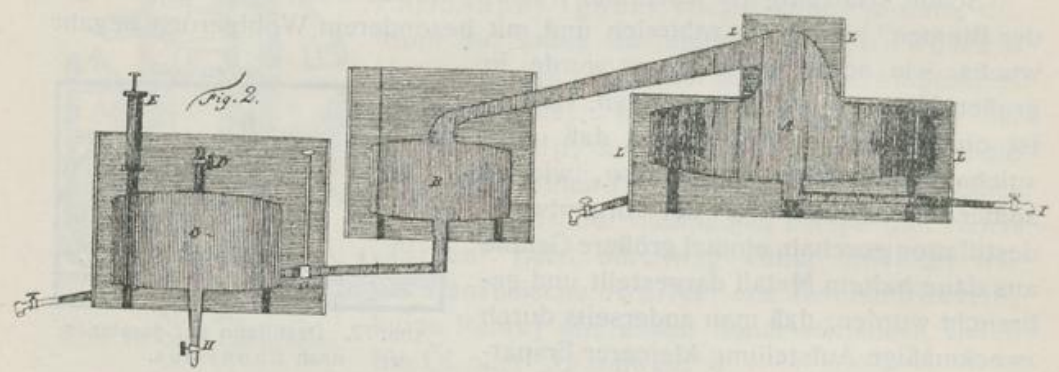

Abb. 73. Destillationsgerät mit Luftpumpe nach Tritton.

Hälfte des vorigen Jahrhunderts hinein herrschte allerdings der einfachste Apparat in den Brennereien (den Brûleries) der Destillateure (Liquoristes, Bouilleurs), wie sie z. B. Demachy im Bilde zeigt. Im Jahre 1818 (ein Jahr später empfiehlt Parmentier noch eine "Methode pratique de la Distillation de l'eau de vie", die sich auf einen altüberkommenen Apparat stützt) erst läßt sich ein Engländer Hen ry Tritt on einen vervollkommneten Apparat für Branntweindestillation ${ }^{1}$ ) patentieren, der in erster Reihe die Unannehmlichkeit des Anbrennens der Maische am Boden der Blase verhüten sollte.

Das wollte Tritton erreichen durch Destillation aus dem Wasserbade, und eine größere Ausbeute sollte das Herstellen eines luftverdünnten Raumes in dem Gerät durch eine an der Vorlage angebrachte Luftpumpe ${ }^{2}$ ) zu Wege bringen (vgl. auch unten). Mit Luftver-

1) Annals of Philosophy, June 1819. Buchner Repertor. 1819, S. 99, Tafel I, Fig. 2.

$\left.{ }^{2}\right)$ Buchners Repertor. 6 (1819), Taf. 1. Die Zeichnung ist ohne Erklärung zu verstehen. Vor Tritton hatte schon ein Ingenieur Philipp Lebon 1796 ein Brevet auf Alkoholdestillation in luftverdünntem Raum genommen. Wie sein Gerät aussah, weiß ich nicht. 
dünnung hoffte Tennant zu erreichen, in einem Apparat, den Buchner ebenda abbildet, mit einem Feuer zwei Destillationen im Gange zu halten. Die Dämpfe des ersten Apparats sollten durch eine zweite Blase gehen. Wenn deren Inhait genügend erhitzt war, sollte die Ablaufröhre seines Helms stark gekühlt werden. Das sollte soviel Luftleere bewirken, daß in diesem Apparat eine Destillation erzielt werden konnte. Die Idee von Tennant führte wohl zu dem später auch von Hager empfohlenen Vacuum-Apparat. Im selben Jahre übrigens hatte schon der jedenfalls sehr tüchtige Apotheker Dr. Romershausen in Aken a. Elbe die Luftpumpe, oder wie er, von der entgegengesetzten Voraussetzung ausgehend, daß die der Pumpe nachströmende Luft als wirksam in erster Reihe in Betracht käme, sagte, die Luftpresse in das pharmazeutische

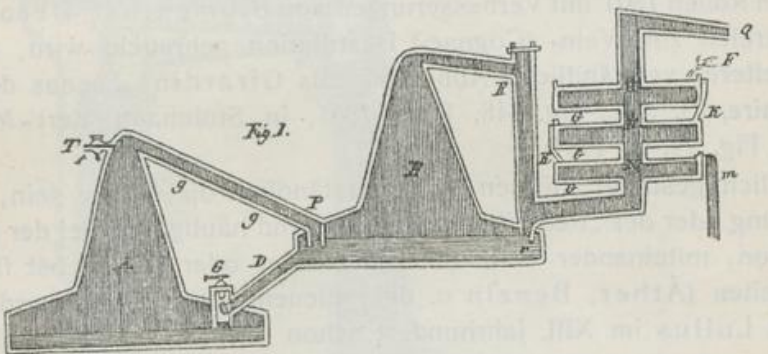

Abb. 74. Cortys Gerät.

Laboratorium eingeführt, und mit ihrer Hilfe destillierte er, „weil sie, selbst mit den schlechtesten Destillier-Apparaten verbunden, viel Zeit und Brennmaterial spart, indem sie zugleich den Ertrag erhöht und verbessert". Im lahre 1822 empfahl er einen Weingeistdestillationsappart mit guter Helmkühlvorrichtung und Luftverdünnung, die allein durch die Verdichtung des Dampfes hervorgebracht ${ }^{1}$ ) werden sollte. Auch hier ist ein MaischVorwärmer vorgesehen.

Gleichzeitig, im Jahre 1818 hatte Joseph Corty in Middleessex sich einen Apparat patentieren lassen, der meines Erachtens in der Anlage alles das enthält, was die unendlich vervollkommneten Riesenapparate als wesentlich an sich haben. Corty $^{2}$ ) empfiehlt zwei ganz flachbodige Blasen mit kegelförmigem hohen Helm. Eine steht etwas höher als die andre. Sie ist durch ein Rohr mit ihr verbunden, sodaß die in ihr enthaltene,

1) In der Art, wie sie von dem oben genannten Tennant und ein Jahr früher von John Barry (Buchner Rep. 11, 316) für Abjampfungszwecke empfohlen worden und bis vor wenig Jahrzehnten noch bei manchen Vacuumapparaten angebracht war. Vgl. Buchner, Repertor. 13 (1822) Taf. 4.

2) Vgl. Buchner Repertor. 7 (1819), S. 616. Taf. 1. Fig. 1 
weil sie erst in zweiter Reihe vom Feuer bestrichen wird, vorgewärmte Maische in die direkt auf dem Feuer stehende erste Blase gelassen werden kann. Die Destillationsprodukte aus ihr treten unter die Maische in der zweiten Blase, die dort erzeugten gehen von der Höhe des Helms in einem senkrecht nach unten führenden Rohr abwärts, die verdichteten Teile fallen zurück in die Blase, die andern gehen seitwärts weiter und dann aufwärts in einem Rohr, das dreimal sich in Becken erweitert, die durch fließendes Wasser, die oberen zuerst, gekühlt werden. Was in diesem Kühlsystem verdichtet wird, rinnt auch in die zweite Blase zurück. Was gasförmig durchgeht, wird, auf dem weiteren Wege verdichtet, nachdem es noch eine Art Sicherheitsröhre oder einen Siphon durchstrichen, aufgefangen.

Einen Apparat, wie er nach einer patentierten Angabe von Edouard Adam in Rouen 1801 mit Verbesserungen von Blumenthal, Derosne u. a. in Frankreich zur Wein- (Cognac-) Destillation gebraucht wird, zeigt die ohne weiteres verständliche Abbildung aus Girardins Leçons de chimie élementaire, S. 354, Fig. 448, Paris 1861, in Stohmann-Kerl-Muspratts Chemie, Fig. 99, S. $498^{1}$ ).

Ähnlich gestaltet müssen selbstverständlich die Geräte sein, die zur Darstellung oder der „Rektifikation" (beide sind häufig, wie bei der Alkoholdestillation, miteinander verbunden) flüchtiger oder gar höchst flüchtiger Flüssigkeiten (Äther, Benzin u. dgl.) dienen. Dargestellt wurde jedenfalls von Lullus im XIII. Jahrhundert schon Äthylnitrit, und sicherlich hatte er auch einen alkoholhaltigen Äther unter den Händen. Nach der Sitte damaliger Zeit hat er jedenlalls in Zirkuliergefäßen tagelang seine Aqua ardens und Salpeter- und Schwefelsäure aufeinander einwirken lassen, und gleichermaßen verfuhr natürlich auch Valerius Cordus oder, richtiger wohl, sein Oheim, der Leipziger Apotheker Ralla, als er aus gleichen Teilen Ol. vitrioli und stärkstem Spiritus Vini den Spiritus Vitrioli dulcis aus einem Gefäß destillierte, das in seiner Gestalt an die genannten erinnert. An seinem helmartigen Kopf ist eine Nase angeschmolzen und ${ }^{2}$ ) eine Röhre vielleicht zum Nachfüllen.

Neu ist in den späteren Apparaten aus der zweiten Hälfte des XIX. Jahrhunderts nur die Hinzuziehung des Wasserdampfes als Heizquelle. Alles übrige bezieht sich auf Verbesserung inbezug auf die Lagerung der einzelnen Teile des Geräts, auf ihre weitere Ausgestaltung usw.,

1) An dieser Stelle möchte ich auf die wenig bekannte Tatsache hinweisen, daß Heinrich II. von England, als er 1171 erobernd in Irland einzog, dort schon die Gewohnheit des Trinkens, aus Gerste selbst destillierten Whiskys [aus dem keltischen uisgebeatha d. h. Wasser des Lebens] vorfand. Solche Kenntnis kann wohl, wenn sie nicht bodenständig war, nur aus unserm jetzigen, damals von A rabern bewohnten Spanien, wenn nicht gar aus dem Orient auf die ferne Insel gekommen sein.

2) Conr. Gesner in dem Sammelband „De artificiosis extractionibus“ Argentor. 1561. Cap. De Oleo e chalcanto, uno austero (s. acido) altero dutci. 
mte

rden

der

nem

allen

ärts

ides

item

mig

loch

auf-

a rd

u. a.

die

mie

atts

zur

101-

ger

len-

ich

der

ine

ren

ler,

uus

ioli

ten

$d^{3}$ )

les

iz -

die

W.,

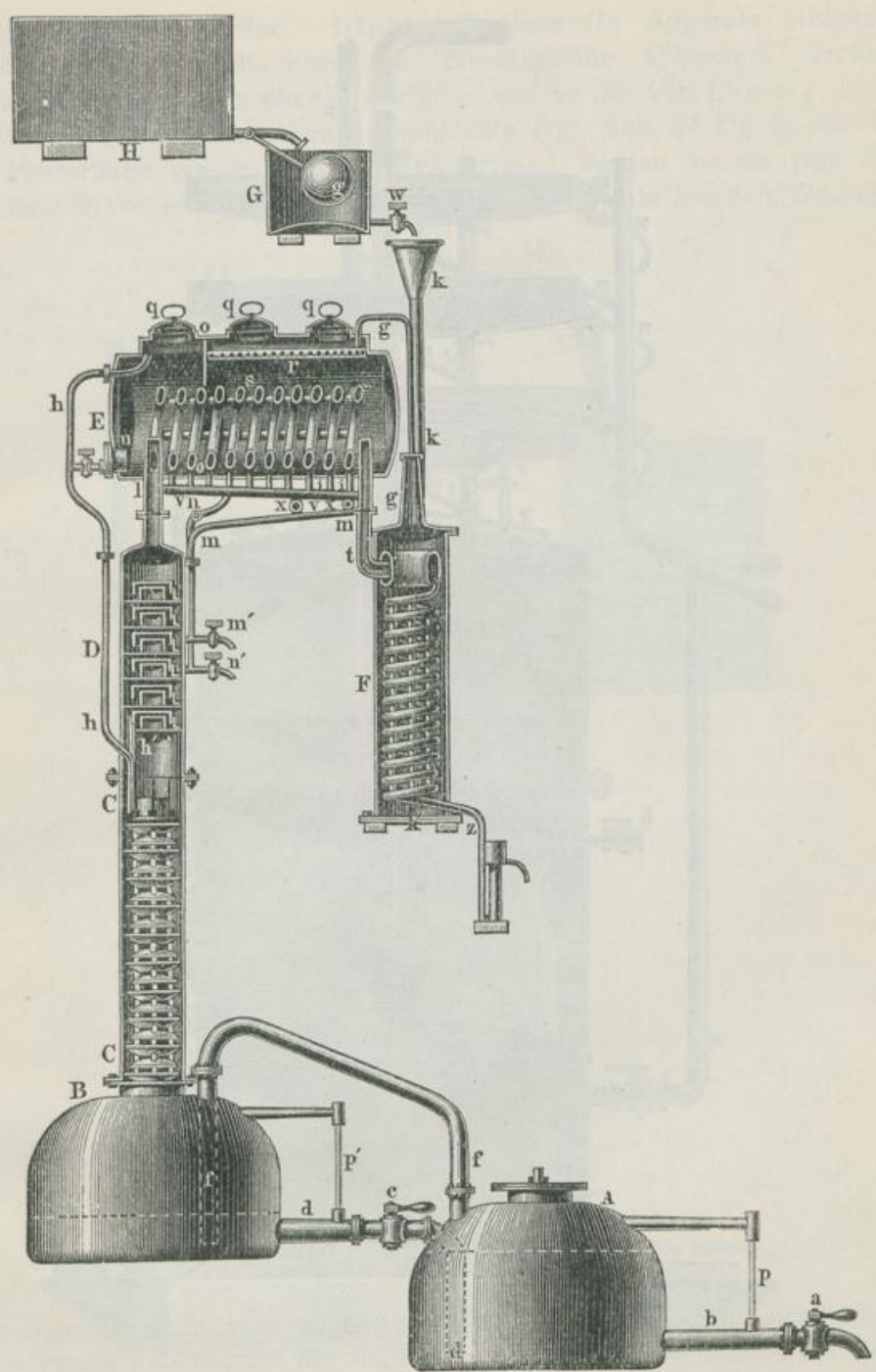

Abb. 75. Cognac-Destillationsgerät.

wie man aus der Abbildung ersehen kann. Sie zeigt einen KartoffelSpiritus-Apparat, der, zusammengedrängt, alle für die Destillation in Betracht kommenden Teile enthält. Ähnliche Vorgänge beobachten wir bei den 


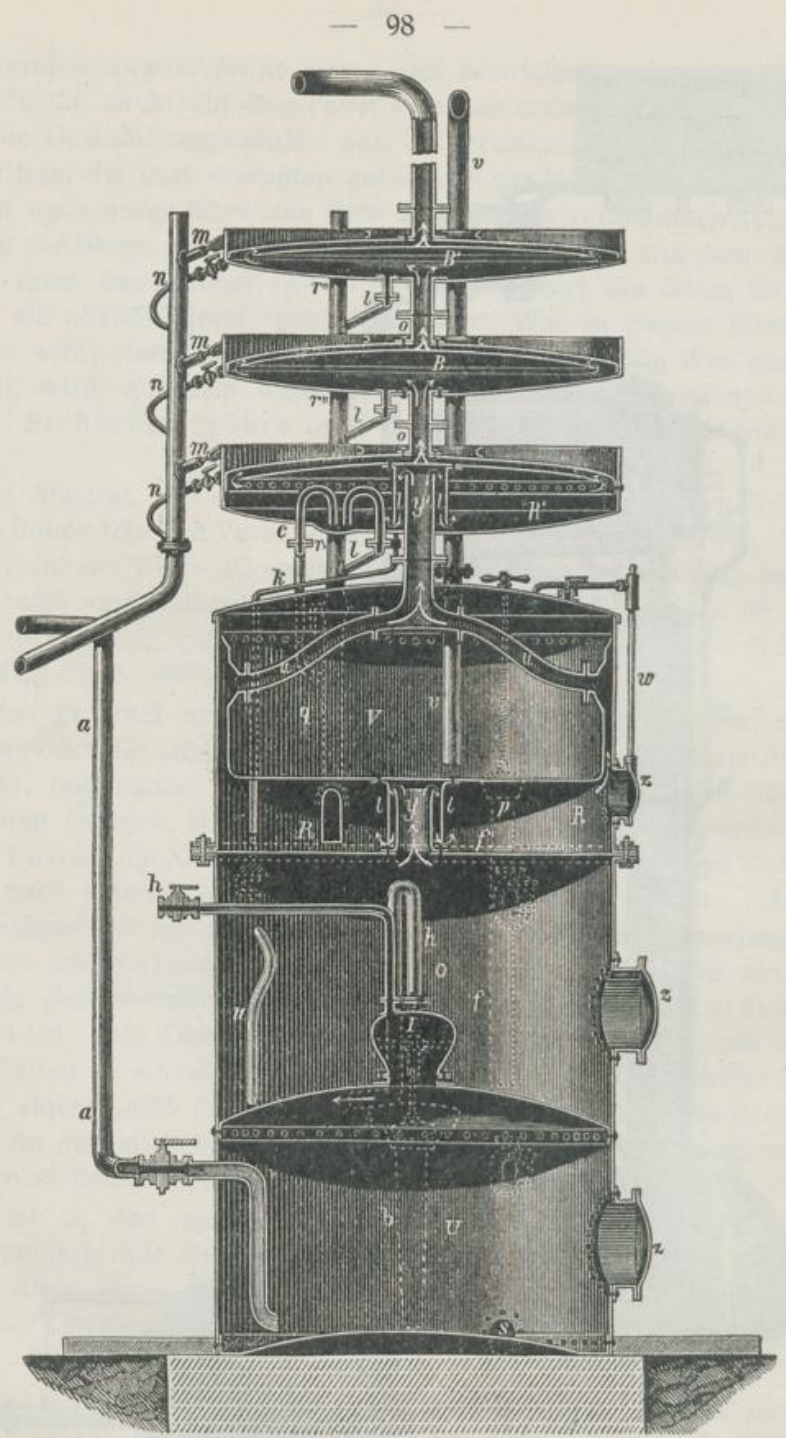

Abb. 76. Dampf-Destillationsgerät für Spiritus.

Geräten für die Destillation der ätherischen Öle, die wie die vorigen auf Grund von Sondererfahrungen in den, bezüglich ihrer Einrichtungen selbst den Hochschullaboratorien überlegenen Fabriklaboratorien aufs zweck- 
mäßigste gestaltet wurden. Dingler-Beindorffs Apparate erhielten auf die einzelnen Öffnungen für Einsatzgefäße schwerere Deckel, die da gestatteten, ganz ebenso übrigens, wie es die von Lémery deutlich wiedergegebene Einrichtung ermöglichte (vgl. Abb. 54 Fig. l), daßs in dem Wasserbade einiger Dampfdruck erzeugt werden konnte (vgl. die Abbildung 68 von einem solchen Apparat). Dampf wurde aus dem Wasser-,

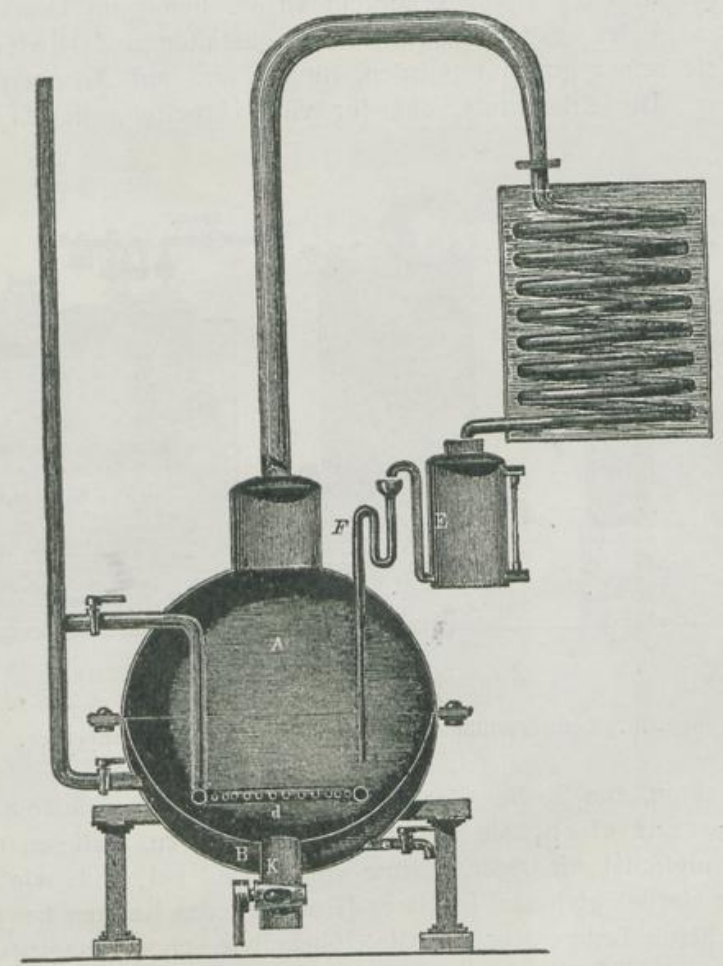

Abb. 77. Modernes Dampfdestillationsgerät für größeren Betrieb.

jetzt Dampfbade in eine hineingehängte Blase unter eine siebähnliche Scheidewand geleitet, auf der die Pflanzenstoffe gelagert waren, die durch hindurchgeleiteten Dampf ihrer Ruchbestandteile beraubt werden sollten. Das ist eine Einrichtung, wie sie, je nach dem etwas umgestaltet, die Dampfapparate der, für die Ölerzeugung früher in erster Reihe in Betracht kommenden A potheken durchweg in den fünfziger Jahren schon zeigten. Die räumliche Trennung des Dampferzeugers und des eigentlichen Destilliergeräts 
(Abb. 78) war der nächste Schritt, ein Gerät, wie es Abb. 77 zeigt, ein weiterer, der von technischen Erwägungen diktiert war. Was z. B. die Weltfirma Schimmel \& Co. in Miltitz, die in ihrer Großzügigkeit und der wissenschaftlichen Ausgestaltung alles dessen, was das Gebiet der ätherischen Öle im weitesten Sinn des Worts betrifft, ihresgleichen sucht, in Anwendung zieht, ist doch auch nur "lange dagewesen“, aber überdeckt von äußerst genialen Verbesserungen und ins Riesenhafte vergrößert.

Auf ein Arbeiten unter erhöhtem Druck liefen im Grunde die Digestionen in den vielfach abenteuerlich gestaltenen $\mathrm{Zirkulier-Gefäßen}$ und wie sie sonst genannt wurden, hinaus und auf Arbeiten bei hoher Temperatur. Die Erkenntnis, daß für viele Arbeiten, die da schließlich

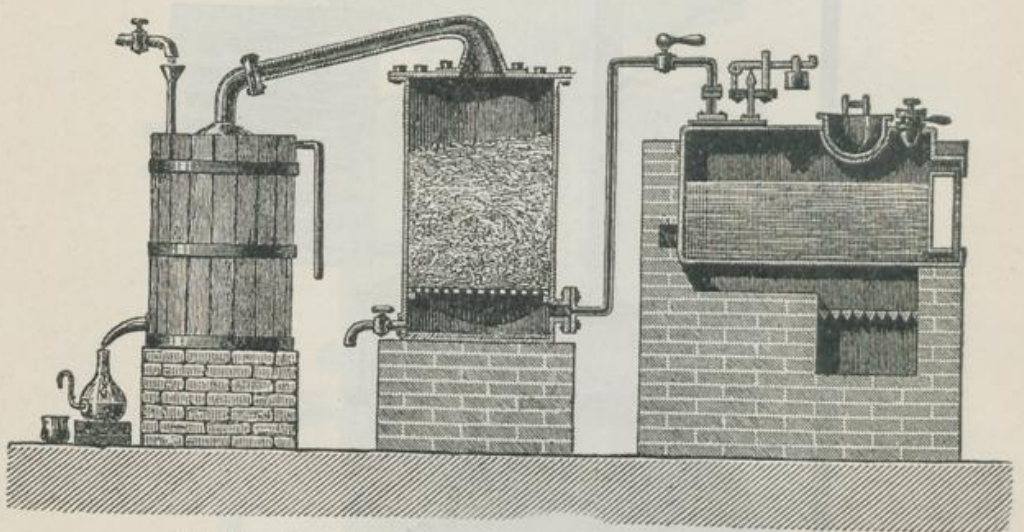

Abb. 78. Dampfdestillationsgerät für größeren Apothekenbetrieb.

alle bezweckten, aus Stoffen der verschiedensten Arten eine feinere Quinta Essentia auszuziehen, sie in ihre Elemente zu zerlegen ${ }^{1}$, die Anwendung möglichst niedriger Wärme von Vorteil sei, daß, wie eben erst Lavoisier klargelegt hatte, Luftverdünnung das Kochen bei geringerer als gewöhnlicher Temperatur gestatte, führte, wie schon gesagt wurde, wohl zuerst Belon (vgl. S. 94) dazu, sie bei der Alkoholdestillation anzuwenden, Bei dem Apparat Trittons sahen wir, wie sie, eigentlich am einfachsten und am nächsten liegend, durch Abkühlung und Verdichtung der verdampften Flüssigkeit zu Wege gebracht wurde. John Barrys Apparat, der 1821 von Buchner, Bd. 11, S. 316, abgebildet und beschrieben wurde, zeigt alles das in verfeinerter, für Laborationszwecke berechneter Art, was für den 1812 von Howard in die Technik eingeführten ZuckerVacuum-Verdampfapparat, wie für den später Hagerschen bezeichnend ist.

1) Vgl. z.B. Gesner-Euonymus Destillationsarbeit, das Separieren von Lém ery usw. 
erer, irma isenchen Anvon Di ißen oher blich

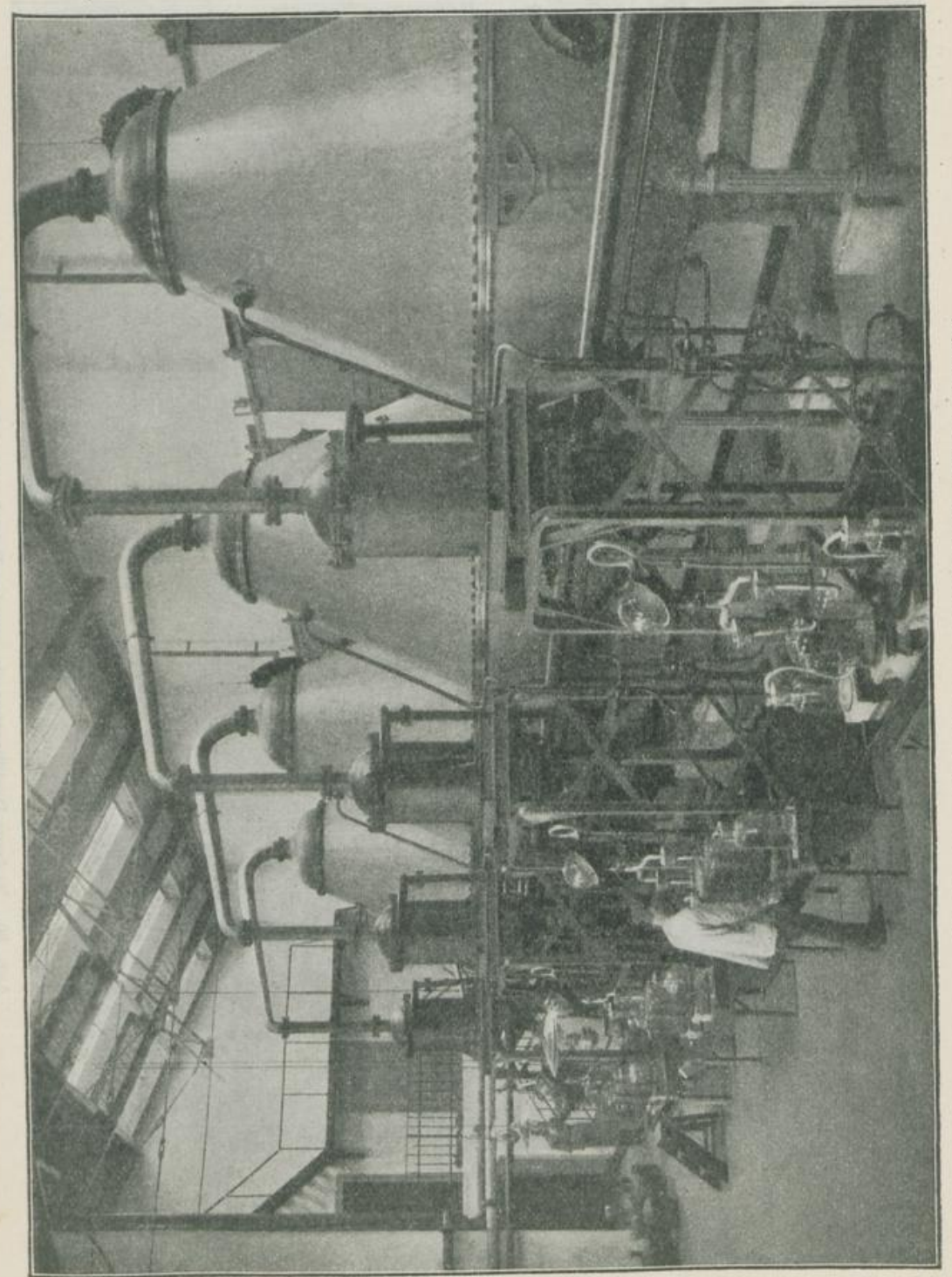




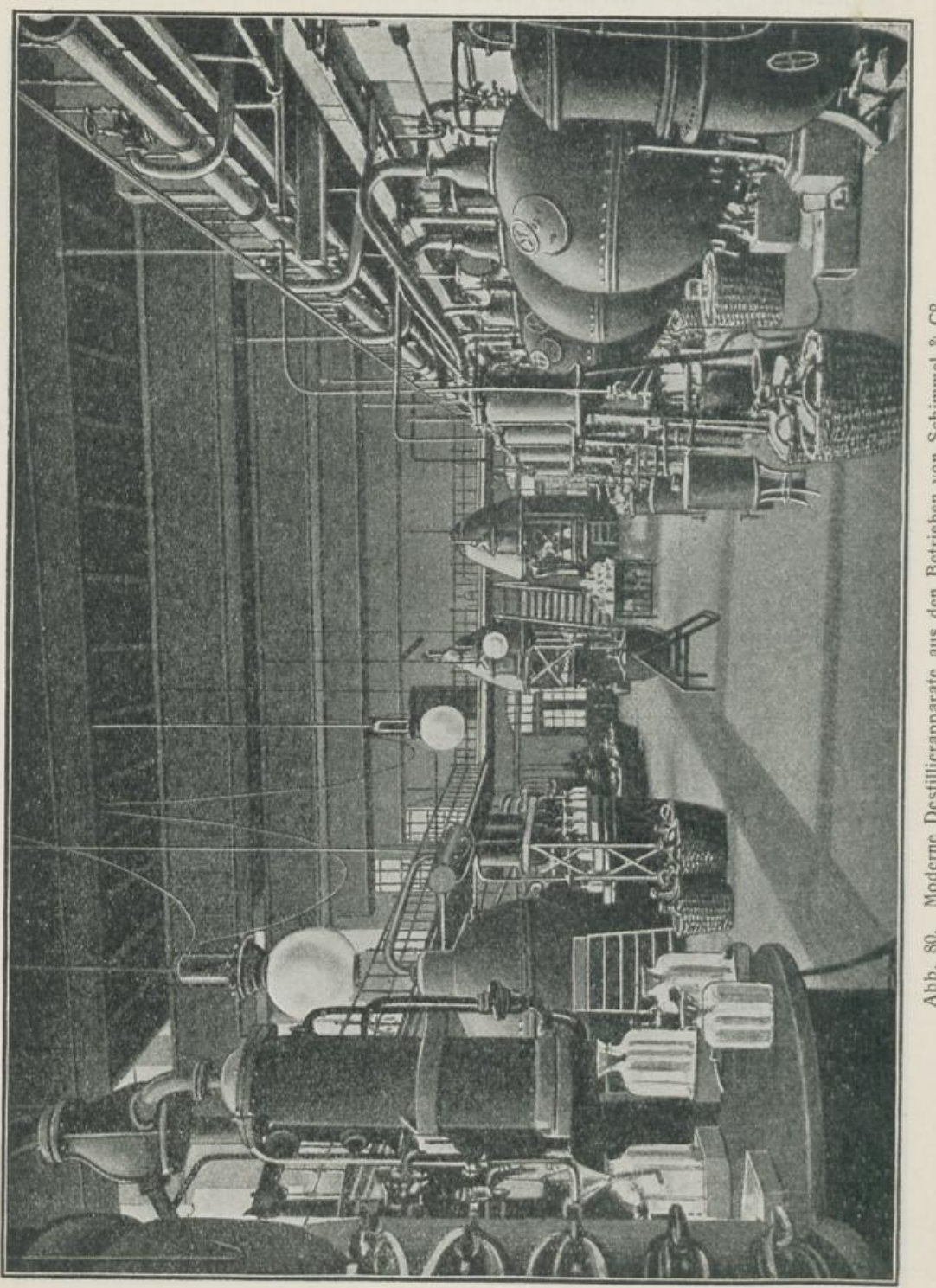




$$
-103-
$$

Auf ganz ähnlichen Grundlagen beruhen die kleinen Digestions- und Extraktionsapparate, die zumeist zu analytischen Zwecken benutzt werden und als Menstruum, [ursprünglich die monatliche, durch Verflüssigen und Lösen bewirkte körperliche Reinigung, die immerhin auch eine Art Destillation war. Vgl. unten S. 120. Ernsting erklärt: Von Mensis, weil die Alten zu ihren Auf-

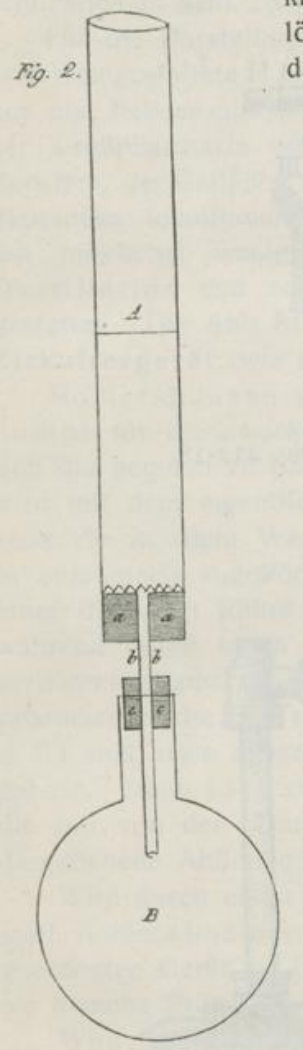

Abb. 81. Döbereiners Extraktionsgerät. lösungen gelinde Auflösesäfte genommen, welche daher lange in der Digestion stehen mußten, ehe und bevor solche Körper

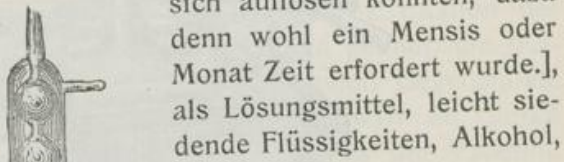

Äther, Chloroform, Benzin und dgl. in Anwendung ziehen. Döbereiner war wohl der allererste, der in seinem Schriftchen „Zur mikrochemischen Experimentierkunst", Jena 1821, eine Vorrichtung, bestehend aus einem Kölbchen, auf dem ein sich nach obenhin erweiterndes Rohr befand, empfahl. In letzteres kam die zerkleinerte Droge oder dgl., in dem Kölbchen wurde das Lösungsmittel zum Sieden gebracht. Seine Dämpfe 


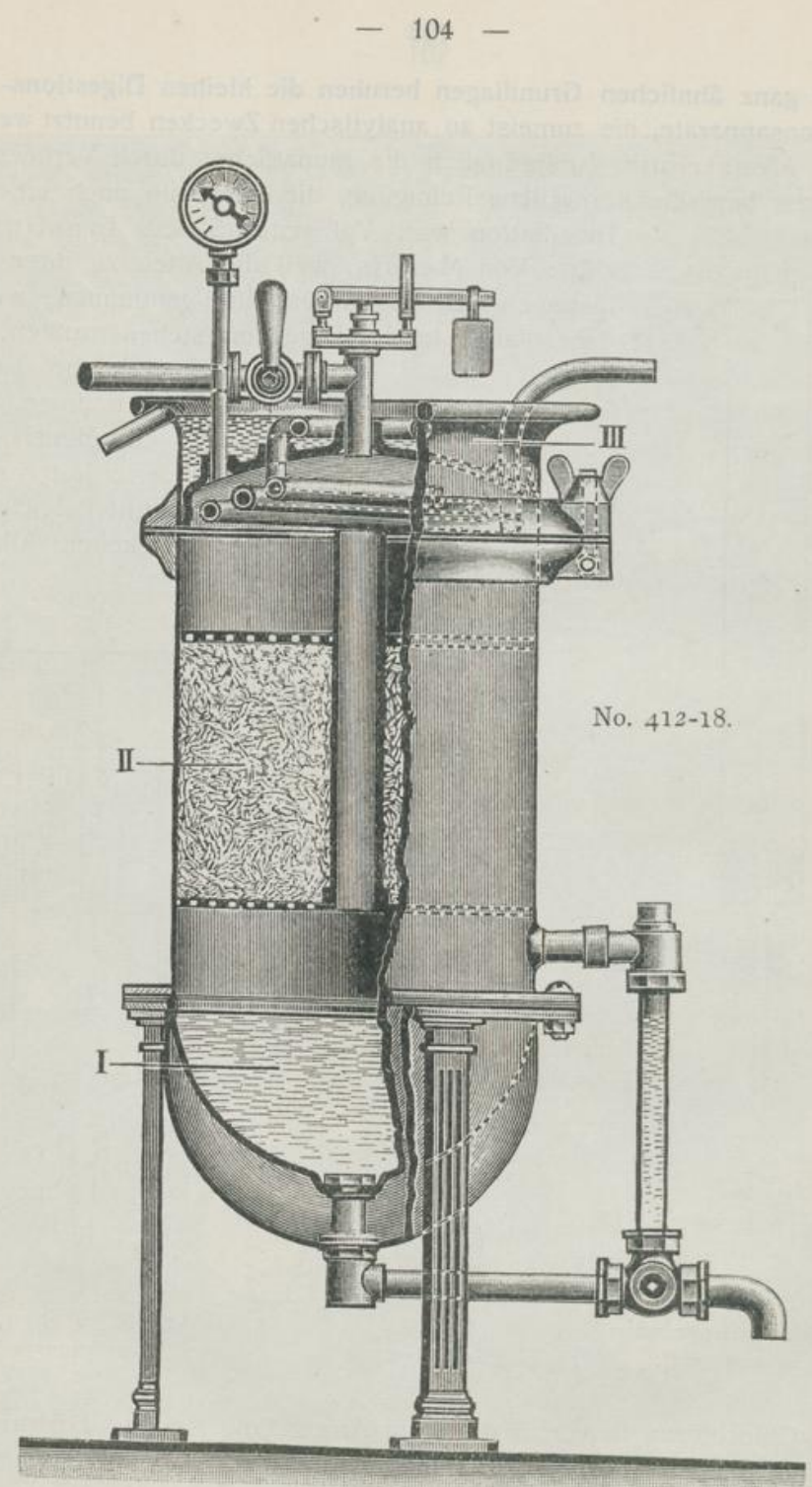

Abb. 84. Extraktionsgeralt der Firma E. A. Lentz in Berlin. 
durchweichten sie, verdichteten sich in einem, das weite Rohr verlängernden Rohr und fielen, wenn die Lampe fortgenommen wurde und durch die Verdichtung der Dämpfe des Lösungsmittels eine Luftverdünnung eingetreten war, dadurch heruntergesaugt, in das Kölbchen zurück usw. ${ }^{1}$ ).

Diese Gerätchen fanden eine Unmenge Um- und Ausgestaltung und schließlich in dem "Soxhlet" ihre kaum zu übertreffende Verbesserung.

Für die Darstellung ätherischer Extrakte im pharmazeutischen Laboratorium gestaltete Hager das Döbereinersche Gerät 1862 entsprechend aus und ließ es aus Weißblech anfertigen. Für die moderne Arbeitsstätte der Großpharmazie oder der chemischen Fabriken (zur Extraktion der Knochen, der Galläpfel usw.) wurden Riesen erdacht und gebaut, die fortdauerndes (continuierliches) Ausziehen der betreffenden Gegenstände mit möglichst wenig Lösungsmittel, sein Wiedergewinnen durch Destillation und schließlich Abdampfen des Auszugs (im Vacuum) gestatten. Die Abb. 84 zeigt ein modernes, in wahrem Sinne des Worts, Zirkuliergerät, wie es die Firma E. A. Lentz in Berlin baut.

Romershausen scheint der erste gewesen zu sein, der die Luftpumpe für die Zwecke der Luftverdünnung heranzog. Sie, in moderner Zeit die bequem $\mathrm{zu}$ handhabende Bunsensche Wasserstrahl-Pumpe, wird mit dem eigentlichen Destilliergerät in einer Art in Verbindung gesetzt, die in allem Wesentlichen darauf beruht, daß der Abfluß luftdicht in eine meist kugelförmig gestaltete Vorlage führt, die nach unten mit einer dünneren Röhre luftdicht auf dem Aufnahmegefäß angebracht ist, während durch einen oberseits angebrachten Tubus das Rohr des Luftverdünnungsapparats eingeführt ist ${ }^{2}$ ). Auch diese Geräte wurden für die pharmazeutische und erst gar technische Großindustrie (Zuckerfabrikation z. B.) aufs beste ausgestaltet und ebenfalls in riesenhaften Abmessungen gebaut. Einen Laboratoriumsapparat mit aufgeschliffenem Glashelm zeigt die mir von der Firma Warmbrunn \& Quilitz in Berlin freundlichst dargeliehene Abildung 86 S. 106.

Wird durch einen Tubus im Helm oder in der Blase ein Gas (Wasserstoff, Kohlensäure oder dgl.) eingeführt, so kann in dem sonst ebenso angeordneten Gerät die Destillation im Wasserstoff- und dgl. Strom, wie sie manche Präparate fordern, vorgenommen werden.

Wird das Auffangegefäß so sinnreich gestaltet, wie es z. B. Brühl (Ber. d. chem. Gesellsch. 1888, S. 3339) oder Raikow (Chem. Ztg. 1888, S. 693) getan, so ermöglicht es gleicher Zeit das Auffangen von Fraktionen") unter solchen Vorsichtsmaßregeln. Vgl. Abb. $88^{2}$ ).

1) Ich nannte in meiner Geschichte d. Pharm. noch E. F. Anthon als ersten auf diesem Gebiete, Er leitete den überdestillierenden Weingeist seitwärts in eine Vorlage, aus der das Destillat wieder durch die bei der Abkühlung entstandene Luftleere zurückgesaugt wurde.

2) Die Abbildung 85 und einige weitere stellte mir dic Firma E. Leybold Nachf. in $K o ̈$ In freundlichst zur Verfügung.

3) Vgl. oben S. 70 . 


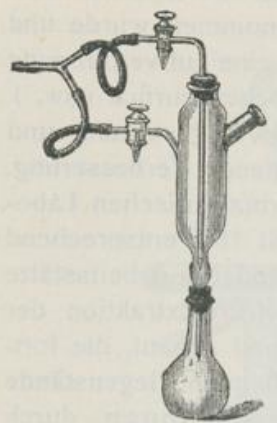

Abb. 85. Vorlage für Laboratoriumsdestillation unter vermindert. Druck.
Hier muß noch einer Art von Vorlagen gedacht werden, die einerseits gestatten sollen, daß das gasförmige Destillationsprodukt in möglichst großer Menge von einer ,vorgelegten" Flüssigkeit aufgenommen (gelöst, absorbiert) wird, daß andrerseits durch das Durchstreichen der vorgelegten, nötigenfalls verschiedenen Flüssigkeiten verunreinigende Beimengungen zurückgehalten werden, um ein reines Produkt durch solches "Waschen" zu erhalten. Wie Icilio Guareschi in seiner schon erwähnten Storia della chimica und zwar in der Lebensbeschreibung von Angelo Saluzzo auf S. $467 \mathrm{ff}$. nachweisen konnte, hat dieser geistvolle Gelehrte im Jahre 1759 schon bei der Darstellung von Ammoniakgas Auffangegefäße

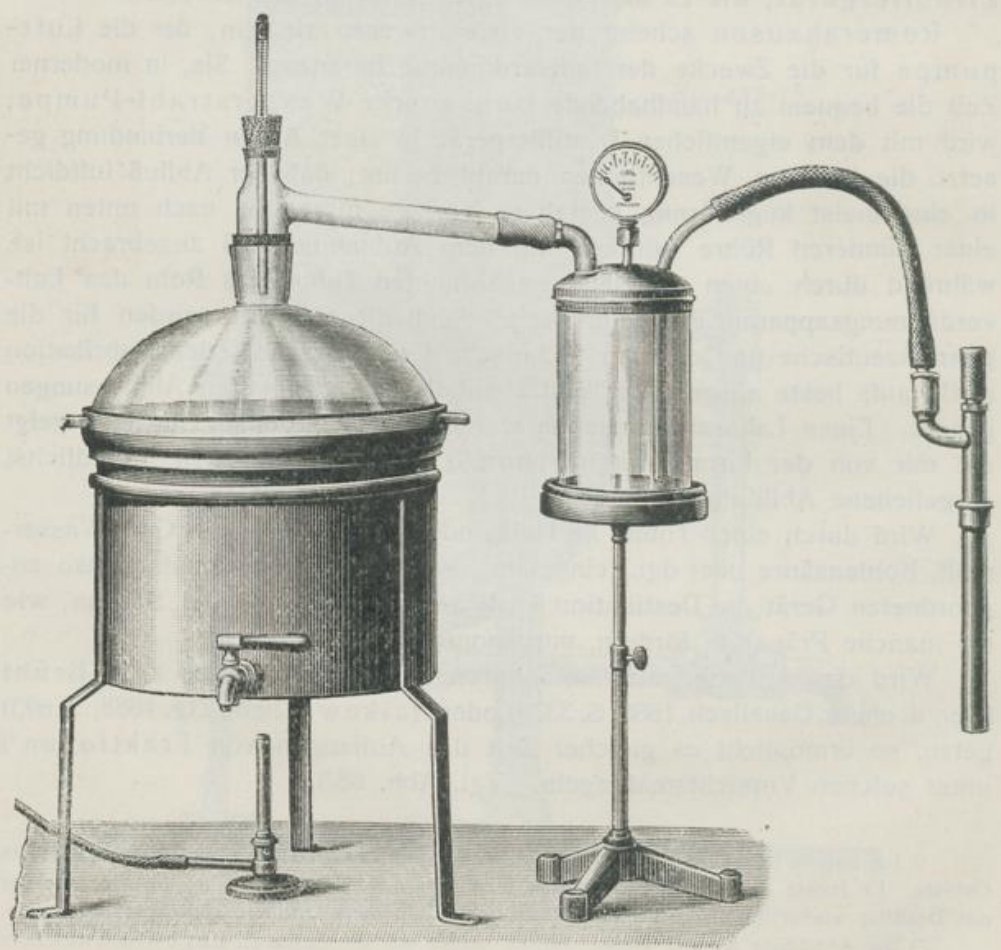

Abb. 86 .

Gerät zum Destillieren im luftverdünnten Raum von Warmbrunn \& Quilitz in Berlin. 
mit 2 und 3 Tubuli angewandt (wie sie die Abb. 91 u. 92 zeigen), die den im Jahre 1767 erst von Woulfe gebrauchten und empfohlenen wesentlich überlegen sind und den in den letzten Jahrzehnten gebrauchten, von den Abb. 88 u. 89 wiedergegebenen, völlig ähneln.

Die Arbeit des Sublimierens (oder seltener des exaltare) stimmt im wesentlichen mit der des Destillierens überein. Lémery erklärt sie als "faire monter par le feu une matière volatile au haut de l'alembic ou au chapiteau". Daß er diese Erklärung aber bei der Vorschrift für die Sublimation des Zinns gibt, zeigt, daß er die Arbeit auf feste Körper beschränkt wissen will. Er läßt einen Teil Zinn und zwei Teile Salmiak in einer

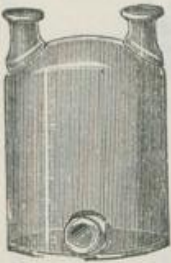

Abb. 88. Moderne Woulfesche Flasche mit zwei Halsen u.Tubulus am Boden.

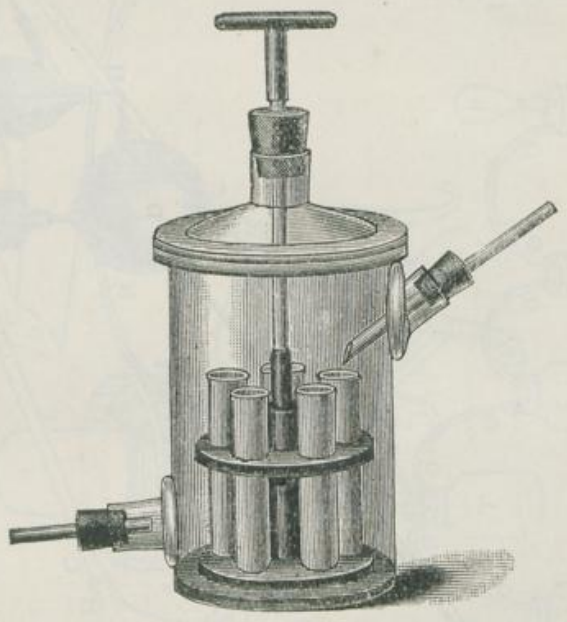

Abb, 87, Vorlage für Destillation im luftverdünntem Raum Auffangen cinzelner Fraktionen nach $\mathrm{Brühl}$.

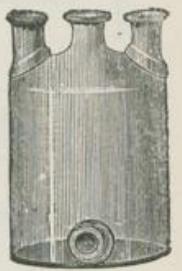

Abb. 89. Moderne Woulf esche Flasche mit drei Hälsen u.Tubulus am Boden.

Curcurbita mit aufgekittetem blinden Helm (Chapiteau) erhitzen, sodaß die „flüchtigen" Zinnblumen dort sich absetzen ${ }^{1}$ ). Auch Joh. Schröder betont, daß es sich um trockene Körper handelt: Rem volatilem siccam in sublimi elevare, ut seorsim haberi possint, und er setzt zu: Res illa elevata vel Sublimati nomine effertur vel florum nomen adsciscit $=$ die, begreiflicher Weise nicht abgetröpfelten Ergebnisse der Arbeit nennt man (nach Westrumb, wenn sie „dicht sind“) Sublimate oder Blüten [weil man in der Natur ausblühen, eflorescieren beobachtet hatte bei den blumenähnlichen Gebilden, die bei Frost an den Fenstern anschossen, beim Alkali minerale, das in der Nähe von Salzseen ausblühte usw.], Flores

1) Vgl, unten die Planche seconde Fig. $k$ von Lémery. Abb. 102. 
chymici (nach Westrumb, wenn sie locker sind). Die für solche Arbeiten nötigen Geräte unterschieden sich nur unwesentlich von denen, die $\mathrm{zu}$ Destillationszwecken gebraucht wurden. Da der Erstarrungspunkt der

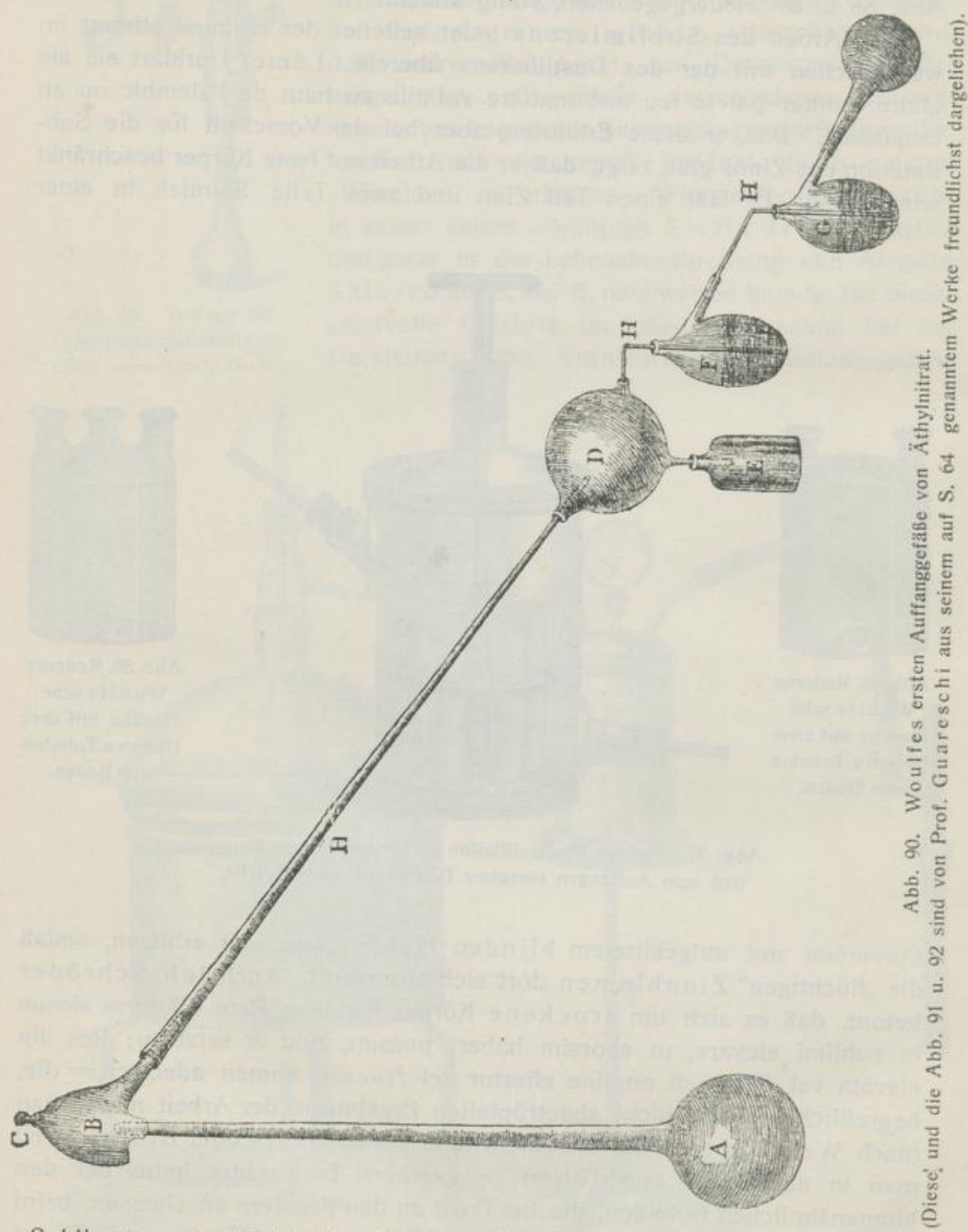

Sublimate wesentlich höher liegt als der flüssiger Körper, brauchte man keine lang sich erstreckenden Abkühlungsvorrichtungen. Dicht über dem Gefäße mit dem zu verarbeitenden Gut konnte das Aufnahmegefäß sitzen 


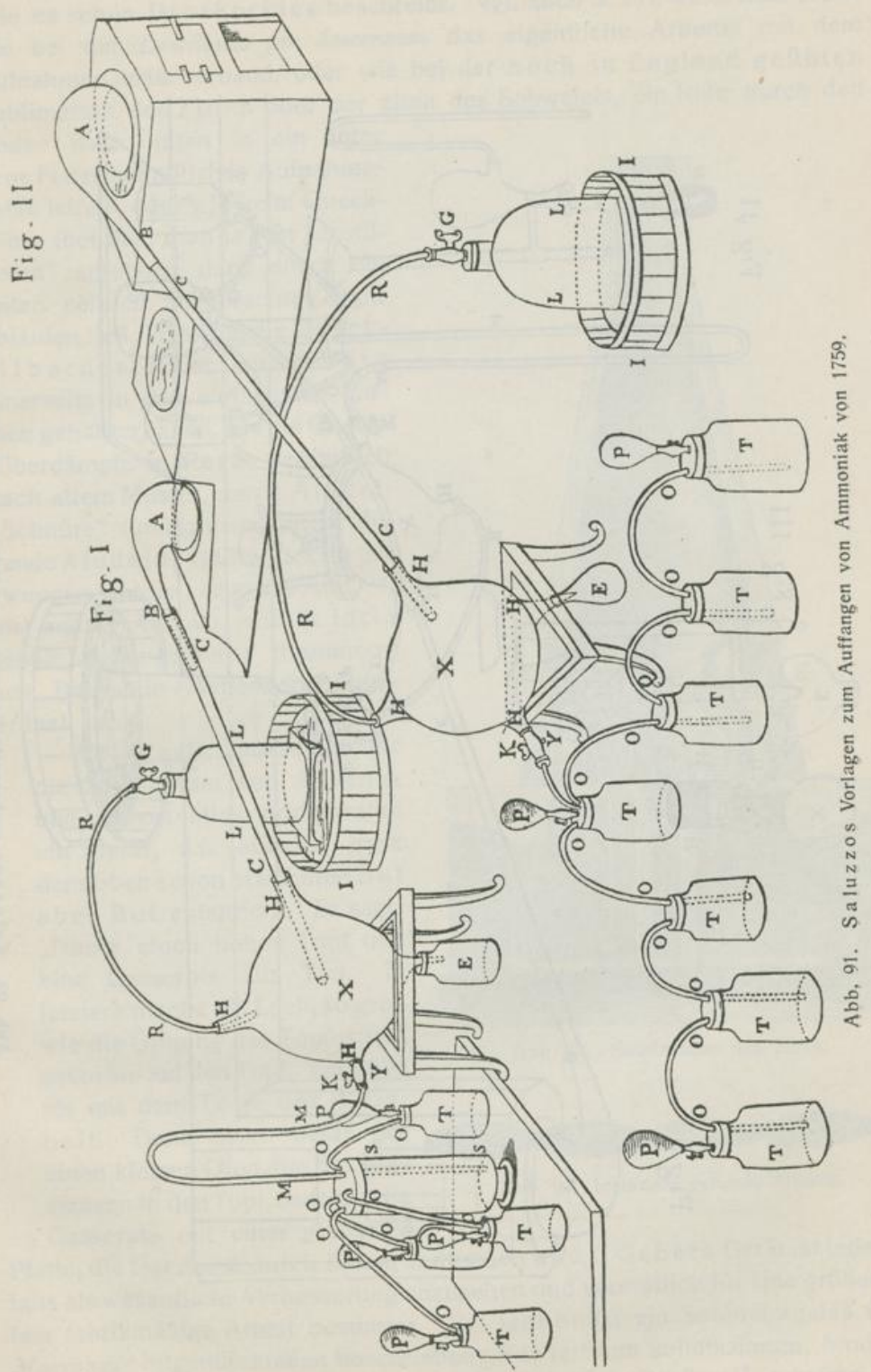




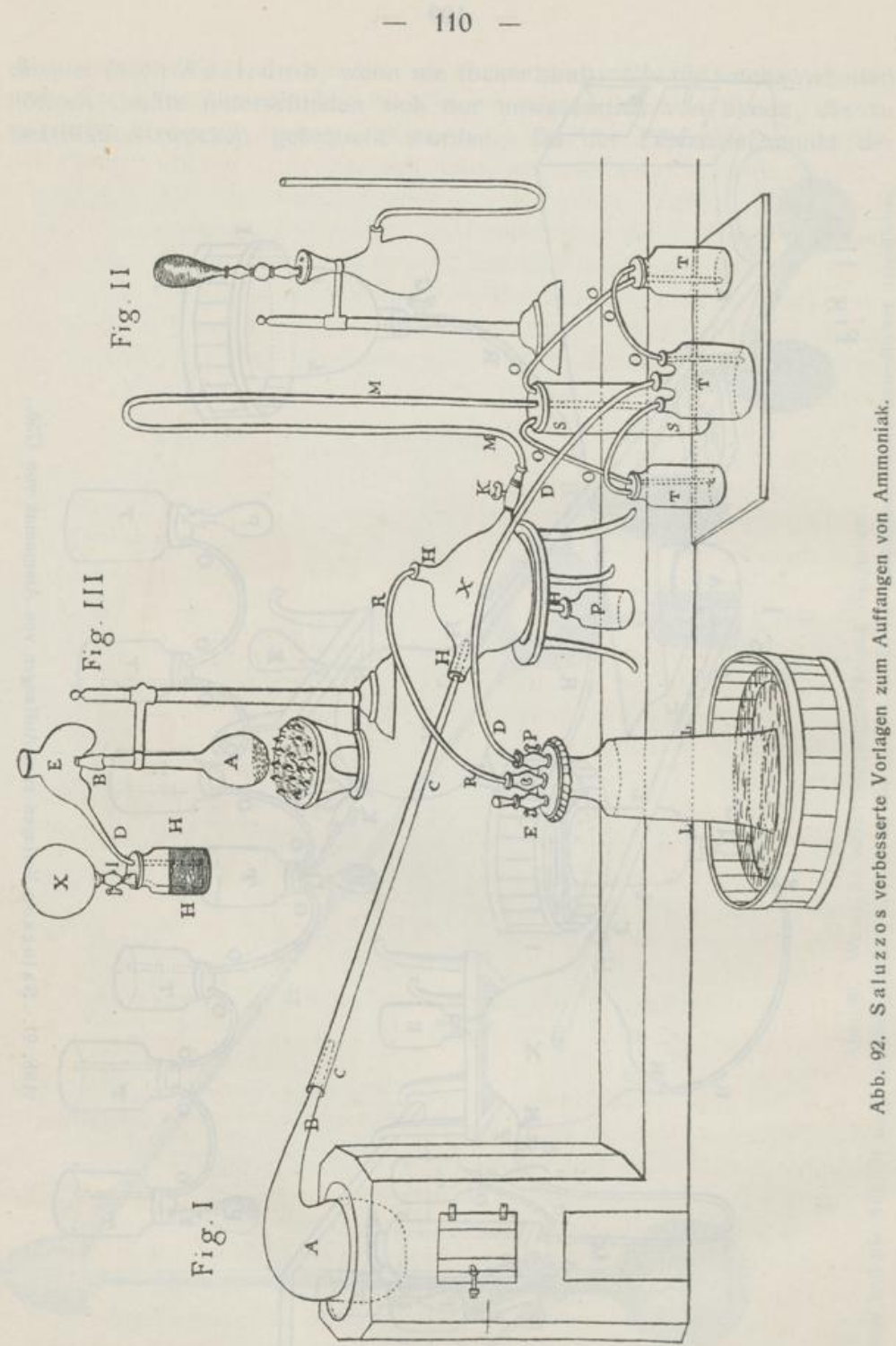


(wie es schon Dioskorides beschreibt. Vgl. auch S. 11), wenn man nicht, wie bei der Destillatio per descensum das eigentliche Arbeits- mit dem Aufnahme-Gefäß verband, oder wie bei der noch in England geübten Sublimation des Zinks oder der alten des Schwefels, ein Rohr durch den Boden nach unten in ein unter dem Feuer befindliches Aufnahmegefäß leitete, oder wie beim Quecksilber (bei dem man ja von "destillieren" sprechen darf) durch ein unten seitlich angebrachtes Rohr ablaufen ließ. Wie sich die Quecksilberdestillationsgeräte einerseits in den einfachsten Formen gehalten haben, wie die Quecksilberdämpfe in Peru, vermutlich nach altem Muster, durch Aludel"Schnüre" (ineinandergetutete liegende Alu de ln, vgl.unt.S.115) gezwungen wurden, zeigt die Abb. 94, die andre, Abb. 95, wie in Idria große Auffangeräume (Kammern) aus Backstein-Mauerwerk angeordnet sind.

Abulkasis beschreibt für die Sublimation von Arsenik und andern Mineralpräparaten ein Gerät, das offenbar ganz dem oben schon erwähnten But eber But entspricht. Er sagt: „Nimm einen hohen Topf und eine Casserole aus Ton. In letztere mache ein Loch, so groß wie die Öffnung des Topfes und setze sie auf den Topf. Verklebe sie mit dem Tone der Weisheit. Dann setze beide auf einen kleinen Ofen, tue die Substanzen in den Topf, bedecke die

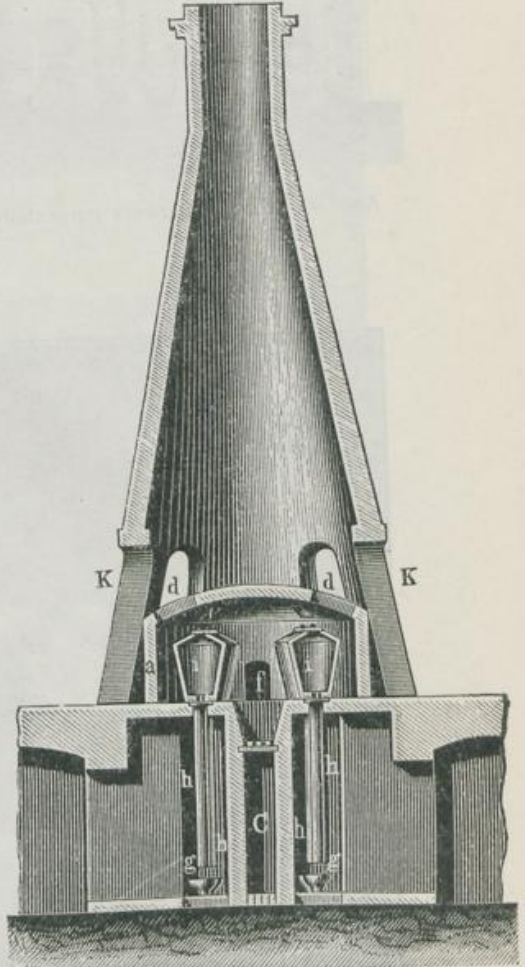

Abb. 93. Sublimation des Zinks.

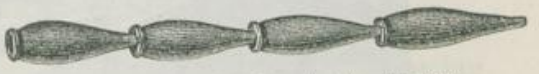

Abb. 94. Ineinandergetutete Aludeln. Casserole mit einer glasierten

Platte, die fest damit durch Lutum verbunden wird." Gebers Gerät ist jedenfalls als wesentliche Verbesserung anzusehen und vermutlich für eine größere, fast fabrikmäßige Arbeit bestimmt. Bei Geber ist ein Sublimiergefäß für Marchasite folgendermaßen beschrieben: Vas ferreum solidissimum, fundus ad similitudinem parapsidis [etwa in der Art einer Schüssel], separari et 


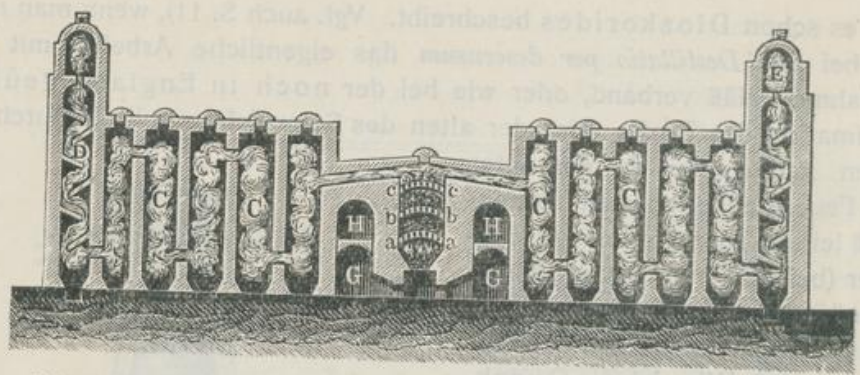

Abb. 95. Aus Mauerwerk hergestellte Quecksilber-Destillationsvorrichtung.

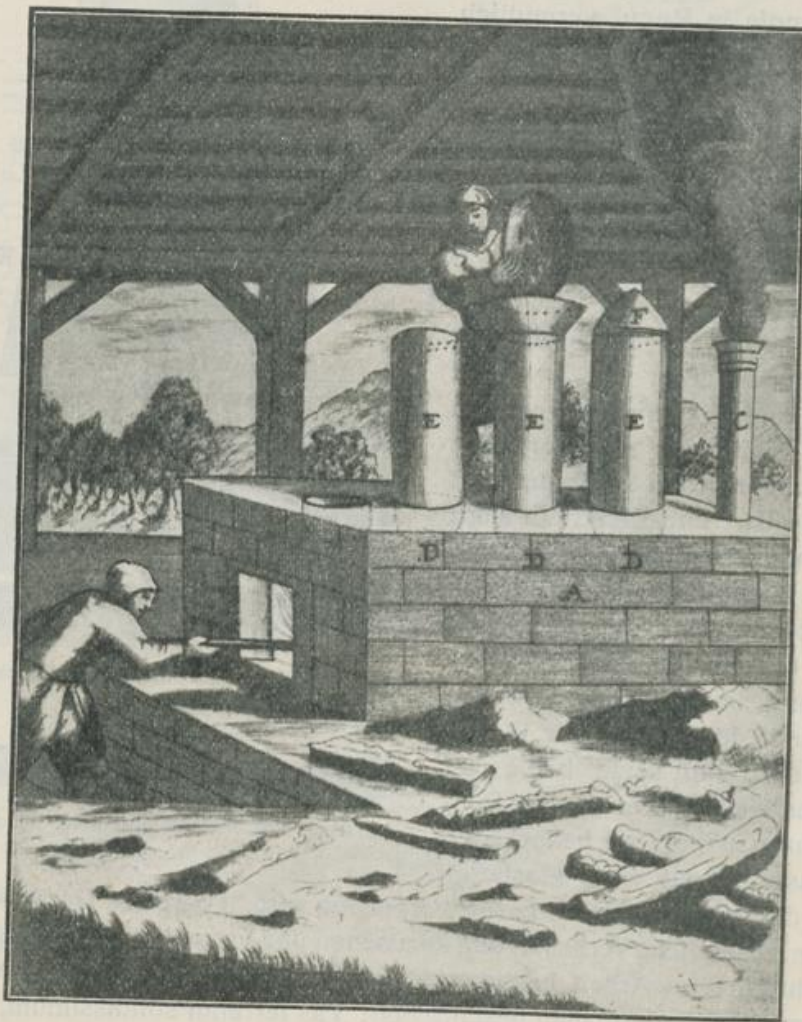

Abb. 96. Kunckels Arsenik-Sublimierofen. 
conjungi possit, vitrificetur. Und auf dieses eiserne, glasierte Gefäß wurde erst, wie die Abbildung, die vielleicht nach einer Zeichnung in der Handschrift oder nach der Beschreibung angefertigt ist, eine zylindrische Erhöhung und schließlich noch ein Alembik als Auffanggefäß mit weiter

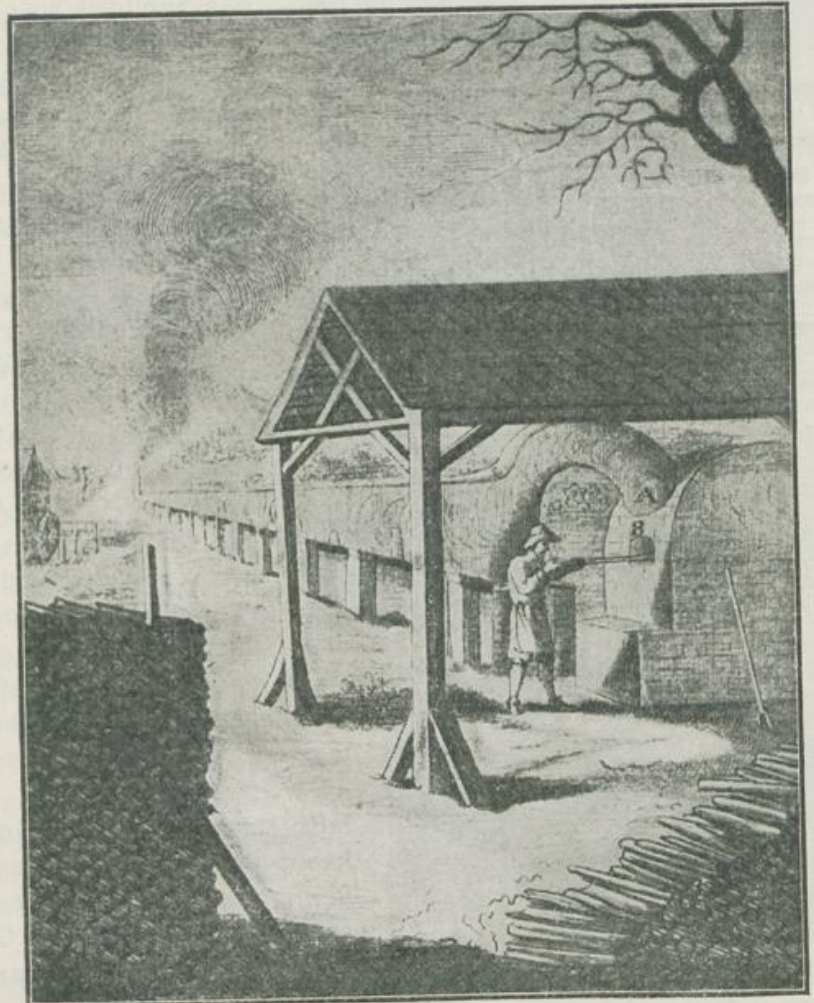

Abb. 97. Auffangeröhren für „Hüttenrauch".

Ablaufröhre, „cum lato nasu" gesetzt, aus welchem gasförmige Produkte entweichen konnten.

Im wesentlichen diesem Gerät nachgebildet ist das für Arseniksublimation empfohlene und von Kunckel') abgebildete. $D$ zeigt das einer Parapsis ähnliche Gefäß zur Aufnahme des zu sublimierenden Gutes. Darauf steht

1) Johannis Kunckelii, Ars vitraria, experimentalis, Frankfurt und Leipzig, 1680, Abb. C auf S. 47 , hier Abb. 96, S. 112. 


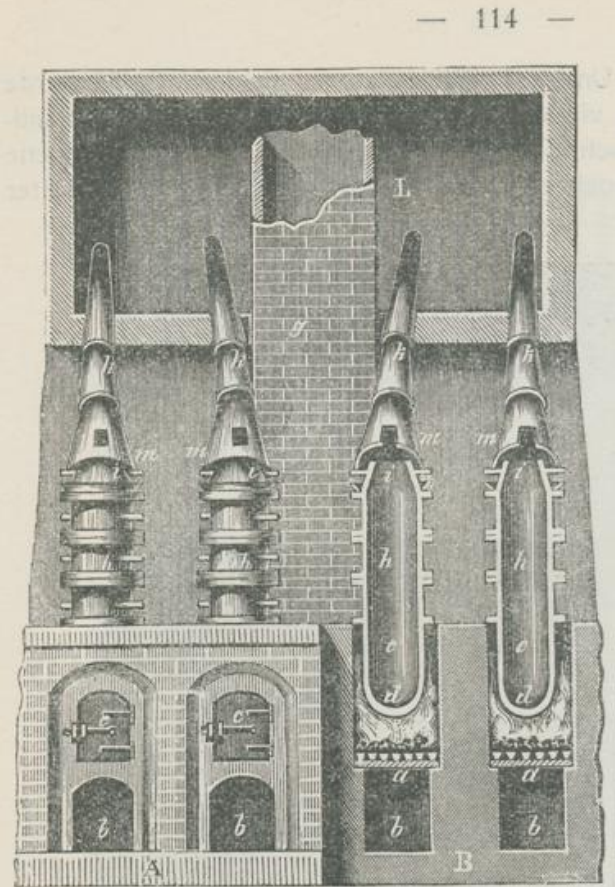

Abb. 98 . Gifttürme.

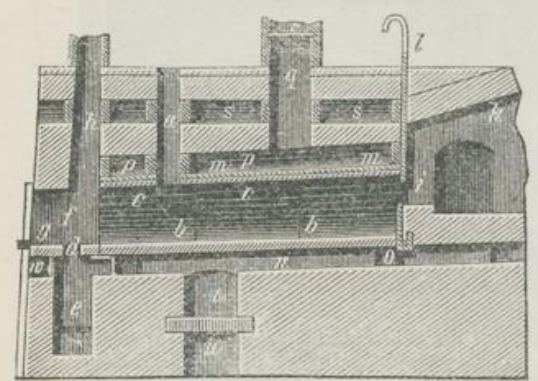

Fig. 99. Fast wagerechter Arsenik-Destillationsofen. die zylindrische Verlängerung, durch die das Gut mittels einer Art Trichter geschüttet wird. Der Deckel schließt sie $a b$ und nimmt das Sublimat auf.

In langen Vorlagen, wie sie die Abbildungen zeigen, aus Mauerwerk dargestellten Rohren ähnlich, fing Kunckel ${ }^{1}$ ) sein Giftmehl auf. Heutzutage führt man die Dämpfe zweckmäßiger in Räume, die in einem Gebäude, wie Stuben, neben- und übereinander angeordnet sind und schließlich in einem Schornstein nach außen führen ${ }^{2}$ ). Daß schon Geber Arsen, das zum mindesten in seinen Schwefelverbindungen, vermutlich aber auch (da man es schmolz, erhitzte usw.) in den Sauerstoffverbindungen dem Altertum bekannt war, zu sublimieren lehrte, daß es weiter im XV. Jahrh. jedenfalls schon als Hüttrauch bekannt und gefürchtet war, läßt vermuten, daß es sicher früher schon hüttenmäßig im Großen dargestellt und in Giftkanälen aufgefangen worden ist. ${ }^{3}$ )

Schon in ältesten Zeiten sêtzte man, wie Ausgrabungen auf altklassischem Boden ergeben haben,

1) Abb, 97 nach Kunckels Fig. B S, 45.

2) Die Abb. 98 zeigt senkrechte „Gifttürme", wie sie z. B. in Reichenstein und Andreasberg in Anwendung kommen (sie erinnern an die Geber-Kunckelschen Geräte), die $\mathrm{Abb}, 99$ ein wagerecht gelagertes Sublimationsgerät. Die Dämpfe werden in Kammern geleitet, die, wie die Abb. 100 zeigt, angeordnet sind.

3) Vgl. in meiner Gesch, d. Pharm, auf S, 347 die Nürnberger Verordnung bez, der Überwachung des Giftverkaufs

W

Ro

Bo

kaı

lär

de!

off

Gr

ihr

le

$\mathrm{Sa}$

16.

$\mathrm{n}$ i

ha

in

wi

ar

la!

w:

lic

m

ih

ur

ül

fä

ut

lo

ol

A

w

äı

ei

$\mathrm{Zt}$

$\mathrm{F}$

u

L

si 
Wasserleitungen in der Art zusammen, daß man konisch zulaufende Rohre, gelegentlich in späterer Zeit geradezu flaschenförmige Gefäße, deren Boden fehlte, ineinander tutete. Selbst wenn sie solche Beispiele nicht kannten, lag es auf der Hand, daß die arabischen Alchemisten, um größere, längere Aufnahmeräume für ihre Arbeiten zu schaffen, anstatt eines $\mathrm{Al}$ atal, der anhanglosen Sublimations-Vorlage, deren eine ganze Anzahl, oben offene übereinander setzten oder, da das jedenfalls aus mancherlei Gründen zweckmäßiger war (sie lagen ohne weiteres sicher, man konnte ihre Reihe nach Belieben noch weiter verlängern), hintereinander legten. Solche Annahme zwingt geradezu zu der Annahme, daß Alonzo Saavedra Barba in Peru 1633 den Aludelofen nicht erfunden hat. $\mathrm{Er}$ hat ihn vermutlich nur so in Neu-Almaden eingeführt, wie er in dem spanischarabischen Almaden schon lange in Gebrauch gewesen war. Libav stellt tatsächlich ein Aludel-Sublimations-Gerät dar, ohne ihren Namen zu nennen, und er endigt die Reihe der übereinander gebauten $\mathrm{Ge}$ fäße, die einem oben und unten offenen, anhangslosen Helmähneln, in einem oben geschlossenen Caput Arimaspinum [Arimaspi waren ein Fabelvolk im

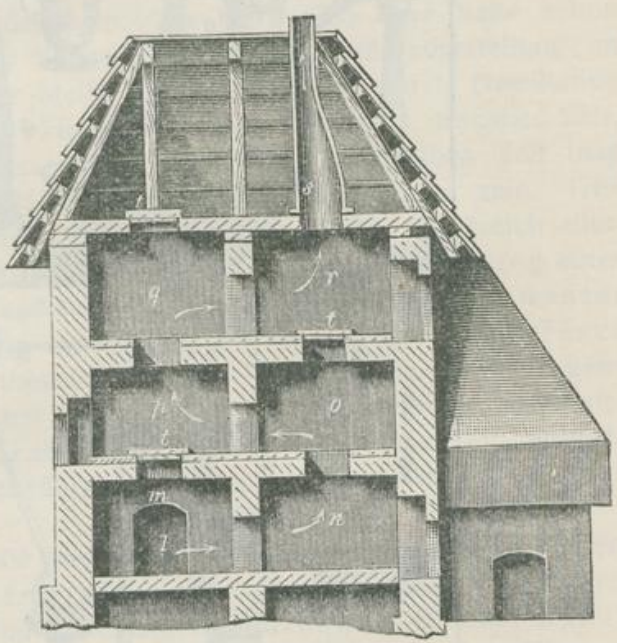

Abb, 100. Auffangekammern für Arseniksäure. äußersten Nordosten des Reichs, in Skythien] oder Cyclopium, das also einen „blinden" Schluß darstellte. Lémery bringt ein ähnliches Gefäß zur Anwendung, dessen Zwischenteile er schon Aludeln nennt. Die Figuren $t, u, x$ auf Abb. S. 116 zeigen es. Vgl. auch die Abb. 94 S. 111. Daß man in einfachster Art auch Benzoesäure sublimierte (Mohr und Hager empfahlen später dieselbe Art, die sie vermutlich in ihren Lehrstellen kennen gelernt hatten, in denen sie, wie Handwerksgebrauch, sich von einem Apothekenbesitzer auf den andern, häufig vom Vater auf den Sohn fortgepflanzt hatte) zeigt eine Abbildung bei Lémery. Als Auffangegefäß ist, übrigens auch wieder nach einer noch älteren Vorschrift bei Turquet de Mayerne und Libav, einfach über den Tiegel eine spitze Papiertute befestigt ${ }^{1}$ ). Von Zeit zu Zeit sollte sie durch eine andre ersetzt

1) Vgl. auf Abb, $101 \mathrm{~g}, \mathrm{~h}$, ferner i, k, 1 ein Sublimationsgerät mit einem Chapiteau aveugle, einem blindgemachten Helm. 
werden, um die später oder bei zu großer Hitze, von gleichzeitig aufsteigendem Öl gelbgefärbten Blüten, wie dort steht: die durch eine „Exaltation" gewonnenen "Sels volatiles", getrennt zu gewinnen. Wenn Lémery weiter sagt, die "Fleurs" hätten eine ,äcidité fort agréable", so denkt er dabei nicht an ihre Säureeigenschaften in späterm und modernem Sinn. Trotzdem

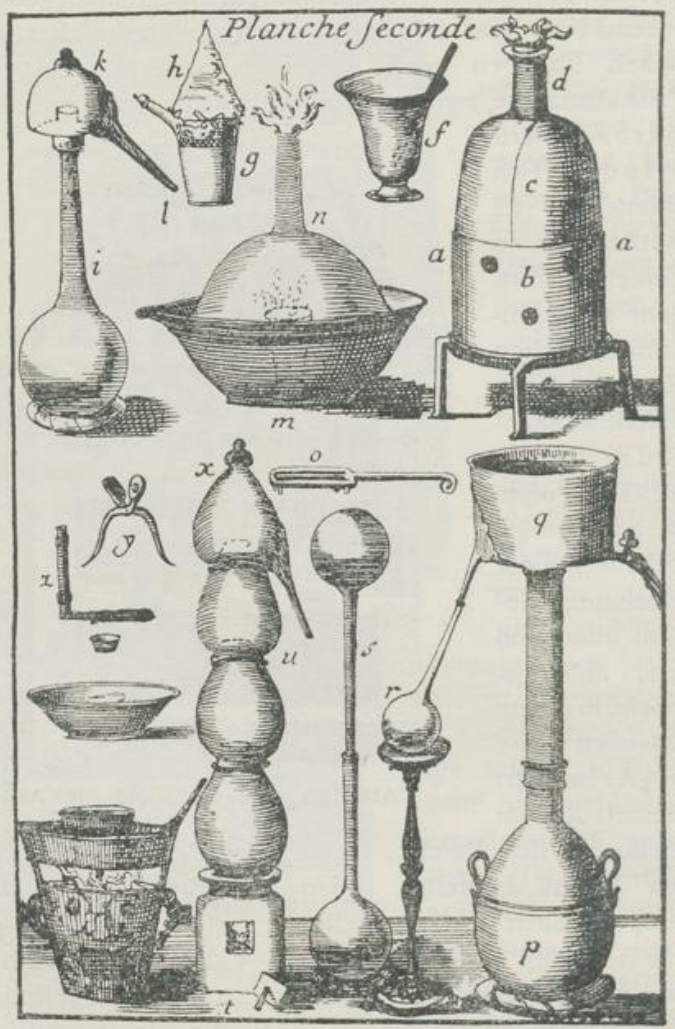

Abb. 101. Nach Lémery.

Tachenius zur gleichen Zeit schon auf die prinzipiell entgegengesetzten Bestandteile der Salze hingewiesen hatte, spricht erst Caspar Neumann von Acida, und erst nach Lavoisier fangen sie die ihnen gebührende Rolle zu spielen an.

Später band man über das untere Gefäß ein Stück Gaze, um rückfallende Benzoe-Blüten zurückzuhalten. Die moderne Technik ersetzte 
die Tuten durch große Holzkästen, hinter welche nötigenfalls eine Reihe weiterer, durch Rohre miteinander verbunden, gelegt wurden, nicht unwahrscheinlich nach dem Muster der Giftkanäle oder der noch älteren Salmiakauffangegefäße.

Von Spezialgeräten, die hierher gezählt werden müssen, sind die für die Darstellung des Spiritus Sulfuris, eines in der ersten Zeit recht schwachen und unreinen Acid. sulfuricum zu nennen. Von bei der Darstellung des Oleum Vitrioli [so genannt, weil es aus glasähnlichem Vitriolum bereitet wurde] gebrauchten galeerenförmig angelegten, zumeist Tonretorten und Vorlagen wurde schon gesprochen. Im Großen soll solche Destillation (nach Darmstädter) im Jahre 1792 von Joh. Dan. Stark, jedenfalls in Deutschland eingeführt worden sein. Im Jahre 1755 aber hatte schon Joh. Chr. Bernhardt über Schwefel- und Salpetersäuredarstellung im Großen geschrieben, und er stellte im selben Jahre durch Destillation stark dampfender Vitriolsäure ein weißes, flüchtiges, trocknes Salz, Sal volatile olei Vitrioli, wasserfreie Säure, dar. Zur selben Zeit mag rauchende Säure schon in Nordhausen destilliert worden sein. 1782 nennt sie jedenfalls Macquer $(\mathrm{V}, 477)$ als bekanntes, in Frankreich allerdings noch nicht dargestelltes Präparat. 1715 wird von dem Privileg eines "Laboranten" König ${ }^{1}$ ) in Magdeburg für Darstellung von Scheidewasser berichtet, und in Lille führte seine Fabrikation durch eine Witwe Tesca und später durch die Apotheker im Jahre $1750 \mathrm{zu}$ Beschwerden seitens der Besitzer der benachbarten Grundstücke. Dementsprechend beschreibt auch Demachy in seinem ,Laborant im Großen" Galeerenöfen, darunter vervollkommnete für immerwährenden Betrieb, und bildet sie ab. Vgl. Abbildung 41.

Schon Porta lehrt 1609 ein Oleum sulphuris per campanam bereiten, und zwar so, wie später Lémery ${ }^{2}$ ) es mit seiner "Maschine" für Esprit de Soulfre, und nach ihm viele andre (Schröder z. B. unter Spirit. Sulfuris Clossaei) zu tun empfahlen, wie es übrigens meines Wissens auch in der Technik viel später noch für Phosphorsäure in Anwendung kam und vielleicht noch kommt. Vgl. die Fig. $n, m$ auf der Planche seconde aus seinem Cours de Chymie, Abb. 101.

Schwefel wird in einer Schale unter einer darübergestülpten, unten etwas abstehenden Glocke oder einem Trichter von wenig geringerem Durchmesser verbrannt. Die sich unter ihm ansammelnde Flüssigkeit entsprach unsrer Schwefelsäure natürlich nur in geringem Maße. Ein jedenfalls wesentlich besseres, stärkeres Präparat, ein Huile de Soulfre, erzielte er dadurch, daß er in großer bedeckter, teilweise mit Wasser gefüllter Schale in einer darin stehenden, das Wasser überragenden

${ }^{1)}$ Vgl. auch meine Gesch. d. Pharmacie S. 596.

2) Beiläufig sei gesagt, daß er angibt „Gutta una olei vitrioli (also der aus Vitriol destillierten Säure) quotidie vino albo mane assumpta, pingues homines demacrare facit". Es galt ihm also die mit Weißwein vermischte Säure als Entfettungsmittel. 
Glocke je 4 Pfd. Schwe fel und 4 Unzen Sal peter mit einem glühenden Hufeisen entzündete und diese Operation genügend oft wiederholte. Schröder nennt das auf diese Art gewonnene Präparat, den wahren Vorläufer der späteren englischen Schwefelsäure, Spiritus campanarius [campana, die Glocke] facillimus S. Closs(aei).

Unter Zugrundelegung dieser Arbeitsart gründete, jedenfalls in der Mitte des XVIII. Jahrhunderts, Ward unter Anleitung von Drebbel in Richmond eine Schwefelsäurefabrik, der später ähnliche in Holland, in

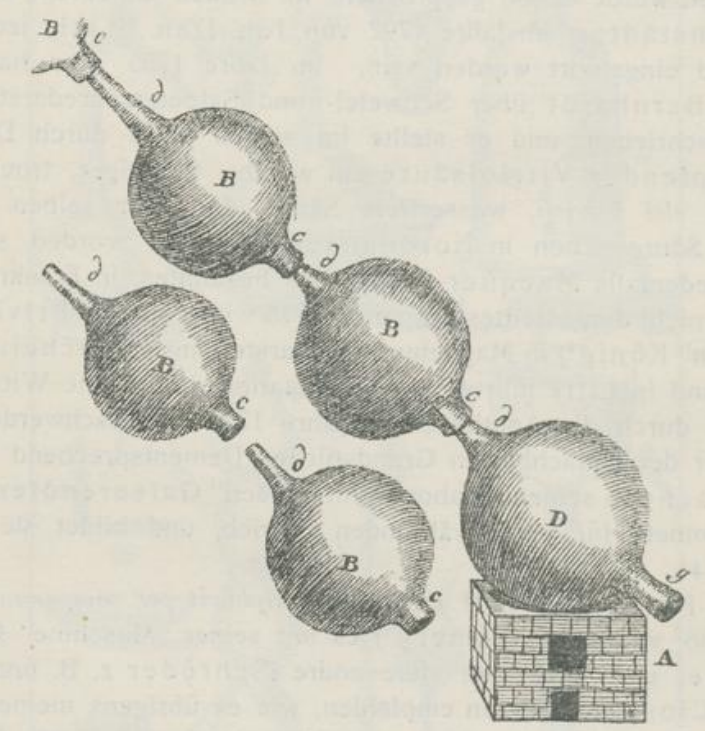

Abb. 102. Schwefelsäuregerät nach Demachys Laborant im Großen.

Rouen usw. folgten. Sie wollten den jedenfalls schon großen Bedarf, insonderheit der Indigofärber, decken. Demachy beschreibt die Methode, die der zweiten von Lémery fast gleich ist, nur läßt er einmal die Verbrennung in großen Glasballons vornehmen, in deren Tubus das Gemisch von Schwefel und Salpeter mit einem langen irdenen Löffel hineingelangt ward, dessen Ende so eingerichtet war, daß es ihn pfropfenähnlich schloß. Solche Ballons würden bis zu einem Oxhoft groß geblasen und zwar in der Art, daß der Glasbläser schließlich den Mund voll Wasser nähme und dieses in den noch kleinen Ballon hineinpustete, was zur Folge hätte, daß es, dampfförmig geworden, sich weit ausdehnte und die gewünschte Form erzeugte. 
Dann gibt er noch eine verbesserte Methode an. Er stürzt mehrere solche Ballons mit ihren einmal nach außen erweiterten, einmal verlängerten etwas ausgezogenen Tuben wie Aludeln ineinander, und in dem ersten Ballon, der auf einem Herd erhitzt wird, nimmt er die Verbrennung vor. Die entweichenden Gase steigen in die etwas erhöht angeordneten weiteren Ballons und lösen sich in dem auch in ihnen befindlichen Wasser Abb. 102.

Von solcher doch recht kostspieligen und vergänglichen Einrichtung zu Gefäßen aus Blei, zu Houses, Zimmern ${ }^{1}$ ) aus diesem unzerbrechlichen, für damalige Säure unangreifbarem Material war nur ein Schritt. In ihnen sollten sich die Dünste, die bei der Verpuffung des Salpeters und des Schwefels entstanden, der Clyssus Sulfuris, zu einer Feuchtigkeit verdichten, wie Macquer das, Bd. I, 553 ff., darstellt.

Über das Wesen des Clissus [jedenfalls von $\tau \dot{o}$ «hiooos, oder richtiger

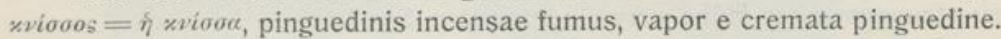
Auf Grund der uralten Beobachtung z. B. beim Brandopfer, daß Feuer nicht nur Fettstoffe in Rauch auflöste, daß das auch beim Destillieren geschehe, und weiter der alten Annahme einer Palingenesie, einer Resuscitatio, eines Wiedererstehens, einer Wiedererweckung alles Seienden aus den Bestandteilen, ein überlegt gewählter, soviel ich sehen kann, nirgends vorher erklärter Name] war man sich kaum einig, und die Ansichten änderten sich. Zu Macquers Zeit, im letzten Drittel des XVIII. Jahrhunderts dachte man sich unter ihm etwa dasselbe wie unter „Quinta essentia, d. i. die von allen unwirksamen geschiedenen, freigewordenen, wieder miteinander vereinigten wirksamen Teile eines Körpers, oder ein zusammgesetztes Sauer, gemeinlich die Feuchtigkeit, die durch die Verpuffung der Körper in geschlossenen Räumen hervorgebracht wird". Das erste deckt sich mit Libavs Erklärung: „Species composita ex ejusdem rei speciebus variis seorsim elaboratis. Quidquid in ea est essentiale ad unum redigitur compositum", sagt er weiter, während Porta ihn als „extractio subtilitatis omnium plantae partium, in unum esse coiens" ansah.

Dieselbe Anschauung tritt bei Poterius zutage mit seiner „Unio quaedam omnium virtutum cujuslibet plantae", während Roch le Baillif sich vermutlich gar nichts bei dem Worte denkt oder sein Wissen verheimlichen will: Vis occulta hinc inde vagans rediensque, ut virtus radicis primum in caulem deinde in radicem". Wie man sich dem Glauben an

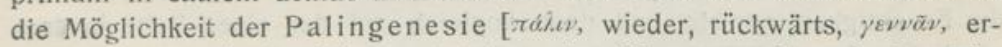
zeugen, gebären], des Wiederentstehens der Körper aus ihrer Asche, hingab, so neigte man sich, im Grunde ganz richtig folgernd, dem Wachsen der Scheidekunst, des Vermögens, die Körper in ihre Bestandteile zu

1) Dossie in seinem „Neueröffneten Cabinet“, S. 56, berichtet darüber, Schröder in seinem „Arzneischatz" zeichnet sie, Göttling im „Handbuch der theoretischen und praktischen Chemie" 1779 ebenfalls. Zeitweise, wohl bevor man sie mit Bleiplatten ausschlug. machte man die aus Holz gezimmerten Häuser mit FirniB-, Wachs-, Terpentin-, oder Pech-Überzug säuredicht. 
trennen, entsprechend, der weiteren Anschauung zu, daß es möglich sein müsse, die Trennungsprodukte wieder zu dem früheren Körper zu vereinigen. Porta drückt diese Ansicht (in der Übersetzung von 1611, S. 161) so aus: "Clissus verhält sich also, wenn nämlich unterschiedliche Stück eines Gewächses in ihren Kräften werden exaltiert oder erhöht und endlich in ein gemein wesen gesamblet". Kaum hat man je einen Apparat nach der von ihm gegebenen Abbildung zusammengestellt, geschweige gebraucht, aber wie er als Grundlage 'des „englischen“ Schwefelsäureverfahrens in einem Kolben entstünden die Schwefel-, im zweiten die StickstoffOxydationsprodukte, aus dem dritten träte Sauerstoff $z u$, um in dem Sammelgefäß sich zu Schwefelsäure zu verbinden - anzusehen ist, so ist der ganze Gedanke der Palingenesie und noch mehr des $\mathrm{Clissus}$ die Grundlage der erst im vorigen Jahrhundert praktisch betätigten und seitdem zu staunenswerter Höhe vervollkommneten Synthese.

Daß von vornherein solches Streben die Absicht der Alchemie oder der Spagirie, die von den Einen für gleichbedeutend mit ersterer oder als

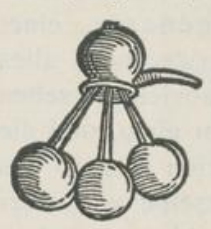

Abb. 103. Gerät nach Euonymus zur Vereinigung dreier Bestandteile. ein Teil von ihr angesehen wurde, war, sagt ihr Name, der, wohlüberlegt, aus oxã $\nu$, auseinanderziehen, und dysipe $v$, zusammenziehen, gebildet ist. „Ihr Arbeit bestand“, sagt Ernsting, „im solvieren und coagulieren; solve et coagula, dieses ist die Regel der Philosophen"1).

Leonhardi beschreibt die Kammern (zuerst wurde jedenfalls nur stets eine in Anwendung genommen und erst später weitere damit verbunden) als prismatisch gestaltet, 6 Schuh hoch, 6 lang, 4 breit. Beiläufig gesagt, berichtet er weiter, daß „starke Walliser Bauernd irn en “ bei der Fabrikation englischer Säure beschäftigt würden, die, obzwar sie nach dem Anzünden des Schwefelgemisches schnellstens fortliefen, doch nach wenig Jahren lungensüchtig zu werden pflegten, daß weiter englische Säure das Pfund noch $10^{1 / 2}$ Kreuzer kostete. Die erste Bleikammerfabrik wurde in Preston-Pans (Schottland) von Roebuck 1746, die erste in Deutschland von Baron von Waitz in Ringkuhl (bei Gr. Almerode) 1818 angelegt ${ }^{\circ}$ ).

Abgedampft („abgeraucht") wurde die Säure dann in offenen irdenen oder gläsernen Gefäßen und zuletzt, „da sie aus der benachbarten Luft die Feuchtigkeit anzieht und dann sogleich auf der einen Seite in dem nämlichen Augenblick das wieder erhält, was sie auf der andern verliert", in guten gläsernen, von Säure nicht angreifbaren Retorten abdestilliert. Erst 1809 sollen (wohl in England) zuerst Platinagefäße an ihre Stelle getreten sein.

1) Vgl. hierzu auch das Synonym für Menstrucum (vgl. S. 103) Clavis mixtionis.

$\left.{ }^{2}\right)$ Die schematisch gehaltene Abb. 104 erinnert lebhaft an das oben in Abb. 103 gezeigte Destillationsgerät von Port a für seinen $\mathrm{Cl}$ is sus. 
ein

en.

us:

Je-

ein

der

hht,

-

off-

em

ist

die

em

ler

als

ne,

ind

be-

ru-

ler

rst

Ien

ich

gt,

on

len

en

las

in

nd

?).

len

uft

em

$t^{\prime \prime}$,

srt.

Ile

gte
In den Handel kam die Säure schon damals in Ballons mit aufgekittetem Tonstopfen, verpackt in mit Stroh ausgelegten und überflochtenen Weidenkörben.

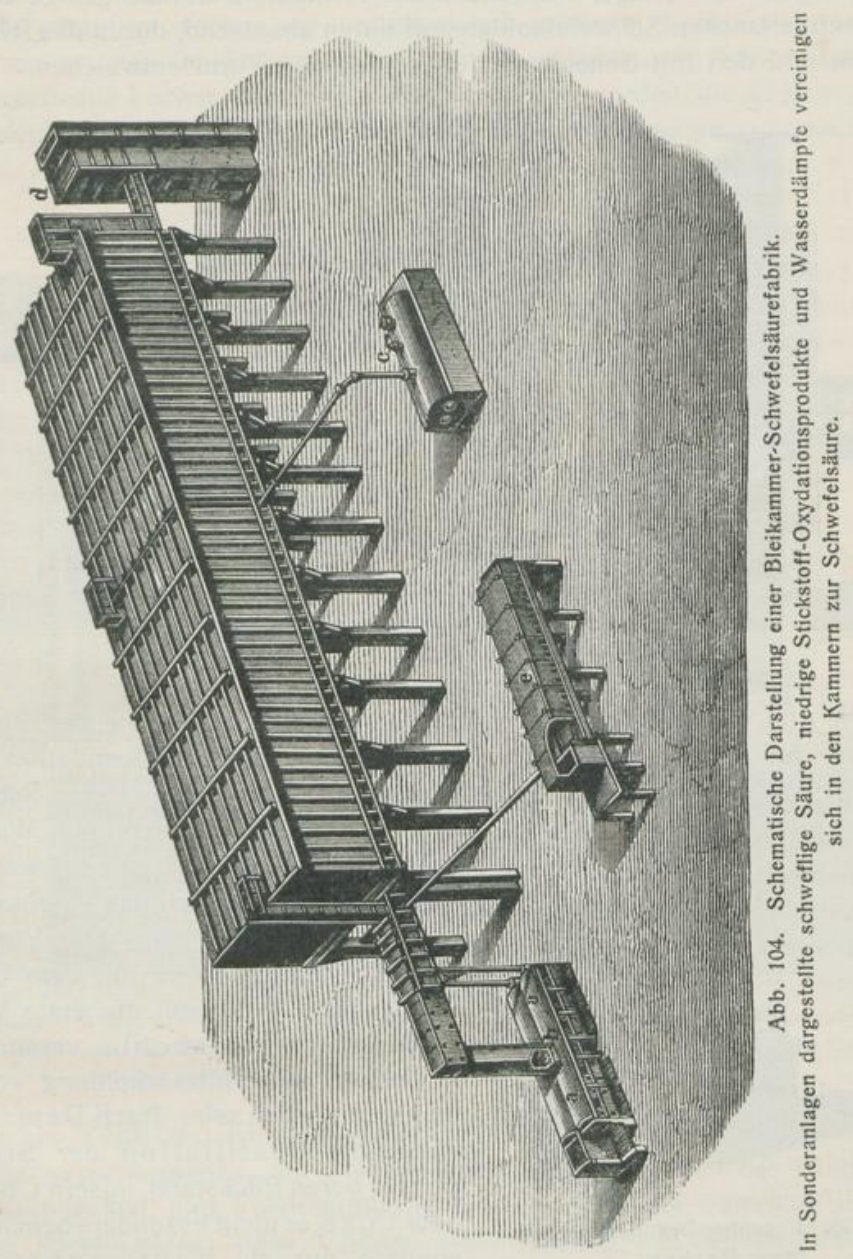

Weil es sich um eine schwefel- und zu gleicher Zeit kohlenstoffhaltige Verbindung handelt, sei hier an einen Apparat erinnert, der, wieder an die Lehre von Clissus gemahnend, der Destillation von Schwefelkohlenst off (den 1796 Lampadius entdeckte) dient. Der stehende Schacht ist 
mit Kohle gefüllt. Durch $a$ (Abb. 105) wird Schwefel zugeführt und beides erhitzt. Durch $c$ entweichen die erzeugten gasförmigen Stoffe. In $d$ verdichtet sich der Schwefelkohlenstoff und fällt in die untergestellte, mit Wasser gefüllte Vorlage, während nicht verdichtete fremde gasige Stoffe, etwa mitgerissenen Schwefelkohlenstoff unten absetzend, durch das Röhrensystem und den mit Scheidewänden versehenen Turm entweichen.

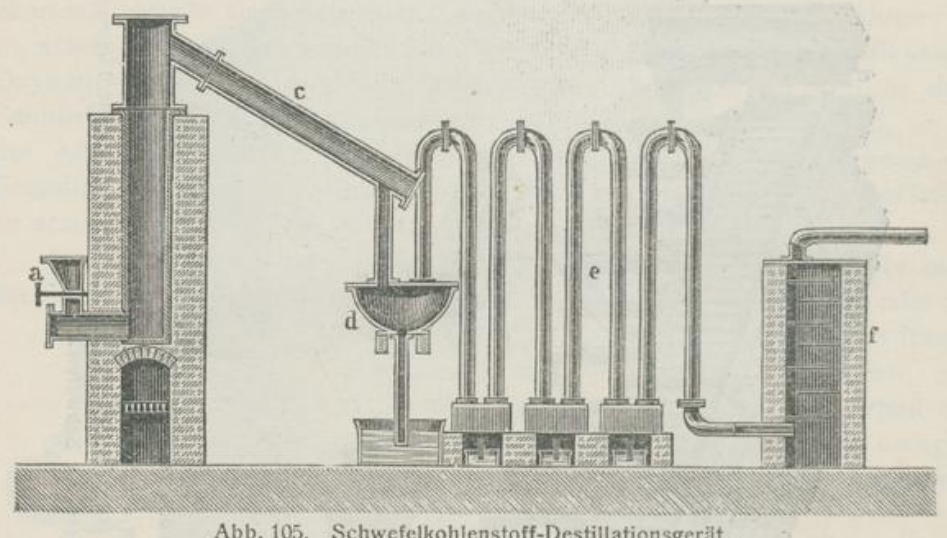

Die Abb. 106 zeigt ein Gerät, wie es der nochmals zu nennende Samuel Parkes im Anfang des vorigen Jahrhunderts, als zur Destillation von Phosphor gebraucht, abbildete. Es handelt sich um eine eiserne Retorte, aus der die Phosphordämpfe durch ein eisernes Rohr gleich unter Wasser

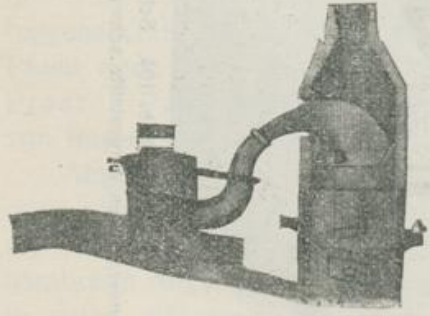

Abb. 106. Phosphor-Destillationsgerät nach Parkes. in einem Vorlagegefäß geleitet werden. Versehentlich hat sich das Originalbild nach oben verschoben. Die Vorlage steht in gleicher Höhe mit dem Ofen.

Im Jahre 1640 soll die erste Verkokung von Steinkohle, vermutlich in der Art der Holzverkohlung vorgenommen worden sein. Nach Demachy wurde die Destillation der Steinkohle, deren Rückstand, unsern Coake oder Coke, er nicht besonders benennt ${ }^{1}$ ), sondern nur als Kaufmannsware

1) Im Jahre 1530 ist der (in $\mathrm{Hamburg}$ noch, vor kurzem wenigstens, lediglich für den Stoff gebrauchte) Name Cinder für "coal from which the gaseous volatile constituents have been burnt", damit die Verkokung von Steinkohle bezeugt. 1669 kommt der Name Coke für burnt Pit-or Seacoal vor, und 1674 "it is now a word of general use" - in Frankreich und Deutschland aber zu Dem achys Zeit offenbar noch nicht. 
bezeichnet, (er stützt sich übrigens auf Pfeiffer „Entdecktes allgemein brauchbares Verbesserungsmittel der Steinkohlen und des Torfs" Mannheim 1777), in gemauerten, unten gepflasterten, oben gewölbten, 24 Schuh langen, 6 Schuh breiten und hohen Räumen vorgenommen, die zu je zweien umgeben waren von entsprechend größeren Umfassungsmauern. Die innern und die äußern hatten zum Beschicken mit Kohie oder Torf entsprechende Löcher, die danach fest vermauert wurden, die äußern weiter Feuerlöcher und Rauchfänge. Die Sohle der innern neigte sich nach der
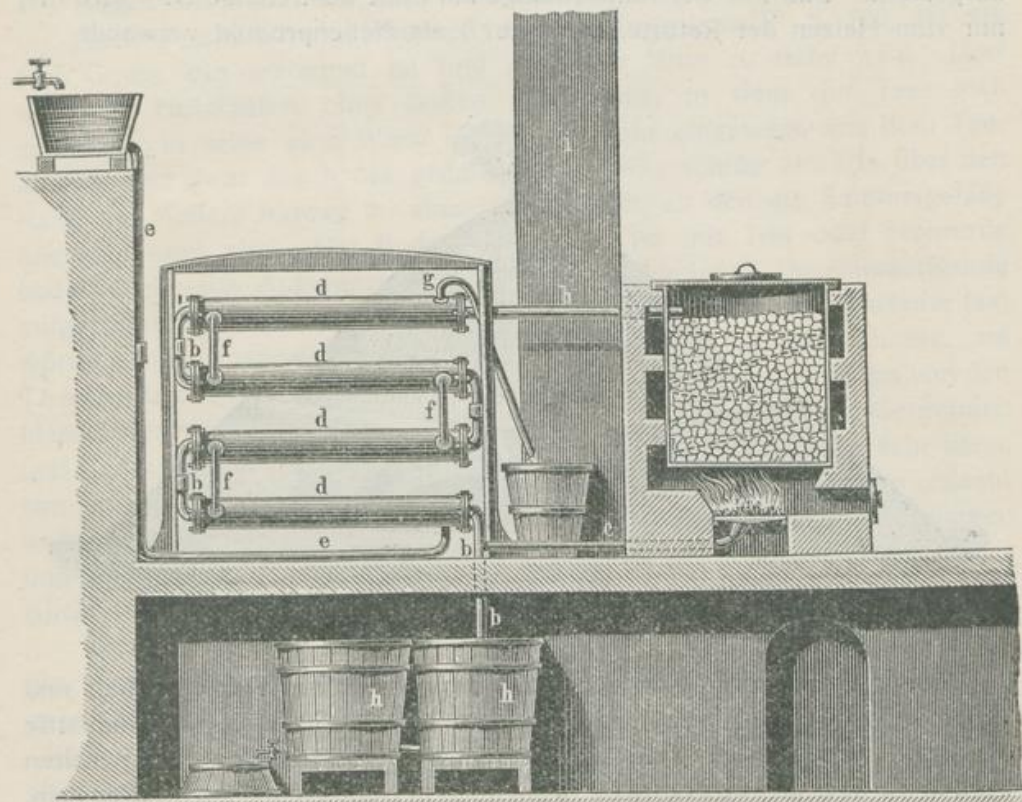

Abb. 107. Gerät für die Destillation von Holz zur Gewinnung von Holzessig und Holzteer unter Verwendung des Holzgases zur Heizung.

Mitte hin 3 Zoll und von dort aus ging unterirdisch ein mit durchlöchertem Deckel verschlossenes, am besten Tonrohr mit Fall nach der Längsseité hin nach außen, eine Vorrichtung die tatsächlich nichts weiter ist als eine antike Destillations- oder Verkokungseinrichtung. In einem genügend großen „Laboratorium", das drei Schuh tiefer neben die Ofenanlage gebaut ist, endigt das Ablaufrohr, und in Fässern, Ballons, Flaschen, je nach der Menge werden die Destillationsprodukte, styptisches Wasser, Steinkohlenöl, saurer Geist aufgefangen. Wenn sie anfangen von verdampfenden ganz leicht siedenten Stoffen (Naphte) „zu dampfen“, werden 
sie durch muffenartig ineinander gesteckte Glasrohre 16 bis 20 Schuh weit nach einem Oberstock der leichten Entzündlichkeit wegen, geleitet und weiter in gesonderten Abteilungen destilliert.

Es war Pierre Belon, der seit 1785 solche Destillationen mit Holz anstellte und der, da seine Pläne, das erhaltene Gas zur Beleuchtung der Leuchttürme zu verwenden, keinen Erfolg hatten, sich auf die Holzessigfabrikation legte. Sein später von Molleratt, Kurtz und Lhomond verbesserter Destillationsapparat ${ }^{1}$ ) ist in der Abb. ohne weiteres verständlich dargestellt. Das aus der Kühlschlange am Ende austretende Gas wird hier nur zum Heizen der Retorte, der $\mathrm{Teer}^{2}$ ) als Nebenprodukt verwandt.

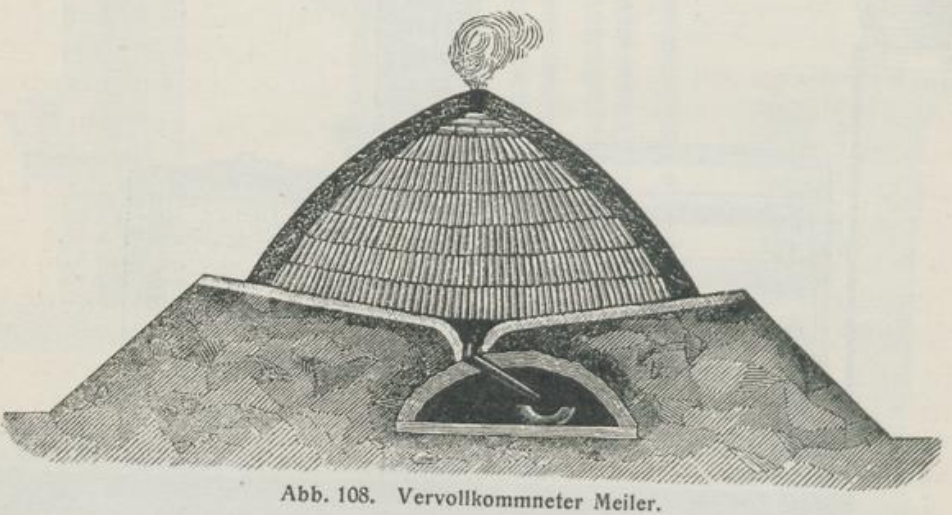

Immer mehr verdrängte moderne, durch törichte Waldwirtschaft und Teuerwerden des Holzes aufgedrängte verfeinerte Holzverwertungsindustrie die uralte, urwüchsige Wander-Köhlerei, die Pechhütten. Nur selten werden sie oder "Pechbrenner" wohl noch in Deutschland anzutreffen sein, und selbst in den Ost-Provinzen dürfte der Smolarz, der das Produkt seiner Tätigkeit, die Smola, Teer zum Wagenschmieren und Kienruß in Rußbutten, aus dünnen Holzdauben zusammengesetzten (etwa $20 \mathrm{~cm}$ langen und $5 \mathrm{~cm}$ im Durchmesser messenden, durch einen mittels des Holzreifens aufgepreßten Lappen verschlossenen) Fäßchen in meiner Jugend noch von seinem Transportkarren aus feilbot, ausgestorben sein. Was sie feilboten, wird wohl durchweg in etwas verbesserten, den uralten Meilern äußerst ähnlich gestalteten Meileröfen (z. B. in Westpreußen) bereitet. Einen

1) Girardin, Leçons de chimic élementaire, Paris 1860 II. S. 425. Vgl. Abb. 107.

$\left.{ }^{2}\right) \mathrm{DaB}$ seine und die von einem Deutschen vermutlich empfohlene Verwendung des Steinkohlenteers zum Streichen der Schiffe, der Dåcher u. dgl. keineswegs neu, sondern bis in klassische und noch frühere Zeit zurück zu verfolgen ist, wurde oben gezeigt. Vgl. S. $8^{ \pm}$ 
solchen Meiler zeigt die Abb. 108. Er wiederholt im Grunde nur was Theophrast schon kannte. Vgl. oben S. 7. In Rußland geht der Köhler
seiner Hantierung noch nach, und in dem jetzt einverleibten Finnland geht das Teerbrennen (in Schweden wird er "gebrannt" und „gekocht") in einem Meiler [einer Tervahauta] vor sich. Das Oleum Rusci, der schwarze Dägen, Teer aus Birkenholz ist ein auf diese Art dargestelltes Erzeugnis. Vgl, meine Arbeit in Pharm. Zentralhalle 1904 und oben S. 59. Bemerken möchte ich noch, daß Plinius, XVI, 30 erzählt, die Gallier „kochten" aus Birken ein Bitumen, also unzweifelhaft Birkenteer.

Nach Tschirchs „Handbuch der Pharmakognosie" S. 130, ist das eine Grube, die kreisrund ist und nach der Mitte $\mathrm{zu}$ tiefer wird. Dort wird ein Holzkasten ohne Boden eingesenkt, in dem der Teer sich sammelt. In seine eine Wand ist ein Holzrohr eingesetzt, aus dem Teer abfließst und zwar durch das gedachte Rohr, das schräg abwärts über den Rand des Meilers hinweg zu einem Kanal läuft, an den die Sammelgefäße angeschlossen sind. Der Boden der Grube ist mit Ton oder Moorerde bedeckt, um das Aufsaugen des Teers zu verhindern. Das kuppelförmig aufgestellte Holz wird mit Moos, Erde und Torf bedeckt. Das ist wieder fast wörtlich die Beschreibung der Destillationsvorrichtung, wie ich sie, auf Theophrast gestützt, wie oben gesagt, auf S. 7 gab, wie sie kaum von den klassischen Völkern aus nach dem räumlich so weit entfernten Germanien und gar nach dem Lande der Sarmaten und Fenni gekommen sein kann, sondern die vermutlich bodenständig, von Vorvätern der genannten erdacht wurde, und die beweist, daß die grundlegenden Beobachtungen, Überlegungen und Versuche zurückgehen, wie ich schilderte, bis in die Zeitspanne der Küchenchemie an dem von der Frau gehüteten Herdfeuer.

Eine Verkokung, bei der aber die gasförmigen Destillationsprodukte die Hauptsache, alle andern Nebensachen sind, wird in den Destillationsapparaten der Gasfabriken vorgenommen.

Becher scheint der erste gewesen zu sein, der 1682 (in seiner „Großsen chemischen Concordanz") auf die Brennbarkeit des bei der Destillation der Steinkohlen gewonnenen Gases hingewiesen hat, und fort und fort beschäftigten sich die Chemiker des Jahrhunderts begreiflicher Weise mit Versuchen, die Hand in Hand gehenden Erscheinungen zu ergründen und alle möglichen organischen Körper in ihren „Clyssus" zu zerlegen. Von spielenden Versuchen, die gasförmigen Produkte, die aus den Koks-Brennoder Teer-Schwel-Öfen durch undichte Stellen oder durch für solchen Zweck angebrachte Löcher entwichen, anzuzünden oder sie, durch Röhren fortgeleitet, an passenden Orten erst zu Beleuchtungszwecken zu benutzen, (wie das seit undenklichen Zeiten mit andern Zersetzungsprodukten organischer Substanzen, den neben Erdölen dem Erdboden entströmenden brennbaren Gasen [Kohlenwasserstoffen], beispielsweise auf der Halbinsel Apscheron bei Baku geschah und geschieht), hören wir erst aus den Fabrikanlagen des Earls of Dundonald, der am 30. Apr. 1781 ein Patent 
auf einen geschlossenen Coke ofen erhalten hatte, wohl wie er oben beschrieben wurde. Wenn der frühere Apotheker, Prof. Pieter Minkeleers 1781 sein Laboratorium mit Steinkohlengas, der Apotheker Erxleben in Landskron mit Gas aus Knochen beleuchtete (es werden wohl organische Substanzen aller Art gewesen sein), wenn Pierre Lebon seit 1785 Versuche anstellte, um in einer Operation aus Holz Kohle, die brennbaren Gase und Teer darzustellen, wenn Lampadius 1799 und der Lübecker Apotheker Kindt 1816 Holzgas darstellten, um es zu Leuchtzwecken zu benutzen, so haben alle als zuvörderst in Betracht kommend, eine jedenfalls den Laboratoriumsgeräten nachgebildete, größere eiserne Retorte benutzt. Glauber hat ein Gerät angegeben, das der

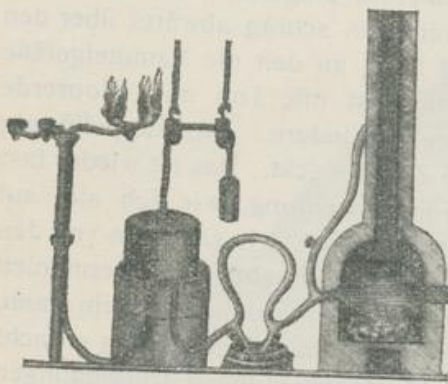

Abb. 109.

Erstes Gerät zur Steinkohlengasbereitung. Retortenform einigermaßen ähnelt, um darin Destillationen vorzunehmen, bei denen immerhin starke Hitze notwendig war, also solche von Weinstein für Spiritus e Tartaro (Brenzweinsäure), Cornu Cervi (für Ol. animale) u. dergl. Sie war aus Gußeisen (gelegentlich aus Ton) hergestellt, „unten etwas weiter als oben und zweimal so hoch als weit, oben mit einem Hals, darein ein Deckel schleußt, eines guten Zwergfingers tief. Der Deckel muß ein Ohr haben, welches man mit einer Zange fassen und also damit abnehmen und wiederum darauf decken kann". Diese Öffnung, statt des gewöhnlichen Tubus für einen Stopfen genügte für das Beschicken und Leeren der Retorte. Um die Zeit der oben genannten Versuche verwandte man schon solche nach dem Muster der für die Vitrioldarstellung
benutzten ${ }^{1}$ ).

Der nächst wesentliche zweite Teil, ein Gas a uf bewahrungs gerät, ein Gasometer, anstatt früher gebrauchter Schweineblasen, war aus der von Hales erdachten pneumatischen Wanne entstanden und wohl von Beddoes 1796 verbessert und von Pepys 1802 zuerst in Anwendung gezogen. Ein solches Gerät, schon unter Berücksichtigung der Beseitigung und des gesonderten Auffangens der flüssigen Bestandteile, stellt Samuel Parkes in seinen "Anfangsgründen der Chemie für Cameralisten", Erfurt 1818, dar. Kaum dürfte die erste Gasanstalt wesentlich andre Retorten gehabt haben, als sie hier dargestellt sind, und vollkommenere Meßäe zur Ansammlung von Gaswasser, Teer usw., Wascheinrichtungen, Meßeinrichtungen, die auch kaum an diese Stelle gehören, sind erst auf

1) Vgl. oben die Abb. 41, S. 67. 
Grund späterer Erfahrungen, je nach ihrer zu Tage tretenden Notwendigkeit, erdacht und eingeführt worden.

Es ist das Verdienst des deutschen, aus dem Apothekerstand hervorgegangenen genialen Chemikers, Friedlieb Ferd. Runge, die Eigenart des seiner Zeit als unbequemes Abfallerzeugnis der Gasfabriken betrachteten Steinkohlenteers studiert und die grundlegenden Entdeckungen für seine Verarbeitung und Verwendung gemacht $\mathrm{zu}$ haben. Aus dem Nebenprodukt ist ein kostbares Hauptprodukt geworden, und in riesengroßen, viele Tonnen enthaltenden Geräthen wird es destilliert. Eine solche Einrichtung, in der der Teer selbst zur Vorkühlung des Destillats verwendet wird und dabei zugleich vorgewärmt wird, zeigt die Abbildung, die einer Beschreibung kaum bedarf. Sie ist einer Arbeit in der Cöthener Chemiker Zeitung, 1910, S. 282, entnommen.

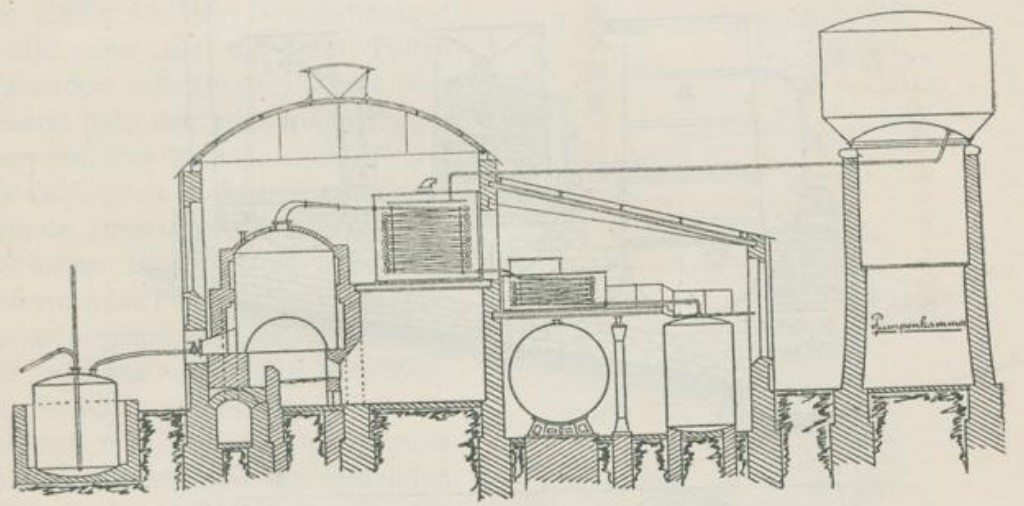

Abb, 110. Steinkohlenteer-Destillationsanlage.

Ganz besonders interessant sind Destillationsgeräte aus den vermutlich allerältesten Kulturländern des Ostens, aus China und Japan, weil sie mutmaßlich auf ein sehr hohes Alter zurückblicken können. Wenigstens scheinbar schlagen sie „ganz aus der Art", und es unterscheiden sich von den bis jetzt beschriebenen, unzweifelhaft im wesentlichen von den Arabern ausgebildeten Destilliergeräten die von den Japanern für ihre Destillation, z. B. des Pfefferminzöls im Großen, gebrauchten Geräte. Sie lassen aber doch die Urform, in diesem Falle das Haus mit nach innen abfallendem Dach (wie es oben als Eigentümlichkeit des Hauses im klassischen Altertum geschildert wurde) klar erkennen. In einem halbkugelförmigen kupfernen Kessel wird Wasser zum Sieden gebracht, und der entstandene Dampf tritt in ein in geeigneter Art darauf gestelltes und dampfdicht daran befestigtes zylindrisches Holzgefäß, das unterseits mit einem siebartig durchlöcherten Boden, oberseits 
mit einem trichterförmig nach innen abfallenden kupfernen Deckel verschlossen und mit Pfefferminzkraut angefüllt ist. Unter dem Deckel hängt unten ein flaches Gefäß, das durch ein Bambusrohr seinen Inhalt, das von dem, oberseits durch aufgegossenes Wasser gekühlten Deckel nach unten abtropfende Öl nach außen in ein Vorlagegefäß abführt.
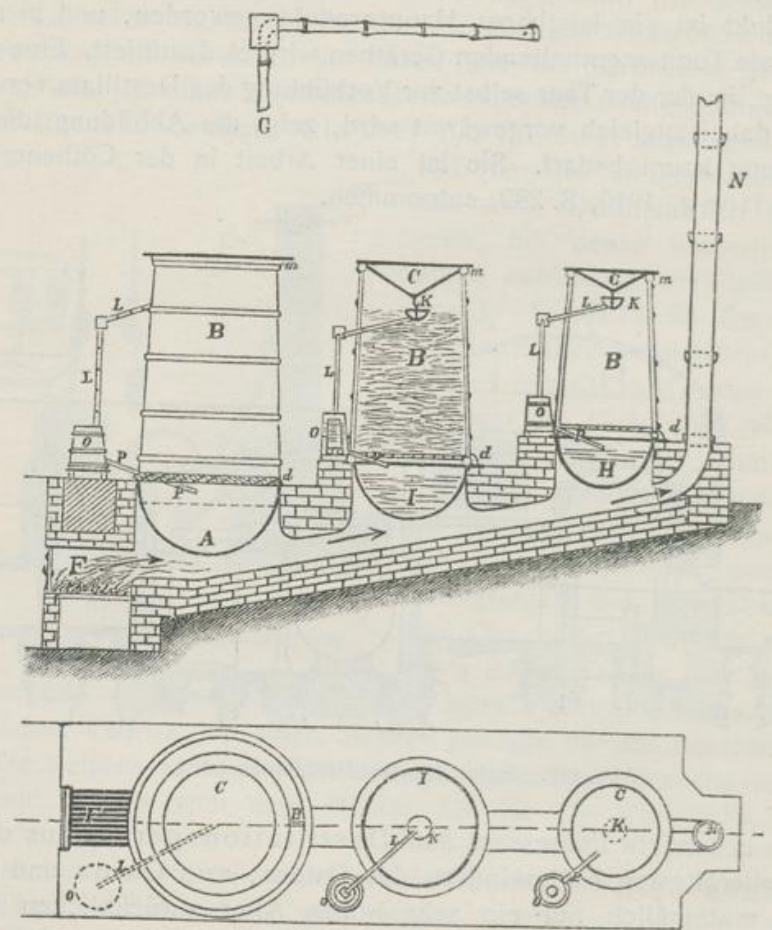

Abb. 111.

Destillationsanlage für Pfefferminze.

Aus ihm flieft das unten sich absetzende Wasser wieder durch ein Bambusrohr in das Wasserverdampfungsgefäß zurück. Zwecks besserer Ausnutzung des Feuermaterials stehen für gewöhnlich einige solche Geräte hintereinander, nach hinten etwas ansteigend, auf einem Feuerkanal. Nach den Angaben, die die vortrefflichen Berichte von Schimmel \& $\mathrm{Co}$. in Miltitz im Oktober 1908 auf Grund von japanischen Originalarbeiten (von Setsusaburo Tanaka) bringen, wird die Destillation von Hakuka 
oder $\mathrm{Hakka}^{1}$ ) schon seit 2000 Jahren, unzweifelhaft vermutlich im wesentlichen in derselben Art betrieben, in Apparaten, die sicherlich altüberkommenen Vorbildern nachgeahmt sind. Meines Erachtens haben sie einige, vielleicht nicht unwesentliche Vorteile vor unsern voraus.

Nur die Krimmischen Kosaken brauchen nach Krünitz Destilliergefäße zur Bereitung ihrer Rauschtränke aus gegorener Milch, die nach dem gleichen Prinzip gebaut sind. Ein eimerähnlicher und etwa ebenso großer Metallkessel ist mit einem möglichst dicht schließenden trichterförmigen, in eine Spitze auslaufenden Deckel versehen, der mit Hilfe von 3 Krampen fest angepreßt wird, nachdem man das Gefäß etwa zur Hälfte mit dem Destillationsgut gefüllt und ein auf drei Füßen stehendes zylindrisches Gefäß eingesetzt hat, das etwa einen Finger breit von dem Deckel absteht. Wenn die Flüssigkeit über mäßigem Feuer gelinde erhitzt ist, wird der Deckel mit kaltem Wasser, noch besser mit Schnee oder Eis angefüllt, das nach Bedarf ergänzt wird, wenn es durch die Wirkung des unten anprallenden Dampfes geschmolzen wird. Er sammelt sich, von der Deckelspitze abtropfend, inmitten der siedenden alkoholischen Flüssigkeit. $\mathrm{Ob}$ das Gerät die Urform des japanischen ist, oder ob es aus ihm vereinfacht für den Kleinbetrieb eingerichtet

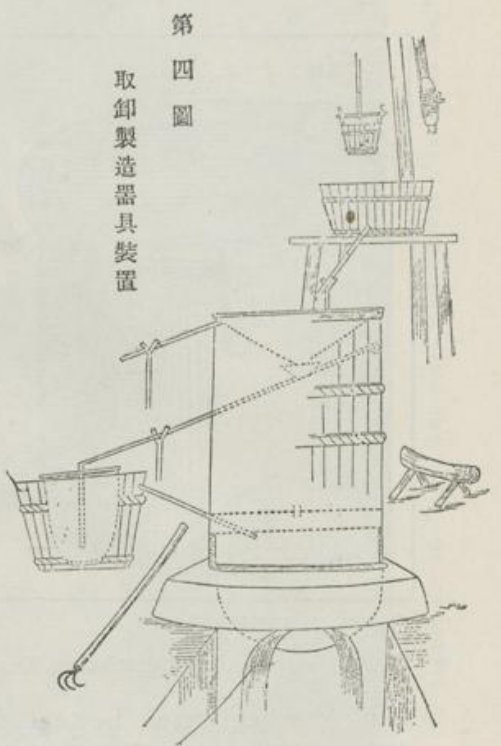

Abb. 112. Pfefferminzdestillieranlage. worden ist, bleibe dahingestellt. Die Beziehungen zwischen den beiden aufzuhellen, hiefse gleichzeitig etwaige Beziehungen zwischen den beiden Völkerschaften und ihren Kulturen klarlegen \%). Vgl. die Abb. 112.

1) Flückigers auf Mitteilung von Schimoyama gestützte Angabe (Pharmakognosic 1891 , S. 726), daß Menthol an 2000 Jahre in Japan bekannt sei, ist wohl irrig. Die obengenannten Worte bedeuten die Pflanze, ihr Öl und Menthol. Nach dem von Schimmel \& C o, angeführten Schriftsteller wurde Pfefferminze seit altersher gebaut. Öl wird in dem ältesten, in Betracht kommenden Werk aus dem Anfang des IX. Jahrhunderts nicht genannt, wohl aber unter dem Namen Megusa (Augenkraut) in dem Schin 1 Ho von 984. Danach mußte es um die Zeit jedenfalls destilliert worden sein. Daß es nicht nach dem Erscheinen der Portugiesen oder Holländer (1609) erst destilliert wurde, scheinen die ganz eigen, ja einzig gearteten Geräte zu verbürgen. Dic Europäer hätten doch sicher ihre Geräte eingeführt. 7) Krünitz, Ökonomische Enzyklopädie, Berlin 1781. Abb. 470, 471 im Artikel Destillation. 
Die Geräte der Kalmücken für ihre Kumys-Destillation sind nach Krünitz den gewohnten klassischen ähnlich, nur äußerst urwüchsig zusammengesetzt. Ich weiß nicht, ob sie ethnologisch den Sagaiern, einem Turkstamm in Süd-Sibirien, stammverwandt sind. Sieht man aber auf der Abbildung ihres Kumys-Arakà-, ${ }^{1}$ ) ihres Milch-BranntweinDestillationsgerätes, wie es Hörnes) zeigen kann, daß es den auf klassischem Boden stehenden völlig ähnelt, so ließe sich schon daraus Stammesähnlichkeit folgern, im übrigen Anlehnung an unsre Kultur.

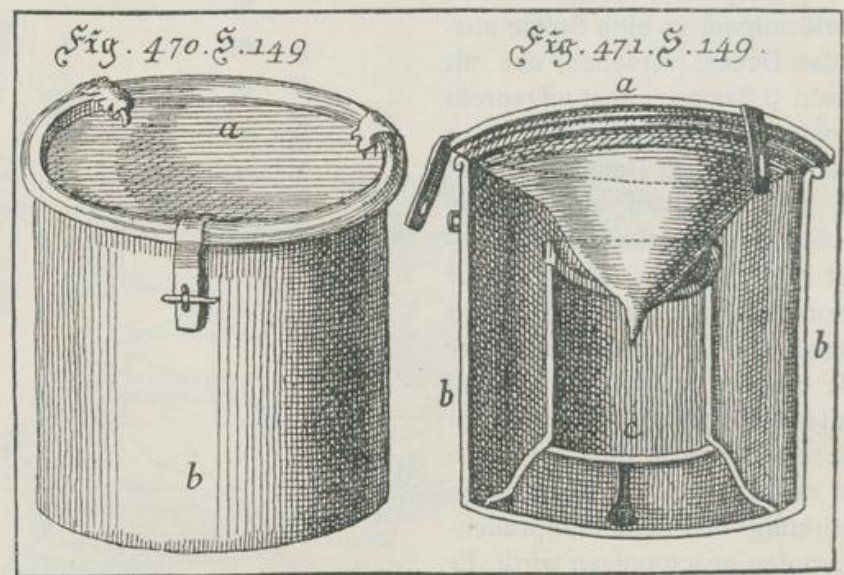

Oec.Enc IX.Th.

Fig. 113. Geräte der Krimmischen Kosaken zur Milchbranntwein-Destillation.

Allem Anschein nach besteht das Arakà-Gerät aus einem tiefem, vermutlich auch für andre Zwecke gebrauchten Kessel, auf den ein ziemlich gleich gestalteter Deckel gepaßst und möglichst dicht, vermutlich durch irgend einen Kitt, mit ihm verbunden ist. Kunstlos gearbeitete (Metall-?) Rohre führen das Destillat in die Vorlagen in einem Wassertrog ab. Dieses sich mit den einfachsten Mitteln Behelfen, wie sie Küche und Haus bieten, erinnert und bestätigt, was oben (z. B. auf S. 17, 39, 43, 87 usw.) gesagt wurde und was in vortrefflicher Art auch die aus äußern Gründen erst an diese Stelle gerückte Abb. 114 aus dem XVII. Jahrh. belegt.

Einen ganz urwüchsigen Eindruck machen auch die Apparate, die in China zur Destillation von Cassiablüten- (und des Sternanis-) Öls gebraucht werden $\left.{ }^{3}\right)$. Das erste Gerät hat immerhin eine gewisse Ähnlich-

1) $\mathrm{Ob}$ die Ähnlichkeit des Ausdrucks mit dem gleiches bedeutenden arab. Wort zufallig ist, kann ich nicht sagen. Vgl. S. 28.

7) In seiner "Natur- und Urgeschichte der Menschen", Wien, Leipzig. Vgl. Abb. 114.

3) Die betr. Abbildungen sind zumeist dem Werke von Gildemeister und $\mathrm{Hoffmann}$ oder der betr. Bearbeitung von Edw. Kremers entnommen. 
nach g zuern, aber einI auf araus

efem, mlich lurch all-?) ieses ieten, esagt erst lie in Öls lichsufällig 114. mann

keit mit den unsern. Auf einem Metallkessel steht ein mit Eisenblech ausgeschlagener Holzzylinder möglichst dicht befestigt. In ihn (der jeden-

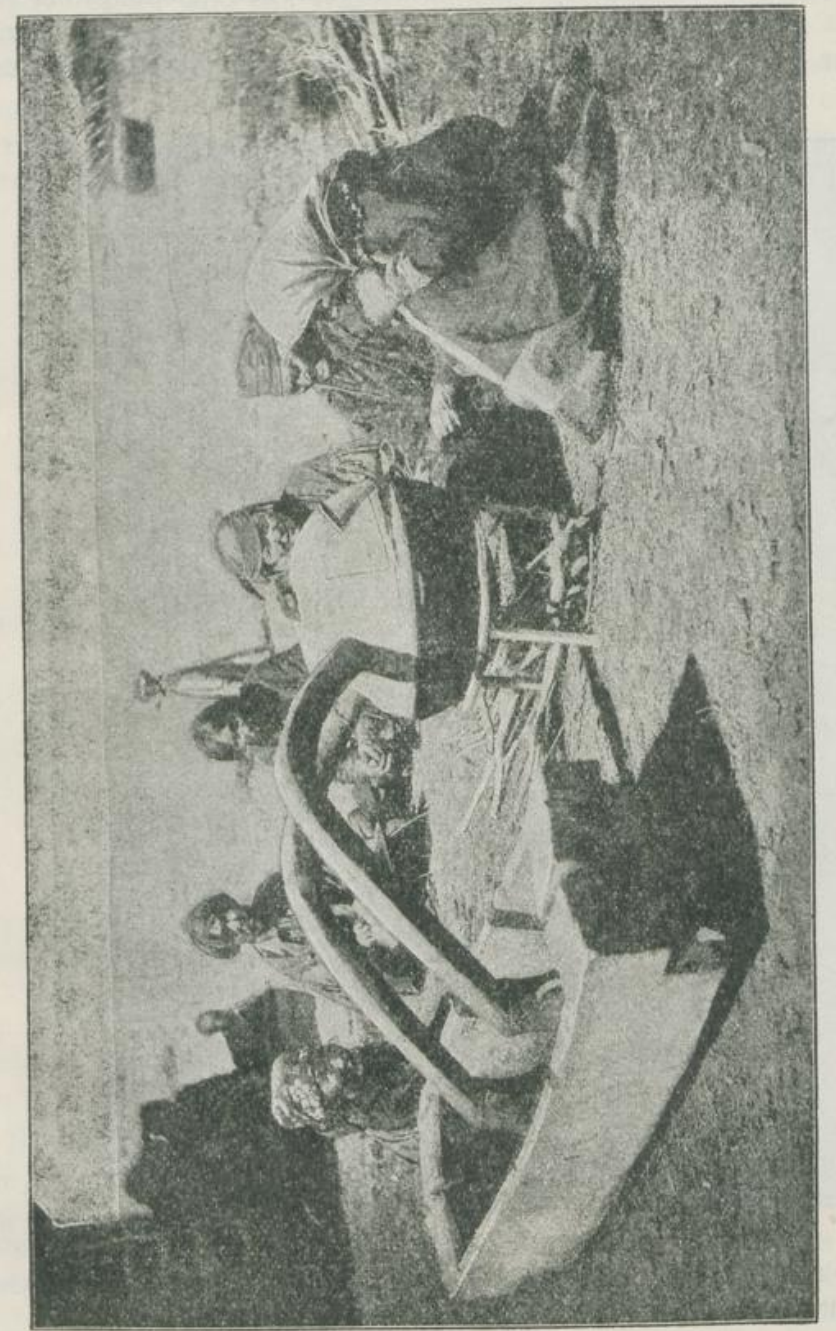

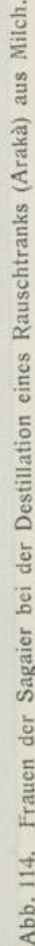

falls unten einen durchbrochenen Boden besitzt, was weder aus der Abbildung noch der Beschreibung hervorgeht) kommt das Destillationsgut, auf ihn ein unten trichterförmig zugehender, wohl dem hölzernen Gefäß 
ähnlich geformter, verhältnismäßig großer (vielleicht um durch die große Außenfläche eine sonst nicht vorgesehene Kühlung zu bewirken) Helm. Aus der auf diese Art gebildeten Kre mpe führt das Ableitungsrohr schräg abwärts in ein eimerähnliches Vorlagegefäß, in dem sich das spezifisch schwere Öl ansammelt, während das Wasser in ein zweites und drittes

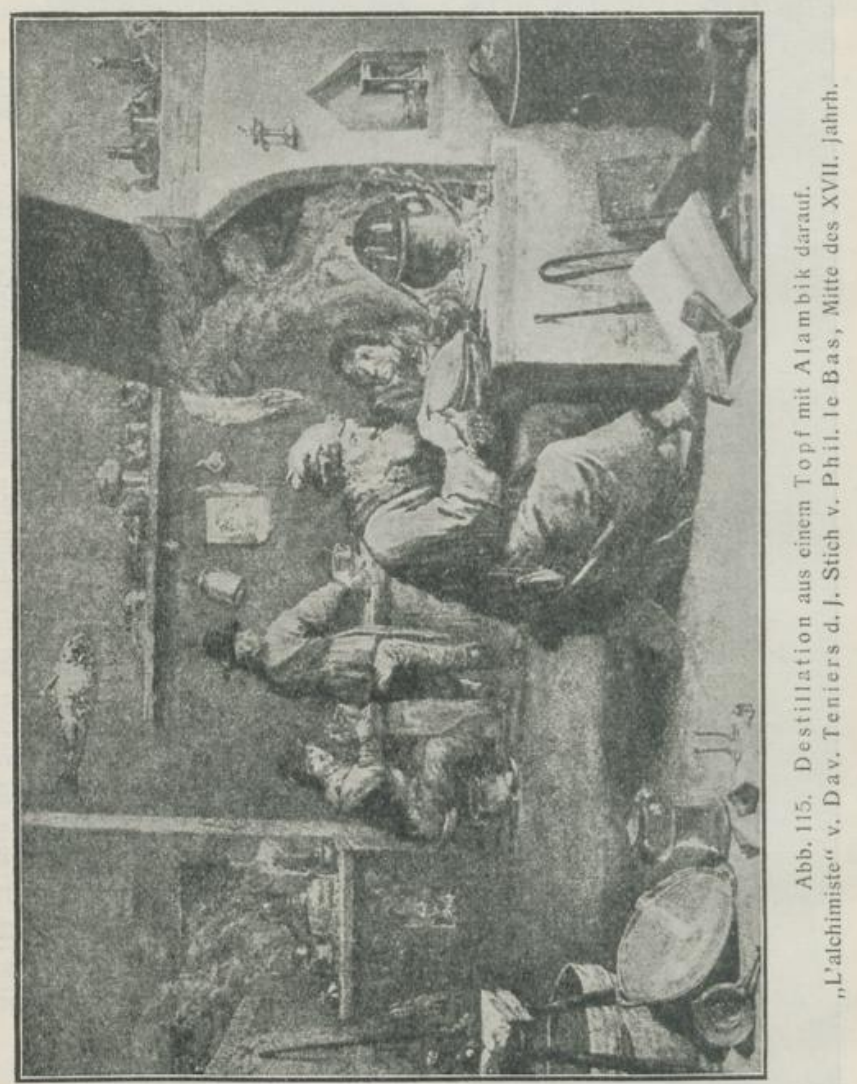

Gefäß oben abläuft, um aufbewahrt und bei späteren Destillationen wieder verwandt zu werden. Vgl. die Abb. auf folgender Seite.

Dem eben gedachten ähnlich, aber technisch vervollkommneter ist das andre in Tonkin für Sternanisöl benutzte Gerät. Auf einem Wasserkessel steht ein Faß, das unten einen siebartig durchlöcherten Boden hat; geschlossen ist es mit einem umgekehrt trichterähnlichen Deckel, unter 
roße lelm. hräg fisch ittes

ieder

\section{- $133-$}

dessen Abflußröhre ein schalenförmiges Gefäß angebracht ist. Auf ihm ruht eine weitere Schale zur Aufnahme des Kühlwassers. Aus der zylinderförmigen Vorlage wird das Wasser mittels Heber wieder in den Apparat geleitet, um nochmals destilliert zu werden. Vgl. Abb. 117.

Bei der Destillation in China ist ein analoges, im Grunde vollkommeneres Gerät in Gebrauch. Interessant ist die verblüffend einfache und zweckmäßige Vorlage: Aus der ersten Abteilung fließt das spezifisch leichtere Öl in die zweite über. Vgl. Abb. 118.

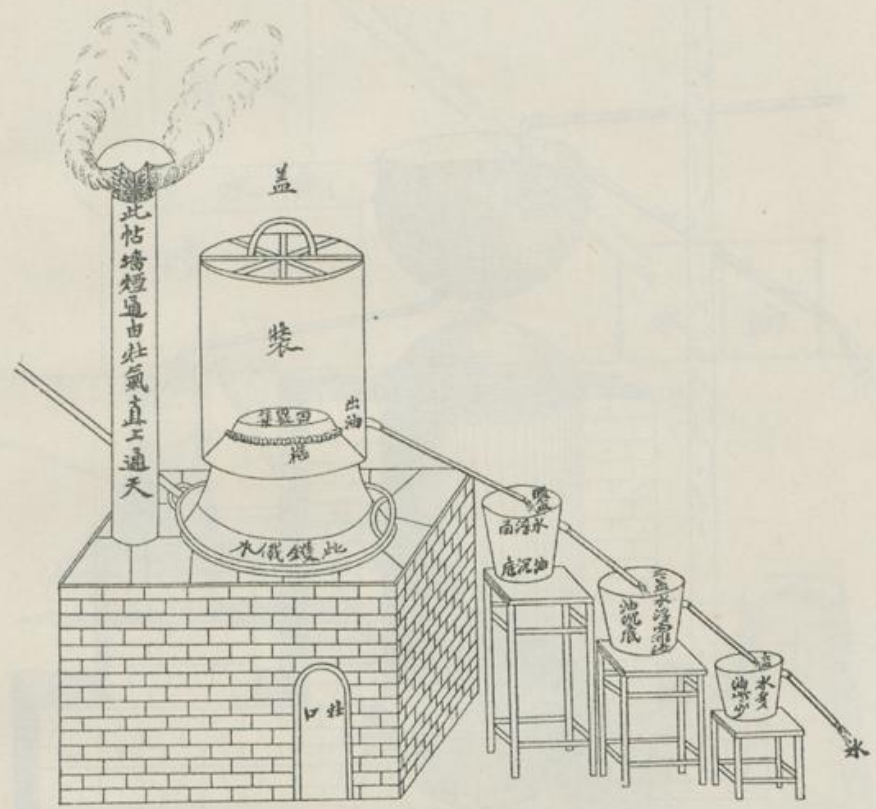

Abb. 116. Apparat zur Destillation von Cassiablütenöl in China.

Im wesentlichen gleicht die sicher nach uralter Art betriebene Campherdestillation in Japan den eben genannten. Zumeist am Abhang eines Hügels ist ein einfacher Ofen errichtet. Auf ihm ruht eine ziemlich flache Pfanne zum Verdampfen des durch einen seitlichen Stutzen zu ergänzenden Wassers. Darüber steht ein nach oben etwas verjüngter Holzbottich, der unterseits mit einem durchlöcherten Boden abgeschlossen ist. Ringsherum ist er unter Zuhilfenahme eines stützenden Bambusgeflechts mit Lehm leicht beschlagen. Er wird mit Campherholzspänen beschickt und mit einem Deckel bedeckt. Wird das Wasser zum Kochen gebracht, so dringt es durch die Späne, beladet sich mit $\mathrm{C}$ ampher und 
tritt durch das Bambusrohr in Kästen mit mancherlei Querteilungen, in denen sich das feste Öl beim Abkühlen absetzt. Über der Heizöffnung werden die aus einem dicht dabei angebrachten Mannloch herausgezogenen abdestillierten Späne getrocknet, um dann verfeuert zu werden $\left.{ }^{1}\right)$. Siehe Abbildung 119.

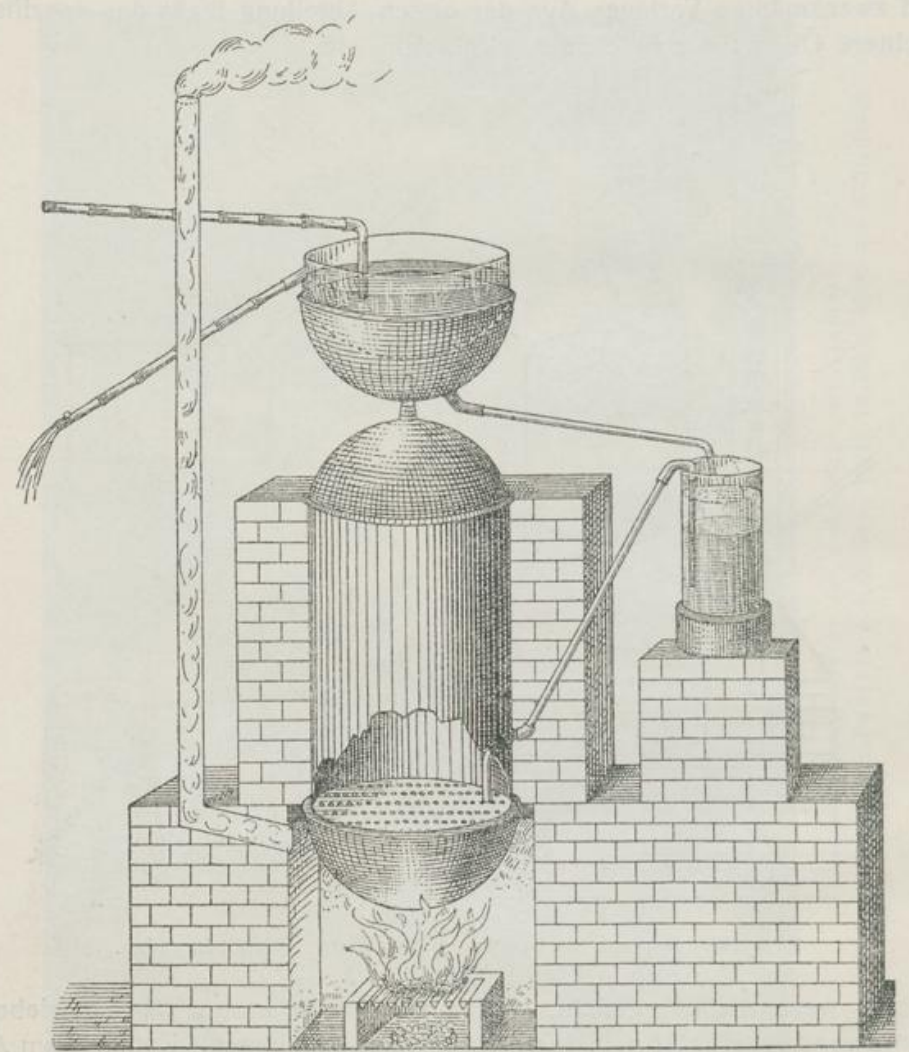

Abb. 117. Sternanisöl-Destillation in Tonkin

Wie oben durch die Abbildung aus Ryff z. B. (S. 47) gezeigt werden konnte, destillierte man im Mittelalter in unserm Vaterlande gleich an Ort und Stelle, inmitten der „Kräutergärten“, wie sie seit langer Zeit her

1) Grassmann, Der Campherbaum, Mitteilgn. der deutschen Gesellsch. f. Natur- und Völkerkunde Ostasiens 1895, S. 277 f. 
$n$, in nung enen jiehe

\section{$-135-$}

(z.B. um Würzburg, dessen Name ebenso bezeichnend ist wie der lateinische Herbipolis, am Michaelsberg bei Bamberg usw.) ${ }^{1}$ ), die Ruchstoffe, und ganz ebenso geschah es natürlich an der gottgesegneten Riviera, wo schon im XIV. Jahrh. zum mindesten ") Lavandula, Hyssopus, Borago,

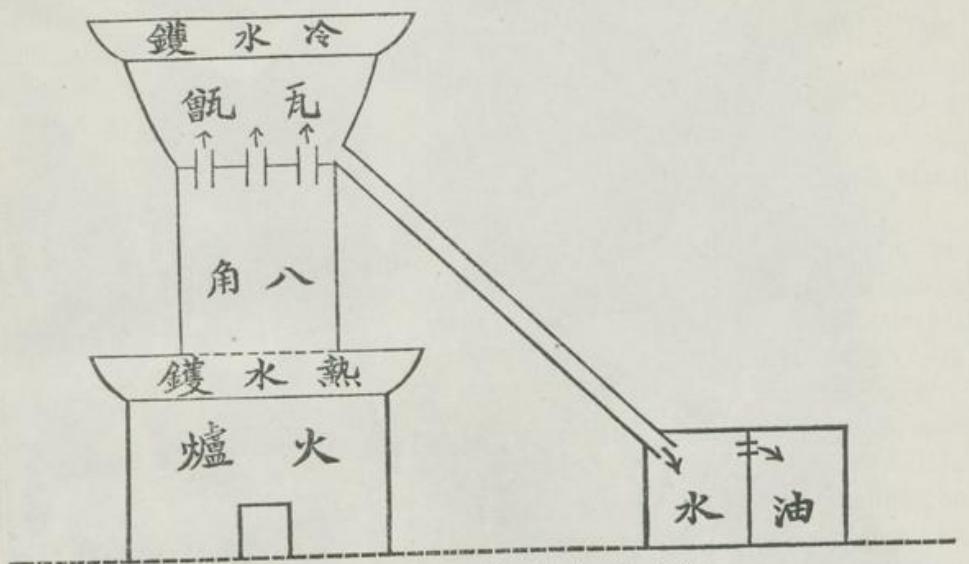

Abb. 118. Sternanisöl-Destillation in China.

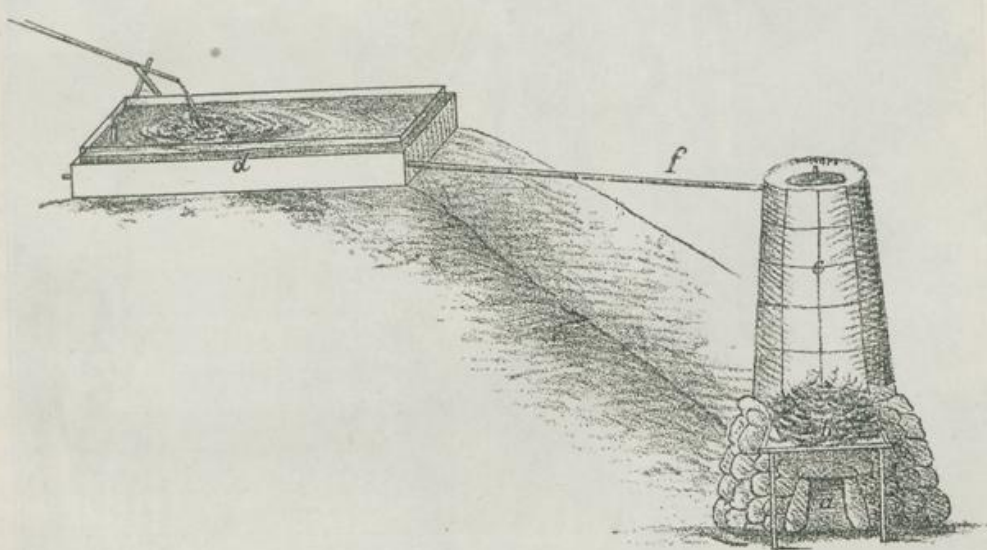

Abb, 119. Campherdestillation in Japan.

Salvia, Viola, Plantago, Rosa usw. in großem Maßstabe gebaut und zu Ruchwässern, später zu Ruchölen verarbeitet wurden. Ebenso natürlich ist, daß man sich da, in einer ganz handwerks- oder gewerbsmäßig, fernab

1) Vgl. darüber die Angaben in meiner Geschichte der Pharmazie.

7) Vgl. darüber B a udot, La Pharmacie en Bourgogne. 


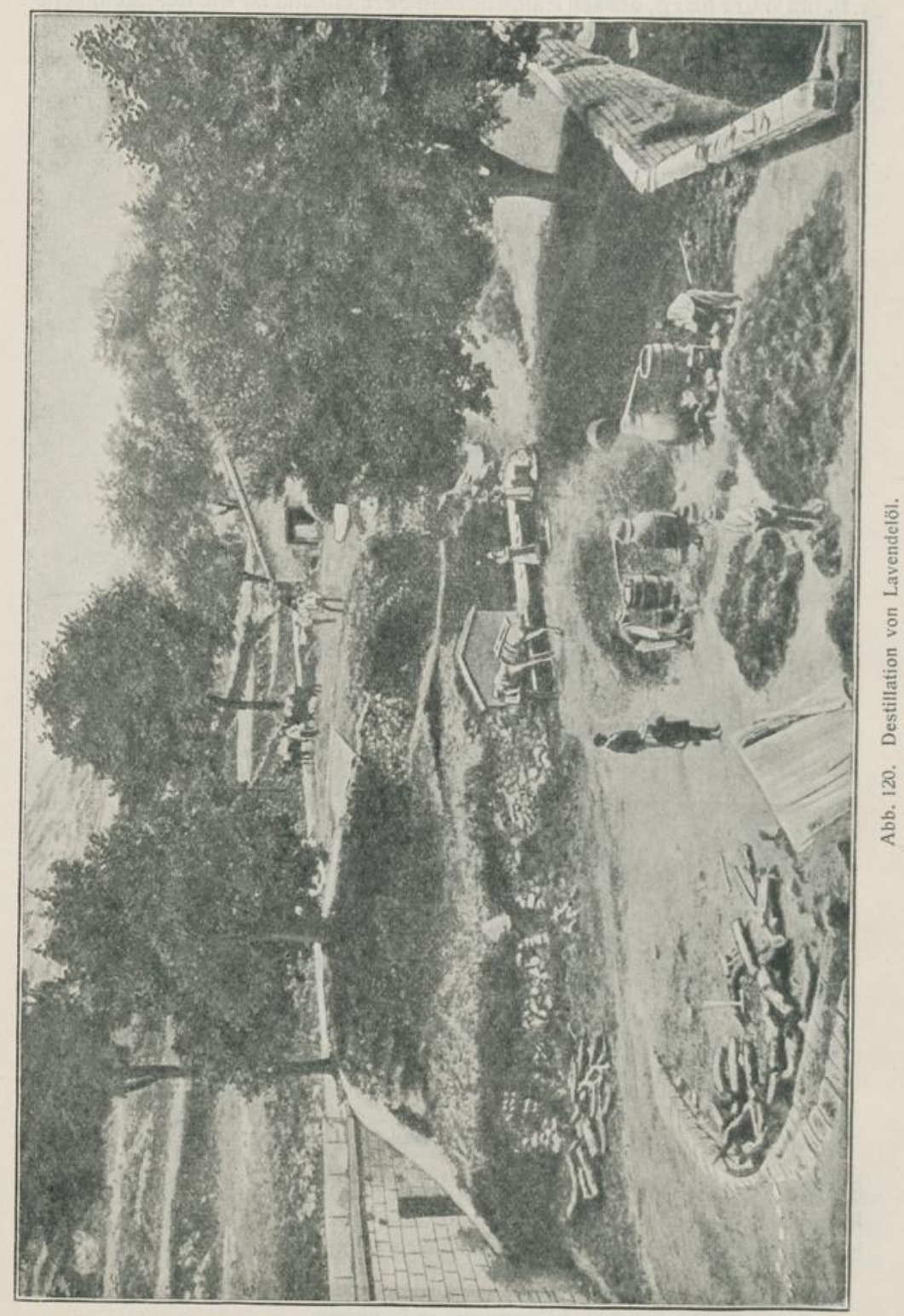


von wissenschaftlichen Erwägungen betriebenen Industrie, altüberkommener von Generation zu Generation vererbter Geräte und Arbeitsart bediente und zum Teil wenigstens noch bedient ${ }^{1}$ ). Ein Blick auf sie, die entweder im Besitz der bäuerlich oder gärtnerisch arbeitenden Blumenzüchter sich befinden, oder Leuten gehören, die etwa wie die Besitzer von Mähmaschinen mit ihren Alambics voyageants von Ort zu Ort ziehen, läßt die allbekannten Formen erkennen, wie ich sie aus den ersten Jahrhunderten unsrer Zeitrechnung vorführen konnte, und wie sie unter den Arabern vergrößert und ausgestaltet wurden. Auf drei Unterlagesteinen, wie das Kochgefäß auf dem Heerdfeuer der ständig wandernden Urahnen, steht der Alambic der Lavendelölbrenner. Vgl. Abb. 120.

$\mathrm{Daß}$ die nämlichen Gerätformen auch da in Anwendung kommen, wo europäische Kolonisten ihre Kultur hintragen und dort bodenständige Ruchgewächse, wildwachsende oder kultivierte, um Fracht zu sparen, gleich an Ort und Stelle, der Regel nach „roh“ destillieren, ist völlig natürlich. Daß sie in den fernen Ansiedelungen selbst in denkbar einfachster Art, gelegentlich unter Zuhilfenahme von Naturerzeugnissen, wie sie der Mensch in der frühesten Zeit zur Hilfe heranzog und der Wilde sie noch als Haus- und Küchengerät braucht, gebaut oder daß heimische Geräte mit solch urwüchsigen Ersatzstücken zurechtgemacht werden, ist selbstverständlich. Diese „atavistischen“ Verhältnisse machen sie aber gerade für allgemein kultur- und in Sonderheit für unsre geräte-geschichtliche Betrachtung äußerst interessant und wichtig. Vgl. Abb. 114.

Cajeputöl wurde auf den Molukken jedenfalls dargestellt, bevor sie von den Europäern betreten wurden. Es wurde als Diaphoreticum von den Eingeborenen verwandt. Das Destillationsgerät, das jetzt auf Lerang, einer der Inseln, zu seiner Darstellung verwandt wird, ist zweifellos in der Grundidee klassisch, europäisch. Ein (vielleicht mit Terpentinöl oder Petroleum aus Amerika eingeführtes) Holzfaß dient als Blase, ein Metallhelm ist auf ihm befestigt, ein Bambusrohr, das einfache Gerät, das die Natur dort bietet (vgl. oben S. 17), leitet das Destillat durch ein mit Wasser gefülltes Faß in ein aus einer Kokosnußschale gebildetes, trichterähnliches Gerät, das in einer mit Wasser gefüllten, weithalsigen Flasche steht. Es wird durch das Destillat in die Kufe, in der sie steht, verdrängt, und wenn die Nußschale mit abgesondertem Öl gefüllt ist, wird sie, der denkbar einfachste Scheidetrichter, nachdem die Ausflußöffnung mit dem Finger abgeschlossen ist, abgenommen und, sobald das Öl entleert ist,

1) Analoge Zustände herrschten auch noch auf andern Gebieten landwirtschaftlichchemischer Gewerbe. An die Stelle bodenständiger germanischer Milchverarbeitung zu Anke und Ostr trat etwa im XIV. Jahrh. nach römisch-italienischem Muster eine verbesscrte häusliche Darstellung von nach demselben Muster benannter Butter [Bovizvoov, eigentlich Ochsen-,

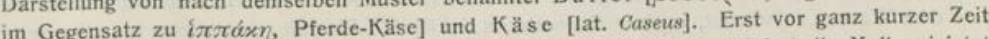
folgte sie wissenschaftlichen Erwägungen, und, "rationell“ betrieben, liefert die Molkerei jetzt Erträge, die in Güte und Größe die alten weit hinter sich lassen. 
wieder an ihren Platz getan. Das wäßrige Destillat wird vermutlich andern Tags wieder auf die neue Blätterfüllung getan ${ }^{1}$ ).

Ganz ähnlich liegen die Verhältnisse bei dem indischen $\mathrm{Palmarosa-}$ Ö1. Das (Motia- oder So(n)fia-) Gras wird in Bündeln möglichst dicht durch Einstampfen mit den Füßen in eiserne oder kupferne Blasen gebracht, die zu dreien bis vieren in einem Ofen aufgestellt sind. Die letzteren sind zylinderförmig, etwa $80 \mathrm{~cm}$ im Durchmesser, aus Platten zusammengenietet, letztere etwas kleiner, annähernd kugelförmig getrieben.

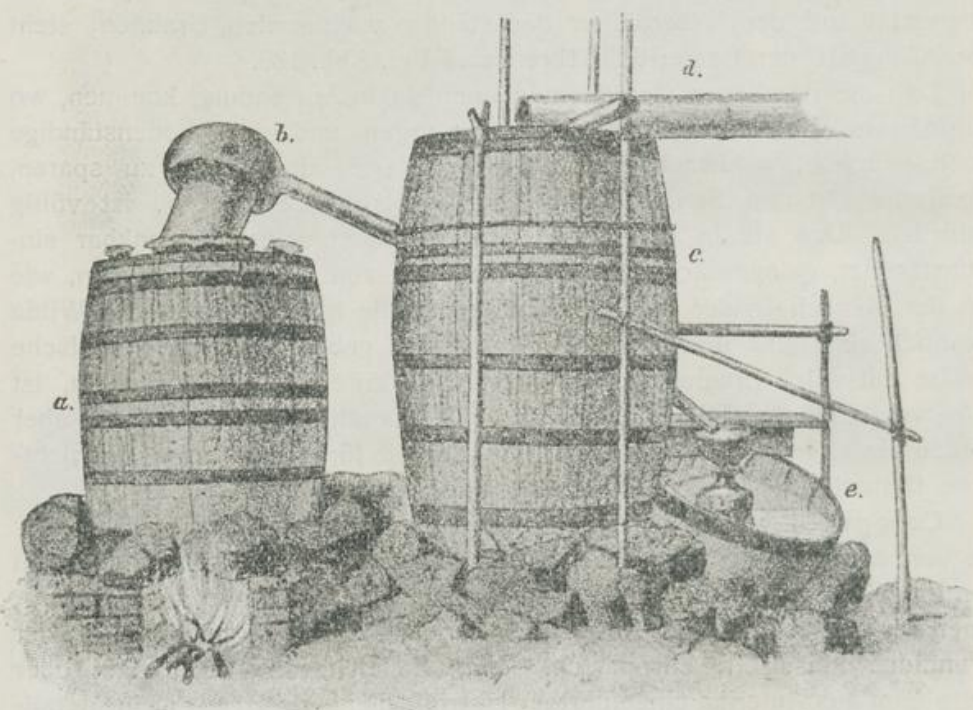

Abb. 121. Apparat zur Destillation von Cajeputöl.

Sie werden erst mit Wasser (etwa 10 bis $12 \mathrm{~cm}$ hoch), dann mit dem Gras beschickt. Ein durchbohrter Deckel wird mit Udidkleister (Bohnenmehl und etwas Kochsalz) und Lehm ${ }^{2}$ ) auflutiert, in gleicher Art ein winkelförmig angeordnetes Bambusrohr darin befestigt, das in einem kupfernen Vorlagegefäß endigt. Sie alle stehen in einem Rahmen in fließendem Wasser. Wenn die Destillation beendigt ist, schöpft der Arbeiter das ÖI mit einem Löffel $\mathrm{ab}$ und scheidet es mit Hilfe eines Blech-Trichters vom mitgeführten Wasser. Vgl. Abb. 122 aus Schimmels Berichten.

1) Vgl. Kremers (Gildemeister u. Hoffmann). Ich möchte annehmen, daß seine Darstellung irrtümlich, die meine richtig ist. Das spezifisch leichte Öl kann unmöglich, da es a uf dem Wasser schwimmt, replace the water in the flask. Sie soll zumeist eine in Indien sehr häufig anzutreffende viereckige Branntweinflasche sein.

$\Rightarrow$ Vgl. die Lut a oben S. 104, 40, 54 . 
ich

sa-

cht

ien

Die

ten

ien.

lem

ien-

kel-

nen

lem

; ÖI

ers

Dar-

la es

sehr

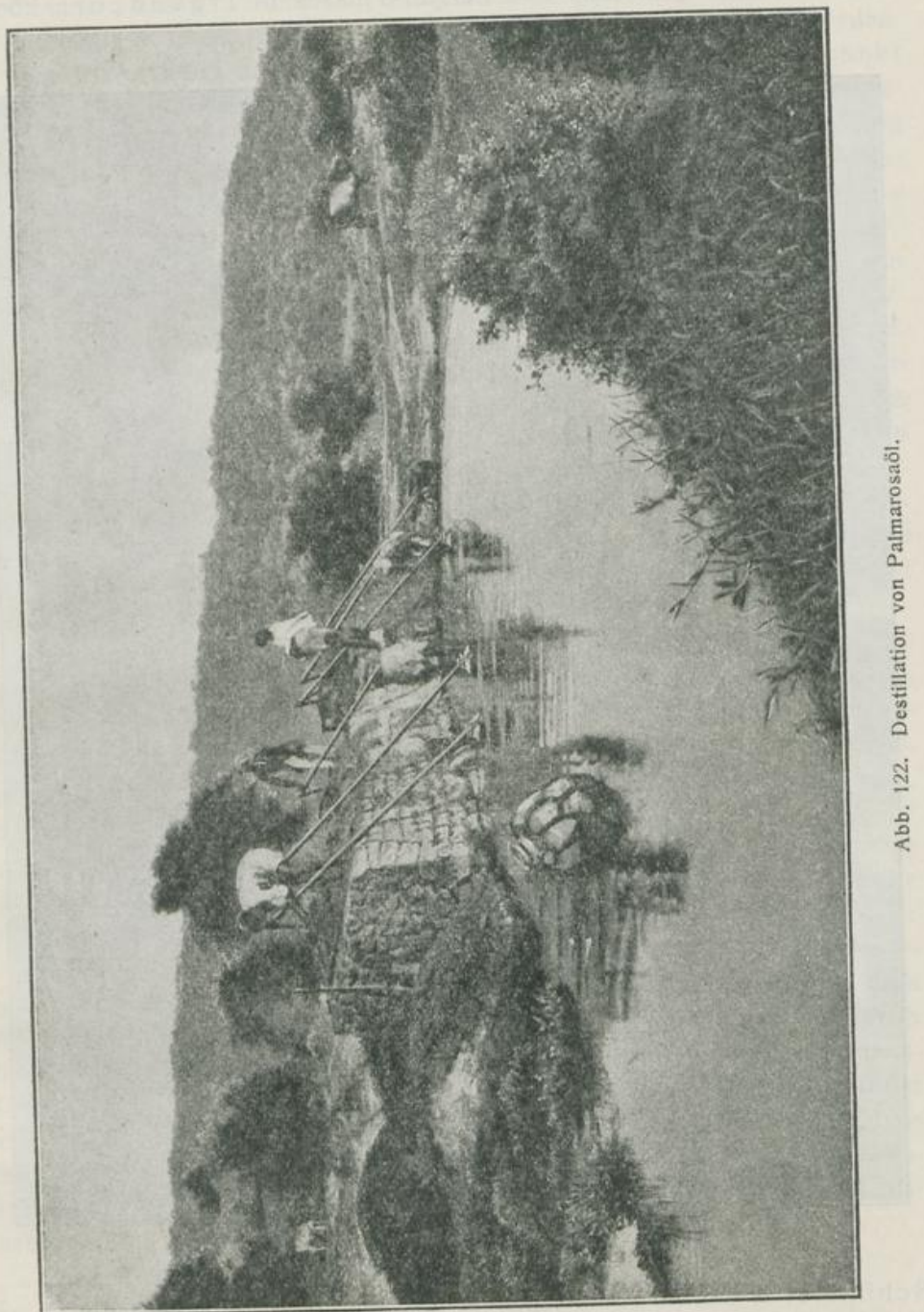


Eine „Native"-Destillationsanlage für Lemongras-Öl, wie es im südlichen Vorder-Indien jedenfalls auch recht lange schon dargestellt wird und zwar eine aus der Nähe des Periyar-Flusses in Travancore können

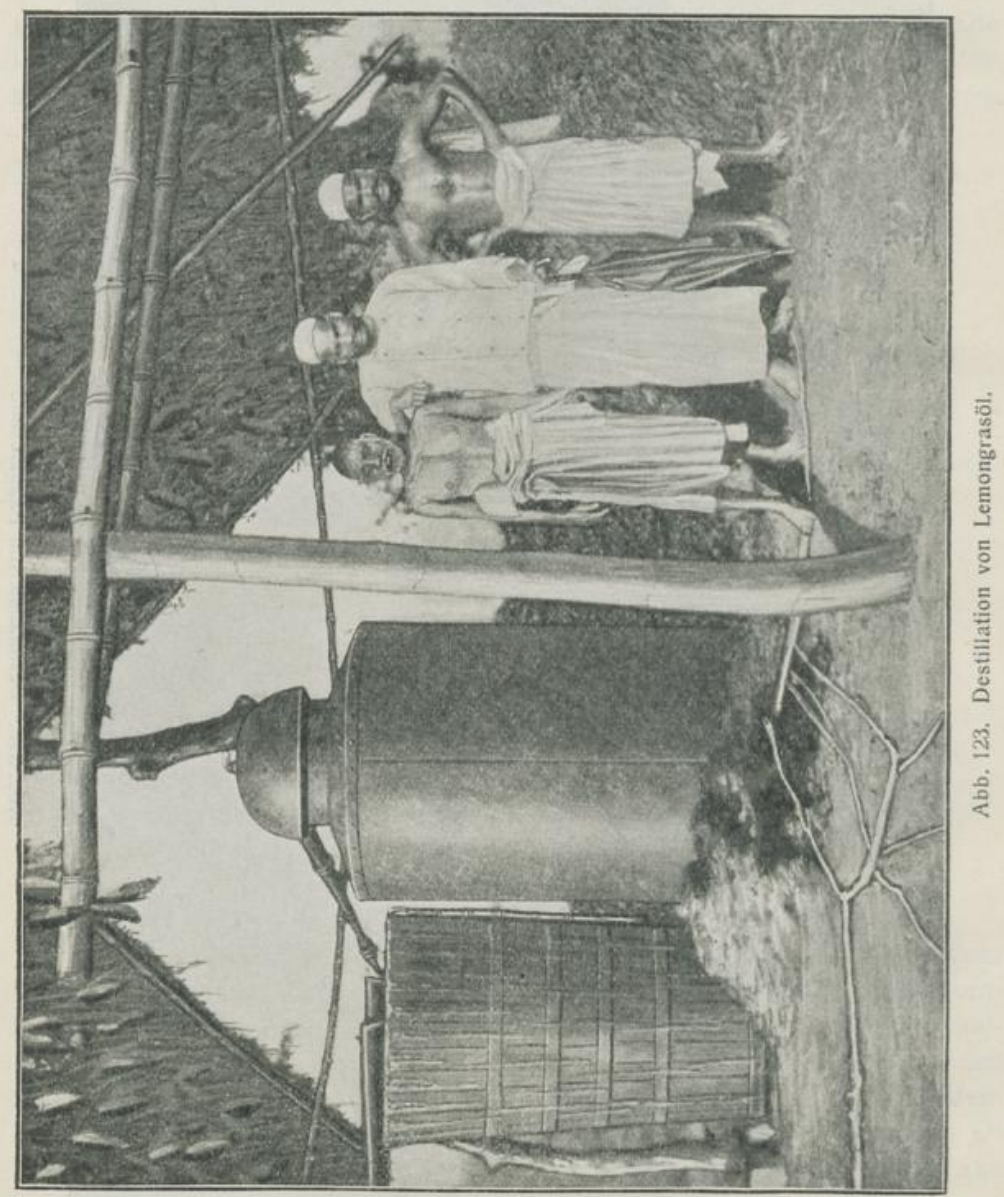

Schimmel \& Co. in ihrem April-Bericht von 1910 nach Aufnahmen von Reinhart an Ort und Stelle zeigen. Das Gerät stellt sich offensichtlich auch wieder als eine Verquickung bodenständiger und eingewanderter Kultur dar. Das Auffangegefäß wurde schon weiter oben auf S. 80 vorgeführt. 
Etwas vollkommener immerhin ist die Einrichtung, die auf der andern Seite der Erde, in Mexiko, zur Darstellung des Linaloe-Öls dient. Die zylindrischen, aus galvanisiertem Eisenblech hergestellten Blasen stehen auf gemauerten Öfen, die mit dem abdestillierten Holz geheizt werden. Der kupferne Helm hat eine Mohrenkopf-Kühlung. Zwei Schnäbel gehen durch ein Kühlfaß, das für gewöhnlich aus den Flüßchen gespeist wird, deren Nähe gesucht wird. Vorlagegefäße sind häufig alte Petroleumkanister. Verschmiert werden die Geräte mit dort gefundenem kohlschwarzem Lehm. Vergl. Abbildung 124 aus Schimmels Bericht 1907.

Eingemauert ist die verhältnismäßig flache und breite Blase, die in Virginien in Nord-Amerika zur Destillation des Wintergreen-Öls ${ }^{1}$ ) verwendet wird, und ähnelt immerhin etwas dem Gerät, das ebenfalls in NordAmerika zur Darstellung des Terpentin-Öls verwandt wird, das in dem

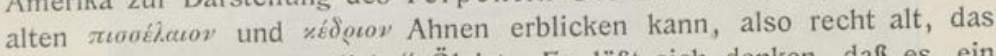
älteste bekannte „wesentliche" Öl ist. Es läßt sich denken, daß es, ein Bestandteil des wohlbekannten Terpentins, zu Darstellungsversuchen geradezu anlockte. Daß es in China und Japan womöglich auf noch ältere Bekanntschaft und Verwendung zurückblicken kann, verrät die jedenfalls uralte Darstellung von Lacken, die unzweifelhaft in Terpentinöl gelöst wurden. Bis in die Mitte des vorigen Jahrhunderts dürfte Terpentin stets "trocken" destilliert worden sein. Lémery verarbeitet dieses Weichharz mit Werk gemischt, erst bei gelindem Feuer, um einen Esprit volatile, bei etwas verstärktem, um ein Huile claire, schließlich jaune und endlich ein rouge zu erhalten, die er "separement" in Phiolen aufbewahrt. Hundert Jahre später destillierte man, wie auch Krünitz z. B. berichtet, mit besserm quanti- und qualitativem Ergebnis den Terpentin unter Zugabe von Wasser, und diese Arbeitsart hat man wohl seitdem fast durchweg in Frankreich, selbst wohl in Rußland eingeführt und nach dem, nachgerade wohl größten Erzeugungsland Nord-Amerika übergeführt. Eine andre wie sie ist jedenfalls in dem von Tschirch in der Abb. 160²) wiedergegebenen Gerät nicht möglich. Man sieht auf ihr links den vermutlich eingemauerten, flachen großen $\mathrm{Alambik}$, dessen $\mathrm{Schnabel}$ querüber nach dem großen $K u ̈ h l f a ß$ geht. Vielleicht ist die „Blase“ metallen, vielleicht nur ein kleiner kammerähnlicher oben gewölbter oder mit einer Metalldecke geschlossener Raum. In der dem Beschauer ${ }^{3}$ ) zugekehrten Wand scheint eine „Abstichöffnung" für den Destillationsrückstand ausgespart zu sein, der wohl, so weit möglich, in den gemauerten Trog gelassen wird.

3) Die Abb. 110 stellt eine auf der Höhe der Zeit stehende Verbesserung dieses sehr einfachen Gerätes dar. 


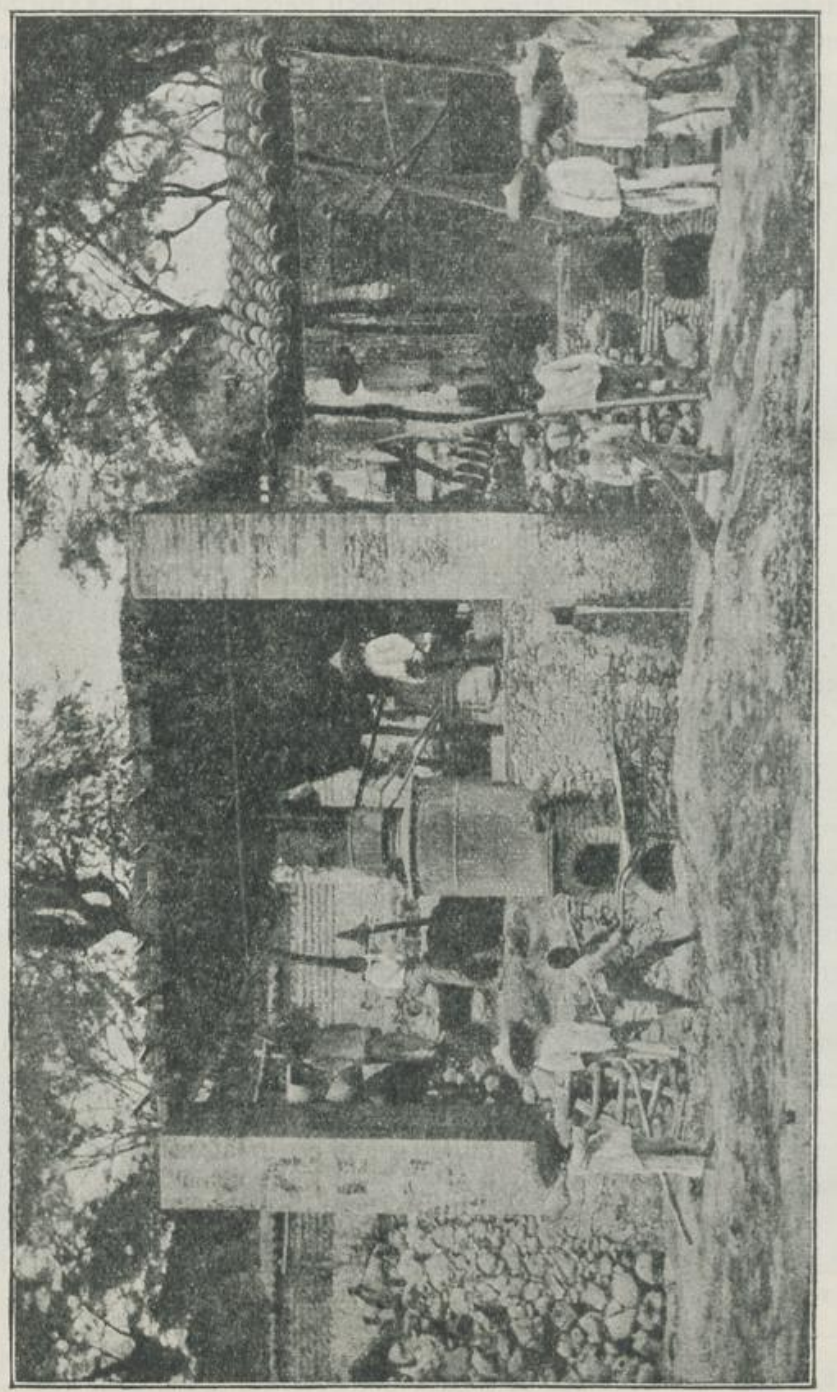


Von Familie zu Familie, vom handwerksmäßigen Destillateur ${ }^{1}$ ) auf seine Söhne und so weiter, erbten sich jedenfalls die Vorschriften für die Rosenöldarstellung wie im Osten, in Persien, dem mutmaßlichen Stammlande der "Königin der Blumen", in Arabien und in den Balkan-Ländern, und ganz ebenso, kann man wohl mit Recht annehmen, bediente man sich nach uraltem Muster geformter Gefäße, auf deren Gestaltung, aus räumlichen Gründen schon, zum wenigsten die für das Abendland maßgebende arabische (Al-)Chemie kaum Einfluß ausgeübt haben kann. In den Rosenöldestillationsgeräten dürften wir also sozusagen direkte Nachkommen allerältester Vorbilder erblicken. Wenn der oben schon erwähnte arabische

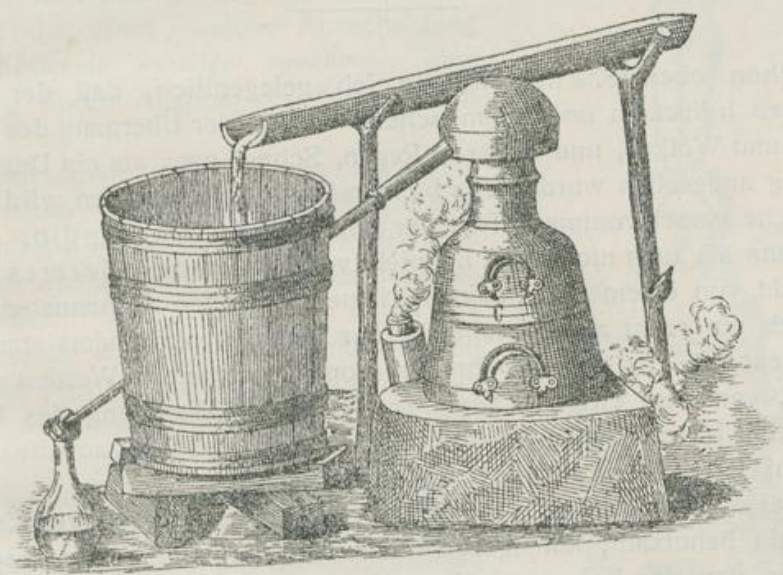

Abb. 125. Destillation von Rosenöl in Bulgarien. Vgl. S. 81 .

Reisende Dimaschqî in seiner Kosmographie über die in der Nähe von Damaskus benutzten Geräte ${ }^{2}$ ) berichtet, daß sie innen eine Art Rinne oder Gesims (Itrîz) trugen, so dürfte das einer Einrichtung gleichen, wie wir sie im kleinen bei manchen Alambik, im großen bei dem auf S. 132 beschriebenen Cassiablütenölgeräte der Chinesen kennen lernten. Die Zeichnung, die Wiedemann ${ }^{3}$ ) von augenblicklich noch in der Nähe von

1) In welcher großzügigen Art die Destillation von Rosenwasser und - Öl schon frühzeitig betrieben wurde, geht aus der Nachricht hervor, die Istach ry, wohl zwischen 915 u. 20 bringt, daß der Staat die Häuser, in denen in der Nähe von Sch iras solches Gewerbe betrieben ward, besteuerte. Daß ihre Erzeugnisse bis China, Afrika und Spanien verschickt wurden, teilte ich schon in meiner Geschichte mit.

2) Vgl. oben S. 35 .

3) I. c. S. 247 . 
Damaskus verwandten Geräten bringen konnte, ist kaum den Tatsachen entsprechend. Man kann sie aber immerhin in Einklang bringen mit der Ausgestaltung der chinesischen Geräte.

Nach den Balkanstaaten kam die Rosendestillation im XVII. Jahrhundert unzweifelhaft vom Orient. Die Geräte aber gleichen völlig den westlichen Vorbildern, die nicht unwahrscheinlich von Italien über Venedig zu ihnen gedrungen sein mögen, bis auf die erwähnte, ganz einzig dastehende Krempe oder einen Sims, den der Helm deutlich erkennen läßt. Vielleicht ist er als Überbleibsel aus der Heimat der Industrie anzusprechen. Eine Antwort auf diese Frage wäre auch in kultur- und handelspolitischer Beziehung interessant ${ }^{1}$ ).

Schon oben (S. 2 ff.) erwähnte ich gelegentlich, daß der Wechsel zwischen irdischem und himmlischem Wasser, der Übergang des ersten in Nebel und Wolken, und weiter in Regen, Schnee usw. als ein Destillationsvorgang angesehen wurde. Als Beschreibung einer solchen wird auch der mystische verschwommene Text der sog. Tabula Smaragdina gedeutet, die, wenn sie auch nicht uralt ist, nicht vom Götterboten Hermes, sondern vielleicht von einem unter seinem Namen gehenden Alchemisten stammt, so doch ein recht altes, vielleicht aus dem XI. Jahrhundert stammendes Dokument ist. Es heißt in ihr, um vom allgemeinen „Werden und Ver-

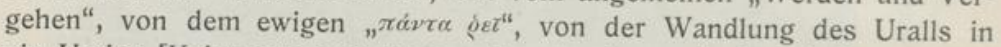
ein Ureins [Universum aus unus und vertere], mystisch auf die erstrebte Möglichkeit der Transmutation hinzuweisen:

„Der Welt Kraft bleibt ungeschwächt, auch wenn sie zur Erde wird. Wenin du behutsam, kunstgerecht das Flüssige vom Festen trennst, so steigt es von der Erde zum Himmel, dann steigt es wieder herab und nimmt die alte Gestalt an. Da hast du das Wunder des Weltalls, und alle Unklarheit weicht von $\left.\operatorname{dir}^{2}\right)$."

Analog und unsern Anschauungen entsprechend, drücken sich spätere Schriftsteller und Gelehrte (Megenberg, Lonicer usw.) $)^{3}$ ) aus. Für das,

1) Es sei an dieser Stelle darauf hingewiesen, daß der s. Z. durch seine Unmenge von kleinen Mitteilungen sehr bekannt gewordene frühere bayrische, dann griechische Apotheker und Prof. der Chemie und Pharmazie in Athen Xaver Landerer im Jahre 1847 (Buchners Repert. 96, 401) berichtete, daß in Macedonien aus in einen Brei gemahlenen Rosen ein Saft ausgepreßßt und an die Sonne gehängt würde. Nach wenigen Wochen hätte sich oberseits Rosenöl ausgeschieden, das von Smyrna und Alexandria aus in den Handel käme. Aus diesem Berichte, der ia kaum anzuzweifeln ist, kann gefolgert werden, daß, wenn Galen (vgl. meine Geschichte S. 175) beobachtete, daß aus seinem Rosensaft sich ein schweres Prinzip, ähnlich der Amurca aus dem Öl, dann ein leichtes, über ihm ein gärendes, schlieflich ein sehr reines abschied, dieses letzte, das Produkt einer "Destillation“ im Sinne des Volks, in der Tat ätherisches Rosenöl war.

\#) Vgl. meine Geschichte S. 186.

") Wie schon oben z. B. S. 3 angeführt ist. 
was man im Makrokosmos, der Welt, zu beobachten glaubte, suchte man im Leben des Mikrokosmos Mensch nach Analogieen.

Nach hippokratischen Anschauungen, die sich später bei Aristoteles wiederfinden, machte sich im Körper das $q \dot{i} \hat{\varepsilon} \gamma \mu \alpha^{1}$ ) [kehrt im lat. flamma wieder], ein zähflüssiger, giftiger Saft, durch Entzündungserscheinungen (im übertragenen medizinischen Sinne) unter Wärmeentwicklung ähnlich geltend wie die im Körper herumziehende Krankheitsflüssigkeit, das

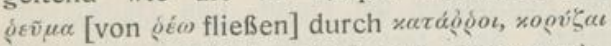

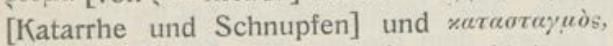

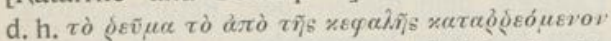

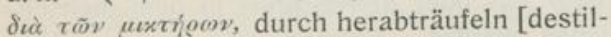
lieren] der ins Haupt gestiegenen Krankheitssäfte aus der Nase, welche Ausscheidung

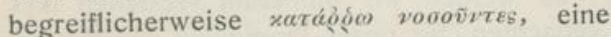
Gesundung durch Ausfluß zur Folge haben mußte ${ }^{2}$ ).

Da mit allen andern auch die Heilwissenschaften von den „trügerischen" Griechen nach Rom gekommen waren, finden sich auch deren Anschauung und die bez. Redensarten wieder. Das Haupt wird durch die Krankheitssäfte schwer, schmerzend, es fühlt Gravedo [vgl. gravidus], Benommenheit, Kopfweh, der Mensch, bekommt Pituita [beiläufig zum deutschen Pips geworden], Schnup. fen, er wird durch häufiges Nasenlaufen geplagt, „vexatur crebris destillationibus narium" (Plinius, Celsus), weil der „hum or (die spätere „Humoralpathologie" fußte auf den eben erwähnten alten Anschauungen und des großen Hohenheim-Paracelsus Anschauungen von der Ausscheidung des Tartarus als Krankheitsstoff ebenfalls) de capite in nares destillat".

Daß solche Anschauungen, die sich ja,

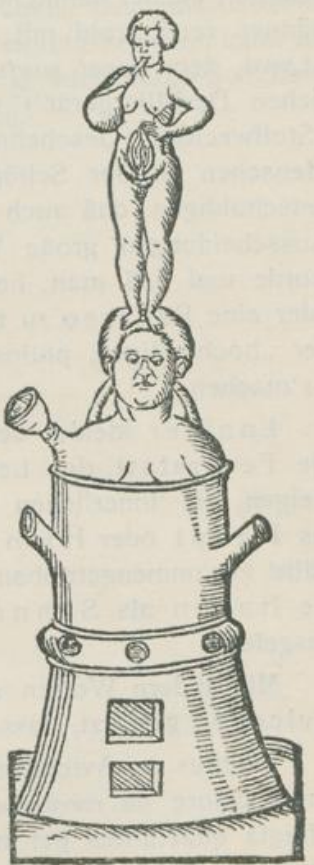

Abb. 126.

Allegorie der Destillation bei Libav. wie gesagt, auf gar nicht anzuzweifelnde Beobachtungen stützen, Bestandteile späterer Wissenschaft wurden, jetzt noch die Volksheilkunde beherrschen und in der modernen Wissenschaft trotz aller Verbesserungen und Ausgestaltungen wieder zu erkennen sind,

1) Vgl. auch oben S. 62.

2) Als Seitenstück sei erwähnt, daß Vergil, in den Georgica, auf das als gefährliche: Gift verschricene, nicht ganz klar zu stellende Hippomanes anspielend, 3,28 singt: Hinc demum Hippomanes vero quod nomine dicunt Pastores, lentum destillat ab inguine virus. 
ist nicht eben wunderbar. An dieser Stelle soll nur darauf hingewiesen werden, daß dem großen Araberarzt und Chemiker Rhazes der Magen als Destillierblase erscheint, der Kopf als Helm, die Nase als Kühlrohr (vgl. die kalte Nase und den kalten Kopf als Zeichen der Gesundheit), aus dem das, was im Magen durch Digestion im alten Sinne erzeugt ward, zum Teil wenigstens, ausgeschieden wird.

Hohenheim, der große Reformator der Natur- und Heilwissenschaften ist der nämlichen Ansicht. Seine tartarischen Ausscheidungen können recht wohl mit den Faeces, dem Blasen- oder Retorten-Rückstand, dem Caput morturu, dem Ex- oder Recrementum in dem menschlichen Destilliergerät ${ }^{1}$ ) verglichen werden. Erinnern wir uns an diese „Stoffwechsel"-Geschehnisse, an die-hohe Stellung des MikrokosmosMenschen in der Schöpfung, so werden wir immerhin verstehen und entschuldigen, daß auch den gedachten, für unser Empfinden widerlichen Ausscheidungen große Wertschätzung als Arzneistoff entgegengebracht wurde und daß man, heiligen Ernstes voll, versuchte, auch sie in Gold oder eine Panacee zu transmutieren, sie zur Grundlage der „áyia $\tau \dot{\varepsilon} \chi^{\prime} \eta^{\prime \prime}$, der „hochheiligen, philosophischen" Kunst des Hermes Trismegistos zu machen.

Lonicer kleidet den Destillationsvorgang in folgende Worte: Durch die Feuerstatt der Leber, die Pfanne oder Capell des Magens steigen die innerlichen Dämpf durch natürliche oder äußerliche Hitz ins $\mathrm{Haupt}$ oder Hirnschal als ein Destillierhelm auf, durch Kälte zusammengetrieben, werden sie als Rotz oder $\mathrm{Schleim}$ durch die $\mathrm{Nasen}$ als $\mathrm{Schnabel}$ herabfallen, durch schnupfen und husten ausgefegt.

Mit andern Worten spricht der Klassiker der Destillation Porta auf Avicenna gestützt, dasselbe aus:

Vidimus ex Avicenna in catharro, quomodo vapores ex corpore a naturali calore ad cerebrum diffusi sua frigiditate in aquam coguntur et diffugia quaerentes per narium canales corriventur et defluxus facientes quasi per alambicis rostrum exprimuntur ${ }^{2}$ ).

Abhold allen Phantastereien der „Alchemisten“ ist Libav. Sein Streben ist, ihre verworrenen Vorschriften, die mehr verhehlen als enthüllen sollten,

1) Vgl, auch oben S. 58 .

$\left.{ }^{2}\right)$ Wie solche Anschauung ins Volk gedrungen, Gemeingut geworden ist, belegt auch für die Wende des XVI. Jahrh. Shakespeare. In Venus und Adonis sagt er: „From the stillatory of thy face comes breathe perfumed - dem Destilliergerät deines Antlitzes entströmt wohlriechender Hauch. In Macbeth heißt es: Memory shall be a fume and the receipt of reason a limbeck [aus Alambik entstanden] only - das Gedächtnis soll in Rauch aufgehen und das Behältnis der Vernunft nichts als ein Destillierhelm sein. Der Ausdruck Mohren-Kopf, Tête de more, spricht übrigens auch schon für die Tatsache des Vergleichs. 
sicher, allgemein verständlich zu gestalten. Aber auch er steht in seinen Anschauungen über die Lebensvorgänge im menschlichen Organismus fest auf dem eben kurz gekennzeichneten Standpunkt, und im Bilde legt er dar, wie er sich das menschliche Destilliergerät denkt. Wenn er für seine Allegorie ein Weib wählt, so ist nicht ausgeschlossen, daß er nebenbei an die Alchemie dachte, die in der Hauptsache "destillierte", als deren Kennzeichen aber "fraus, vanitas, dolus, sophisticatio ${ }^{11}$ ) angesprochen wurden, die mit dem Weibe auf die Welt gekommen sind. Vermutlich aber überlegte er, daß als Personifikation des Alls, des Universums, des Makrokosmus in seinem ewigen Fluß kaum jemand anders in Betracht kommen kann als das Weib, dessen hoher Bedeutung das Altertum ja auch durch Schaffung

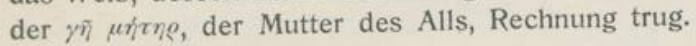

1) Geschichte der Pharmazie S. 242. 


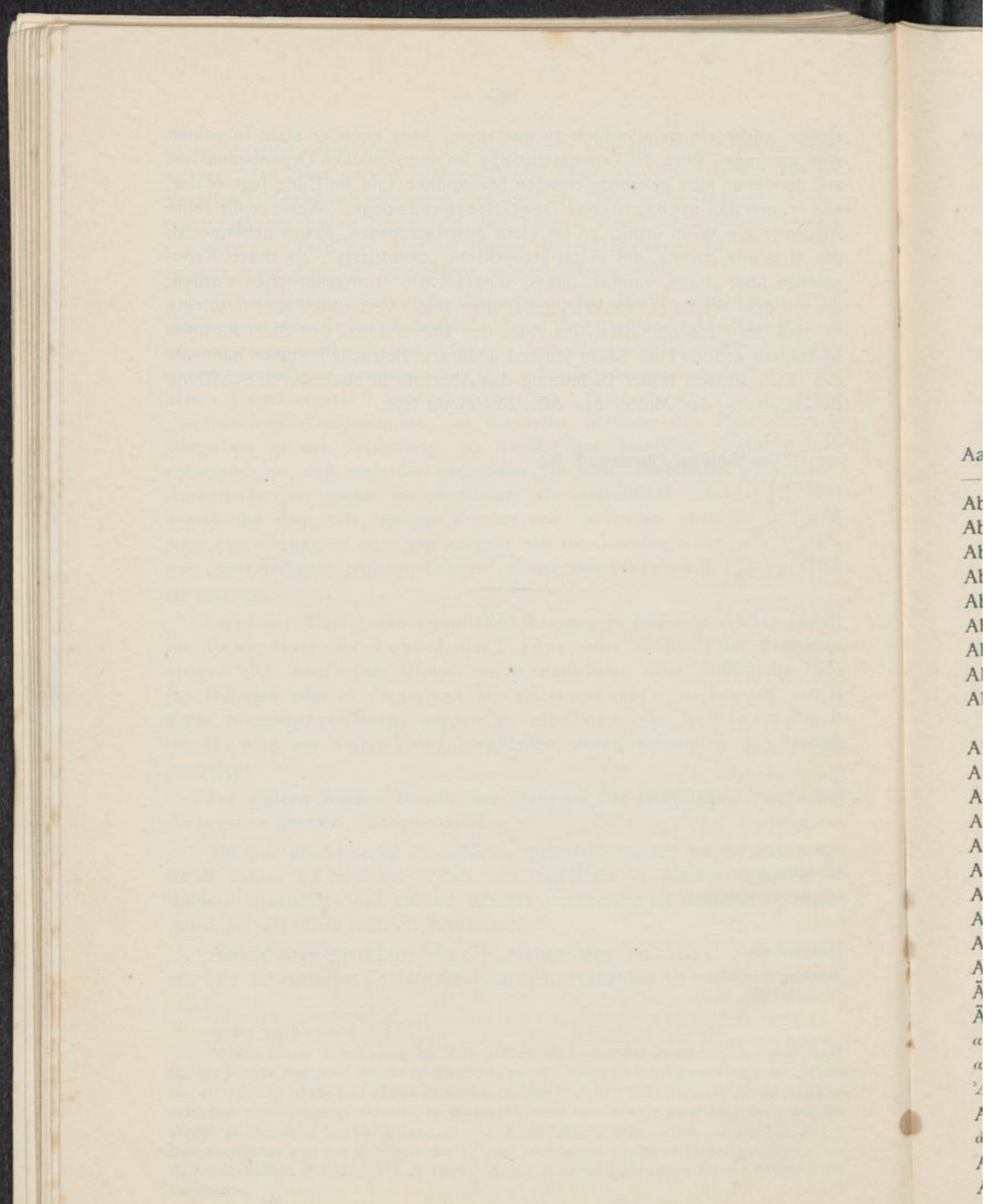




\section{Inhaltsverzeichnis.}

V. bedeutet Vorwort, [] = etymologische Angaben.

A

Aas $3^{1}$

\section{-Pflanzen $3^{1}$}

Abacus 82

Abdampfen von Schwefelsäure 120

Abfallrohr 23

Ablauf 19, 20, 52

Abscheiden der Öle 77, 132, 137

Absorbieren von Gasen 106

Absinth 48

Abu Abdallah Dschafir al Sadik 25

Abu Bekr Mohamed Ben Zakerija

el Razi 27

Abul Kasim 32, 74

Abu Musa Dschafir 25, 111

Acestides 11, 26

Acida 116

Acidité agréable 116

Acid. sulfuric 117

Activa instrumenta 14

Adam, Ed. 96

Aëtius von Amida 26

Agdah 32

Ägypten 20,264

Ähnliches verwandt 6

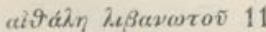

àiท่อ 43

Axaxia $12^{5}$

Akazien-Gummi $12^{\mathrm{s}}$

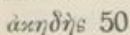

Akestiden 11, 26

Alambic, nouvelle construction 85
Alambics voyageants 137

Alambicus coecus $30,31,32$

- rostratus 31,32

Al 'Amâ 28, 31

Al 'Amjâ 28, 31

Alambik 51, 52

- turmähnlich 48

Al Anbiq Dât al Chatm 28

Al Aqdâh 28

Al Atâl 28, 32, 115

Al Atûn 29

Al Auwan $28^{\circ}$

Al Batn $28^{1}$

Al Butaqa 28

Alcara $28^{3}, 51$

Alchemie 42, 120

- Kennzeichen 147

- trügerisch 147

Alchimiste, Le 132

Alechil 81

Alembik siehe Alambic

Alexander 17

Alexandria 25, $144^{1}$

Al Gaubari 38

a Hamâm al madmûm 31

Alkali minerale 107

Alkohol 35, 93

Alkoholisiert $35^{1}$

Al Kur 28

All, das 6, 143

Allegorie der Destillation 147

Alliaraeus $58^{1}$ 
Allium 17

Allonge 82

Al Mauqid 28

Al Mizza 35

Al Nâfich 29

Alonso Saavedra Barba 115

Al Quabila 28

Al Qanânî 29

Al Quara 28

Al Qawârîr 29

Al Salaja 29

Al Tabistân 29

Al Tannûr 33

Aludel 25, 32, 33, 115.

- -Ketten 32

- -Schnüre 111

Alumen $23^{1}$

Aluta 28

$\measuredangle \mu \beta \iota \xi 12^{2}, 28$

Ameisenwärme 91

Amerika, Nord- 141

Ammon carbonat 26

Ammoniak $26^{1}$

- -Absorbtion 106

Ammonium 32

Amplexantes 57, 58

Ampoule $52^{2}$

Ampullen $52^{2}, 55$

Amurca $144^{1}$

Anbiq 31

Anchusa Italica $36^{1}$

Andreasberg $114^{2}$

Anemius 32, [50]

Anis $30^{1}, 48$

Anke $137^{1}$

Anthon $105^{1}$

dขv paxev่s 10

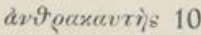

'A $v 9$ охххе 32

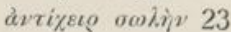

Antimon 35

dสóo $\tau \alpha \grave{s} \iota \varepsilon$ 23"

Apotheke 40,59

- Kapuziner- 82, 83
Apotheke, Laborator., Dampfapparate 99

- - Destilliergeräte 99

- mangelhafte $74^{1}$

Apscheron 125

Apyron $23^{1}$

Aqua ardens 96

- A(u)rantiorum venalis 46,48

- Cichorii $36^{8}$

- coelestis foetida $58^{1}$

- - virginea $58^{1}$

- eximie fragrans 46

- fortis 68,82

- Hungarica 35

- mercurialis $58^{1}$

- Naphae 46

- quatuor florum cordialium $36^{4}$

- Violarum $36^{4}$

- vitae $35,41,43$

- - simplex 63

Aquavit-Women 41

Araber-Art 36, 38, 81, 90, 96 1143

Arakà 130

Arak al Khamr 28

'A oyiélucuc $12^{5}$

Arimaspi 115

Aristoteles $5,7^{2}, 16,18,21,145$

Arnaldus von Villanova $35,40,49,59$

Aromatica 41

Arsen 32

- -Sublimation 111

Artemisia 48

Artifex hermeticus 56

Artificium hermetice stringendi 55

Arundo 19

Asbest 54

Asche, Erstehung aus der 119

Aschenbad 22, 31, 67

Aschensalz $74^{1}$

Assakar 28

Assyrien 20

Athanasia 43

Athanor 31, 32, 50, 67, 93

Äther 42, [77], 96 
Ätherisch [43]

Äthylnitrit 42,96

Atramentum librarium 3

Ätzende Holzdestillationsprodukte 7

Aufbewahrung der ätherischen Öle 74,76

Auffangerohre 11

Aufschließen der Körper 73, 76

Aufstellen der Vorlagen 80

Augsburg 49, 67

Auripigment 32

Aurum potabile 92

Ausbeuten an ÖI 48

Ausblühen 107

Auslaugen 46

Ausscheidungen, tartarische 146

Aussüßen 46

Ausziehen siehe Extrahieren

Authepsa 29, 32, 33

Autoclaven 58

Avicenna 146

\section{B}

Backen 8.

Backofen 12, 59

- -wärme 91

Bad mit Dampfheizung 73

Badachsan $26^{1}$

Bäder s. u. Asche usw. 67

Bagdad 25

Baldrian $3^{1}$

Balkan 143, 144

Ballon 119

- -blasen 118

Ballons f. Säure 121

Balnea 61 ; s. auch Bäder

Balneum Mariae 22

- Maris 22

Balsame 17

Balsamkocher 18

Bamberg 135

Bambus 19, 128

Banausen 18

Bär $57^{1}$
Barba 32, 115

Barcelona 35

Barry $95^{1}, 100$

Bas, le 132

Basiatio 58

Basra 25

Baudot, A. $48^{3}, 66^{1}, 135$

Bauerdirnen 120

Baumé, A., 66, 79

Becher 32

Becher, Joh. Jak., 125

Bechergläser 32

Beckenkühlung 62

Beddoes 126

Behelfe 130, 137

Beindorff $87,88,99$

Beleuchtungsgegenstände $33^{\text {1 }}$

Bellifortis 73

Belon 100, 124

Benedictiner 41

Benzin 96

Benzoesäure 115

Berchile 32

Bernewyn $65^{1}$

Bernhardt 117

Bernstein $65^{1}$

Beschlagen 31, 33, 67

Beschränkung bei Geräte-Anschaffung 88

Berthelot 24

Berzelius 28 ${ }^{1}, 31,67$

Beya $58^{1}$

Biringucci $62,63,64,91$

Birkenteer 59, 125

Bitumen Betulae 125

Blanchet 70

Blase (Tier-) 51, 125

- -balg 12, 29, 40, 51

- -tisch $56^{1}$

Blätterchen $52^{2}$

Blechschere 29

Bleierner Hut $61^{\text {3 }}$

Bleiglasur $49^{2}$

Bleikammern 119 
Bleiweiß 54

Blinde Ambik 32, 55

- der und die, 28

- Kolben 54

Blumenthal 96

Blut 54

- faulendes $3^{1}$

Böhmen 59

Bohnenmehl 138

Borago 36ํ․ 48, 135

Boerhave 82

Botia 51

Botrus 51

Bouilleurs 94

Bourgogne 48

Brandenburg, Joachim Friedrich von $21^{1}$

Brandopfer 16

Branntwein $65^{1}, 94$

- -brennerei 94

- -destillat. im Gr. 85

- pest 41,42

Breathe $146^{2}$

Brennen $65^{1}$

Brenner und Brennerinnen 41

Brennzeug, gläsernes 65

Brevet auf Gerät $94^{2}$

Brotteig 90

Brühl 105, 107

Brûlerie 94

Brunschw(i)y(g)(c)k, Hieron. 43, 45, $49,51,53,58$

Buccia 32, 51, 52

Buchner, Joh. Andr. $88^{2}$

Büchsen-Pulver $65^{1}$

Buglossum $36^{1}$

Bulbula 38

Bulgaren 80, 81, 143

Bulkasis (s. a. Abulkasis) 32

Burghardt, G. H. 70

Bussen $65^{1}$

Bût eber B. 29, 111

Butaqa 27

Butter [137 $\left.{ }^{1}\right]$
C siehe auch $\mathrm{K}$ und $\mathrm{Z}$.

Cajeput 137

Calamus 19

Calor naturalis 92

Caelum [4]

- philosophor. 522

Calcinieren 61

Campana 117

Campanien 18

Campher 27, 135

- -destillation 133

- -säure 48

Calamus 19

Canalis 9, 19

Candelae 92

Capelle 10, 22, 25

Capella cinerea 31

Caphura 27, 48

Capillarität 15,26

Capitella sibi imposita 32

Capua 17

Caput [29 $\left.{ }^{1}\right]$

- Aethiopis 61

- Arimaspinum 115

- Cyclopinum 115

- mortuum 46, 48, 68, $74^{1}$

Cara 51

Carbonarius 10

Carbones coquere 10

Cardamom 38

Cardanus $28^{1}$

Carminativa 41

Caryophylli 38, siehe auch Nelken

- abdestillierte 48

Cassel, Hofapotheke 74,77

Cassiablüten-Destillat. 130, 134, 143

Caudata penula 90

Cedrus 13

Centifofie 18

Cerea $33^{1}$

Ceratio 32

Cereficatio 32

Cerebrum 146

Chabat $29^{1}$ 
Chalder-Weit 5

yaixiov 23

Cham 20

Chapiteau 107

- aveugle $115^{1}$

Charas, Mos. 78, 79

Charha 51

Cheiri flores $36^{3}$

Chemiker Ztg. Cöthen 851, 127

China, Destillat. 20, 127, 130, 133, 141 yovoozousic 21

Chyrotecae 48

Cichorie $36^{5}$

Cinder $122^{1}$

Cinnabaris 12

Citrus 14

Clavis mixtionis 120

Cli(y)ssus [120], 121, 125

- Sulfuris 119

Coagulieren 120

Co(a)k(e) 122, 126

Coelius Apicius $9^{1}, 22$

Cognac-Destillation 96, 97

Cohobieren 46, 47, 48, 56, 73

Cokeofen 122, 126

Colcothar 50

Collum productius 82

Coelum siehe Caelum

Comes obsequii 27

Confortantia 41

Congelatio 32

Continuierliche Extraction 105

Coquere 6, 8, 124

Cordova, Kalender von 28

Cordus, Euricius 20

- Valerius $77^{1}, 96$

Cornu cervi-Destillation 126

Cornue [56]

Corty 95

Cöthen siehe Chemiker Ztg.

Cucurbita 14, 19, 30

- coeca 32

- fundo globosa 52

- lata 52
Cuines 68

Cydonia 20

Cypern 11

Cyperus 19

Cypressen 10

D

Dach 4

Dacht s. Docht

Dägen, schwarzer 59, 125

$\delta \dot{\alpha} \iota s, \delta \dot{\alpha} s=$

dúxovov 7

Dambergis 232

Dame Jeanne 51 .

Damascus 25

Dampf 60

- -apparate 99

- -destillation 94

- - erste 72

- fälschlich dafür gehalten 72

- Heiz- 73, 93

Dariot $64,65,66,71,72,74,84$, 88,94

Darius 17

Darmstädter, Ludw., Handbuch zur Geschichte d. Naturwissensch. u. d. Technik, 1908117.

Daru 26'

Dauerbrenner 49

Dee, John 21

Demachy, J. F., 62, 67, 68, 69, $77^{5}$. $94,117,118,122$

Demijohn $51^{2}$

Dentiscalpia $76^{2}$

Dephlegmatoren 23, 62

Dephlegmieren durch Schwamm 63 - - Perlen 63

Descensorium 25

Destillateurin 21

Destillieren, Erklärung [19], 59, 144

Destilliergeräte mit Dampf 99

Destillierknechte 81

Destillatio calida 61

- humida 59 
Destillatio obliqua 60,68

- per arenam 61

- ascensum 60

- balneum roris 61

_ - balneum vaporis 61

- cinerem 61

- descens(ori)um 14, 29, 59, 60, 74,111

- - descens(ori)um calida 30

- descens(ori)um frigida 30

- filtrum 26, 30, 78, 79

_ formicas 91

- - inclinat. 60

- limaturam ferri 61

- limaturam martis 61

- vesicam 61

- recta 60

- sicca 59

Destillation durch Wolle 15

- feuchte 59, 60

- im Großen 20

- - luftverd. Raum 94, 105, 106

- Wasserstoff 105

Destillationszusätze 74

Destillieren in Apotheken 40, 83

- Klöstern 40

- trocken 11, 59

- s. auch die einzelnen Gegenstände

Deutsche Tüchtigkeit 65

Deutsch stinkend Wasser $58^{1}$

Dichten 29

- mit Leinenstreifen 32

Diergart $20^{2}, 49$

Digerieren 25, 54, 56, 90, 100

Digeriergefäß 43

- blindes $28,31,32,54,55$

Dijon 48

Dimaschquî 26, 35, 37, 143

Dingler 87, 88, 89, 99

Dioskorides $8,11,12,15,18,20$, $21,22,39,111$

Diploma 24, 30

Dirham $38^{1}$

Distillatio $=$ Destillatio
Döbereiner, J. W. 103, 105

Dochte 26, 78

Dominikaner 41

Dörren 6

Dossie $119^{1}$

Douille [92]

Drebbel 118

Dreifüße 80,81

Dresden, Hofapotheke 49, 67

Drewo 15

Druck in Gefäßen 58

Dundonald, Earl of 125

Dunstan $58^{1}$

Dünste 2, 68

Dunstsammler 43

Dy(i)otae 55

\section{E}

Eau de Nafe, Naphe $36^{4}$

Edfu 20

Edulcorieren 46

Einbalsamieren 13

Einbuchtung 58

Eisenfeile 54, 67

Eisenoxyd 74

Eisenrost 40

Eisenvitriol, kalziniert 71

Eiweiß 54

Eiweißkitt $12^{4}$

Elemente, vier 69

- in die, zerlegen 100

Elephantenschnabel 56

Elicieren 46

Elisabeth von England $21^{1}$

El-ixir 39, 42

Elixir ad longam vitam 43

zi.jरxyvov 92

Empedokles 6, $17^{2}$

Empirephma 71

Empyreumafreie Öle, darstellen 71

Endiviae $36^{5}$

Enfleurage 48

England, Elisabeth von 21

- Zinksublimation 111 
Ens 43

Entfettungsmittel $117^{2}$

Entzündungen 145

Ėrıyia 24

Ererbte Geräte 137

Erfindung der Salbendarstellung 18

Erlenmeyers Kolben 79

Ernsting, Arth. Conr., Nucleus totius medicinae $1770,30,32$, $51,57,59,60,69,76,103$

Erwürgen 32

Esprit recteur 43

- volatile 141

Esse 43, 119

Essentia [43], 48

- quinta [43] 48

Essentiell 43

Essig-Destillation 34

Euonymus Philiater 61, 62, 68, 69, $70,78,92$

Euphorbium 7

Evangelista pharmacopoeorum 34

Exaltation 46, 107, 116

Excipiens 78

Excrementa 146

Exhalatio 46

Extrahieren 40, 54

- bei Luftverdünnung 100

- kontinuierliche 105

- mit Rückfluß 103

- der Tugenden aus den Heilstoffen 64

Extraktivstoffe, bittere und würzige 41

Exsudare 7

Fabrica $58^{1}$

$\mathbf{F}$

Fabrikation in Klöstern 41

Faeces 46, 146

Fackeln $7^{5}$

Farnüß 12

Farsistan 18

Fässer, verpicht $108^{*}$

Fauler Heinz, siehe Heinz 50

Fäulung 76
Felssprengen $20^{1}$

Fenni 125

Fermentescere 76

Fermentum aureum $58^{1}$

Ferrum alcoholisatum $35^{1}$

Feuer, grade siehe Gradus und Ignis

- Prinzip 6

- griechisches 20

Feuerbaum 14

Feuerblasrohr $20^{\prime}$

Feuersetzen $20^{1}$

Fichten 10

Filioli $52^{2}$

Filtrare $78^{\circ}$

Filtrum per deliquium 30

Fimus 91

Firmament 4

Fistulae 19

Flaschen, langhalsige 29

Florenz 41, 79

Florentiner Flasche 79

Flores 107

Foculi 34

Formicas, per 91

Fornax [12]

Fornus 12

Foetisare $58^{1}$

Foetus spagyricus $58^{1}$

Four 12

Fourneau 12

Fournaise 12

Fraktionen $57^{1}, 69,70,92,104,105$

Fraktioniergerät 57

Frankfurter Taxe $48^{2}$

Frankreich 48, 69

Friedrich I. von Hohenzollern 42

Fuligo 7

Füllöfen 49

Füllschacht 49

Fumarium 7

Fumo siccare 7

Furnus 7,28

- Acediae [50]

- Incuriae [50] 
Gädda 88,90

Gadolin 85

Gagates 60

Galatia 10

Galeeren zu Scheidewasser 67, 68 - Öfen 69, 93, 117

Galen 11

Galenus dat opes 41

Gallier 125

Galmei 40

Garaye, de la, Chymie hydraulique. Paris 1746

Gärung 76

Gasfabrikation 125

Gas, Holz- 124, 126

- Knochen- 126

- -Teer 126

- -Wasser 126

Gasometer 126

Gay Lussac 85

Geber $14,25,26,34,78,111,114$

Geheimnisse, Buch der 28

Geist, saurer 123

Geister 31

Gelsomin 48

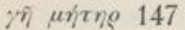

Geranium [57]

Geräte, erste 8

- aus Küchen- und Hausbedarf 80

- erste Destillier- 10

Gerstenalkohol $96^{1}$

Gesner, Conrad (Euonymus Philiater) $92^{1}, 95^{1}, 96^{2}, 100^{1}$

Geruch, Verbreitung $17^{2}$

Geschlecht der Geräte $31^{2}, 52^{2}, 57,58$

Gewölbe 4

Giftkanäle 26, 114

Giftmehl 114

Gifttürme 114

Giftwasser $58^{1}$

Gignere $58^{1}$

Gildemeister, E., V, $130^{3}$

Girardin $96,124^{\prime}$
Gläserne Geräte 65

- - gegen Bruch 67

- geboten 49

Glasbläser 56, 118

Glaspulver 54

Glasur $46^{2}$

Glauber, Joh. Rud., Furni novi philos. 1648 u. Pharmacop. spagyr. 1654 14,55

Glut, volle 61

Gluten spagyric. aquilae $58^{1}$

Gmelin $\mathbf{7 1}$

Goldblättchen 92

Goldschmiede 29

Göttersagen 6

Göttling, Joh. Friedr. Aug., Einltg. in die pharmazeut. Chemie 1738 $84,119^{1}$

Grabaddin 34, 72

Grade des Feuers 34, 60, 61

Gradus ignis $34,60,61$

Grassmann 234

Gravedo 175

Griechen, trügerische 144

Grundprinzip 6

Guajac 60

Guareschi, Icilio, Storia della chimica $64^{2}, 106$

Gummi Arabicum 7

Gur $35^{3}$

H

Haare, Tier- 54 *

Hagel 5

Hagen, C. H. 26 ${ }^{1}$; Lehrbuch der Apothekerkunst 1778 und später Hager, H. 43, 115; Kommentar zu den Pharmak. 1845

Hagers Dunstsammler 43

- Extraktionsgerät 105

- Vacuumapparat 95, 100

- Vorläufer 95

¿yía réxun 146

Hahnemann-Demachy 67 
Hakka 129

Hakuka 127

Hales, St. 126

Halitus 60

Halq 36

Hälse 36

Hamburg 122'

Hammer 29

Hammerschlag $30^{1}$

Handschrift in Cassel 24

- in Paris 24

- in San Marco 23

Handschuhparfüm $48^{1}$

Hannibal 20․, 76

Haraha 51

Harmkolben 52

Harz 7

Hasselquist $26^{4}$

Haupt 146

Häuser als Vorlagen 11, 119

Heber 78

- Stech- 62

- Winkel- 62

Hefe 74

Heiden, Anton de 46, 59, 92

Hein, Freund 50

Heinrich II. von England $96^{\circ}$

Heinz, fauler [50], 67

- roter 50

Helm 52

- Einbuchtung im, siehe Sims, Krempe, Einbuchtung usw.

- blinder 107

Helmkühlung 95

- mit Schnabel 28

Helmont, Joh. Bapt., 60; Ortus medicinae, Amsterdam 1648, 60

Heraklit $17^{2}$

Herauslocken, -saugen, -ziehen siehe extrahieren

Herbipolis 43, 135

Herd 28, 30

Herdfeuer 8

Hermes 6, 144
- Trismegistos 146

Hermetische Kunst 52

- Verschluß 31, 55

Herrenkolben 52

Hessen, Friedrich II. von 85

Hessen, Moritz von $21^{1}$

Himmel [4]

Hinrik 50

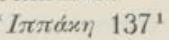

Hippokrates 145

Hippomanes $145^{2}$

Hirnschale 146

Hochheilige Kunst 146

Hoffmann V, $130^{3}$

Höfler 8

Hohenheim (Paracelsus) 77', 145, 146

Höhlen 4

Holland 118

Holzdestillation 7, 8, 9, 123

Holz-Essig 123, 124

- -gas 124

Homberg, W., + Paris 1715, 79

Honig 74

Horaz 19?

Hörnes $129=$

Houses 11, 119

Howard 100

Huile claire 141

- de Soulfre 117

Humor(alpathologie) 145

Hütte 8

Hüttenbetrieb siehe Arsen 114

- -Rauch 11, 12, 113, 114

Hydra 57

Hyssopus 135

\section{J (I)}

Jacobs $65^{1}$

Jahja Ben Maseweih 32

Japan, Destill. 127, 133, 141

Jasmin $17^{\circ},[48]$

latrochemie 43

latro-Chemikers Hauptaufgabe 64

Ichthyol 14 
Jericho 18

Jerichorosen $27^{1}$

Jerusalem, Tempel 18

Jesemin 48

Igniaria $17^{3}$

Ignis s. auch Feuer

- Artephii $61^{1}$

- blandus 61

- lentus 61

- parabolic 61

- lap. philosoph. 61

- sapientium 61, 91

- suppressionis 61

Incuria 50

Indien 20, 39

Indigofabrik 118

Infundibulus 77

Instrumenta activa 14

- nocturna $33^{1}$

- passiva 14

Joachim Friedrich $21^{1}$

Jordan $58^{1}$

Jorissen $83^{1}$

Irland $96^{1}$

Isis 22

Istachry $143^{1}$

Istichrâg 35

Itrîz 143

Juncus 19

Juniperus [14]

Jupiter Ammon, Oase des $3^{2}, 25$

Justinian 27

\section{K siehe auch C}

Kabsch Qaranful 38

Kadmeia 11, 12

Kahlbaum $22^{1}$

Kalmücken 130

Ká̀auos 19

Kalender von Cordova 28

Kaliumchlorid 74

Kamelmist $26^{4}, 34$

- -Feuer 25

Kaนйviov 21, 25

Kamillen 48

Kamin [21], 25

Káuevos 10

Kammern als Vorlagen 11, 119)

Kа́ $\nu \nu \alpha 19$

Kapillarität 63

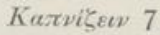

Kárvos 7

Kaput gehen, schlagen $29^{1}$

Kapuziner-Apotheke 82, 83.

Karthäuser 41

Käse [137 1 ]

- riechender $3^{1}$

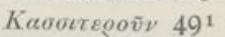

Kastner 93

Katarrh 145, 146

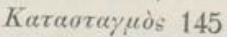

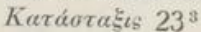

Kédoเov 141

Kedrion, Destillation 13

Kédoos 15

Keramik 8

Kegotášs 34

Kerze 31, 91, 92

Kessel 30, 38

Kette, goldene, des Zeus 6

- - des Homer 6

Khamr 28

Kiefern 10

Kieniges $\mathrm{Holz} 17$

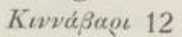

Kitab al Asrâr 28

Kitt $12^{3}, 19,30,40,54,137$

- feuerbeständiger 54

- Rezept, Preis 55

Klagk 74

Kleopatra 21, 32, 42

Khioga 119

Khißavos $11^{1}$

Khiбoos 119

Klöster 40

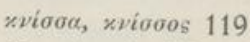

Knochendestillat 126

Knochenröhre 17 
Knochenverkohlung $12^{5}$

Ko(a)kbrennen $12^{5}, 122,126$

Koch-(Dampf-)Apparate 99

Kochsalz 54, 74, 78

Kochtopf 30

Kochversuch, erster 68

Kochen bei Luftverdünnung 100

Kochl 35

Kóyog $12^{2}$

Kohlen, tote 49

Kohlenbrennen 9

Kohlendampf 7

Kohobieren siehe Cohobieren 73

Kokosnußschale 137

Kolben 51

- mit Schnabel 30

Kolbenhals 52

Kölle 90

Kolophon 10

Kółzos 4

Komanos 21

Komarios 21

Konfizieren 40

König 117

Königin der Blumen 143

Kผิขย 15

Konstantes Niveau 30

Konstantin IV. $20^{1}$

Konzentrierte Wässer 45

Korinth 18

Kopf 146

- kalter 146

Körbe über Ballons 121

Körpervorgänge 145

Korsetts siehe Schnürbrüste 48

Koryza 145

Kosacken 129, 130

Kos 18

Koshti Apparatus 40

Kranwitholz 14

Kranzförmige Unterlagen 80

Kräutergärten 44, 47, 134

Kreidestopfen 54

Kreislauf der Elemente 6
Kremers V, $130^{3}, 138^{1}, 141$

Krempe 23, 37, 132, 143, 144

Krimm 129

Krüge 31

Krummhals 56

Krünitz 1291, 141

Küchenbehelfe 9, 130, 137

Küchenchemie 3

Küchengeräte 9, 130, 137

Küchenkunst 9.

Kufa 25

Kühlvorrichtungen 84,88

Kühler, Rückfluß- 57

- Weigel-Liebigs 66

Kühlgefäß, wagerecht 66

Kühlung auf dem Alembik 19, 40, 50

- durch Becken 62

- Schwamm 11

- Rindsblase 61

- Schlangen- 51, 64

- Stockwerke hohe 62

Kühlwasser, oben ablaufend 51

Kuhmilch 40

Kulturen von Pflanzen 27

Kunckel, Joh. 56, 112, $113^{1}, 114$

Kupferne Gefäße verboten 49

Kûr 31

Kürbis 14, 51

Kurpfuscher $49^{3}$

Kurtz 124

Kuwwa 33

Kütt siehe Kitt [20]

Kymia 51

Kyrene 18

\section{L}

Laborator. pharmazeut. 88

- Kapuz.-Apoth. 82, 83

- Universit. Altdorf 82

- Leiden $83^{2}$

- Utrecht 83

Lacke, Terpenthin- 141

Lacrima 7

Lac virgin. $58^{1}$ 
Ladanum 7

Ladenburg 71

$\operatorname{Lag}(0)$ enae $19^{2}$

Lagerfeuer 8

Lampadius, W. A. 121, 122, 126

Lampen 21, 31, 32, 92

Lana philosophorum $12^{1}$

Landerer $144^{1}$

Lateres 74

Laterinum, Oleum 74

Laterne 92

Lauge $65^{1}$

Lavendel 48, 135, 136, 137

Lavoisier, A. L. 100, 116

Lebensäußerungen 145

Lebenselexiere 41

Lebenswasser 25,35

Leber 146

$\lambda \epsilon \beta \eta=21^{3}, 22$

Lebon $94^{2}, 126$

Lefêvre $77^{5}$

Leinenstreifen zum Dichten 34

Lémery, Nic. $28^{1}, 43,47,55^{*}, 57^{2}$, $60,66,70,72,73,74,75,99,115$, $116,117,118,141$

Lemongrasöl 80, 140

Lentz 104, 105

Leo ruber $58^{1}$

Leo viridis $58^{\prime}$

Leonardo da Vinci 15, 26

Leonhardi 120

Lerang 137

Levkojen $36^{\circ}$

Leybold Nachf. $105^{2}$

Libav, Andr. 30, 48, 52², 55, 56, 64, $67,78^{2}, 81,84,87^{1}, 90,91,92$, 115,145

Liber servitoris 74

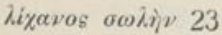

Lichter 21, 32, 69, 92; s. a. Kerzen Liebig, J. v. $67^{1}, 71,84,86$ àyvìs 3

Lilien 18

Limbek 146=
Linaloe 141,142

Lippmann, Edm., O. v. 20 ? 22

Liquoristes 94

Livius $20^{1}, 76$

Löffel abheben 138

Lonicer, Adam 35, 61, 70, 72, 144, 146

i.oxìs $122^{2}, 23$

Loricatio [67]

Lötrohr 55

Lowitz, Tob. 13, 63

Lucerna $33^{1}$

Lucretius Carus $4^{1}, 7^{3}, 17^{2}$

Luftpresse 95

Luftpumpe, Wasserstrahl- 105

Luftverdünnung 94

- durch Abkühlung 95, 100

- - Pumpe 94

Lullus, Raymund 96

Luta 19, 37, [53]; s. a. Kitt

Lutum philosophos 54.

- sapientiae 54

Lychnuchum 92

M

Macbeth $145^{2}$

Macquer, P. J., Chymisches Wörterbuch, bearbeitet von J. G. Leon-

hardi, Leipzig $1781 ; 117,119$

Mädchen zur Arbeit 120

Mafâtîh al 'Ulûm $28^{3}, 29,31,32,34$

Magisterium lapidis 34

Magellan 86, 88

Magen 146

Magdeburg 117

Magistrales 52

Mairan $17^{\circ}$

Majoran 18

Maisch-Vorwärmer 95

Maistre tuiau 23:

Makrokosmos 5

Mamoon 18

Mann, roter $58^{\prime}$

Manna coelestis 74 
Marchasit 25, 110

Maria 22, 24, 57

Marienbad 22, 70

Markasit 25, 110

Masch'al 31, 91

Matara 51

Mater $43^{1}$

Materie, tingierende $23^{1}$

Mat(h)eras 52

Matracia 52

- coeca 54

Matthioli, P. A., $36^{2}, 37,46,49^{2}$

Matulae 52

Mayerne, de 115

Mebellum 52

Midsias हैhaiov $26^{5}$

Megenberg, Conr. von 3, $7 \stackrel{2}{2} 12,59$, $61^{3}, 65^{1}, 144$

Megusa $129^{1}$

Mehl 54

Mehren $35^{2}$

Meiler 9, 125

Meiler, vervollkommneter 124

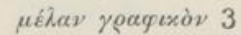

Memphis-Inschrift $24^{1}$

Mensch, Destilliergeräth 146, 147

Menstruum [103], $120^{1}$

Menthol $129^{1}$

Mesue 15, 34, 74

Metretae 52

Mexiko 141

Michaelsberg 44, 135

uıрòs 23

Milchrauschtrank 129, 130

Mineral-Zusätze 76

Minkeleers 126

Mirgal 30

Mist $26,32^{5}$

- Kamel- $26^{4}$

- Ochsen- $26^{4}$

Mitscherlich, Eilh. 90

Mohr, Carl Friedr., Lehrb. d. pharm.

Technik $1847 ; 103,115$

Mohrenkopfkühlung 51, 61, 63, 66, 141
Mollerat 124

Molucken 137

Mönch $51^{2}$

Montpellier 35

Moritz v. Hessen 21 ${ }^{1}, 77$

Moschus 38

Moschusweide 36

Motia 138

Mulierum opus $9^{1}$

Mustauqad 30

Mutajjan 31

Myrepsoi 17,18

uv์oov 17

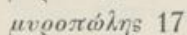

Myrrha $7,17^{2}$

\section{N}

Nachfüllvorrichtung 30

Nachttopf 52

Nanfa $36^{4}$

Naphe $36^{4}$

Naphte 123

- versüßte $17^{1}$

Narden-Wasser 27

Nares 145

Nase 3, 146

- kalte 146

Nasenlaufen 145

Nasus 113

Nasuta figura 90

Natrûn 29

Nau-scha $26^{1}$

Neapel 37, 45

Nebel [5]

Nebengeruch, störender 71 veixos 6

Nelken s. Caryophilli

Nelkenöl 77 ; s. a. Olea

- Darstellung 74

veqúl $\eta 5$

Nephtar $26^{5}$

Neroli $36^{4}$

Nestudar $26^{1}$

Neumann, Casp. $55,73,77^{1}, 78,116$ 
Nifl 4

Nitrum fixum 30

Nonne $51^{2}, 52^{2}$

Nordhäuser Vitriolöl $30^{1}, 37,69,93$, 117

Nosadar 26

Nubes 4

Nürnberg, Nationalmuseum 42

- Verbot von Kupfergefäßen 49

Nuschâdir 26

Nusiadal $26^{1}$

Nymphaea $36^{5}$

Nysadir $26^{1}$

\section{0}

Oase Ammon 25

Oberscheden 80

Obturatoren 54

б̆хего 9

Ochsenmist $26^{4}$

Ochsenzungenwasser 35

Ofen $28,88^{1}$

- chymischer 50

- Füll- 49

- Meidingers 49

- schwedischer 49

- sich selbst blasender 29, 33

- Wind- 50

Officinae 77

Ölbaumblüten $12^{5}$

Öle s. a. Olea u. unter den Namen der Rohstoffe

- äth., Aufbewahrung 74

- Darstellung 74

- mangelhafte $74^{2}$

Olea aquae innatant. 77,78

- aether. [77]

- Asphalti 60

- Buxi 60

- cadinum 14

- Caryoph. 30, 60

- Cerae $74^{1}$

- de Chalcantho $77^{1}$

- cocta 18
Olea Cornu cervi 60

- essentialia 78

- fundum petent. 77,78

- Gagates 60

- Heracl. ligni 60

- Juniperi oxycedri 14

- de lateribus 15

- mirabile 35

- philosophos 15

- Rusci 60, 125

- sanctum 60

- sapientiae 15

- Succini 60

- Sulfur. p. campanam 117

- Tartari p. deliquium 30

- Vini $77^{1}$

- Vitrioli 48, 74, 117

Onbelcata 51

Onbelcora 51

Opferaltar $8^{1}$

Opium 7

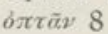

Orangenblüten $36^{4}$

Oribasius 14

Orientalisches Vorbild $96^{1}$

Orsini, Herzogin Flavio $36^{4}$

Österreich 39

Ostr 137

Ouvrir les corps 73

Ova vitrea 32

Ovum philosophor. vitreum 52

ởó์ขeส 24

ov̀อavḋs 24

ov̉oí 43

\section{P}

Palingenesie 119,120

Palmarosa, 138, 139

Panacea 43, 146

Panem, per 91

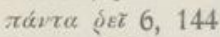

Papins Digestor 58

Pappel-Salbe 59

Parabolas, per 92
Parac

Paré,

Parfü

Parfü

- fü

- fü

Paris

Paris

- N

Parke

Parm

Passi

Patar

Patel

Pate

Pech

$-4$

$-1$

$-\mathrm{s}$

Pelit

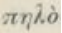

Pent

Peps

Pept

Pepy

Perf

Per

Peri

Pers

zío

Pete

Petr

Petr

xहvंs

Pew

Pfel

Pfei

PfeI

Pfla

Pha

Phi

Phi

Phi

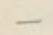


Paracels. 64, 145; siehe Hohenheim Paré, Ambr. 49 1

Parfüms 17

Parfüm für Handschuhe 48

- für Schnürbrüste 48

- für Tiere $3^{1}$

Paris 35, 62

Paris, Kapuziner-Apotheke 82, 83

- National-Bibliothek 21

Parkes 62, 122, 125, 126

Parmentier 94

Passiva instrumenta 14

Patana-Yantram 39

Patella $12^{2}$

Patent auf Kokeofen 126

Pech 7, $10^{2}$

- brenner 124

- Hütten 124

-schmelzen 59

Pelikan 57

riphos $12^{2}$

Penula 90

Pepsin 8

Pepton 8

Pepys 126

Perfectio 34

Per fumum 8

Periyar 140

Perser 17

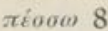

Peters, H. $73^{1}$

Petroleum 74

Petrolkanister 141

สвиंx 7

Pewterer 49:

Pfefferminze 71, 127, 128, 129

Pfeiffer 123

Pferdedünger 61, 91

Pflanzenauszüge durch Digestion 17 Pharmazie $9^{1}$

Phiale 23, 25, 52, 74

Philippi 18

Philosoph. Kunst 42, 146

- Regel 120
Phiolen 29, 32, [52], $55^{3}$

Phipps, Lord 88

Phlegma [62], 77, 145

q. $6 \xi 52$

Phosphor 122

Phosphorsäure 117

qळ̃ $21,32,91$

Physica 42

Phytochemie 73

Phytochemie, Begründer 47

Picaria officina 10

Picem coquere 10

Piger Hinricus [50]

Pips [145]

Pirotechnica 91

rioru 15,17

Pisselaion $10,15,141$

สıтrovejòs 10

zexนoveysion 10

tux roveyic 10

Pituaia 10

Pituita 145

xirvs 10,15

Pityusa 10

Pix 7, 15

- liquida 15

Plantago 48, 135

Platinageräte 120

Platon 6

Plinius 10, 12, 13, 14, 16, 18, 21, 29, $40,49^{1}, 90,125$

Plumbata vasa $49^{\circ}$

Plutarch $9^{1}$

Pluvius 5

Pneumatische Wanne 126

xvyzis 10

Pompeji 14

Pompholyx 11

Porta, Giov. Batt., De distillatione Rom 1609; $29^{1}, 36^{4}, 45,48,51$, $56,57^{1}, 61,70,79,117,120,146$

Pott, Joh. Hch., 92

Prennen [65]

Preston-Pans 120 
Primum ens metallorum 23

Puff, Mich., 43

Pumpe 77

Putrefizieren 54, 56, 76, 90

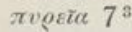

Pyronomia 91

Pyrotechnica 63, 64

\section{Q}

Qadah 31

Quadus $28^{3}$

Qandil 29, 91

Qaranful 38

Qarûra 27

Quatuor semina frigida min. $36^{5}$

Quecksilber 39

Quecksilberchlorid 23

Quecksilberdestillation 12

Quecksilbersublimat. 111

- in England 111

- - Idria 111

- - Peru 111

Quercetanus, Jos., Pharmacop. dogmaticorum restituta, Paris 1603 und später $60,65,73,74,76,77$ Qidr 38

Qinnîna 29

Quinta essentia 73, 100, 118

Quitte 20

Quittenblüten 18

\section{R}

Raikow 105

Ralla $77^{1}, 96$

Rad. Althaeae $76^{2}$

- Liquir. $76^{2}$

- Malvae $76^{2}$

Rasaratna samucchaya 39

Ratl $38^{1}$

Rauchfänge $32^{1}$

Ray, Pr. Ch. $39^{2}$

Reber, Burgh. $\mathbf{8 3}^{1}$

Receptacula (Vorlagen) 17, 51, 78

Recrementa 146
Recipiens 78

Regen 4, 5

Reibestein 29

Reichenstein $114^{2}$

Reif 5

Reinhart 140

Reiskleie 54

Reismehl 54

Rektifizieren 46, 96

Remora 82

Renodaeus, Jean, Instit. pharmaceut. libr. VI 1609. 92

Resina 7

Resuscitatio 119

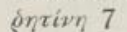

Retorte 26, [56], 57

- eiserne 126

Reverberieren 61

Rezeptbücher 19

Rhazes (Abu Bekr Mohamed Ben Zakerija el Razi), (Liber- medicinalis, Basel 1563. 27, 28, 30, $54,55^{1}, 90,146$

Rheuma 145

Richmond 118

Rindsblasenkühlung 61

Ring des Platon 6

Ringkuhl 120

Rinne 143

Riviera 135

Roch le Baillif 119

Roebuck 120

Röhrlein, so Wasser ziehen 62,78

Rokeach 18

Romershausen 95

Rondelet 64

Rosen 18, 48, 135

Rosenbrennen $61^{3}$

- Destillation von $65^{1}, 143^{1}$

Rosenhut 37, 43

- iraqische 38

Rosenknospen 38

Rosenöl 19, 143, 144

Rosenpreis $35^{3}$ 
Rosensaft $143^{1}$

Rosenwasser $18,27,28,35,37,93$

- Rezept 38

ఏó

Rösten 8

Rotz 146

Rouen 96, 118

Ruchstoffe, ihre Entdeckung 3

- vor störenden Einflüssen zu bewahren $17^{\circ}$

it.

Ruchwasser 27, 28, 35

Rückflußextraktionsgeräte 103

Rückflußkühler 57, 62

Rückstände zum Destillieren 48

Rumford 93

Runge 127

Ruß 3, 11, 124

Rußbutten 124

Ryff, Gualtherius (Walther), Destillierbuch, Frankfurt 1567. 15

\section{S}

Sagae 43

Sagaier 130, 131

Saigern 30

Saigervorrichtung 29

Saladin 18

Sal Alkali 74

- armoniacum $26^{1}$

— digestivum Sylvii 74

- mirabile 74

- Tartari 30

Salben 16

- -darstellung, Erfindung 17, 18

- -schrank 17

Salerno 35

Salia acida 74

Salmiak 26, 32

Salpetersäure 25, 96

Saluzzo 106, 109, 110

Salvia 48,135

Sambucus 19

San Marco 21

Santa Maria Novella 41
Saporta 64

Sarmaten 125

Säure, Essig- 25, 34

- versüßte $77^{1}$

Savonarola 62

Scammonium 7

Scamna 81

Schallverbreitung $17^{2}$

Scheere 55

Scheidevorrichtung s. abscheiden

Schiefspulver $65^{1}$

Schiffs-Destillation 87

Schiffe dichten $10^{2}$

Schildkröte $57^{1}$

Schimmel \& Co. 100, 101, 102, 128, $129^{1}, 140141$

- Verlagswerke, V.

Schimoyama $129^{1}$

Schin I Ho $129^{1}$

Schiras $18,53^{3}, 143^{1}$

Schlacke [29 $\left.{ }^{1}\right]$

Schlackenhalden $30^{1}$

Schlangenkühlung 51, 64

Schlauch 28

Schlauchähnliche Deckel 32

Schleim 146

Schmelztiegel 28

Schmieder, C. Chrph., Geschichte d. Alchemie, Halle $1832 ; 24^{1}$

Schmiedezange 55

Schnabel $30,31,56$

- -kühlung 63

Schnaps 41

Schnauzenförm.-Ablaufrohr 40

Schnee 5

Schnupfen 145

Schnürbrustparfüm 48

Schornsteine 26

Schraubtischchen 82

Schrick 43, 44 (siehe auch Puch)

Schröder, Joh. Pharmacopœia medico-chymica $1669 ; 28^{1}, 59$, $77,117,119^{1}$

Schröpfköpfe $19,28^{3}, 51$ 
Schutz vor Springen 67,80

Schwammkühlung 51

Schwanz 28, 31

Schwefel 32

- -äther $77^{1}$

- -fäden 52

- -kitt $12^{4}$

- -kohlenstoff 121

- -säure 25, 96

- englische, Preis, 120

- - fabrik 118

Schweineblasen 126

Schwelprodukte

Secernieren, Abscheiden

Secretis, de $28^{1}$

See 4

Seefelder Teer 14

Seerosen $36^{2}$

Seewasserdestillation 16,88

Sell, E. 70

Sels volatiles 116

Sem. Scariolae $36^{5}$

Separator 77

Separieren 71

Seplasiarii 17

Serapion 48

Serpentine 68

Setsusaburo Tanaka 128

Shakespeare $48^{1}, 49^{3}, 146^{2}$

Sicherheitsrohr 96

Siedekölbchen 71

Siedepunkt, verschiedener 69

Sigillum Hermetis 55

Signa naturae 6

Signatura Hermetica 55

aเxúa 51

Silberglätte 54

Simhagupta 39

Simhagupta 39

Similia similibus 6

Sims 23, 37, 52, 143, 144

Siphon 96

Sirupe 34

- aus Ölen 74
Smola 124

Smolarz 124

Smyrna $144^{1}$

Sohn des Tiegels 29

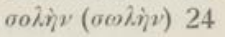

Solutio 34

Solvieren 120

So(n)fia 138

Sonnenwärme 92

Sordes $29^{1}$

Soxhlet 103, 105

Spagyrisch $58^{1}$ [120]

Spallanzani 39

Speter $85^{2}$

Spezial-Brennzeugmacher 67

Spiauter $49^{3}$

Spicken $92^{1}$

Spiegel zum Auffangen der Sonnenstrahlen 93

Spielmann, Jac. Reinbold, Pharmacopcia generalis $1783 ; 26^{1}$

Spiritus campanarius 118

- mineralis 61

- Salis 74

- Sulfuris 117

- Clossaei 117

- Vini 96

- Vitrioli dulcis 96

Sprengen 52

- -ring 52

Springen, Schutz vor 67,80

Staffelweise Aufstellung 38, 46, 47

Ständer 81

Stapleton $26^{2}$

Stark 117

Stechheber $77^{\text {s }}$

Stehkolben 52

Steinkohle, Destillation 122, 126, 127

- -ÖI 123

- -Teer 124.

- -Verkokung 122

Stein zum Reiben 29

Stein der Weisen 42

Steinöl 26" 
Șterilisieren 39

Tendo(u)r 33

Sternanis-Destillation $130,132,133$, 135

Steuer auf Alkohol 42

Stillatoria anguinis 64

Stillatory $146^{2}$

Stomachica 41

Stopfen 54

Storchschnabel, Abb. 27, 56

Storm, Georg 49, 67

Stramen tortum 81

Straußenmagen $58^{1}$

Streitkolben 19

Stridden 81

Strohkränze 51,81

Struve 93

Suber montanum 54

Sublimation 11, 39, 107

Südfrankreich 44

Suhâla 54

Sulfur $23^{1}$

- philosophor. $53^{1}$

Superius et inferius Hermetis 6

Sustentacula $81,82,85$

Synthese 10, 120

avọọoì 9

Tabula Smaragdina 144

Tachen, O. 116

Tachnîq 32

Taeda $7,13,33^{1}$

ráovos 7

Tartar. Ausscheidungen 145, 146

Taschmi 34

Taschwija 32

Tau 3

Teer $12^{\prime}, 124$

- destillation 12

- Seefelder 14

- Steinkohlen- 124²

Teilchen, kleinste Riech- $17^{2}$

İะัoข $23^{\prime}$

Temperiert Feuer 70

Teniers 132

Tennant $95^{1}$

Tennor 33

Tsoв Bivios 15

Téouev ๆos 15

Terpentin 10, 15

Terpentinöl 35, 70, 74, 141

reoaxiven 7

Tervahauta 125

Tesca 117

Testudo $57^{1}$

Thales 4

Theophrast 9, 12, 18, 24, 49 1 , 125

Thermospodium [22], 24

Thoraces 48

Tibiae 17

Tiegel 29

- Sohn des 29

Tierische Wärmè 91

Tille s. Tülle

Tingir 38

Tiryakpatana Yantram 40

Tischchen 81

Ton $31,33,40,46^{2}, 138,141$

- Beschlagen mit s. Beschlagen

- der Weisheit 54, 111

- -dichtung 29

- -einlage 34

- gebrannter 54

- -gefäß 67

Tonkin 132

Töpferei 8

Trachter $77^{3}$

Tractarius $77^{\text {s }}$

Trajectorium $77^{3}$

Transferendi liquores $78^{2}$

Transmutation 6,144

Transsudatio 30

Travankore 80,140

Trechter $77^{3}$

Trennung der Körper 64

Toißıxos 24

Tribicus [24리 
Tributzahlung 18

Trichter [77], 138

Trinkbecher 28

Tripedes 81

Tripodes 81

Tritorium 77

Tritton 94, 100

Troja 17, 19

Trommsdorff, J. B. $88^{2}, 93$

Tropfensammlung 23

Trostspiegel, Meister des 43, 51

Tschirch, A. 125,141

Tuberculin $52^{2}, 55$

Tubi 19

Tubulus 79, 107, 126

Tüllen [92]

Turkmenen 130

Turquet 115 .

Tyro 65

Tyrrhenien 10

\section{U}

Udid 138

Uisge- beatha $96^{1}$

Ulstadt, Phil. 35, 49, 52 55 , 62

Umbilicata 51

Unguenta s. Salben

Unguentarii 18

Unio virtutum plantae 119

Universal-Tinktur 42

Universum 5, 6, [144]

Unterlagen 81

Unterlage von Ton 30

Urall 144

Ureins 144

Urin, fauler $26^{1}$

Urinale sublimator. 52

Urinalia 32, 52

Ursus $57^{1}$

\section{V}

Vacuumapparate 95

Vaisseaux de rencontre $57^{1}$

Vapores 60
Varunas 4 .

Vaterländ. Destill. 137

Veilchen $48,52 \% 135$

Venedig 26, 37, 46, 67

Venter equinus 91

Ventori Bened. $49^{1}$

Verbreitung von Geruch $17^{2}$

- Gesicht $17^{\circ}$

- Schall $17^{\circ}$

Verbrennungsgase 7

Verfälschung der Drogen 60

Vergil $145^{\circ}$

Verkitten s. Kitten 30

Verlängerung des Halses 82

Verpuffung 119

Verschluß, hermet. 55

Versüßt $77^{1}$

Verzinnte Gefäße 49

Villanova s. Arnaldus

Vinca 48

Violen s. Veilchen

Virginien 141

Viridarien 44

Virus $a b$ inguine $145^{2}$

Vitriolsäure 117

Vitro incrustare $46^{\circ}$

Vitruv $12^{2}, 49^{1}$

Vorlage 28,78

Vorlage für Fraktionen 105, 107

Vorlagen f. Gase 106

Vorstoß 82

Vorwärmer 95

\section{W}

Wacholder 10,15

Wacholderholzöl 34

Wachsstopfen 54

Wagenschmiere 59

Wahrzeichen, Flaschen- 192

Waitz, v. 120

Walter, Ph. 71

Warmbrunn und Quilitz 105, 106

Wärmegrade 90

Wärmequellen, Grade der 60 
Warmes Wasser lauft oben ab 66

Wasser des Lebens $96^{1}$

- deutsch stinkend $58^{1}$

- konzentriertes 46

- Prinzip siehe Aqua 6

- Narden- 27

- Rosen- 27, 28 3 , 30

- Ruch- 27

- styptisches 123

Wasserbad 22, 34, 70

Wasserblei 54

Wasserbrenner 41, 49

Wasserbrennerinnen 41

- geschworene 43

Wasserdampf beladet sich mit ÖI 15

Wasserleitungen 66, 114

Wedel, Joh. Wolfg. 82

Weib, Destilliergerät 147

- trügerisch 147

- weißes $58^{1}$

Weigel, Chrn. Ehrenfr. 84, 85, 86

Wecker, Joh. Jac., Antidotar. generale, Basel 1553. $28^{1}$

Weihrauchruß $8^{1}, 11,19$

Weinbrennen $61^{3}, 65^{1}$

Weindestillation 16, 25, 34, 35, 92

Weingeistlampe 92

Weinschenken $19^{2}$

Weinschwefelsäure $117^{2}$

Weinsteinspiritus 126

Welt 5

Wesen(tliche) Öle [43]

Wesentliches 73

Westrumb, J. F., Handbuch f. d. Anf. der Apothekerkunst, 1795.60 , 107, 109.

Whisky [96 $\left.{ }^{1}\right]$

Wiedeman, Eilh. 27, $35^{2}, 36,37$, 93,143

Wiedererweckung 119
Wiedergewinnen des Lösungsmittels 105

Windofen 21, 33, 50, 51

Wintergreen 141

Wischnu 18

Woulfe, Pet. 107, 108

Würzburg 44, 135

Würzen für Speisen 46

\section{$\mathbf{Y}$}

Yantra 39

\section{Z}

Zahnstocher $76^{2}$

Zahnpinsel $76^{2}$

Zahnbürsten $76^{2}$

Zange 55

Zarnich 32

Zedern 10

Zeise 93

Zelt 4

Zerlegen in die Elemente 100

Zibl 26

Ziegelbrocken 74

Ziegelsteinöl 15

Zimmer 119

Zink $40,49^{\circ}$

Zinkoxyd 11

Zinksublimation 111

Zinnsublimation 107

Zinnerne Gefäße 49

Zinnober 26

Zirkulation 25, 46, 57, 99

- moderne 100, 105

Zirkuliergefäße 96

Zosimus 21

Zucca 51

Zuckerabdampfgerät 100 .

Zuckergläser 32

Zucker, roh 40

Zusätze bei den Destillationen 74,76 
Geschäftsdruckerei Schimmel \& $\mathrm{C}$, Miltitz bei Leipzig. 


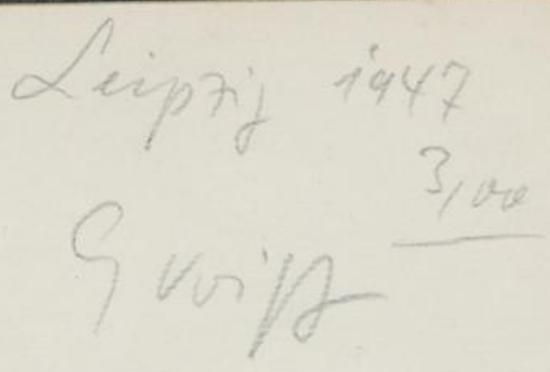




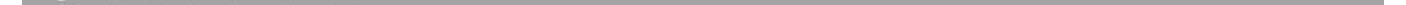

